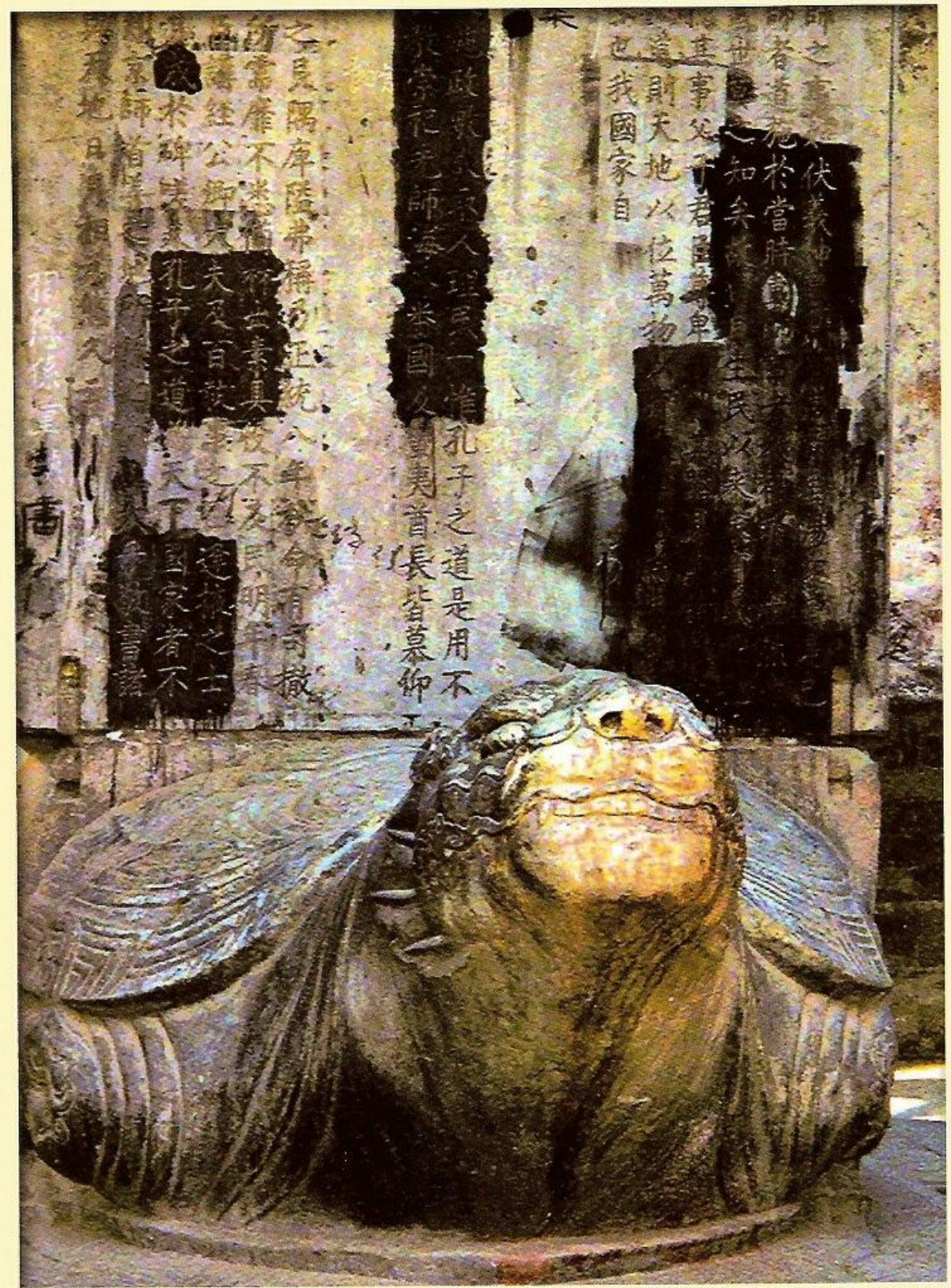

STRATEGIC DECISION-MAKING PROCESSES:

\title{
THE ROLE OF INFORMATION
}

CHARLES L. CITROEN 
STRATEGIC DECISION-MAKING PROCESSES: THE ROLE OF INFORMATION 
Promotion Committee:

Professor dr. Hans E. Roosendaal (promotor)

Dr Peter A.Th.M. Geurts (assistant promotor)

Professor dr. ir. E.J. de Bruijn, (University of Twente)

Professor dr. J. van Hillegersberg (University of Twente)

Professor dr. C. Oppenheim, (Loughborough University, Loughborough, UK)

Professor dr. R.A. Stegwee (University of Twente)

Professor mr. J.T.P.M. Troch, (University of Twente)

Strategic decision-making processes: the role of information

$\mathrm{PhD}$ thesis, University of Twente, The Netherlands, 2009.

ISBN: 978-90-365-2821-4

DOI: $10.3990 / 1.9789036528214$

Copyright (c) 2009 by Charles L. Citroen, Zoetermeer, The Netherlands Cover photo: Stele with the names of scholars at the Confucius Temple, Beijing, China; photograph by the author. 


\title{
STRATEGIC DECISION-MAKING PROCESSES: THE ROLE OF INFORMATION
}

\author{
Dissertation
}

To obtain

the degree of doctor at the University of Twente, under the authority of the rector magnificus, prof. dr. H. Brinksma, on account of the decision of the Graduation Committee to be publicly defended on Thursday, 14 May 2009 at $15.00 \mathrm{hrs}$

by

Charles Louis Citroen

born on 18 May 1939

in Amsterdam. 
This dissertation has been approved by

Prof. dr. Hans E. Roosendaal (promotor)

Dr Peter A.Th.M. Geurts (assistant promotor) 

The Art of Warfare

"If you have a thorough knowledge of yourself and of the enemy you are bound to win in all battles. If you know yourself, but not the enemy, you have only an even chance of winning. If you know neither the enemy nor yourself you will suffer defeat in all battles".

Sun Tze (China, $~ 300 \mathrm{BC}$ ) 



\section{Preface}

"What is life without a dream?"

(Rostand, in 'La princesse lointaine')

An academic study is not considered to be complete without a doctoral research project followed by the writing of a dissertation and a PhD doctorate. In the author's case, having taken up a job immediately after the master (doctorandus) study in chemistry, this finishing touch had to wait until after retirement.

From 1967 to 2003 the author was engaged in developing and providing information services and giving advice about such services to industry, mostly the chemical industry, being employed by four consecutive profit and non-profit organisations.

During all those years, uncertainty and curiosity remained as to what actually did happen with the information that we distributed by our services. This gnawing question I strive to answer in this research.

After in fact starting to phrase the question of interest in the summer of 2002, I mailed a brief proposal to six learned persons that might also be concerned about this subject matter. Fortunately, Hans Roosendaal and Peter Geurts of the School of Management and Governance of the University of Twente were willing to consider this proposal and explore in which way it would fit in their own research programme. With some adaptations and additional issues to be included, they accepted the proposal and agreed to facilitate and guide me in accomplishing this research project.

The actual motive for the subject of this study is the pervasive presence of computers and telecommunications that have changed the daily live at home and at the office. The question I pose myself is, does this trend influence to the same extent the way executives manage their daily decision-making activities. In my case, I truly could not have performed this research and completed this project without access to the Internet, databases, electronic journals and e-mail. The services of the university libraries of Twente and Delft have been superb and enabled me to work for eighty percent of this research from my own study room at home.

I trust that the research I did and the report I have written about this issue do provide some answers to this question as far as a single person's efforts can find evidence of a development in the real world.

This is also the section to thank those that have made it possible for me to devote such a large part of my retired live to this reverie.

In the first place Hans Roosendaal and Peter Geurts who accepted me as a 'senior student' knowing that such a person is less malleable and more refractory than a regular youngster would be. They took the risk and I hope I have not disappointed them. They offered constructive criticism every time I came to visit them and made me realise that there are many fundamental and philosophical facets of relevance to the science of management and information management. 
The fifteen executives that consented in an interview and agreed to discuss with me step-by-step the process of strategic decision-making provided the basis for the empirical part of this study. I am grateful for their co-operation.

My parents I can only thank posthumously for letting me pursue an academic study that was not common in our family. Not in the last place, I am grateful to my wife, Elisabeth for her constant patience and support during these years of study. 


\section{Contents}

I.

$\begin{array}{ll}\text { Introduction } & 11\end{array}$

$\begin{array}{ll}\text { I.1. The process of strategic decision-making } & 12\end{array}$

I.2. Information as a management tool in strategic decision-making 13

$\begin{array}{ll}\text { I.3. Relevance of this research } & 15\end{array}$

I.4. Research questions and objectives 17

II. Theoretical framework: Strategic decision-making 19

II.1. The process of strategic decision-making 21

II.1.1. Quality aspects of the decision-making process 23

II.1.2. A rational approach to decision-making 26

II.1.3. A 'satisficing' approach to decision-making 33

II.1.4. Intuition in strategic decision-making 37

II.1.5. Influences of national and organisational cultures 41

II.1.6. The process of strategic decision-making - Conclusion 44

II.2. Information as a factor in the strategic decision-making process $\quad 45$

II.2.1. Information overload 67

II.3. Conclusion 71

III. Information and communication technology and the Internet in industry $\quad 73$

III.1. The development of computer hardware 76

$\begin{array}{lll}\text { III.2. } & \text { Applications of computers for strategic issues in industry } & 78\end{array}$

III.3. Technology: networks and the Internet 84

III.4. Information sources for the chemical and food industry 92

$\begin{array}{ll}\text { IV. } & \mathbf{9 7}\end{array}$

$\begin{array}{lll}\text { IV.1. } & \text { Strategies } & 97\end{array}$

IV.2. Fieldwork 102

V. Results and discussion $\quad 109$

V.1. Outcome of the research: strategic issues 109

V.2. The role of information in the decision process 119

V.3. Quality of information for strategic decision-making 125

V.4. Changes in decision-making processes due to increased availability of information 126

V.5. Developments of ICT services in industry 128

$\begin{array}{ll}\text { V.6. } & \text { Strategic value of decisions } \\ & \text { Conclusions }\end{array}$

$\begin{array}{lll}\text { VI. Conclusions } & 131\end{array}$

VII. $\quad$ Reference List 139

Summary $\quad 159$

$\begin{array}{ll}\text { Samenvatting } & 165\end{array}$

$\begin{array}{ll}\text { List of figures } & 172\end{array}$

Annex 1 Description of phases in the decision process. 173

$\begin{array}{lll}\text { Annex } 2 & \text { Companies interviewed for this study. } & 177\end{array}$

Annex 3 E-mail questionnaire 178

Annex 4 Sample of web pages with business information for the chemical

and the food industries. $\quad 181$

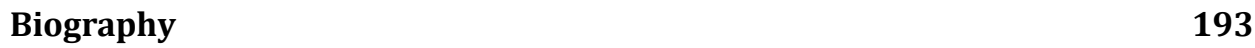




\section{STRATEGIC DECISION-MAKING PROCESSES: THE ROLE OF INFORMATION}

\section{Introduction}

The basis for our research is reflected in the motto of this dissertation, borrowed from the treatise by the Chinese strategist Sun Tze ( 300 BC) entitled 'The Art of Warfare': "If you have a thorough knowledge of yourself and of the enemy you are bound to win in all battles. If you know yourself, but not the enemy, you have only an even chance of winning. If you know neither the enemy nor yourself you will suffer defeat in all battles" (Ho, 1997).

This citation explains how the quality of the process of strategic decision-making is contingent on the quality of the supporting information. Knowledge of one's own organisation as well as knowledge of other organisations on the battlefield is needed in order to be able to compete successfully. Looking inward only will not be enough.

In this research we aim to analyse how information is used by company executives during their strategic decision processes and how these processes have changed in recent years e.g. under the influence of increased availability of information resources. A definition of the word 'Strategy' in the strategic management context of this thesis is 'a carefully devised plan of action to achieve a goal, or the art of developing or carrying out such a plan.' The word strategy derives from the Greek word ' $\Sigma \tau \rho \alpha \tau \eta \gamma \alpha^{\prime}$ ', which referred to a military commandership at the Battle of Marathon (Herodotus, $440 \mathrm{BC}$ ). Decisions taken by executives of large corporations are mostly of a strategic nature; they are complex, non-routine, cannot be solved easily by existing procedures and have not previously been encountered in the same form. The strategic issues that are the subject of the decisions we studied are similarly combative and can be summarised as affecting the long-term direction of the organisation and involving considerable change such as strategy development and execution, mergers and acquisitions, large investments and organisational changes. The subject of the quality of the decision making process is of importance in view of the way strategic decisions directly affect the nature and future of the organisation.

An essential factor playing a role in the process of decision-making is the information on the internal and external environment of the organisation, relevant to the situation to be considered. Precisely there, in the availability of information, a revolution has taken place in recent years with new information acquisition and analysis methods such as the Internet becoming common practice, often called the 'third industrial revolution' (Smith, 2001). The diversity of information sources offered by news agencies, business information publishers, patent offices etc., may benefit from a better understanding of the actual use made by an influential section of their clientele.

There is an extensive literature available on the subject of strategic decision-making focusing on studies of the psychological and sociological motivation of group decision making, of the choice behaviour in these processes using modelling techniques from 
mathematics and statistics and on analysis of the influences exerted on the decision makers such as company politics and power clashes. We will concentrate our research on factual accounts of the way executives reach these decisions and the information used in this process.

\section{I.1. The process of strategic decision-making}

Many studies in strategic management take the position that executives reach strategic decisions after a structured process of careful consideration of circumstances, alternatives and consequences. Information on matters such as competition, markets, technologies and the societal environment affecting the organisation specifies the implications of the feasible alternatives for the decision to be made and plays a crucial role in obtaining the parameters of these alternatives. Making decisions presupposes that adequate information is available that enables an executive director or a board of directors to reach the best possible decision under the circumstances (Corner, Kinicki and Keats, 1994; Noorderhaven, 1995 p.29; Hoskisson et al., 1999; Baum and Wally, 2003; Citroen and Hooghoff, 2003; Weirich, 2004 p.21, 212; Nutt, 2005; Hammond, Keeney and Raiffa, 2006). This approach is known as a 'rational process'.

This position however is not uncontested. In several studies, arguments are presented claiming that human beings only have limited cognitive capabilities and can only comprehend and use a limited amount of the information that is available. As a consequence they have to rely on bounded rational processes rather than rational processes. In strategic decision-making, this leads to the view that executives reach decisions in a basically unstructured process accepting 'satisficing' instead of optimal solutions (Simon, 1960 p.6; Eisenhardt and Zbaracki, 1992; Conslik, 1996; Williams, 2002 p.15). This approach is known as a 'satisficing process'.

Again another point of view is that in some cases decisions primarily based on an intuitive process can lead to equally proper outcomes (Sauter, 1999; Khatri and Ng, 2000; Sinclair and Ashkanasy, 2005). This approach is known as an 'intuitive process'.

As indicated above, the decision-making process studied in this research concentrates on strategic issues in industry such as strategy development and execution, mergers and acquisitions, large investments, divestments and sometimes disinvestments, new products and new markets, make or buy options, organisational issues and long-range planning strategies. These issues have a basis in the importance of the target industries selected in this research for the national and international markets. Such strategic issues are common features in text books and are also regular items in business newspapers and news magazines such as The Economist, the Financial Times and Het Financieele Dagblad (Dean and Scharfman, 1996; Johnson, Scholes and Whittington, 2005 p.6; Choo, 2006). Tactical matters and operational decisions are nowadays more often delegated to middle management. The same holds true for routine or programmed decisions. 
Most authors of strategic decision-making research agree with the view that in general the decision-making process passes through a number of distinct phases, but not all of them agree that this view implies that these specific phases indicate a structured process based on available information.

Our research centres on the use of information as a factor that influences the structure of the strategic decision-making process that can clarify which approach is actually followed by executives in industry.

\section{I.2. \\ Information as a management tool in strategic decision-making}

"Information is something that changes the state of its recipient or, more specifically, the knowledge state. A slight variation is to say that information is what determines a decision or allows a choice to be made. Making a decision represents a change of state (from undecided to decided) on the part of the decision maker".

(Meadow \& Yuan, 1997)

We are interested to ascertain what the role is of information that is available for the decision-making process in supporting this process. As implied, the executive that follows a rational approach collects and uses ample information in a structured decision-making process passing through a number of distinct phases in time. In this process, information plays an all-important role throughout.

The satisficing executive follows a decision-making process that is based on using a limited amount of information of all that is available and the decision-making process is less structured.

For the intuitive executive, the exact role of information cannot be determined and the decision-making process is unstructured as mostly previous experience and learning constitute the knowledge base for the decision in an intuitive process.

The manner in which information is used in the decision-making process thus differs in each of the three approaches to this process. Investigating the role and extent of usage of information in the process therefore can be a factor in discerning which approach to the decision-making process is actually followed by the executives.

The quality requirements for the information that is used in a decision-making process are strict. Relevant, up-to-date and trustworthy information is a prerequisite for reaching proper decisions. The way executives use information thereby is an indication of the level of structure of the decision-making process.

In studies of strategic management theories (e.g. Simon, 1960; Porter, 1980; Hammond et al. 2006), several elements of the decision process are considered, however, in those publications information often is merely a hidden aspect. Moreover, in most studies on company performance, management information is considered a production factor that is readily available and its accessibility is taken for granted in the process (Li, 2003). 
The subject matter of the information that is relevant to strategic decisions in general and that is considered in this research consists of such items as market structures, competition and competitors, technologies, regulations and public affairs. For these areas, opportunities, threats and risks of the market place and the business environment and most importantly, current developments and trends in those features are essential (Citroen and Hooghoff, 2003; Brenner, 2005). Some publications analyse the use of ICT applications such as communication tools and the analysis of large amounts of data, but the content of the information is seldom discussed.

The so-called third industrial revolution is associated with the development of new and pervasive information and communication technologies (ICT). Futurists predict a world where everyone will have all information required available at ones fingertips without any delay. Realists know that such a situation has not arrived yet, if it ever will. Both Negroponte (1995, p. 183) and Smith (2001) argue that the Internet, 'invented' around 1974, is at the heart of this third industrial revolution and Smith formulates this as follows: "the Internet has forced companies everywhere to re-invent themselves and the way they do business. The extraordinary growth of the Internet surpasses any technological innovation ever developed and this transformation in business practices has fuelled unprecedented gains in productivity, generated both by improvements in efficiency and by the creation of new markets".

Over the last few years, resources for management information have increased with the change of the Internet from mainly a research-oriented system to one that has additionally become a source of relevant information also for a business audience by its diverse content. Because of these developments, the question is no longer whether some required bit of information is available, but where this item can be found in the shortest time. Also, new methods have become available for the task of collecting information in each step of the decision-making process such as preparing for a case, constructing, documenting and comparing alternatives, thus enabling faster and more comfortable choices. There is a risk associated with this increased availability of information, that of being plagued by an overload of information. There are however several methods to cope with this problem by proper organisation of the information flow, if needed, assisted by computer procedures.

Equally, checking the reliability of a received piece of information from an uncertain source is facilitated by the new methods of ICT techniques, e.g. statistically or by comparison with other data.

This subject as such is not new, the consultancy firm KPMG authored in 1995 a report entitled 'Information as an asset, the Board agenda' (The Hawley Committee, 1995). One of the conclusions of the report is that "the Board should determine the organisation's policy for information assets....ensuring that, at every level, the information provided is necessary and sufficient, timely, reliable and consistent as required for effective operation..... must include summary information for decision support at the various levels of the organisation". Especially for the chemical industry, 
the number of external information sources has grown, so much so that it often requires a chemical information specialist to keep an overview. However, even for non-specialist managers, many of these sources can provide interesting and essential information to aid in the decision making process. Targeting relevant information at this group is a development taken up by several information providers and publishers. The question here is whether managers are aware of those possibilities and are willing to devote an effort to understanding and using them. Either they can order information to be delivered to their desktops from external sources or they can delegate these searches to their information specialists and market researchers that are experienced in creating a complete picture and separate the real data from the noise. Lohman (1999), in his dissertation entitled 'The effectiveness of management information', concludes that making use of information by managers is not to be taken for granted as the appropriate information is not always available. Causes of this deficiency can be the problem of transforming available data into useful information and the discrepancy between the information that is requested by the managers and that the information that is provided by the service.

In some cases, information that is indeed available, is not used at all or is not used properly because of reasons such as unbelief, unconstructive group processes, political issues or misinterpretation. Examples are the disasters with the space shuttles and those through errors by military strategists, both through disregard of already available information. Unfortunately, similar failures in industrial strategies are not so well documented and come to the surface only occasionally; examples are recalls of medicines from the market by pharmaceutical companies that waived away adverse side effects that had been observed and documented. In such cases the decision-making process cannot be called rational because in some phase of the process the use of information was not optimal.

\section{I.3. Relevance of this research}

Study of the literature of strategic management showed that the subject of the usage of information in the decision-making process has not been researched intensively, or to be more precise, has not been published extensively in the literature (Choo, 2002; de Alwis et al., 2006).

The purpose of our research therefore is to investigate whether or not executives, when making strategic decisions, pursue primarily a rational and structured approach that is based on the use of available management information. By collecting real-life data from these executives, we examine and discuss which process underlies the strategic decisions that they have actually taken recently. This theme has become of interest now that improved information acquisition and analysis methods such as the Internet facilitated by new information and communication technologies (ICT) have increased the accessibility and availability of information that plays a key role in such a rational process. 
By studying a number of actual strategic decision-making processes of executives in the chemical and food industry and by a discussion of the information accessed and used and the reasoning behind their approaches, we will put these approaches to the test.

The emphasis thereby will be on the process, not on the resulting decision itself.

As observed by Simon (1960, p.40) the focus and the complexity of the decisionmaking are in the process whereas the usual image of the decision-maker "falsifies decision making by focusing on its final moment, ignoring the whole lengthy, complex process of alerting, exploring, and analyzing that precedes that final moment".

In this thesis, we concentrate on the environment of an industrial company and on the strategic decisions that require attention from the executives that form the Board of that company. In much of the literature on strategic management, information that we consider to be an important factor for this process, is considered to be present without deserving any special attention. There is little awareness therefore for the question of obtaining relevant information and the value of information as a tool to reduce uncertainties or to methods for sifting useful or even crucial information from information noise. For that reason we investigate in this study whether we can add a new viewpoint to this field, specifically that of the value of modern information resources and access as a prerequisite for the structuring of strategic decision-making. In our research we concentrate on the process of strategic decision-making and we will not study the implementation or the consequences of a decision.

In the theoretical chapters of this thesis, we discuss our analysis of the literature of strategic management as far as it concentrates on the decision-making process and the information needed in that process. Thereby we have kept in mind admonitions by Popper $(1935,1959)$ that we cannot verify any theory, but only attempt to falsify its conclusions.

From these reflections stem the objectives of our research on decision-making processes in strategic management of organisations. Do they follow a distinct structured pattern and do executives make use of the increased performance of information and communication technology (ICT) that is available nowadays? In order to be able to draw conclusions for this study, we have considered several aspects of information requirements such as the quality, the sources and the actual use of available information during the process of strategic decision-making.

We have taken up this research in order to contribute to the theoretical framework of strategic management as well as to the practical development of information content services designed for managers. If the results of this research project can help to better understand the way information is made available, selected and used, then it will become a piece of the puzzle, contributing to the literature on strategic management. Hopefully it will thus inspire later further research in optimising information utilisation and dissemination methodologies and in that way help improve the strategic decision process. 


\section{I.4. Research questions and objectives}

The above discussion leads to four questions put forward and to be answered by this research:

- $\quad$ By which process do executives manage strategic decisions with the purpose to come to the best feasible results: by a rational, structured process, by a satisficing process or by an intuitive approach?

- How important is information, both from within the organisation and external from the environment of the organisation as a basis for the taking of strategic decisions by executives; can the value of such information be ascertained and is there a case for an information overload?

- $\quad$ Do executives thoroughly check (or have checked) for its quality all information that is believed to be appropriate as a supportive resource for the decisionmaking process?

- Does the enhanced availability of information resources and information acquisition and analysis methods predominantly through new information services such as available on the Internet, have a noticeable effect on the quality of the strategic decision-making process?

In order to facilitate the analysis of the structure of the decision-making process and test the hypotheses, we have developed a model that shows the successive phases in this process: starting with the preparation for a decision-making process by formulation of the issue and setting the objectives, followed by collection of internal information and external information on the environment of the organisation, next the specification of potential alternatives, then limiting the options by choosing between these alternatives and finally, reaching a decision.

\section{I.5 Research design: interviews}

Research on strategic decision processes has been reported based on a multitude of technique and methodologies of which six schemes stand out, ranging from theoretical to case studies, 'hands-on' analysing actual issues.

- $\quad$ theoretical discussions and analyses of the decision process

- $\quad$ case studies of a limited number of targets

- $\quad$ analysis of published accounts of the process behind actual decisions taken

- $\quad$ surveys or questionnaires

- $\quad$ 'hands-on' laboratory experiments

- $\quad$ analysis of the reported processes with the aim to test specific notions and models developed for this topic.

No guidelines can be given as to which of these methods would be more valid for the research study that we have planned, they all have their merits and treat aspects of the spectrum of tasks in strategic decision-making. All of them bring new insights and help improve the quality of management techniques. 
In order to obtain an insight into current strategic issues and the approach taken by executives from large industrial companies in several recent strategic decision processes, we have interviewed a sample of those executives asking them for information on the decision-making process by recalling in detail every phase that was pursued during the process. In preparation for the interviews, we had collected information about the target group of companies from public sources such as news releases, annual reports and Internet web sites.

We have chosen this form of open personal interviews with executives because in this way we could accurately collect relevant first-hand data on the way they undertook the decision-making process and observe how they used information in specific recent issues that came on their agenda. The responding executives were all members of the Board or executives directly reporting to the Board of companies in the chemical and food processing industry with a turnover of $€ 300$ million or more in The Netherlands and to a lesser extent in Germany. We chose that segment of the industry as our target group as we are familiar with it and because this limited segment of industry could be covered by a significant number of interviews to be able to generalise our findings about the decision-making processes and the use of information thereby to the population of strategic decision-making processes in this industry. 
II.

Theoretical framework: Strategic decision-making

"Strategic decision-making is of great and growing importance because of five characteristics of strategic decisions: they are usually big, risky and hard to reverse having significant long-term effects, they are the bridge between deliberate and emerging strategy, they can be a major source of organizational learning, they play an important role in the development of individual managers and they cut across functions and academic disciplines".

(Papadakis and Barwise. 1998, p.1)

In our research on the strategic decision-making process, as discussed in above citation, our aim is to study the approach executives follow in this process and the manner in which information is used in this process. This subject is relevant because of recent changes in the availability and use of information and the fact that strategic decisions are the major task of executives in organisations.

Making strategic decisions is required to control the short-term and long-term goals of the organisation for which these executives are responsible. Strategic decisions directly affect the nature and the future of the industrial organisation that has to cope with the challenges of the competitive and increasingly global market place. Consequently, there is much research and there are many comments made on this process of which the main discussion lines will be cited here.

Strategic decision-making has been described as "a dynamic capability in which managers pool their various business, functional, and personal expertise to make the choices that shape the major strategic moves of the firm" (Fredrickson, 1984; Eisenhardt, 1989; Judge and Miller, 1991).

Mintzberg et al. (1976) define a decision as "a specific commitment to action, usually a commitment of resources" and a decision process as "a set of actions and dynamic factors that begins with the identification of a stimulus for action and ends with the specific commitment to action". Dean and Scharfman (1996) comment that "managers have the power to affect the success of strategic decisions. Decision processes influence the strategic choices managers make which in turn influence the outcomes affecting the firm." Miller, Hickson and Wilson (2002, p. 74) indicate why decision-making has to be studied, because it is "crucial to the comprehension of how and why organizations come to be what they are and to control whom they do. Organizations need decisions to be made in order that they can function effectively".

Seminal contributions on the subject of decision-making research in the general management literature originate from Simon (1947, 1957, 1978), Cyert and March (1965, republished in 1993, 2002), Mintzberg et al. (1976), Frederickson (1984), Eisenhardt (1992, 1998), Papadakis and Barwise (1998), Meadow and Yuan (1997), Choo (2002, 2006), Weirich (2004) and Nutt (2005). 
Reasons for this wide interest according to Mintzberg et al. (1976) are "...that the range of views on strategic management is quite divergent: subjective or objective, prescriptive or descriptive, based on experience or exploratory, reverting to economics, psychology, political science, anthropology or political sociology. All these viewpoints have successively had their advocates and thus have been the objects of research and subsequent publications."

Strategic decisions in particular concern issues such as the design and planning strategies of the organisation, initiatives for mergers and acquisitions, large investments in new products or markets, required disinvestments, make or buy options and internal reorganisations (Cray et al., 1988, 1991; Dean and Sharfman, 1996; Nutt, 1999; Partovi, 2007). Those are the strategic issues that are common in textbooks and also show up as regular features in business newspapers and news magazines such as The Economist, the Financial Times, Business Week, Handelsblatt and Het Financieele Dagblad. An illustration of such news items is taken from an issue of The Economist:

The board of Portugal Telecom rejected an improved $€ 11.8$ billion ( $\$ 15.5$ billion) bid from Sonae, a Portuguese conglomerate...

Banco Bilbao Argentaria made its biggest acquisition outside Spain when it agreed to buy Compass Bancshares in a $\$ 9.6$ billion transaction....

EADS, the parent company of Airbus, delayed launching a long-awaited restructuring plan because of "cross-national" difficulties about job costs and workloads...

(C) The Economist (20 February 2007)

These strategic issues differ from those of an operational or tactical character in that such latter decisions are often routine, based on information that is already available or can be procured on short notice and such decisions can in principle be delegated to middle management and settled by a well-structured or 'programmed' routine decision-making process, applying known procedures (Simon, 1960 p.6, 46; Baum and Wally, 2003).

As stated, executives are responsible for decisions that direct the corporate strategy affecting the range of businesses in which the company will compete, but they must also consider the business strategy that concentrates specifically on the manner in which the company is to compete with respect to each business and the functional strategy, that concentrates on the use of each of the business functions, such as marketing and production (Hussey, 1979; de Wit and Meyer, 2005). In each of these three strategies, the Board decides whether the decision to be made is of a strategic nature. Strategic decision-making processes are also characterised by a number of distinct perspectives, an organisational perspective - what business units are affected by the decision, by each alternative and how should the implementation be organised; a rational perspective - this concerns the preparation of the decision-making process, the measurement of variables, the collection of information - ; a judgment or political 
perspective - this describes the attitudes of people involved in the consideration of outcomes (Allison, 1971, 1999, p. 169; Koopman and Pool, 1997, p. 3, Meijaard, 1998 p. 19, 43). In our research, the focus on the process is independent of the type of strategy or its perspective.

\section{II.1. The process of strategic decision-making}

An important part of the research in strategic decision-making is devoted to the process or approach that is followed in making a decision and the structure of this process. Some of this research also focuses on the psychological and sociological motivation and the dynamics of group decision-making, an issue that we will not treat in our research (Cyert and March 1965, republished in 1993, 2002; Drucker, 1973; Mintzberg, 1973; Boles and Messick, 1995; Mellers et al. 1998; Schwartz and Cooke, 1998; Edwards and Fasolo, 2001; Pettigrew, 2001; Hutzschenreuter and Kleindienst, 2006). Many of these studies are based on theoretical discussions often leaving out empirical research. There is also a body of research, analysing actual life issues, mostly from questionnaires sent out to firms or from studies of published company reports and news items (e.g. Dean and Sharfman, 1996; Brouthers, Andriessen and Nicolaes, 1998; Hoskisson et al., 1999; Baum and Wally, 2003).

Another element of this literature are studies that result in instructive examples of methods to better organise decision processes: Simon (1947), Mintzberg (1973), Drucker (1973), Mintzberg, Ahlstrand and Lampel (1998) and Partovi (2007) have analysed strategic decision processes and offer pragmatic managerial decision methods and tools. Strategic management textbooks often offer pragmatic illustrations and tools to better organise the strategic decision-making process. Drucker (1973), Mintzberg (1973), Porter (1985), Johnson, Scholes and Whittington (2005) and Hammond et al. (2006) have presented authorative 'best practice' normative guidelines that are widely cited and applied (e.g. by Schendel and Hofer, 1979, p. 53; Brouthers, 1998; Miller et al. 2002; Hough, 2003;). In some cases, these guidelines are based on many years of practical involvement in management and thus on observations of actual activities of executives, in others they are based on theoretical models that describe the process and its results.

There are diverging opinions on the approach taken by executives for strategic decision-making. Many argue that this process follows a structured and thus phased rational process. This approach is supported in many studies in strategic management, taking the position that executives reach strategic decisions after a structured process of careful consideration of circumstances, alternatives and consequences. Information on matters such as competition, markets, technologies and the societal environment affecting the organisation specifies the implications of the feasible alternatives for the decision to be made and plays a crucial role in obtaining the parameters of these alternatives. Making rational decisions presupposes that information is available that enables an executive director or a board of directors to make the best possible decision under the circumstances (Corner, Kinicki and Keats, 
1994; Noorderhaven, 1995 p.29; Hoskisson et al., 1999; Baum and Wally, 2003; Citroen and Hooghoff, 2003; Weirich, 2004 p.21, 212; Nutt, 2005; Hammond, Keeney and Raiffa, 2006). A typical rational decision-making process thus consists of a number of phases that have to be followed without forming a premature opinion about the eventual decision whereby the decision itself is the last phase. We will not treat in our research the implementation phase of the decision and the evaluation of the results as both are phases that occur after the decision-making process proper (Boles and Messick, 1995; Baum and Wally, 2003; Miller et al. 2004).

The opinion that executives follow a rational approach is however not uncontested. There are studies claiming that strategic decisions by executives are taken relying on bounded rational processes rather than rational processes because of the fact that human beings only have limited cognitive capabilities and can only comprehend and use a limited amount of the information that is available. This leads to the view that executives take strategic decisions in a basically unstructured process accepting 'satisficing' instead of optimal solutions. The notion of 'satisficing' is a fabrication of 'satisfying' and 'sufficing', coined by Simon (1960, p.6); it expresses the principle that people seek to obtain a satisfactory and sufficient solution to a problem, not necessarily the optimum solution. Eisenhardt and Zbaracki (1992), Conslik (1996) and Williams (2002, p.15) discuss this approach and accept it as an explanation of the way decisions are reached.

A related point of view in yet other studies is that in some cases a 'gut feeling' primarily based on an intuitive process can lead to equally valid decisions (Sauter, 1999; Khatri and Ng, 2000; Sinclair and Ashkanasy, 2005). For the executive deciding on such feelings, the exact role of information cannot be determined as mostly subjective insights constitute the knowledge base for the decision in such an intuitive process and the decision-making process is unstructured as there are no phases that follow each other in an organised way.

In addition, in research on cultures in specific countries and companies, cultural values are also assumed to have an influence on the process of decision-making. We will discuss this later in paragraph II.1.5.

These discussions imply that the approach taken by executives during the decisionmaking process is dependent on the way information is actually acquired and used in this process. Given the fact that modern computer and communication technologies such as the Internet have increased greatly the amount and the accessibility for information as well as the information management options that are available, the question is justified whether these changes have a noticeable effect on the strategic decision-making process. Investigation of the role and use of information therefore is a proper test for the approach taken during the decision-making process that is followed by executives. 


\section{II.1.1. Quality aspects of the decision-making process}

Quality is often considered to be a subjective attribute, but as shown by the International Organization for Standardization (ISO) it can indeed be quantified. Pirsig (1974, p.228) phrases this as "the whole purpose of scientific method is to make valid distinctions between the false and the true...., to eliminate the subjective, the unreal, imaginary elements from one's work so as to obtain an objective, true picture of reality. When one says that 'Quality' is merely subjective, this implies that quality is imaginary and can therefore be disregarded in any serious consideration of reality". But quality is also a way of defining conformance to specifications and in this way, quality does become a concrete, measurable quantity.

Executives will surely make all possible efforts to pursue an effective and efficient decision-making process in order to reach the most appropriate decisions. However one can easily argue that the result of the decision-making process cannot under all conditions be the optimal solution to a specific problem, even if the decision was taken in a fully rational process.

In strategic management quality is an issue that is researched intensely. Feigenbaum, (1961, 1991 p. xxi) describes quality is as "the single most important force leading to the economic growth of companies in international markets". Elsewhere is stated that "the concept of 'quality' is one of the most frequently repeated themes among managers and executives in contemporary organisations" (Reeves and Bednar, 1994). Therefore, the study of the decision-making process, which is in essence a study into the quality of this process is highly relevant.

Is there a way to judge if the decision-making process practised by executives was indeed the best possible course of action, and as a follow up of this question, do decision makers reach the 'best possible decision'? This matter can only be resolved in retrospect, looking at the outcome in a longer perspective.

There will always be circumstances that interfere with an optimal performance as decision processes are not made in isolation. Disturbing factors are lack of accurate information, ambiguity of alternatives, time pressure, budgetary constraints or uncertainty of the environment. If later in time doubts arise on the good judgment throughout the decision-making process, an analysis of the process that was followed will have to be made taking into account the restraints that existed at the time and the information that was or that could have been available then (Dean and Scharfman, 1996).

Nutt (2005) attempted to find an answer to this question, in his research where he studied over 300 decisions made, he asked the decision-makers whether, in retrospect the outcome of a decision had been positive. The intrinsic value of a decision to the 
organisation would provide a kind of success indicator. To measure value, objective data describing the economic returns or benefits of a decision would give an answer. However, two-thirds of the decision makers in his study would not provide access to information describing money lost or gained, or claimed that reconstructing the economic benefits of a decision would be prohibitively expensive.

Whether strategic decisions are part of a continuous strategy or go up a more or less new alley has an influence on the quality of the process. In most cases an earlier approved strategy, the result of strategic planning will form the foundation for fresh decision-making. In some cases however, sudden unexpected opportunities present themselves or sudden emergencies occur and the decision process has to be accelerated. Mintzberg and Waters $(1985,1990)$ state that in a well-organised environment, executives anticipate on such contingencies as well as is possible by taking continuously small decisions so as to be able to give a fast rational reaction when such an issue arises. Information collected with foresight will often be of significant assistance in such cases.

Of the many factors that influence the quality and direction of strategic decisionmaking, the potentially contrasting motivations of actors in the process have been studied intensively. A commonly accepted theory is based on the concept that interests of individuals in an organisation can deviate from the best interests of the organisation itself or from interests of other stakeholders in the firm. A conflict could arise if both agents are primarily utility maximisers. Agent theory discusses these interests that have an influence on the direction a company is taking, especially when in an organisation the executives have an informational advantage over the shareholders (Davis et al. 1997; Eisenhardt, 1989; Jensen and Meckling, 1976). This is illustrated in a scenario whereby the executive is depicted as "individualistic, opportunistic and self-serving" (Tosi et al. 2003). Present day government regulations on company management should have made this way of operating less likely.

\section{A standard for quality in strategic management}

Quality in the decision-making process, though seemingly a subjective parameter with no fixed definition, can be approached by objective measures. In order to become a tangible entity, quality has to be related to an object by means of concrete criteria such as elapsed time or throughput, satisfaction or - in our case - , observable phasing and the resulting structure of the decision-making process.

A measure of quality is found in the published standards of the International Organization for Standardization (ISO) that represent an international consensus on good management practices with the aim of ensuring that the organisation can constantly deliver the product or services that meet the customer's quality requirements and applicable regulatory requirements. The ISO standards "specify what requirements a quality system must meet, but does not dictate how they should be met in an organisation - which leaves great scope and flexibility for implementation in different business sectors and business cultures as well as in different national cultures". 
ISO has long been active in specifying standard procedures for operational tasks in both private and public sector organisations. ISO has also embarked on standards for managerial tasks such as decision making in ISO 9001. This international standard specifies requirements for an organisation's Quality Management System. It is part of a family of standards published by the ISO often referred to collectively as the 'ISO 9000 series' (ISO Standards Compendium, 2003).

"The ISO 9001 standard specifies requirements for a quality management system for any organization that needs to demonstrate its ability to consistently provide products that meet customer and applicable regulatory requirements and aims to enhance customer satisfaction. The standard is used for certification/registration and contractual purposes by organizations seeking recognition of their quality management system (ISO Examples, 2007). "The ISO 9000 family of standards are among ISO's most widely known standards ever and is implemented by some 900.000 organisations in 160 countries. ISO 9000 has become an international reference for quality management requirements in business-to-business dealings".

An example of the ISO 9001 standard in use:

A large chemical processing company was required by its major customers to gain registration/certification to ISO 9001. In order to obtain additional benefits, company leadership planned a comprehensive management strategy based on ISO 9000 and ISO 9004. A thorough review of their business processes indicated that all elements of ISO 9001 were applicable to their quality management system.

(C) International Organization for Standardization, 2003.

This ISO 9001 standard is applicable to all processes of the organisation and consequently the quality management principles on which it is based can be deployed throughout the organisation, including the executive management level. The focus of this standard is the achievement of ongoing improvement, measured through the satisfaction of customers and other interested parties. The standard consists of guidance and recommendations but is not intended for certification, regulatory or contractual use; but it opens the possibility to have a quality system that is certified by an external certification agency.

The standard specifies in four sections the activities that need to be considered to implement such a system. The requirements - Quality management system, Management responsibility, Resource management and Measurement, analysis and improvement - apply to all organisations. The standard defines what a company should do consistently to provide products that meet customer and applicable statutory or regulatory requirements. In addition, companies seek to enhance customer satisfaction by improving their quality management system. The ISO 9001 standard recognises that the word 'product' applies to services, processed material, hardware and software intended for, or required by customers. 
Included in this standard are guidelines for organising management procedures. One such procedure, shown below, is the 'factual approach to decision-making'. It summarises many aspects that lead to the best quality for a rational decision process.

The ISO 9001 quality standard is based on eight quality management principles: customer focus, leadership, involvement of people, process approach, system approach, continual improvement, factual approach to decision making and mutually beneficial supplier relationships.

The 'Factual approach to decision making' certifies that effective decisions are based on the analysis of data and information. The key benefits are:

Informed decisions.

An increased ability to demonstrate the effectiveness of past decisions through reference to factual records.

Increased ability to review, challenge and change opinions and decisions.

Applying the principle of factual approach to decision making typically leads to:

- $\quad$ Ensuring that data and information are sufficiently accurate and reliable.

- $\quad$ Making data accessible to those who need it.

- $\quad$ Analysing data and information using valid methods.

Making decisions and taking action based on factual analysis, balanced with experience and intuition.

There are many different ways of applying these quality management principles. The nature of the organization and the specific challenges it faces will determine how to implement them. Many organizations will find it beneficial to set up quality management systems based on these principles.

The ISO Quality Management System

(C) International Organization for Standardization, 2003.

\section{II.1.2. A rational approach to decision-making}

There are many arguments that point to the option that strategic decision-making can be approached as a straight forward, structured and rational process, based on a logical reasoning and formal analysis, dictated by accepted procedures, that progresses efficiently as a choice between a number of alternatives by the executive responsible for the issue at hand. The basis for a rational decision-making process is an understanding of the implications of all identified and thereby feasible alternatives. Rationality implies that this process is characterised by the fact that the decision is reached without a prejudiced opinion about the eventual decision. "The emphasis in so doing is on dispassionate, impersonal and objective logic whereby each potential solution of an issue is compared against predetermined criteria in order to assess the degree of fit" (Miller et al., 2002). 
The structured approach of the decision-making process is shown by the fact that the decision is reached after dealing in due consideration with a number of distinct phases that are programmed in time and that can be observed and studied in a rational and objective way. Several authors e.g. Drucker (1967), Mintzberg et al. 1976, Nutt (1999) and Johnson et al. (2005) have formulated conditions for such a rational and structured process, which are nicely summarised by Koopman and Pool (1997, p. 7, 17):

- $\quad$ the issue or problem is properly identified and the objectives of the decision are well defined by the decision-makers,

- the decision-makers actively search for information on potential alternatives,

- $\quad$ they carefully weigh the advantages and the disadvantages of these alternatives and the chances of success for each of them,

- even when a preliminary solution is in sight, new information or expert judgement is accepted, studied and analysed even if it is in contrast with earlier ideas and preferences,

- before a final decision is made, positive and negative consequences of all alternatives are re-examined,

- provisions for implementation of the decision are prepared, (including a contingency plan that might be required if the implementation fails),

- $\quad$ a procedure is defined for follow up of the decision to judge if the purpose has been achieved or has to be reconsidered.

Input of information is essential in the course of these phases in order to be able to consider parameters such as the business environment, internal and external influences, alternative lines of thought or changes in earlier available information. The way that executives decide to acquire and make use of information is a determining factor in the process of decision-making, rationality involves choosing which information to order and read and which not to (Schwenk, 1986; Hussey, 1998, p. 18; Choo, 2006, p. 104). Formalised routines improve the flows of information throughout the organisation, including information to strategic decision-makers and thereby speed up strategic decision-making according to Baum \&Wally (2003) in their study of firm performance.

The rational approach to strategic decision-making requires that the process be properly structured even if the issues to be resolved will evidently often be unstructured. Mintzberg et al. (1976) explain this as follows: "the decision-maker deals with unstructured problems by factoring them into structurable elements".

The term 'unstructured' in this context can be clarified as involving "a process that has not been encountered in quite the same form and for which no predetermined and explicit set of ordered responses exist in an organization" (Mintzberg et al., 1976). They conclude that "decision processes are programmable even if they are not in fact programmed... a basic logic or structure underlies what the decision maker does." Not unexpectedly, Frederickson (1984) found that chances for a rational decision-making 
process are more positive in a stable organisation than in an unstable one because critical decision variables can be more easily identified and taken up in a stable organisation.

The rational approach does not imply that every titbit of information must be located, accessed, retrieved, analysed and utilised before a decision can be reached. Such thoroughness would result in less than optimal decision-making because unlimited continued looking for and accessing every piece of information that might be of use and whose existence is assumed would lead to infinite regress (Popper, 1935 s.4, 1963, p.21). Utility maximisation and awareness of diminishing returns stipulate that equilibrium be reached between the cost of obtaining additional information on which to base the decision-making process and the expected benefit of this additional information in order to prevent a regress about 'deciding how to decide' (Noorderhaven, 1995, p. 29; Weirich, 2004, p. 98; Winter, 1964 in Weirich, 2004, p. 221). However, the last few years have seen an increase in information resources and coverage that can be accessed and utilised via the digital services such as the Internet. Our purpose is to test whether this change has an effect on the decision-making process, to what extent this process is supported by information and whether it can nowadays be more easily a rational process.

\section{Modelling the decision-making process}

'A picture is worth a thousand words.'

Visualising the outcome of studies on the structure of the decision-making process in a flow diagram often clarifies the message of the study. Illustrative models of the decision-making process have been developed by Simon (1960), Corner, Kinicki and Keats (1994), Williams (2002), Carrington (2003) and Lee and Cummings (2004). Some authors consider implementation of the decision and evaluation of the results to be an integral part of the decision-making process (Baum and Wally, 2003; Boles and Messick, 1995).

In fact, most of the models of the decision-making process mentioned here follow similar basic ideas of the approach, indicating a sequence of phases or steps to be passed and provide insight in the structured decision-making process from different viewpoints that each has its own purpose and merit.

Feasible other approaches are not as easy to model in a flow diagram as they are not equally structured.

In most of these models, a number of criteria are indicated for each of the phases in the decision-making process that is pictured:

- from what situation does the present phase originate,

- what are the inputs from within the company,

- what are the inputs from external sources,

- to what phase in the decision-making process does the result of the phase under consideration provide further input. 
Some models go in much more detail to be able to research influences of a large number of potentially occurring conditions.

In a simple linear model, Simon (1960, p.40) proposes the four phases: "intelligence (fact-finding) $->$, design of courses of action $->$, choice from alternatives $->$, review of past actions $\rightarrow$, implementation".

Cyert and March (1993, p.161) model the process by specifying a set of four relations, "the (quasi) resolution of conflict, the avoidance of uncertainty, 'problemistic search', i.e. searching for solutions, and organisational learning".

A different approach, highlighting the psychological processes in the decision-making process is shown by Corner et al. (1994) in figure 1 .

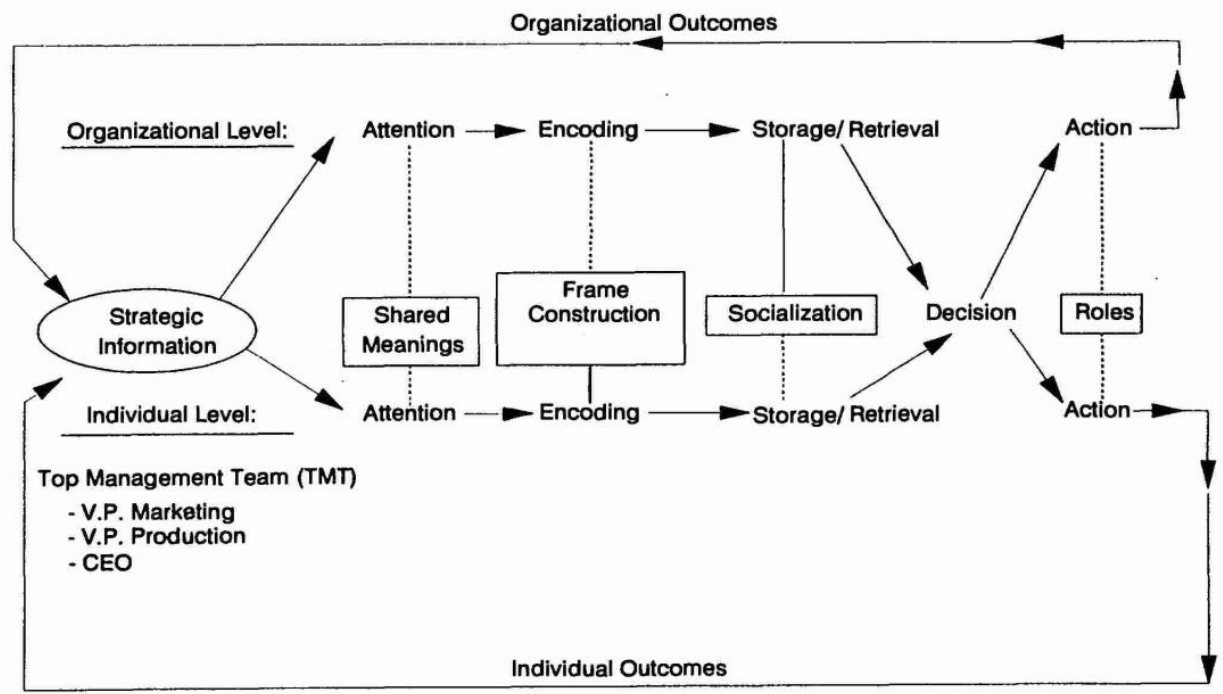

Figure 1: A parallel process model of strategic decision-making (Corner et al. 1994).

They depart from the premise that in organisations the information processing for strategic decision-making occurs in two parallel processes that take place at the same time: on an individual and on an organisational level, often a management team. At the individual level are the members of the top management team since they are responsible for all strategic decision-making. The way these two process levels interact is shown in the model that they designed.

In the first stage, the attention is focused on the collection of information. In the second stage, the information is 'encoded' in order to be understood. In the third phase, before the decision, the information is stored, for the individual this will be in his or her own memory, for the organisation in a collective memory. The decision then for both levels is based on information retrieved from storage.

On the line 'Attention-Encoding-Storage' are the decision-making processes; 'attention' is a focus on information and is the first stage in the process because 
information must capture the executives' attention before it can be processed and given a sensible meaning. The solid lines in the model indicate causal sequences and the dotted lines show the way the 'stages' in the process are filled. The boxes show the interactions between the two levels of the group. The phases after the 'attention' will be explained later in the paragraph on the information factor in decision-making.

A model with a large number of steps (Williams, 2002, p.17) starts off by giving an account of criteria to be met, suggesting four main phases as starting points: defining the problem, defining criteria, generating alternatives followed by implementation of the decision but then this model-building continues by specifying sub-steps within each of those phases, 24 in total. This model may be useful for a theoretical treatment but in our view does not allow for an analysis of empirical results as observing decision-making in such detail would not be feasible.

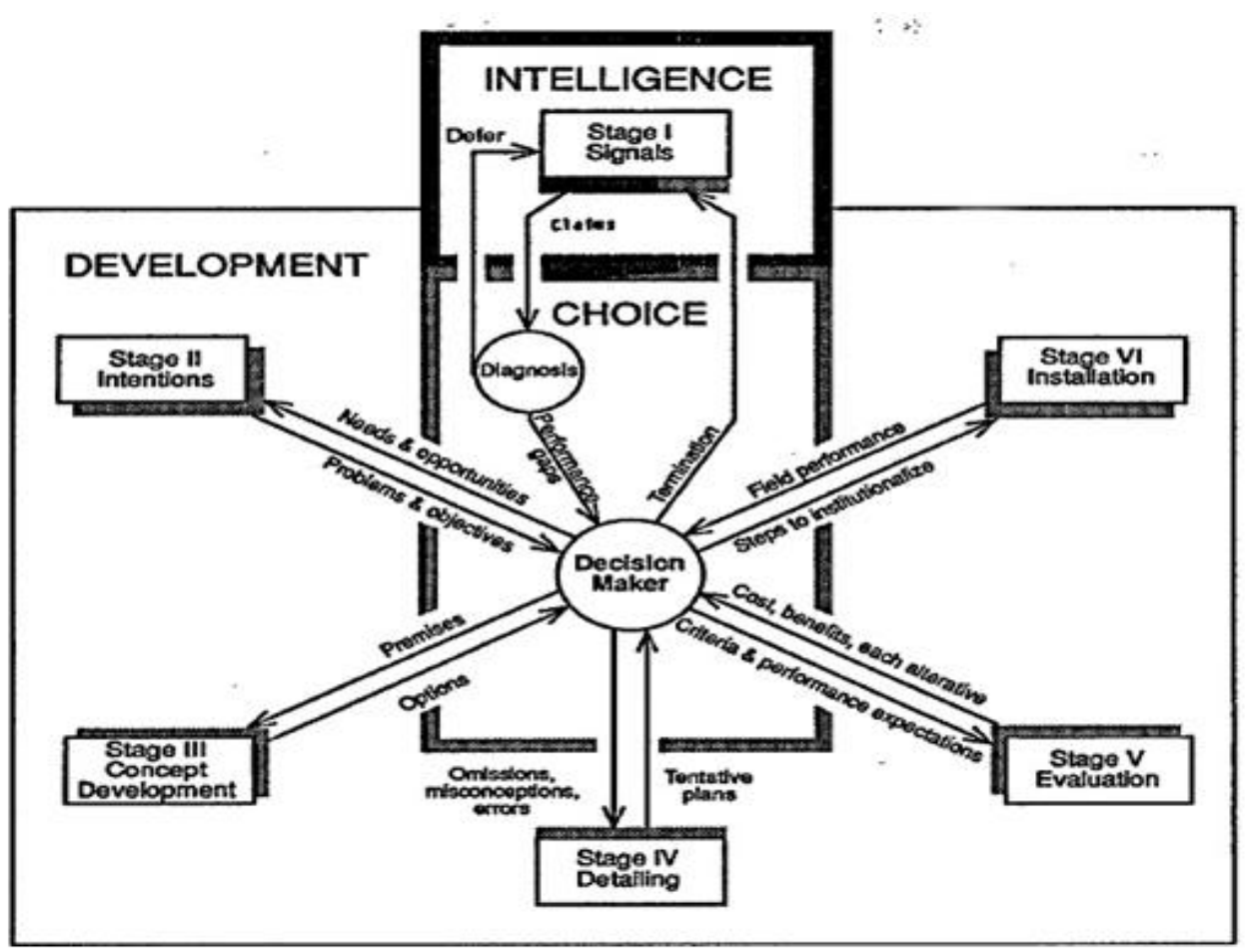

Figure 2. The transactional representation of decision-making (Nutt, 1993).

In a detailed transactional representation of the decision-making process, Nutt (1993) pulls together the phases and routines identified in several studies in the literature on strategic decision-making that he analysed (figure 2).The three major blocks of activity are intelligence, choice and development.

The stages (we call them phases) and routines refer to organisational decisionmaking, planning and design, innovation, policy formulation, organisational change and organisation theory. The boxes in the model represent decision-making stages 
that identify the types of information that should be collected. The circles identify where choices are made by a decision maker to monitor information gathering. The arrows originating from the decision-maker point to the decision-making stages or phases that identify actions called for by the decision-maker and others involved in the decision process. The arrows pointing towards the decision-maker indicate the direction of feedback from the activities and the information that flows between a decision-maker making choices and his team of technical staff and department managers, the 'support team'.

Stage I, is initialised by signals interpreted as information from either within the company or from the environment. Depending on the substance and urgency of the matter, it is recognised as a 'claim' that needs attention or can be deferred to later. Claims that need attention are called 'performance gaps' that trigger a decisionmaking activity here.

Notable is that Nutt in a much later paper (Nutt, 2005) states that "decision making begins when an idea surfaces and decision makers make a cognitive adaptation, drawing on their intimate knowledge of the situation", a more open-ended approach. But anyway, the 2005 paper builds on the 1993 scheme.

In stage II, called 'intentions', the decision-maker specifies needs and opportunities suggested by the claims. In stage III, called concept development', premises are identified that indicate ways to deal with the issues at hand. The support team collects options which are tested and detailed in stage IV by the decision-maker. In stage $V$ the alternatives are further evaluated for their criteria and expectations such as costs and benefits. This evaluation can result in a search for alternative solutions. Stage VI represents the installation or implementation of the preferred option that is selected in this decision process. This model is different from most others in that it is not linear, but illustrates the dialogues between members of a support team and the decision-maker that according to Nutt are essential for successful decision-making.

\section{Model developed for this study}

In order to facilitate the analysis of the structure of the decision-making process and to test the hypotheses, we have developed a model in a flow diagram (figure 3 ) that illustrates the successive phases in a structured process and the information obtained in this process, based on the models presented in the literature discussed above. For our purpose, i.e. to test whether the model is a valid representation of the observed processes, the model does not per se have to follow a generally accepted management theory. The model combines sufficient detail for our purpose of describing the specific phases and their inputs during the process.

We will evaluate whether the observed approaches and the information used in these processes of actual strategic decisions taken by executives in industry can be adequately fitted in this model. 


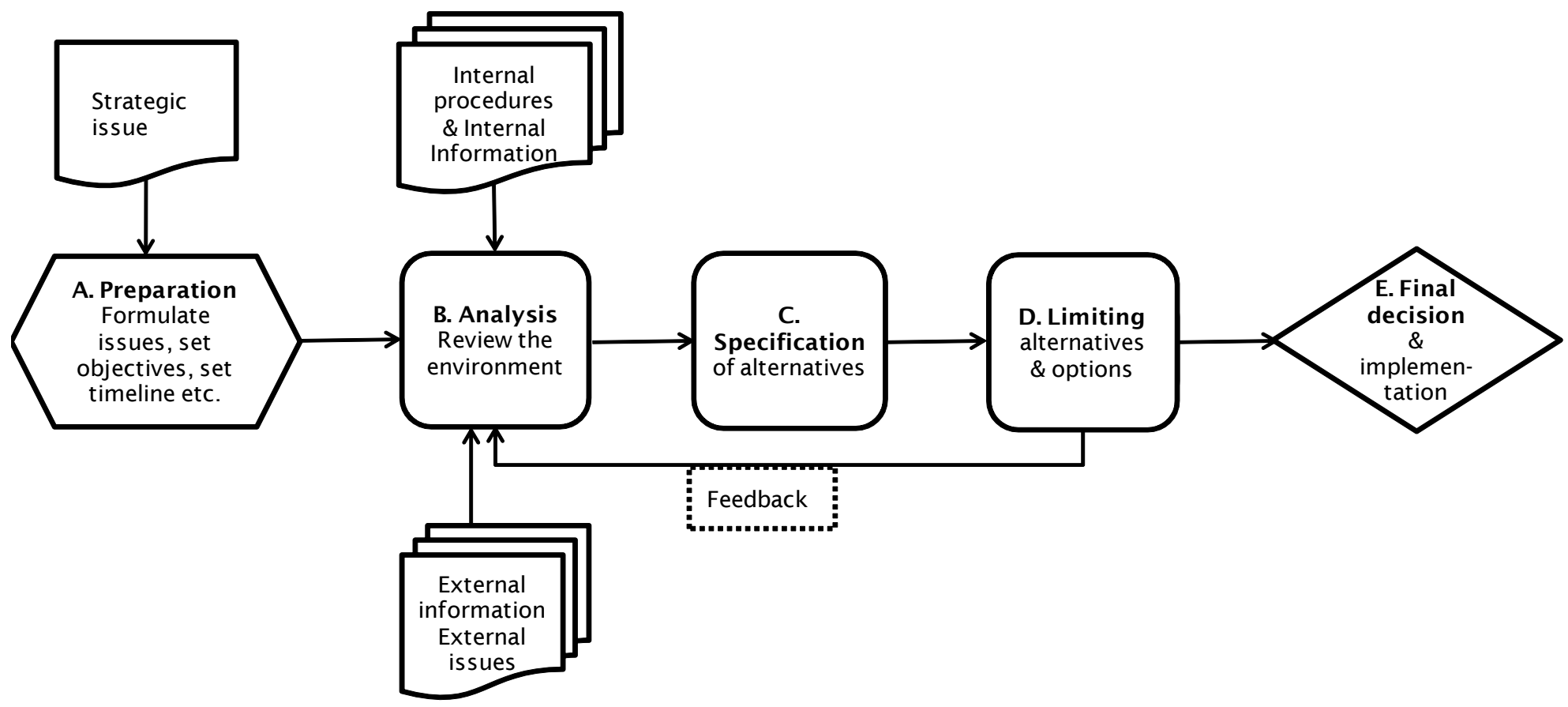

Figure 3: Model proposed in this study for the structure of the decision-making process.

Boxes indicate the five phases in the decision process and contain parameters that provide input for the indicated actions. Arrows indicate the main direction of interactions. 
The model contains five distinct phases that are each delineated in time. For each phase arrows indicate the inputs - from what situation does the present phase originate - and the outcomes - to what phase in the decision-making process does the result of the phase under consideration provide further input. For the first two phases, the internal and external information sources are shown, what are the inputs from within the company, what are the inputs from external sources; the last three phases each derive from the previous steps in the process.

The successive phases in the model are:

- $\quad$ preparation by formulation of the issue and set objectives for a discussion on the strategy to be followed and possibly set a timeline for the decision-making process to follow

- collection of internal and external information, review and analysis of internal issues and procedures as well as the technical and economic environment of the organisation

- $\quad$ specification of alternatives, analysis and design of options and preparing a plan of action, including an implementation plan

- limiting options by choosing between the potential alternatives that are considered

and finally,

- $\quad$ reaching a decision, followed by implementation of the route chosen.

We expect that in some cases the phase designed to limit the potential alternatives (phase D) will need to apply feedback to the phase that analyses the environment (phase B) in order to look at additional information and draw conclusions that need to be recycled through the specification phase before a conclusion can be drawn.

As the model aims to give an insight into the approach that executives take when making strategic decisions, the issues discussed with the executives will be analysed for occurrence of distinct phases during the decision-making process. If such phases are recognised, they will be mapped onto the proposed model and in that way the model can be tested for its suitability.

This research thereby focuses on the process of decision-making and the information flow that is called for and not on the substance or quality of the actual decisions themselves.

\section{II.1.3. A 'satisficing' approach to decision-making}

"Rational human behaviour (in decision making) is something intermediate in character between chance and physical determinism..... Some of our decisions are 'snap-decisions', taken without deliberation, since we often do not have enough time to deliberate".

(Popper, 1972, p.228) 
The approach taken by executives to strategic decision-making processes does not have an absolute connotation but is part of a continuum between fully rational and fully irrational behaviour as indicated by Popper. We have seen before that several studies nevertheless claim that decision makers can only deal with 'bounded rational' processes. Managers faced with strategic decisions therefore cannot do so in perfect rationality applying expected utility judgements but can only meet the needs of the moment by making these bounded rational decisions rather than looking for optimal decisions. Simon has coined the word 'satisficing' for such decisions that are satisfying and sufficiently fitting (Simon, 1957, p.196, 1960, p.6; Schwenk, 1988; Eisenhardt and Zbaracki, 1992). This notion is upheld by an argument stating that "there are valid reasons to keep in mind the issue of bounded rationality in economic models as it helps explain much of the behaviour of decision makers" (Conlisk, 1996; Williams, 2002, p.15).

None of these discussions touches upon the fact that in a rational and structured approach, limited capabilities of executives are equally admitted; but within these limitations, a rational process of a decision can result, accepting that attempting to collect and analyse complete information would lead to infinite regress.

Although most authors of strategic decision-making research do agree with the view that in general the decision-making process passes through a number of distinct phases, advocates of satisficing decisions do not accept that this view implies that these specific phases are based on procedures that can be defined as being elements of a structured process. These authors all refer to publications of Herbert Simon (e.g. 1947, p.72 and p.80) where he analyses the rationality and psychology of strategic management decisions. Although the demarcation between a structured decisionmaking process and an unstructured process should not cause an argument, several authors have commented on the basis of this distinction. Apparently, they believe that the decision-making process, thus described as ill- or un-structured, consists of phases that are themselves unstructured in such a way that they cannot be related to a clearcut time sequence. (Perkins and Rao, 1990; Kettelhut, 1991; Teng, 1996; Eom, 1998; Partovi, 2006; Power, 2007).

Simon $(1960$, p.40) initially agrees that there are a number of phases that imply some structure when he states: "Our usual image of the decision maker pictures him as a person at the moment of choice, ready to plant his foot on one or another of the routes that lead from the crossroads. This image falsifies decision making by focusing on its final moment and ignores the whole lengthy, complex process of alerting, exploring, and analyzing that precede that final moment, and the process of evaluating that succeeds it." But Simon also speaks in a different tone by stating that strategic decisions "are basically ill-structured and non-programmed and deserve a custom-tailored treatment" (op. cit. p.6) and that "(strategic) decisions are non-programmed to the extent that they are novel, unstructured and .... that there is no cut-and dried method for handling the problem" (op. cit. p.46). This point thus confirms his much quoted view that if an issue is unstructured by itself, it follows that the process of decision-making is unstructured 
as well, even if a number of phases can be distinguished in that process. Simons' view seems to imply that the decision-making process, if it concerns novel and strategic issues, is in practice unstructured and therefore cannot be observed and analysed in a proper scientific way. As we have seen earlier, Mintzberg et al. (1976) have rebutted this view, explaining that in deciding on issues that have not been encountered in quite the same form and for which no predetermined and explicit set of ordered responses exist in an organisation, "the decision-maker deals with unstructured problems by factoring them into structurable elements".

Organisational choice takes place in response to a problem and involves identifying alternatives that are acceptable from the point of view of the goals stated here. In the case of companies studied by Cyert and March (1963, 2nd ed. 1993, 2002), they have recognised goals that aim at maximising profit, increasing market share, optimalisation of inventory management and most favourable production conditions. They state that 'uncertainty is a feature of organizational decision-making with which organizations must live'. Such uncertainties exist with respect to the performance of the market, the deliveries of suppliers, the attitudes of shareholders, the behaviour of competitors, the actions of governmental agencies etc. Frederickson (1984) defines uncertainty "as the difference between the information needed to perform a task and the information that is available". Cyert and March (2002, p. 152, 166) commenting on uncertainty, state that a way often taken by organisations "is to avoid uncertainty by giving preference to making decisions on pressing short term problems rather than developing long range strategies". In their view uncertainty prevents a rational search for information but leads to a search for information that they call a 'problemistic search', which is 'simple-minded and biased', leads to satisficing decisions and does in no way increase the learning curve for the organisation.

Explaining the concept of 'bounded rationality' in some cases involves a discussion that ridicules rational decision-making and reverts to absurd reasoning; such an example is given here, in which the impossible range of 'all' criteria, options etc. are seemingly required for a rational decision approach. On the other hand, decisions based on 'self interest' and 'favoured options' are equally exaggerated. 


\begin{tabular}{|lll|}
\hline $\begin{array}{l}\text { Decision-Making } \\
\text { Step }\end{array}$ & $\begin{array}{l}\text { Rational Decision } \\
\text { Making }\end{array}$ & Bounded Rationality \\
\hline Problem definition & Real problem is identified & $\begin{array}{l}\text { Problem primarily reflects the } \\
\text { decision maker's interests, } \\
\text { understanding, and needs }\end{array}$ \\
Criteria definition & $\begin{array}{l}\text { All relevant criteria are } \\
\text { identified and weighted } \\
\text { appropriately }\end{array}$ & $\begin{array}{l}\text { Limited criteria are identified, } \\
\text { and evaluation is influenced by } \\
\text { self-interest }\end{array}$ \\
$\begin{array}{l}\text { Alternative generation } \\
\text { and evaluation }\end{array}$ & $\begin{array}{l}\text { All options are considered, } \\
\text { and all consequences are } \\
\text { understood and taken into } \\
\text { consideration } \\
\text { All participants understand } \\
\text { and support the solution }\end{array}$ & $\begin{array}{l}\text { favored option is aiven priority, and } \\
\text { consideration halts when a "good } \\
\text { enough" solution is found }\end{array}$ \\
$\begin{array}{l}\text { Implementation } \\
\text { influence the amount of acceptance } \\
\text { and commitment to the solution }\end{array}$ \\
\hline
\end{tabular}

Figure 4. Model comparing rational decision-making versus bounded rationality (Williams, 2002, p.15)

(The concept of intermediate steps in the process has been discussed earlier)

Such a model seeks to indicate the characteristics of rational decision-making versus decision-making under bounded rational conditions in an overly schematic way. The model indicates how in each step the processes are based on different views. These views are summarised as differences in objectivity: real problem and all relevant criteria on the rational side versus needs, limited criteria and self-interest on the bounded rational side. A problem with such a scheme is that it attempts to show how a decision maker can be excused for irrational behaviour and lack of control by listing the motives that are given for this behaviour.

Williams in this model also proposes the limited option that "consideration halts when a good enough (satisficing) solution is found" apparently meeting the basic requirements for a 'satisficing' decision. We observe that this motive by itself is already sufficiently rational and certainly not 'bounded' as is indicated by the theorems of Popper, warning for infinite regress. As such, the model is an oversimplification. Kets de Vries, (2005) has found that in such cases there may be a manifestation of neurotic behaviour, leading to "artificial differentiation by which an unwarranted, almost neurotically self-centred behaviour - defined as 'bounded rationality' - is set against an exaggerated rationality based behaviour - defined as the real problem covering all criteria, all options and all participants". But these observations do not aid in better understanding the issue of bounded rationality in current decision-making.

The discussion on bounded rationality in strategic decision-making is certainly not closed. This is made clear e.g. by Foss $(2002,2003)$ in his opposing commentaries of less than rational behaviour that call bounded rationality "dressing up a theory with arguments that are essentially empty in an explanatory sense, but are nevertheless made 
because they help to persuade... which is specifically invoked in the rhetorical practice of organizational economists"; and In the same way Foss later critically states that bounded rationality is "much cited, but little used" giving as reasons the fact that Simon phrased his publications on bounded rationality in such a negative way, blaming the decision-maker for his mistakes, that most authors do not like to be associated with such an explanation of failures of optimal decision-making.

Weirich (2004 p. 21, p. 212) offers a more philosophical rebuttal, stating that the effort made by decision-makers to maximise expected utility under all circumstances in order to reach satisfaction, by itself is not enough to guarantee rational behaviour. On the other hand, without this effort, no rational behaviour is possible and as long as the decision-making process is based on available information and as Weirich asserts can be called reasonable, there is no cause for blame. This is further specified by Weirich, stating that "calling someone irrational or not rational, is to blame him, because excuses are exemption from blame".

\section{II.1.4. Intuition in strategic decision-making}

There are also a number of studies in which authors value an intuitive approach to decision-making. Intuition then apparently substitutes for fully rational behaviour or at least exerts a stronger influence on the process than rationality does. A difficulty in commenting on this statement is that there is no clear-cut definition of intuition and that the impact of intuition can never be objectively measured or proven. In some cases serendipity, which can be verified may have been mistaken for intuition; in other cases, intuition is explained as 'built up experience' or 'internalised tacit knowledge', which both suffer from the same condition, they cannot be measured and if in a specific case an intuitive decision seems to yield to quantification, it is no longer an intuitive decision, but it has a rational basis.

If a plausible definition of intuition would have to be given, an example could be: 'understanding by quick and ready insight, seemingly independent of previous experiences or empirical knowledge and without apparent effort'. The word 'seemingly' is noteworthy here as most authors that discuss intuition positively agree that the basis of intuition lies, if anywhere, in fact in managerial experience, "the subconscious integration of all the experiences, conditioning and knowledge of a lifetime" (e.g. Bonabeau, 2003). Miller and Ireland (2005) have called intuition a "subconscious process of gut feeling or a holistic hunch", but then again mention this to be based on "synthesis of diverse experiences". We would argue that 'previous experiences' as a basis for intuition falsifies the issue, as managerial quality is always based on experience and therefore cannot be equated with 'intuition'.

Allowing intuition to form the major or even more unlikely the only basis for specific cases of strategic decision-making would constitute a special case of irrational behaviour. A more rational approach would be if intuition were the starting point of a decision-making process which is then followed up and justified by a sound analysis. 
Examples of authors supporting intuition as a basis for decision-making are Agor (1986), Simon (1987), Harper, (1988), Sauter (1999), Khatri and Ng (2000), Miller and Ireland, (2005) and Dane and Pratt (2007). The titles of the publications of these authors are indicative of how they view intuition as a 'tool' in decision-making by executives. But none of these authors favour a decision-making process exclusively based on intuition and they all mollify their initial statements in their conclusions. In order to get a clearer picture of the substance of these studies we present a number of arguments put forward for this 'tool'.

- Agor (1986): 'The logic of intuition: How top executives make important decisions'.

- Simon (1987): 'Making management decisions: the role of intuition and emotion'.

- $\quad$ Harper (1988): 'Intuition: What separates executives from managers'.

- $\quad$ Sauter (1999): 'Intuitive decision-making: Combining advanced analytical tools with human intuition increases insight into problems'.

- $\quad$ Burke and Miller (1999): 'Taking the mystery out of intuitive decision-making'.

- $\quad$ Miller and Ireland (2005): 'Intuition in strategic decision-making: Friend or foe in the fast-paced 21st century?'

- $\quad$ Sinclair and Ashkanasy (2005): 'Intuition: Myth or decision-making tool?'

- $\quad$ Dane and Pratt (2007): 'Exploring intuition and its role in managerial decisionmaking'.

Agor (1986) studied intuition by conducting a psychological test - the Myers-Briggs Type Indicator (MBTI) - scoring 2000 managers in diverse public organisations for their ability to use intuition and their actual use of this skill. One of the results of this study was that "intuitive ability varied by managerial level. Managers at the top in every organization studied, scored higher than middle- or lower-level managers on their ability to use intuition to guide their key decisions". He then later interviewed specifically those managers that scored in the top $10 \%$ on his intuition scale and obtained responses from 70 of these 'top-executives'. The conclusion from these 'intuitive' managers only was that almost all of them use their intuitive ability to guide their most important decision-making process. Though "as a group, they were quick to point out that they considered intuition to be only one tool of many to use in guiding their decisions. They did not advocate relying exclusively on intuition or abandoning traditional management practices."

Interestingly, less than half of the top executives in the sample were willing to share with colleagues the fact that they used intuition to guide their most important decisions. Instead, "they spent time and resources covering up how they actually made decisions, because intuitive executives often felt that their colleagues did not or would not understand that intuition can be a reliable basis on which to make important decisions". 
Simon (1987) calls intuitive decision-making 'non-rational' when he observes that "sometimes the term rational (or logical) is applied to decision making that is consciously analytic, the term non-rational to decision making that is intuitive and judgmental, and the term irrational to decision making and behaviour that responds to the emotions or that deviates from action chosen rationally". Simon explains intuition by stating that experienced managers have gained a large amount of knowledge that causes them to arrive often at problem diagnoses and solutions rapidly and intuitively without being able to report how they attained the result. But Simon also recognises that intuition does not operate independently of analysis, "rather the two processes are essentially complementary components of effective decision-making". Here too, it is hard to see where experience ends and intuition apparently begins.

Harper (1988) maintains that "top executives seem to possess skills that other managers lack...whether called insight, judgment, intuition, executive extrasensory perception (ESP), or wisdom, these skills help executives see things that other people don't see and incorporate factors that computer still cannot handle." And elsewhere Khatri and Ng (2000) state that "this quality, more than any other, may be what separates the true executive from the hundreds of thousands of managers".

In several publications on decision support systems (DSS) intuition is quoted as the reason that these systems are required as they can help sort out complicated relations. Intuition then has a very general connotation as the cure for any relation that is not apparent at first sight. Sauter (1999), author of several handbooks on DSS gives an example of this interpretation when she attempts to analyse intuition in order to better design decision support software. In doing so, she claims that managers employ intuition because they "are increasingly dissatisfied with established procedures for making decisions". Sauter recognises several types of intuition. Examples of these types are

- $\quad$ 'illumination': a sudden awareness of information

- 'detection': when a manager working on another issue, suddenly can draw relationships among facts previously appearing to have no relationship (we would rather use the word 'serendipity' for this effect)

- 'evaluation': this involves a feeling such as 'it doesn't feel right in response to data analyses or reports, such intuition can help users decide if analytical-based information is sufficient, or if inconsistent measures exist

- $\quad$ 'prediction': involves developing hypotheses without first analysing data.

She continues by making the 'paradoxical' (our words) claim that "to support managers in making intuitive decisions, Decision Support Systems can provide a means of locating and displaying previous problems, the decisions made, and the consequences of those decisions. The availability of descriptive modelling tools, such as statistical tools, helps decision-makers develop intuition". But then she continues with a cautionary comment, namely that "intuition can be negative as intuitive managers become 
impatient with routine, details, or repetition. They may reach conclusions too quickly, ignore relevant facts, or follow an inspiration when it is clearly wrong". Although we will never know for certain as the 'quality' of an inspiration is as immeasurable as the intuition itself, in the end, this inspiration can be the start of a rational process.

Sinclair and Ashkanasy (2005) define intuition as a "non-sequential informationprocessing mode, which comprises both cognitive and affective elements and results in direct knowing without any use of conscious reasoning". They subsequently attempt to develop a testable model of integrated analytical and intuitive decision making with the aim to measure intuition so defined. They identify several measures in the literature that are used to test intuition as a complex and multifaceted construct based on interviews, questionnaires and visual observation. However, none of these tests requires that intuitive and analytical decision-making are measured separately which is an absolute constraint if one wants to establish dissimilar mechanisms for these two types of decision making processes. Hence they raise the question "as to whether a comprehensive measurement is ever going to be achievable by means of a single tool".

Dane and Pratt (2007) first determine the various definitions of intuition of which they have found 17 different examples. They point out that psychological studies have shown that "a large proportion of cognitive thought occurs outside of consciousness". They then make an interesting distinction, "while the outcomes of intuitive judgments, are clearly accessible to conscious thinking, how one arrives at them is not". They maintain that intuition can be a useful tool if a decision involving a judgmental task has to be made under extreme time pressure. In their conclusions they also stress that "managers should be wary of using intuitions when faced with intellectual tasks".

Several success stories are mentioned in the literature that are attributed to intuition: Honda's entry into the US market (Schneider, 1989), Sony's development of the walkman, the purchase of the McDonalds brand by Ray Kroc (Gross, 1997). These stories can be discarded as urban legends (apocryphal, business legends) created "to bolster the heroic gambler" (Miller and Ireland, 2005).

Bonabeau (2003) similarly analyses some decisions that were apparently made intuitively, but he shows how the same executives blundered on other cases: Two examples are the successful creation, despite widespread criticism by Fred Smith of the Federal Express service; but Smith also later started a service called Zapmail that turned out to be a complete failure.

In another example, the investor Soros intuitively beat the currency market and so earned a fortune; but later he lost a similar fortune betting on Russian securities.

It should be realised that success in these cases is after the fact attributed to smart intuition, but this can of course not be proven. Moreover apparent failures of intuition, especially those based on 'gut feeling', that must undoubtedly also exist, will not readily be acknowledged or be made public. 
Some of the authors cited attempt to rationalise intuition by referring to the view that our two brain halves are functioning differently in 'hemispheric specialisation'; the left hemisphere supposedly is 'analytic' or 'logical' while the right hemisphere is 'holistic' or 'intuitive'. Right-brained decision-makers supposedly use an unstructured and spontaneous procedure of considering the whole rather than its parts, even when information is inadequate (Simon, 1987; Harper, 1988; Sauter, 1999). But scientists who have actually investigated hemispheric specialisation rarely made broad claims and have stated that both hemispheres together are deeply involved in activities such as music, mathematics and logical reasoning (e.g. Hellige, 1990).

All authors are also wise to give out a warning against the sole or major application of intuition in the decision-making process, it is often seen to be on a scale from entirely intuitively to entirely rationally.

This can be summarised as "intuition does not replace quantitative analysis if and when complete, accurate and timely information is available" (Harper, 2001) or "decisionmaking research shows that intuition is much less reliable than people believe and is thus disturbingly risky" (Schoemaker, 1993). Miller and Ireland (2005) are explicit when they state that "our analysis suggests that despite the increasing interest and the generally positive evaluations in articles written for executives and managers, intuition presents itself as a troubling tool. By explicitly considering an organization's goals, intuition's pitfalls become clear."

Bonabeau (2003) is also clear: "intuition has its place in decision-making, but anyone who thinks that intuition is a substitute for reason is indulging in a risky delusion. Detached from rigorous analysis, intuition is an undependable guide. This is also true for highly complex situations. The more options one has to evaluate, the more data one has to weigh and the more unprecedented are the challenges one has to face, the less one should rely on instinct and the more on reason and analysis".

Such objections clearly must be made to the above intuition theories as it has not been possible to measure intuition scientifically or to objectively determine whether a decision was made intuitively, while on the other hand a rational process can indeed be demonstrated methodically. Rather intuition seems to be used to explain explicitly and positively the final result of a process without paying sufficient attention to the decision-making process itself. Having said so, in our research we will still examine if we can find a manifestation of intuition as a relevant option in the interviews with executives.

\section{II.1.5. Influences of national and organisational cultures}

Strategic decision-making in some studies is mentioned to be influenced by a national or organisational culture that is the result of established values and morals. Culture in the context of this study is defined as the collective mental programming which distinguishes one group or category of people from another' and that can be an aspect of a national grouping or of an organisational entity. As discussed before, the decisionmaking process requires an assessment of environmental developments, threats and 
opportunities and strengths and weaknesses of the organisation. These considerations cannot be assessed fully objective, many are necessarily a function of personal or group perceptions and analysis and of accepted values. Therefore, in addition to the factors discussed in earlier paragraphs, the way the decision-making process takes form might also be influenced by such cultural differences (Scheider, 1989; Noorderhaven, 1995, p. 156; Hofstede et al., 1990; Hofstede, 2001).

Objections can be raised to strong attribution of culture to decision-making processes; firstly, company culture and national culture are 'phenomena of different orders' and should not be confused; secondly, the arguments for a homogeneous national culture are questionable with perhaps the exception of comparisons between Western countries and those in the Far East (Gerhart and Fang, 2005). Moreover, as globalisation has resulted in the fact that most industrial companies are no longer managed by executives from just one nationality or from one distinct culture, these companies have become truly international conglomerates (Carr, 2005).

Company culture is still expected to have an influence as it can be qualified as being either 'formal' or 'informal' and this type of cultural difference may have an influence on the intensity with which information moves upward from internal departments to the Board. But even so, in a formal organisation, if the organisation has an official information management policy (which is adhered to) for guiding new facts and trends to higher levels, this will have a positive effect on the decision-making process (Mintzberg, 1979, p.49; Noorderhaven, 1995, p.133; Kolman et al. 2003).

A manifestation of cultural differences is likely to be found primarily in the first phases of the decision-making process where it is decided whether an issue is worth to be put on the Board's agenda as a strategic issue or not and what type of information is acceptable. Scheider (1989) argues that culture "will influence how information is gathered and how information is interpreted within the organisation. As the use of information is embedded in social norms, the strategy formulation process cannot be considered culture free".

As an example, one of the parameters that is often cited in culture studies is riskaversion. In a risk aversive environment, preferably issues may be put on the agenda that have been identified beforehand and are already on a checklist. Furthermore, quantitative information is more easily accepted there and qualitative information is likely to be ignored as having the risk of being ambiguous (Noorderhaven, 1995, p. 156, Schneider, 1989). Along these lines, Teng et al. (1996) have found that the use of IT based decision support systems (DSS) has more influence in Far-Eastern countries that are assumed to be more risk aversive, than in Western countries. This can be explained by the fact that these systems yield mostly quantitative data as basis for decisions. In a later paper by the same authors, they find that the actual use of IT has more influence on communication during the decision-making process in Far-Eastern countries and the resulting information is taken more seriously than in Western countries; the reason probably being that the information is more analysed and thus 
takes longer to reach executives in those countries. Other parameters of IT usage such as the influence on problem formulation or generation of alternatives were shown to differ only marginally between these countries (Calhoun et al. 2002).

Min Chen (1995), quoted by de Alwis and Higgins (2001), mentions similarities in the major Far Eastern management systems, namely the Japanese, Chinese and Korean, countries that are considered to be influenced by the Confucian tradition - Confucian thought is directed at the ethical and loyalty aspects of human interaction such as the morally superior person who leads by example (Dollinger, 1988). As far as managerial control is concerned, these management systems are believed to have a strong vertical information sharing and control system. In terms of leadership styles and decisionmaking, the degree of authoritarianism is observed to be generally high, though Japanese managers seem to be more interested than the others in collecting information and seeking opinions from their subordinates.

Choo (2002, p. 242) - based on a study by Prusak and Matarazzo (1992) - mentions that there are noticeable differences in approach towards information management between successful Japanese firms and the conventional view of corporate libraries in Western companies. Japanese firms place a large value on information and information management is considered an essential cost of doing business so there is little concern about how to justify the investment or measure the payback of an information centre. Incoming information is almost always discussed in its contextual setting, which may be historical, political, technical, or cultural/sociological while the mission of the information function is closely aligned with the strategic thrust of the organisation.

Japanese decision-making is further characterised by an emphasis on the first step in the process, the defining of the question to discuss, this entails collecting as much as possible relevant information on alternatives before the discussion on the actual steps to be taken begins (Drucker, 1973, p. 374; Dollinger, 1988; Martinsons, 2006).

Another aspect of cultural diversity is that in the literature study we have performed, using generally available information sources such as internationally renowned printed and electronic journals and a variety of internet sites, 50\% of the reported research on decision-making and the contribution of information to that process is carried out at universities in the United States, 10\% in the UK, 30\% in 10 European countries and the remaining 10\% in Canada and Australia. This localisation of research predominantly in the USA and the UK probably causes some slant toward the Anglo-Saxon attitude in management practices. As Carr (2005) states from a study of 100 strategic investment decisions, "despite globalisation pressures, there are still significant differences in strategic investment decision practices internationally. In Anglo-Saxon companies the influence of financial figures is frequently pronounced, in terms of motivating the investment", this in contrast with the opinions in other parts of Europe, often referred to as the Rhenish model. Albert (1991), shows the differences between these two models explaining that "the Rhenish model of capitalism 
(Rheinischen Kapitalismus) is institutional, collective and based on consensus and stakeholder value, i.e. it consists in reconciling the interests of clients, employees, shareholders and the social environment in general. Anglo-Saxon managerial thinking advocates methods of management and organisation that are more transparent but predominantly based on shareholder value and financial gains and thus is more restrictive".

We would have liked to include the aspect of European-continental/Rhenish versus Anglo-Saxon management styles in our research, but obtaining data from these latter countries proved not possible because Anglo-Saxon CEO's did not give priority for this type of research and did not agree to an appointment for an interview.

We can conclude that culture has a marked influence on the way information is collected and communicated internally, but there are no convincing concrete indications of this influence on other aspects of the decision-making process as studied here.

We consider that basically a rational and structured decision process as discussed in previous paragraphs will continue to function in diverse cultures because personal qualities and capacities of executives in large multinational companies have a larger influence on this process than national cultural differences. Moreover, just as with decisions based on intuition, there are no accurate scientific methods to measure the effect of culture.

\section{II.1.6. The process of strategic decision-making - Conclusion}

The result of our discussions is that we now can distinguish the approach taken by executives in strategic decision-making by analysing the structure of the decisionmaking process. In order to facilitate analysis of this decision-making process, we have developed a model (figure 3) that represents the distinct phases in a structured process.

We have phrased a hypothesis based on our first question relating to the approach taken:

\section{Hypothesis 1}

Strategic decisions by executives are reached in a rational, well-structured process with the purpose to come to the best possible results under the conditions that apply in each specific case.

In order to test this hypothesis, as a first step in our research we will examine if we can establish that the process that is discussed was aimed at a strategic goal, that the phases that we identified in a decision-making process are in fact present and that they follow a distinct pattern in time. In order to base our considerations we need to ascertain what actually these phases in the decision-making process contain and whether they are always followed or only in a fraction of the total number of issues 
that we study. Furthermore, we have to look for indications of a bounded-rational or intuitive approach.

\section{II.2. Information as a factor in the strategic decision-making process}

"An organization behaves as an open system that takes in information, material and energy from the external environment, transforms these resources into knowledge, processes and structures that produce goods or services which are then consumed somewhere in the world. An organization uses information strategically to make sense of changes in its setting, to create new knowledge for innovation and to make decisions about its course of action".

(Choo, 2002, 2006).

As indicated by Choo, companies need information as a basis for strategic management and ensuing decisions. The influence of information on the strategic decision-making process and its role on the consideration of alternative solutions that are available will vary according to the requirements of each specific decision-making process. There is a distinct difference in the manner in which information is actually utilised under each of the three approaches discussed before. This is indicated in the boxes in our model (figure 3) that show how information is supplied in each of the phases in the decision-making process. This issue, which has a profound influence on the way strategic management is accomplished, will be the subject of the theoretical and practical treatment of our study.

Given the fact that modern computer and communication technologies such as the Internet have increased greatly the amount and accessibility of information, the question is justified: whether improved information acquisition and analysis abilities have a noticeable effect on the approaches taken during this strategic decision-making process. Therefore, we aim to study the process that is the foundation of strategic decision-making and the influence of information utilisation on the structure of this process as it is followed by the executive Board in industrial companies.

Executives of large companies need adequate high-quality information pertinent to their business in order to be able to manage their organisations in the most appropriate way. Auster and Choo (1996) and Choo (2006, p. 1) put it even stronger: "information is an intrinsic component of nearly every activity in the organization".

This information is a resource that can take many different forms during all the various phases of the decision-making process. The proper procurement, analysis and use of information is a crucial factor in this process and has a large influence on the eventual outcome thereof. March (1991) goes so far as to define decision-making primarily as "an act of information processing: the transformation of knowledge and information into managerial action". 


\section{Data, information and knowledge}

Knowledge generally is based on information. This raises the question of how the upgrading of information to knowledge has been achieved in the industrial environment. Van Riel et al. (2003, p. 14) call the development of rational knowledge "a deductive and analytical logical process. The decision-maker follows a series of predetermined and communicable steps that transform given external or internal information according to these rules of logic. Reasoning is thus seen as the processing of selected cognitive content, using the logic of causality: an intentional, constructive, rulebased and conscious activity. The building blocks of this analytical or rational knowledge are pieces of information or judgments." They further (op. cit. p.17) suggest that "there is a positive relationship between the amount of information available to the decisionmaker and the extent to which decision-makers are likely to make use of rational analysis to increase useful knowledge".

Nonaka (1991), who 'invented' the term 'knowledge management', states that "information is a flow of messages, while knowledge is created and organised by the very flow of information, anchored on the commitment and beliefs of its holder". He stresses that knowledge within the company has to be used to contribute to the decisionmaking process by the Board. This concept is the basis for Nonaka's treatises on knowledge management where he distinguishes two types of knowledge, tacit or implicit knowledge that is privately held by individuals in the organisation and explicit knowledge that is shared among individuals in the organisation. In other words, knowledge management has explored the differences between 'know how' and 'know what', an essential distinction according to its pioneers, supposedly first made by Aristotle (Prusak, 2001). As an example, Fahey and Prusak (1998) illustrate how information about customers becomes knowledge when decision makers determine how to take advantage of the information. In this way, knowledge is inseparable from thinking and acting.

Nonaka (1994) further explains how knowledge management (KM) in its current sense aims at identifying and analysing knowledge with the objective to maximise the value of this knowledge for the organisation. This effort entails opening up the 'private' intellectual capital of employees. Thus making more explicit and generally available the knowledge objects that reside within these employees' heads or private files but that are relevant for the organisation as a whole or - when it concerns strategically valuable knowledge - for executives on top of the organisation. Within an organisation, the exchange of information and ideas among knowledgeable members can result in new insights that are more powerful than the individual pieces of information. This process is called 'externalisation'

The kind of knowledge that is relevant here consists primarily of background information, analyses, opinions, argumentations, best practises etc. (Auster and Choo, 1996; Mackenzie Owen, 1999; Oppenheim, 2003a). Much of the literature on KM centres on the motivation of employees to bring their tacit knowledge in the open and 
share it with colleagues or store it in a company-wide information system such as an Intranet (e.g. van der Meij, 2007).

The result is a more "intelligent organisation, which is also a learning organisation that is skilled at creating, acquiring, organizing and sharing knowledge and at applying knowledge to design its behavior" (Choo, 2002, p. 12).

Another term used in relation to information, is 'data'. As a difference between data and information is often given that data is 'potential information' (Meadow, 1997; Oppenheim, 2003); a message or set of data may potentially be information but the potential is not always realised. In this report we will use the term 'information' as the basis for decision-making processes even if in many cases this information will have been 'internalised' to knowledge before it can properly be applied. Our study examines the influence of information, the gathering, availability, selection, value and its use during the strategic decision-making process.

\section{The strategic role of information}

"Information is something that changes the state of its recipient or, more specifically, the knowledge state. A slight variation is to say that information is what determines a decision or allows a choice to be made. Making a decision represents a change of state (from undecided to decided) on the part of the decision maker. A message understood by the recipient and which changes that person's knowledge base".

(Choo, Information management for the intelligent organization, 2002.)

The strategic role of information in decision-making is clearly put with the phrase that the knowledge state of the executive is changed by the use of information; in other words, information aids in reducing the uncertainty about an issue to be decided and thus is an important factor in the whole process of decision-making (Rowley, 1998).

However, this role is not always recognised, in strategic management theories and normative treatises that claim to cover all elements of the decision-making process, information as an essential factor in this process is often merely a hidden aspect (e.g. Drucker (1973), Mintzberg (1973), Hammond et al. (2006) and Porter (1985). The issue of the substance of strategic management information is seldom discussed or analysed as such in this context (Li, 2003). Moreover, in many studies on company performance (e.g. Hitt et al., 1998, Porter, 1985), management information is considered a production factor that is readily available and its accessibility is 'taken for granted' in the process.

Another symptom of the lack of appreciation of information as a basis for knowledge creation is when Porter and Millar (1985) mention how "the information revolution is affecting competition in three vital ways: It changes industry structure and, in so doing, alters the rules of competition, it creates competitive advantage by giving companies new ways to outperform their rivals and it spawns whole new businesses, often from within a company's existing operations". But there is one hitch with these statements of 
Porter and Millar; what they really discuss is 'information technology' instead of information, exposing a distinction that is often misapprehended (Wilson, 1997).

Porter (2001) later in his discussion of the advantages but predominantly of the dangers (myths) of the Internet, indeed does make this difference between information as a precursor to knowledge and information technology himself. He warns there that uncritical diminishing attention by firms to strategy development by depending unrealistically on the Internet information technology, can weaken the profitability of these firms. But he also states that the "great paradox of the Internet is that it's very benefits - making information widely available also makes it more difficult for companies to capture those benefits as profits", because this information then may become available to every competitor in equal amounts. We would judge that when a company intends to obtain a strategic advantage from open information sources, the strength is in the proprietary analysis of the information leading to new strategic insights.

On the other hand, several authors are quite aware of the value of information in the decision-making process. Cyert, Simon and Trow (1956, p.247) found that in many decisions, the largest share of man-hours in the decision process was devoted to gathering information to determine the consequences of several alternatives.

Mintzberg et al. (1976) studied 25 cases of decision-making processes, mostly in industrial organisations and found that in over $75 \%$ of these cases, the first step after identification of an issue was to start tapping existing information sources and opening up of new sources in order to clarify and define the issues and identify alternatives. But he also mentions that in research on decision-making little attention is paid to this step in the process. Later, Mintzberg et al. (1998, p. 69) warn against unfounded relying on uncontrolled and hard information without proper reference to the conditions of validity.

Drucker (1973) comes close when he describes the way Japanese managers do not begin the decision-making process by looking for answers, but pay much attention to the preceding diagnosis of the problem. But even then Drucker does not mention specifically the fact that diagnosis needs to be supported by information. Alwis and Higgins (2001) mention that in Far Eastern companies, specifically Japanese managers consult with subordinates in order to collect information and opinions.

Weirich in his book 'Realistic decision theory' (2004, p. 20) claims that "utility depends on information and so, under the idealisation of full information, the principle of optimization may be restated as a principle of utility maximization".

The concept of a 'mental image' of the decision problem helps to understand the relationship between effective decision-making on the one hand and the need for knowledge and information on the other (van Riel, 2002, p. 19). "Decision-makers must have a reasonably accurate and complete mental image in a business process and its interfaces with the world in order to be able to make decisions effectively and exert control over the process". Managers will therefore attempt to improve their 
understanding of the situation by making use of external information to make better decisions. "The resulting improvements in the quality, scope and detail of the mental image of the decision problem can be understood as increases in the utility of the knowledge that a decision-maker possesses for executing decision tasks in the process" (van Riel, 2003).

As a result of the important changes of the role of information, often called the 'information revolution' (Porter and Millar 1985; Negroponte, 1963 p. 163; Wegberg and Witteloostuijn, 2001), executives have witnessed the growth of the impact of information on the operating processes of their companies. The next step in this process is that improved information resources have an equally significant impact on their strategy. The increased reach of information as they like to call it, "will alter the structure of entire industries, making executives rethink the strategic fundamentals of their businesses and not just in high tech and information industries but in all sectors of the economy" (Evans and Wurster, 1997, 2000, p.25). These authors have also analysed the change in the flow of information, they have found a trade-off between sharing of valuable information with a very small number of people and sharing less valuable information with a larger number of people as is now common in digital networks such as the Internet. "This phenomenon is creating a new economics of information whereby decision makers will have to keep in mind that others can use the same information as they have".

But to be effective, managers have to make optimal use of available information. This is not always the case, Lohman, in his dissertation (1999, p. 4, 133) on "The effectiveness of management information' concludes that making use of information that is in fact available to managers is not to be taken for granted. Causes can be the problems of transforming data to useful information for this user group and the discrepancy between the information that is requested by managers and the information that is provided because the difficulty to properly phrasing a precise request for information that is as yet not available.

Information is valued by business managers, but they feel shortcomings in the absorption process as shown in a recent study by the software integrators Information Builders entitled 'No barriers to good decisions' (2007). Over 600 managers in 8 European countries were queried as to what barriers they experience when they prepare for their decisions. The analysis shows that:

- $\quad 54 \%$ answer that they lack accurate, consistent and complete information

- $\quad 88 \%$ claim not having the right tools

- $\quad 68 \%$ do not get their information delivered in easy to use format

- $\quad 72 \%$ believe the key for faster decision making is more/better information.

\section{Failures in the use of available information}

A saying is that "bad information travels faster than good information and is often exaggerated". An example of this principle is seen when a potentially defective 
product is recalled from the market; such a fact is known all over the world in hours and remembered even if the product proves to be harmless in hindsight.

Not all information leads to correct decisions. A situation that will certainly occur is that the information is indeed available but is not used or not used properly because of reasons such as time pressure, unbelief, unconstructive group processes, political issues or misinterpretation. Nutt (1999) studied over 300 decisions taken in US industry and concluded that half of them had failed. There are numerous examples of failed decisions, such as disasters through errors by military strategists; unfortunately, similar failures in industrial strategies are not so well documented; some failures are shown in the following box.

\section{Failures of proper usage of available information.}

The attack in 1944 by British forces under command of general Montgomery on Arnhem ('A bridge too far'), using operational maps dating from 1913 missing a 1934 road bridge (Kist, 1991), and the 1961 invasion of the Bay of Pigs by Cuban exiles, supported by the Kennedy administration ignoring the available information on the organisation of the Cuban army and air forces and the weakness of the internal resistance (Allison 1971; Allison and Zelikov, 1999, p. 83, 329), are examples of disregard by the military of readily available information.

The space shuttle Challenger disaster in 1986 was caused by neglecting data on the freezing temperatures tolerance of a washer material; the accident with the space shuttle Columbia in 2003 could have been avoided had the available information on foam detachment and tile strength been properly communicated as later reported by the investigating board (www.nasa.gov/columbia/caib/; Allison and Zelikov, 1999, p. 160).

In industry, erroneous decisions come to the surface only occasionally but have to be deduced. If one looks at reports on the write-offs that have become necessary on values of recently acquired companies, there must be many such cases. Similarly, the recalls of medicines from the market by pharmaceutical companies because of so called undocumented side effects of these drugs, are often later confirmed as having been hidden in the information from the clinical trials but not considered relevant at the time; examples are Vioxx from Merck and Meridia from Abbott (Science, 2003; Lancet, 2004; P-D-R, 2008).

In a study, not yet published, Arnold ${ }^{1}$ mentions that when companies get rid of its paper archives, they easily get into a position where their employees cannot find anything; he states that poor data quality can cost an organisation $25 \%$ of its revenue.

1 Personal communication, October 2008. 


\section{Competitive advantage}

A way of seeing the influence of information on the correctness of decisions is to judge how information gives a company competitive advantage. Executives may use the information service for the generation of ideas or to create specific business opportunities.

Choo (2006, p. 2, 5) elaborates on three areas in which the creation and use of information play a strategic role in determining an organisation's capacity to grow and adapt, 'sense making', 'knowledge creation' and 'decision-making'. Sense making implies looking back in time, knowledge creation is looking around in the present and decision making relates to the future. As there is a strong dependency of an organisation on its environment, this forces the organisation to make sense of changes and developments in its external environment, Choo calls this 'environmental scanning'. "The organisation that has developed early insight on how the industry and markets are moving will have a competitive edge. Unfortunately, messages and signals about events and trends in the environment are ambiguous and are subject to multiple interpretations. As a result, a crucial task of management is to discern the most significant changes, interpret their meaning, and develop appropriate responses".

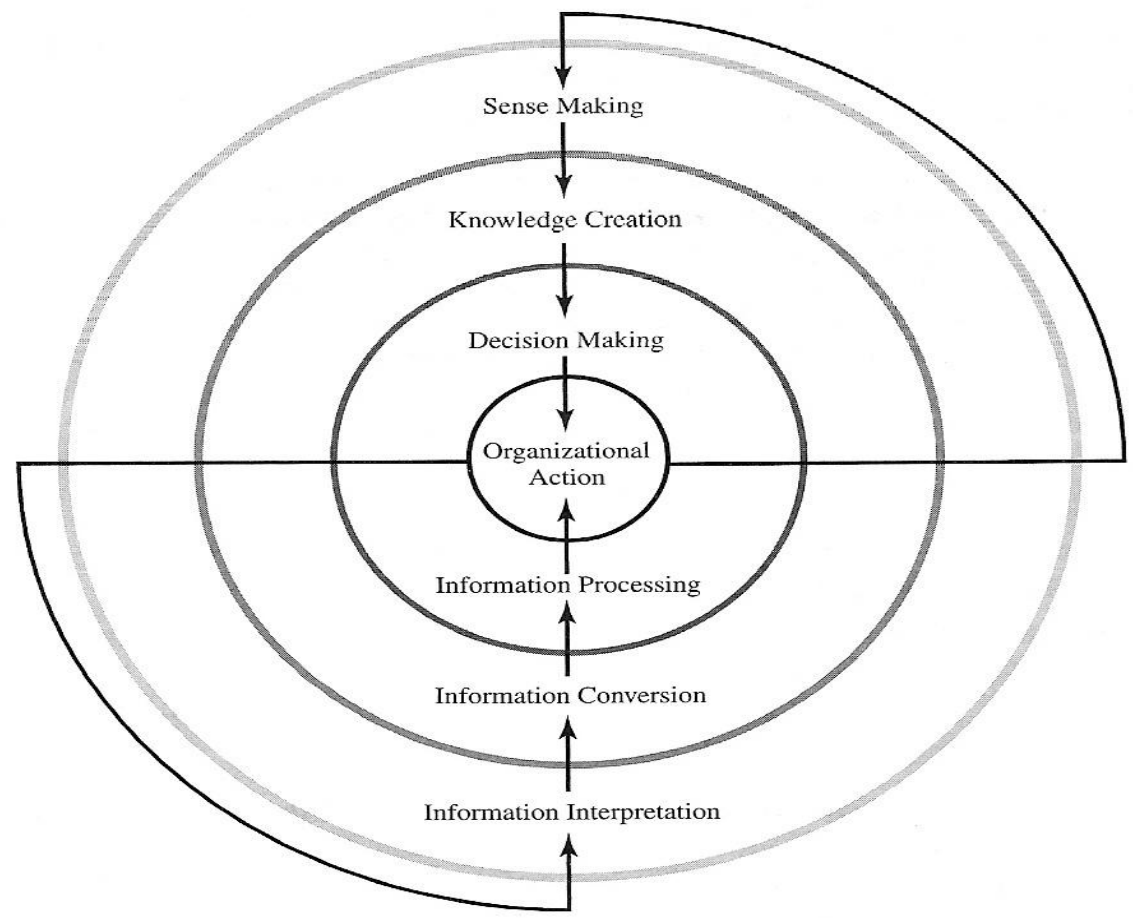

Figure 5. Strategic role of information. (Choo, 2006, p. 3). 
The second step in this process is that of knowledge creation that consists of interpreting data and information and through organisational learning, transform this into useful knowledge for managing the firm. Choo sees these activities as essential steps for rational decision-making: "organisational life is not just about choice but also about interpretation, and the process of decision-making must embrace sense-making and knowledge creation. These three apparently distinct processes are in fact complementary pieces of a larger canvass, and the information behaviours analysed in each approach interweave into a richer explanation of information use in organisations". Organisations that are able to integrate effectively these three processes are what Choo calls 'knowing organisations'. Choo schematises sense making, knowledge creation and decision-making as an onion with specific layers indicating the accompanying information processing steps as shown in figure 5 .

Choo's theory is not without criticism (Wilson, 1997; van Heusden and Jorna, 1999). These last authors argue that "in sense-making, according to Choo, organisations create or reconfigure parts of their environment. In knowledge-creation and decision-making, knowledge is actualised through formalisation and externalisation, and available knowledge is used to make decisions about the course of action to be taken. In the latter cases, individuals work with meanings that are given but not (yet) fully used. No new meanings arise". This is in fact a definition of an aspect of knowledge management, the re-use of existing but not generally available (within the organisation) information. What Choo calls knowledge-creation, should rather be called 'externalisation of knowledge'. But these authors agree with Choo (2006, p. 23) that decision-making underlies the whole organisational structure.

The Confederation of British Industry set up the Hawley Committee to improve the understanding of information amongst larger UK corporations. The Committee consisted of 40 executives/managers of which 27 represented private companies. The main recommendations from the Hawley report entitled: 'Information as an asset: The Board Agenda' (Hawley Committee, 1995, p. 7; Oppenheim, 1997, 2003, 2003a) are that "The Board is responsible for the assets of the organisation it governs. Information is an increasingly vital asset of strategic importance, but less well understood and less well handled than other recognised assets such as property and finance". Furthermore, "The Board should determine the organisation's policy for information assets, ensuring that, at every level, the information provided is necessary and sufficient, timely, reliable and consistent as required for effective operation and decision support at the various levels of the organisation."

Following these findings, the business information service of Reuters $(1996,1997)$ commissioned a number of surveys among managers in industry to estimate the value of information for the company Board; these studies have been critically reviewed by Oppenheim (1997). The subject of the studies was to get an insight in the need for and use of information by managers. The questions aimed to discover various aspects: how much money companies spent building and maintaining their information 
databases, understanding how much that information is worth to a company, both in financial and operational terms and investigating whether companies currently capitalise that information on their balance sheets. Notably from the results of the study again is that information is considered to be readily available and in none of the many questions asked of these managers the search for or the sources of information were covered. The consequence of such studies is that the concept of operational information about internal processes and products is probably mingled with that of information about the external environment.

In the 1997 Reuters' study, 66\% of respondents claim that very high levels of information are needed to perform effectively and 54\% collect 'a great deal of information' to use in decision-making. Oppenheim (1997), from an earlier Reuters' study, cites that most of the managers had no idea about the cost of collecting and maintaining this information and showed little ability or inclination to manage it as an asset. Looking at how senior managers value information, the greatest recognition is among marketing directors, who believe their companies' information to be worth between $£ 10,000$ and $£ 100,000$. This is likely to be the marketing department's customer, prospect and competitor databases. One of the outcomes is that less than $1 \%$ of the respondents use their company library as a source of information, information officers and archivists were totally ignored.

\section{Developments in sources and supply of information}

Policy statement on information as a commodity and its importance to economic development (Australian Library and Information Association 1996).

The Australian Library and Information Association advocates the development of an informed society that can partake and participate in skilled decision-making. Accurate, relevant and timely information is the key ingredient to effective decision-making. Australia's long-term economic development is dependent on its ability to use information to make decisions that enable growth, progress and productivity.

The library profession contributes to an informed society by acquiring, organising, archiving, retrieving, using, synthesising and analysing information and thereby empowering users so that they can utilise this information in their decision-making processes.

Obtaining relevant information can be easy if it is readily available, but most times the correct information required will have to be searched for and then it will have to be accessed and analysed. The library profession sees itself as an important contributor in this respect, but there are hardly any studies that show an appreciation for this role. In many cases, the first step of management will be to delegate this process to a staff department requiring them to find an information resource that can be accessed that contains this information. Berg et al. (2003), (see also TUDelft Library, 2006 p.17, VKC,2006) have developed external services that assist in performing that task for a 
technical audience, e.g. in specialised 'portals' or 'virtual knowledge centres' on the Internet. (Dias (2001) discerns portals that have an "emphasis on decision support" and some that assist in "decision processing by capturing information that is stored in corporate or external warehouses".

Before a proper search for relevant information can be started, the question must be formulated correctly. But according to Drucker (1994) "senior managers often do not assume the responsibility of defining in detail what information they require". Choo, (2002, p. 29) agrees that "unveiling information needs is a complex, fuzzy communication process. Most people find it difficult to express their information needs to their own satisfaction. Personal information needs have to be understood by placing them in the real-world context in which the person experiences the need, and to the ways in which the person will use the information to make sense of her environment and so take action".

Schneider (1989) and Toms (2000) have found that in those cases that information is gathered through scanning and selection activities by the decision-makers themselves, scanning activity may vary in the degree to which it is active - through searching - or reactive - through monitoring. The searching can be either focussed or broad, systematic, comprehensive, formalised or serendipitous. Information, once gathered, needs to be interpreted; the method of interpretation can in the first stage be superficial with the aim of judging its value and quality. If it passes this first scrutiny, the interpretation must become more critical and can be systematic and analytic, i.e. based on logical deductive reasoning or mathematical models, or more general to see whether it fits in prior models or deviates from previous outlooks.

The search for information can follow several distinct paths. Nutt (2005) studied over 300 decisions, made by senior managers and CEO's both from for-profit and not-forprofit organisations aiming to classify the search types employed in decision-making according to a model defined earlier (Nutt, 1993). He observed for each decision the order of events and how shifts in search approach occurred. A search was called 'opportunistic' if the decision making process began with a solution. Here solutions materialised in signals calling for action before directions were set. If the solution emerged after a target had been set and a protocol engaged it was termed 'emergent opportunity'. This was linked to chance because the idea sprang up outside of the formal search effort and pre-empted it. An unanticipated, shift in the search approach arose when an opportunity was abandoned and steps were undertaken to find a replacement solution. This was called an 'undirected search' because no target was set. Finally, search was termed 'rational' when a target was set, followed by a protocol to find the solution.

In an earlier paragraph (II.1.2. and figure 3), we presented the model of the process of strategic decision-making by members of the 'top management team' given by Corner et al. (1994). In this model information plays a crucial role, passing through stages 
given successively as 'attention', 'encoding' and 'storage/retrieval'. 'Attention' is a focus on information and is needed in the first stage of the decision-making process because it is the input source that needs to be filtered and screened before it can be used. 'Encoding' as defined by Corner et al. is a way of interpreting information and comparing it with prior knowledge and thus is 'infused' with a specific meaning, of relevance to the strategic issue in hand. 'Storage' is the preservation of the interpreted information in memory, either an individual memory or a collective memory of the management team so that it can be retrieved when a strategic decision is required.

The way information is stored in the organisation is in 'routines', such as procedures or recorded earlier strategies. Mintzberg et al. (1976) call the retrieval from this store "memory search, i.e. the scanning of the organisation's existing memory, stored in humans or on paper".

Decision makers have profited much from development of computer systems that store results of previous experience and published research and that are able to continuously analyse company performance against scorecards or benchmarks. This development is accelerated now that resources for business and management information have increased tremendously with the change of the Internet from mainly a research oriented system to one with practically no limit in content and audience including the business community - over the last few years (Auster and Choo, 1996; Smith, 2001; Àguila-Obra et al., 2007; Kendrick, 2007).

As a consequence of these developments the question is often no longer whether some required bit of information is available, but where this item can be found reliably and completely within the time that is available. External information sources thus play a more important and valuable role in decision-making by industry management than was possible before. In the next chapter several examples will be given of such benefits.

In decision-making, firms should take a broad view of where their real competition is. Not only other firms producing the same product or service should be viewed as 'competitors', but also the firm's suppliers, banks that supply investment money, customers who want to buy at lower prices and anyone who makes a claim on a company's profits can be viewed as such (Porter, 1985, p.212). The information that is needed by executives for strategic decision-making concerns to a large extent the condition of the company and the external business environment such as expressed by opportunities, threats and risks, market structures, competition and competitors, regulations and public affairs and most importantly, current developments and trends in those themes. This information can be distinguished in categories, some of these issues are covered by internal sources only, but most issues need access to both internal and external information sources. Taking into account recent studies on required information (de Alwis and Higgins, 2001; Citroen and Hooghoff, 2003; Oppenheim, 2003a; van Riel, 2004; Brenner, 2005; Murphy, 2006), the following listing is a compilation of these categories. 
First information generated and collected mostly from internal sources and experience:

Product information, e.g. the depth of knowledge in particular technologies that support particular products. This includes both registered and non-registered intellectual property rights

- $\quad$ Generic technology information such as technology related R\&D issues and trends, patents and technical market issues

- $\quad$ Specialist knowledge and information for operating in a particular area, which is often in people's heads, knowledge management content

- Human resource information or people management, e.g. skills databases, particularly in project-based organisations such as consultants in a technology company, who need to be brought together to support a client project

- $\quad$ Specific customer information; mostly internally collected data such as trends in consumption patterns but also customer contact persons, financial matters such as credit, from whom else do they buy etc.

- Supplier information, e.g. trading agreements or networks of contacts for services or product development

- $\quad$ Business process information that underpins the workings of the own business; also called 'management information', particularly that on which major policies, competitive decisions or strategic plans will be based, e.g. share price, internal and external economic statistics, production figures or cost base information

Information, mostly collected from external sources:

- Competitor information from business intelligence, yielding detailed data on competitors, their strategies and moves, their performance, use of base materials, product brands and trademarks, building permits etc.

- General market and customer information, e.g. regional utilities have large amounts of data on every household in their regions; trade names and trademarks, trade statistics, trends in relevant generic markets, forecasts and consumers' trends

- Accountability, legal and regulatory information, e.g. legally required information including shareholder information, health and safety information or environmental pollution evidence

- Information about the environment in general. This includes generic items such as economic and political developments, ecological issues and related legal issues.

- Information from governments, the European Union and Non-Governmental Organisations. This relates to permits and other legal issues such as import and export regulations, environmental conditions and directives on potentially toxic chemicals. Relevant NGO's are environmental action organisations and citizen groups that can influence decisions too, even major investments. 
The Hawley Committee report (1995, p.9) lists only eight such categories of information assets that are consistently identified by the 40 UK managers that were interviewed, economic statistics, specialist knowledge (this type of knowledge is also now addressed in part by knowledge management techniques but, at the time of the Hawley Report, knowledge management was not a well-established activity), human resource information, market and customer information, product information, supplier information, financial business process information and accountability or legal \& regulatory information. Interestingly the main issue missing from the Hawley list is the strategic information from competitor intelligence. Oppenheim, (2003a) in his review of the Hawley report concludes that competitive advantage gained from information assets requires its identification as a separate information asset.

Frishammer and Hörte (2005) analysed responses from over 170 CEO's from manufacturing firms in Sweden and found that "a positive relationship exists between scanning of technological factors and innovation performance". Although innovation is predominantly connected with $R \& D$ activities, the ultimate decisions on new ventures rest with the Board.

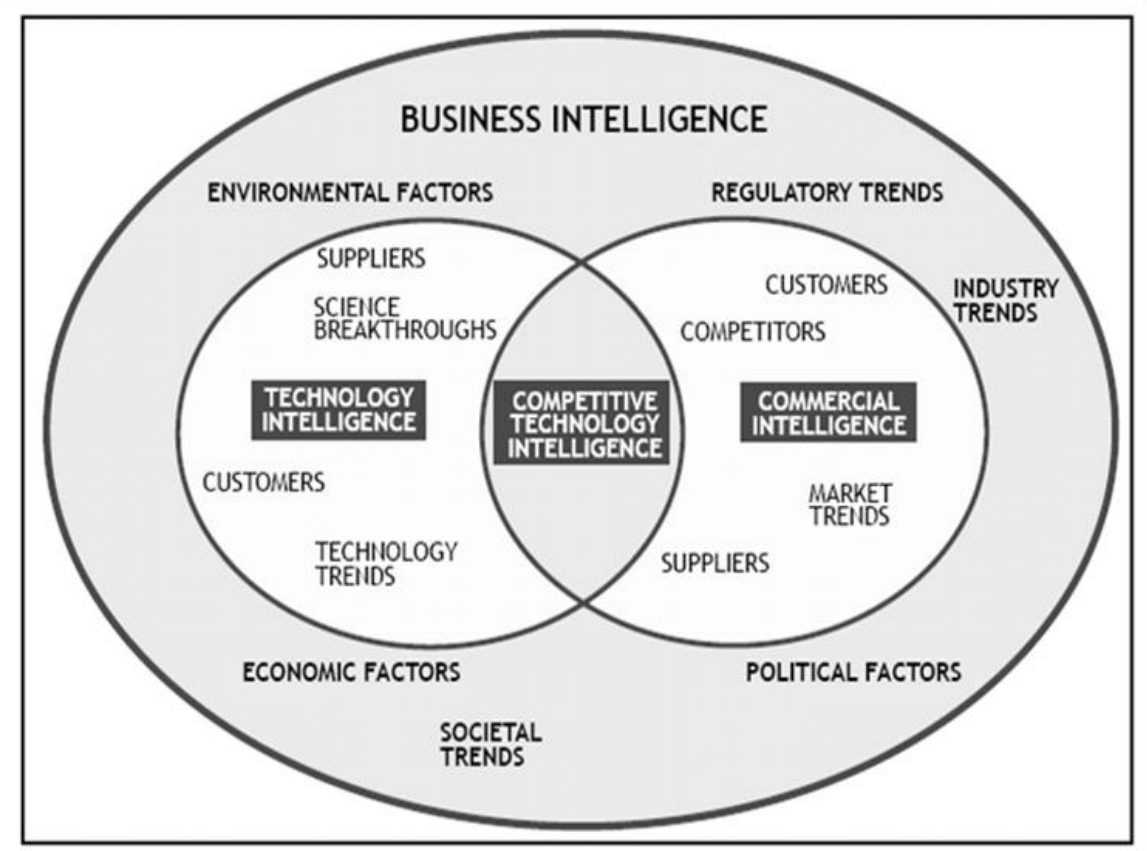

Figure 6. The world of business intelligence (Brenner, 2005).

Information gathered from external sources is illustrated by Brenner (2005) in figure 6. The figure indicates well the relation between the different types of information of value to the company.

Brenner (2005) explains that information just by itself is not sufficient; methods that assist in using correct condensed derivatives must provide the executive with more 
tailored information. An example are early warning systems that assist in anticipating new developments and provide the analytical tools to make sense of the incoming information, to determine trends, and to evaluate alternatives. "Good technology intelligence is not rocket science--it is about early identification of opportunities and threats; it is about capturing knowledge that is often already available within the organization and leveraging those insights; it is about getting people to talk about the right things in a systematic learning approach that drives to agreement on the conclusions, implications to the organization, and future actions. Good intelligence makes implicit assumptions explicit and balances the biases we all bring with external information and perspectives".

On occasion, competitors change into acquisition targets. Usually a thorough analysis is needed for such an acquisition process. The specific form of information search and collection, the scrutiny of all relevant facts about a company, including potential damaging 'skeletons in the closet' is obtained by due diligence (Haspeslagh and Jemison, 1991, Annex1; Harvey, 1995;Tai, 2002; Lehner and Nuhn in Berens et al. 2005; Brenner, 2005; Murphy, 2006). Hitt et al. (1998) studied successful and unsuccessful acquisitions of US firms that had recently acquired another firm, or that had been the target of an acquisition or that was the result of such a merger. They identified attributes and effects both from successful and unsuccessful acquisitions. An attribute for a successful acquisition was e.g. "careful and deliberate selection of target firm and conduct of negotiation". An example of an attribute of an unsuccessful acquisition was "inadequate evaluation (due diligence) of the target company".

Information for strategic decision-making, especially when it concerns competitor information is often also called 'intelligence' or considered to be obtained by intelligence ${ }^{2}$ activities. Van Riel (2002, p. 145; 2004) distinguishes three important types of intelligence that companies need and collect:

- $\quad$ customer intelligence, e.g., information about trends in consumption patterns and customer requirements

- competitive intelligence, e.g. information about the strategic moves of competitors in the marketplace

- technological intelligence, e.g. information with respect to innovations, costefficiency, and success of currently used technologies in the industry.

Such information that supports strategic decision-making becomes available in the form of unstructured data, publicly offered reports and also industry, company or product specific commissioned consultant's analyses, competitor intelligence accounts, business updates but also regular news items and trend analyses.

\footnotetext{
2 Intelligence is a word with several meanings. One has to do with conflict, spying, and the like. In that sense, intelligence is information about an adversary, usually arrived at secretly. Here it refers to information that is obtained legally but with some effort from open sources.
} 


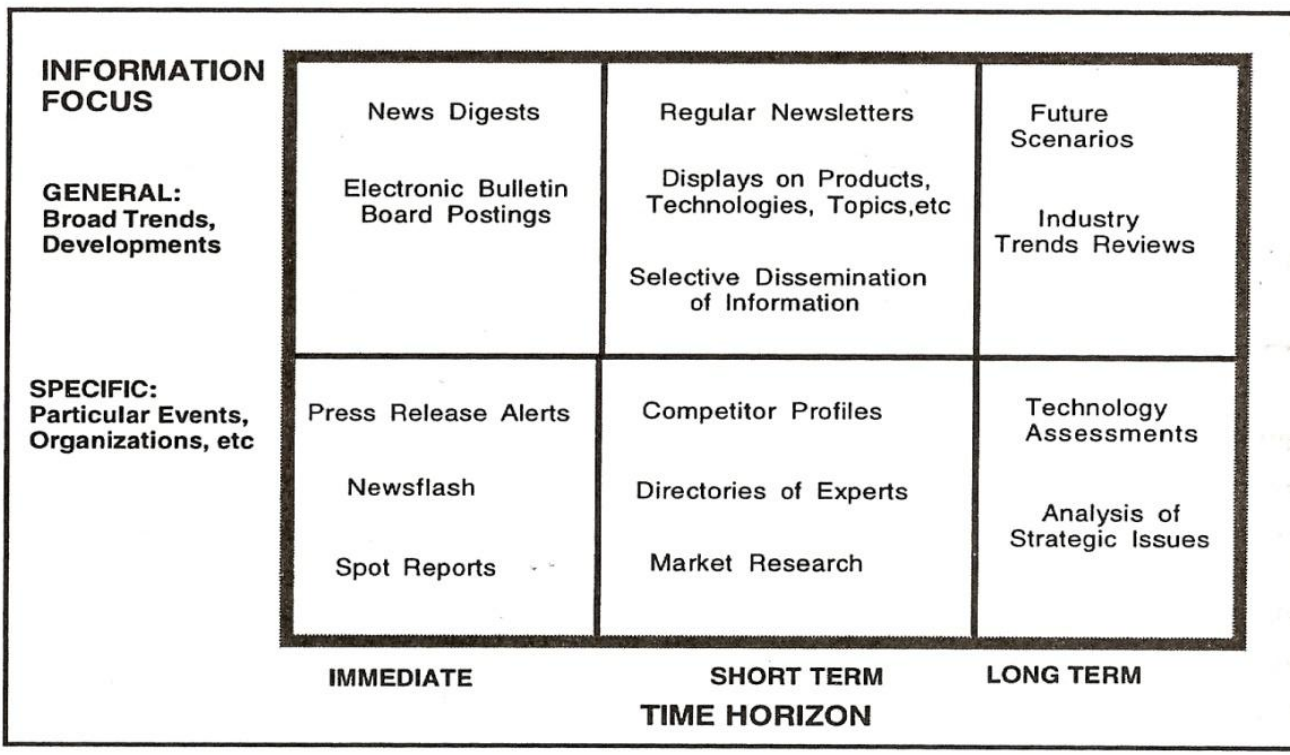

Figure 7. Matrix showing a topology of information products and services (Choo, 2002, p. 38).

Another way to categorise information is by looking at the specificity or focus of the message and at the time horizon that determines its urgency. Choo (2002) has constructed a matrix (figure 7) that he calls 'a topology of information products and services'.

It adds a few categories of information not specifically given above -memo's, future scenario's, selective dissemination of information, directories of experts - that can however be fitted into our listing as they are of a type that intersects with the content based approach taken before. The value of such a matrix is that it shows along two independent axes how information products can be shaped according to the users' requirements.

Communication of information to the Board as background for decisions is a practice that can take many forms, by word of mouth from staff meetings, in printed or in electronic form. Face-to-face communication can be organised formally or exist informally. In both forms it is the richest way of communicating as it allows immediate correction or clarification as a result of feedback. Printed reports can go much deeper into a matter but often are too verbose to be taken in completely. Electronic texts of reports and studies are (still) mostly printed out and then suffer from the same drawbacks. More recent ways of communication such as e-mail have changed the way and pace by which businesses are prepared and conducted. Messages received from 'push technology' or RSS - a family of Internet web feed formats in the form of short up-to-date reports based on a specific profile of interest, are used to alert to frequently updated content such as news headlines and stock markets - often attract 
immediate attention and can be quite effective aids of keeping up-to-date. The matrix above shows examples of a number of these forms of communication.

Marketing research departments and staff departments such as the financial group in companies play a significant role in regularly supplying specific information to the Board based respectively on surveys of market trends or analyses of internal processes.

The following box shows just one example of a now common strategy to gather information on a crucial issue that requires continued attention from a company's top management, in this case a bank:

A function of the Department of Eastern European Developments was conducting and providing studies of Eastern European 'countries' into which the bank had expanded after the fall of the Berlin Wall. These country studies were significant research projects: each study was about sixty to eighty pages and took months to complete. A country was represented by a computer file and a cardboard file of papers. The files initially had a number of empty chapter slots and titles that were standard across all country studies. These included slots for sections on the banking laws of the country being studied, the interbank market, the economic competition in the country, economic projects conducted there, strategy and action plans and a slot for a profit and loss statement. Mapping the country, then, meant assembling information on these topics.

The information sources used by the analysts included items gathered from the daily news, documents and statistics issued by the observed units, other government and trans-governmental agencies' analyses and reports (e.g., OECD reports) and commercial information providers' public and intranet materials. But also ideas they obtained when meeting someone or encountering something connected with the observed entity.

These studies supported the investment decisions of the bank's management committee, and this staff department was seen as being of strategic importance, reporting directly to the CEO. From these studies the department produced analyses such as an in-house monthly newsletter and prepared custom-made files for executives when they went on discussion or fact-finding trips to these countries.

(Knorr-Cetina and Preda, 2001; Choo, 2007)

Intelligence of this type can now be gathered rather easily from reports by consultant firms that scan a wide variety of printed and electronic sources either on demand or subscription or made available at a unit cost. Examples are SRI (connected to the Stanford Research Institute) for science and technology issues and Gartner Inc., specialised in information technology. Another such source is based on cooperative input of data, e.g. to an association of specific industries. Examples are the European Chemical Industry Council (CEFIC) in Brussels with chemical industry associations 
from 22 European countries as members, PlasticsEurope, an association of a specific group of chemical manufacturers and more specifically directed at information sharing, the Pharma Documentation Ring with 21 contributing companies worldwide 3 .

Not all companies are aware of the capabilities of these information sources. In a recent study (Atherton and Vile, 2007), the question was asked whether the company had an overall business intelligence (BI) strategy in place. At a strategic level, less than a third of all large (5000+ employees) organisations had an overall BI strategy, with numbers tailing off significantly for smaller sized companies. The outlook improved for the near and medium term though, with the majority of medium and large organisations stating that a BI strategy was either underway or was at least planned.

\section{The role of information specialists}

In most larger industrial companies internal information departments employ professional information specialists or information scientists that collect and analyse information in a way that enables easy 'digestion' in the forms of interpreted listings or bulletins. Usually they supply this type of information as a current awareness service or in reply to an ad-hoc demand to the intermediate levels in the company that in turn are responsible for informing higher or top levels in the company (Choo, 1995; Hyams, 1997; Edmunds and Morris, 2000; Bendien, 2006). But as Oppenheim remarked in 1997, in the Reuters' studies less than $1 \%$ of the respondents mentioned that they use their company library as a source of information. This can perhaps be explained by the indirect services delivered to intermediate staff levels and not directly to the Board. The efficacy of communication between these different levels influences how well and how fast information is transferred and is diffused throughout the organisation. The quality of formal and informal organisational communication thus affects the availability of information to the decision-makers (Prusak and Matarazzo, 1992; van Riel 2002, p. 146; 2004).

The result of the gap in appreciation of the work of information professionals is that professional organisations of these information workers are frequently signalling to their members to educate themselves better and play a more active role in the company. Choo (1995, 2002, p. 241, 269), analysing the increasing need for an 'intelligent and constantly learning organisation' expresses "an analysis of these processes suggests new strategies for maximizing the value of information in organizations and for a reinvention of the roles of information professionals (recast their function), be they librarians, information providers, information technologists, or information scientists". And: "because these individuals have the skills that are most needed to effectively acquire, organize and distribute information, the intelligent organization cannot afford to do without their contribution and participation in its strategic activities".

\footnotetext{
${ }^{3}$ www.gartner.com, www.sri.com, www.cefic.org, www.plasticseurope.org and www.p-d-r.com.
} 
Berkien (2006) notices the increased needs of companies for professionals that are capable of interpreting information into intelligence and recommends " $a$ transformation from information specialists into business intelligence professionals". This is possible now that "an increasing number of companies have invested in information management focussed on strategic business performance and decision making".

A satisfying solution for filling in the need for such information specialists is to employ the services of consultants working at specialised information services that have access to a wide variety of business and technology information sources (Citroen and van Loen, 1994). Edmunds and Morris (2000) mention increasing the role of information specialists as one of their methods of coping with a so called information overload because these specialists in information handling can package with added value relevant and useful information as "appropriate for stressed business organisations". This would be a better solution than just employing ever more ICT (Information \& Communication Technology) power.

\section{Definitions of information value}

An organisation behaves as an open system that takes in information, material and energy from the external environment, transforms these resources into knowledge, processes and structures that produce goods or services which are then consumed somewhere in the world. An organisation uses information strategically to make sense of changes in its setting, to create new knowledge for innovation and to make decisions about its course of action. All organisational actions are initiated by decisions and all decisions are commitments to action. (Choo, 2002, 2006).

Information has often been referred to as a commodity, e.g. Allen (1990), but commodity is a term with more than one meaning. In one connotation, a commodity stands for anything for which there is a demand and a price; but information can often also be obtained free of charge and "exist and be transferred without being sold or exchanged for something of value". In another connotation, a commodity is taken as a service which is intangible. In that case Meadow and Yuan, (1997) offer the phrase: "information can be bought and sold but you cannot drop it on your foot". But these authors also note a difference of information from most other commodities, "one does not pay the farmer for producing grain, one pays for the grain, but one pays a lawyer for the effort of providing information, and the client would not want the same advice as given out last year".

Moreover, information differs from most other intangible commodities such as labour or capital "with these units the more one uses them, the less one has left. Information on the other hand can be a substitute for other resources like money or manpower and then a piece of information can be 'consumed' without the value of the information being decreased when it is used; on the contrary, in some cases one can state that the more it is used, the more profitable it becomes. Information transactions do not always make it change hands, if one gives away a piece of information, one still has possession of it. It 
can be used over and over again in different contexts to create value in multiple ways" (Cleveland, 1981; Repo 1986; Auster and Choo, 1996).

Information can also be called a resource that is offered by an information service. In the end, these definitions of information, commodities or resources, refer to an object that serves to decrease uncertainty in a person or in an organisation. The value of a 'piece' of information to a person or an organisation thus seems to be dependent on the value of the wish to reduce this uncertainty just like the value of a commodity depends on the wish of a person or an organisation to fill a scarcity. When information is considered as a commercial commodity, its price or cost is an important factor. The laws of supply and demand then apply up to a certain extent (Allen, 1990; Rowley, 1998).

Even so, the value of an information item is difficult to measure as the real benefit can only be discovered after its use. "While capital equipment deteriorates in value from use and wearing off, the world's stock of knowledge remains here forever. Its economic value however, diminishes from its diffusion to, and use by competitors" (Eliasson 1996, p. 4). Conversely, if a piece of information or an information service is hard to access or to obtain or is unique, its value does increase just as any other commodity. The requestor will have to weigh the cost of an information item, giving the benefits of knowing the facts contained in the item against wilfully ignoring it or obtaining it from a less secure and cheaper source.

Most research on the value of information in industry is carried out on research and development decisions (King, 1991, Meijaard, 1998). But several authors have studied the impact of information for strategic decision-making and come to the conclusion that such value considerations apply likewise, even if additionally time and quality judgements will be more significant for executives (Marschak, 1968; Repo,1987, 1989; Allen, 1990).

\section{The value of management information}

"Information used to be the invisible ether that permeated an organization - everyone was enveloped in information, but no one knew the complete story of where it came from, where it was going, and how it was really being used, if at all".

A development that changed the role of information in organisations was that "organizations began to learn how to ride the waves of the information deluge. Information is now seen as an economic resource that is as vital as land, labour, or capital". Information is also seen as "the invisible goldmine" (Waddington, 1995; Auster and Choo, 1996).

Company internal knowledge is a significant asset in industry as shown by the interest and subsequent investments in company knowledge management. One quarter of the respondents in the Hawley study (1995) answered that their companies capitalised their internal information on their balance sheet or hope to do this soon. This is confirmed by the fact that a number of companies now produce an 'Intellectual capital 
report' in addition to their standard annual report. Fortune (2001) published a ranking of its largest 500 US companies based on their knowledge capital.

\section{Knowledge capital}

Knowledge Capital is defined by B. Lev for Fortune as 'Earnings divided by Knowledge'. As there is no historically tested rate of return for knowledge assets, Fortune puts the average profits of two industries that depend largely on knowledge assets: software and biotechnology at $10.5 \%$. By inserting it in the formula, one can put a dollar figure on a company's knowledge capital. To produce $\mathrm{M} \$ 425$ in earnings, our imaginary company would need $\mathrm{M} \$ 4.000$ in intangible assets, assuming they produced a $10.5 \%$ return.

The top 10 of the traditional Fortune top 500 ranking is dominated by industrial companies, like General Motors, Ford, Toyota, BP and Shell. In the alternative ranking providing a more balanced view of traditional and information age, General Electric 8 on the standard list - comes out on top with a knowledge capital of M\$254.000, Pfizer - 138 on the 500 list - comes second with M\$220.000 and Microsoft - 201 on the 500 list - third with over M\$200.000.

Apparently chemical companies score much lower, DuPont has about the same number of employees as Pfizer or Microsoft, and yet, DuPont's knowledge assets total only M\$41.000, there doesn't seem to be much extra profitability there.

It is notable that after the year 2001 Fortune has not kept up these knowledge capital listings, in the end such statistics did apparently not contribute to the accounting values that convince shareholders. Still, in a report to the European Commission (Andriessen and Stam, 2004), this work by Lev is used to estimate the intellectual capital of the European Union. They define intellectual capital as "all intangible resources that are available to an organisation, that give a relative advantage, and which in combination are able to produce future benefits." Since 2004 there exists an International Journal of Learning and Intellectual Capital (Interscience Publishers).

Several companies nowadays include a chapter on their human capital as it is called now more often, in their annual reports, but this is never quantified in a € figure; Wildebeest (2002) only found one measurement and several qualitative indicators of human capital in a analysis of 180 companies in The Netherlands.

\section{Quality of management information}

Information that is obtained and applied as a basis for a decision-making process has to satisfy a number of minimum quality requirements (Crawshaw, 1992; King 1991; Noorderhaven, 1995, p. 29; Meadow and Yuan, 1997).

- The information must be of high quality, that is to say that it can be characterised as reliable, accurate, robust, truthful, credible and valid. 
This implies that :

- $\quad$ The information must preferably be obtained from a trustworthy and reputable source, organisation or person,

- $\quad$ its contents must be as complete as is possible with a wide coverage of relevant sources, countries and languages and with sufficient detail and depth,

- $\quad$ precise, comprehensible and clear, if necessary indicating shortcomings and limitations in order to avoid misunderstandings,

- $\quad$ timely and updated, if necessary also kept up to date continuously during the decision-making process, this often will imply that it is novel and created at a recent date,

- $\quad$ consistent or at least having an explanation if there are inconsistencies.

And also:

- $\quad$ Properly accessible by standard means,

- $\quad$ delivered in a format that is easy to use,

- $\quad$ at a reasonable cost/value ratio based on marginal cost benefits.

Each of these requirements has to be met in order to satisfy the need for accurate information as a basis for the decision-making process. Some of these points may seem to be contradictive, e.g. being delivered in an easy format may interfere with timeliness and the wish for a reasonable cost may diminish completeness. These conditions have as result that the executive at the receiving end of the information will have to judge for himself which requirement in a specific case is prevailing.

In judging reliability, the source of the information should be a major indicator of its value: a report from a trusted consultant scores significantly higher than a more or less anonymous item from an internet web site; but on the other hand, an observation of customer behaviour is sometimes as significant as a formal marketing report.

Information from sources that become available via automated systems, based on analyses by specialists, are generally trusted by industry management and considered to be sufficiently robust if the source of the information is known to be trustworthy.

If there is any doubt, information from external sources should be checked and confirmed before it is used as input to the decision-making process. If these requirements are not met, or not fully met, it becomes even harder for decision makers to make a decision based on this information. On the contrary, once a piece of information is proven to be faulty, any further piece of information on the issue at hand or from the same or a similar source will be mistrusted. Trusting and accepting information as a basis for decision-making without making a proper assessment of its reliability entails great risk for the correct outcome of the decision. If someone has a disappointing experience with a piece of information that seemed to be of sufficient quality and robustness, that later proves to have been e.g. incomplete, incorrect or outdated, the confidence in the source of that information and possibly of the system 
that supplied the information may be seriously hampered and not consulted anymore despite its value in a later case (Redman, 1998).

However, in practice complete correctness of information is apparently difficult to meet and as the quality of a piece of information cannot always be determined, executives sometimes have to rely on opinions of experts (Mintzberg et al., 1998, p. 69). Mintzberg exemplifies this problem by stating that "the messy world of random noise, gossip, inference impression and fact must be reduced to firm data, hardened and aggregated so that they can be supplied regularly in digestible form".

Appraising the effectiveness of management information requires that sufficient insight is available about the condition of the data. Lohman (2003) states that in practice this condition is apparently difficult to meet. Data that are the basis for information management sometimes are incomplete, incorrect, inconsistent, inaccurate, untimely or inaccessible. Having data quality problems requires that intensive effort be spent on cleaning activities or gathering additional data. In this way inaccurate or incorrect data might still be transformed into valid management information (Molloy and Schwenk, 1995). It can even be embarrassing if decisionmakers are not informed about the quality of their data, i.e. wrong decisions might be taken due to incorrect data. A problem also is that "hard information (resulting from formal processes) is often limited in scope, lacking richness and often failing to encompass important non-economic and non-quantitative factors, is too aggregated for effective use in strategy making and arrives too late to be of use" (Mintzberg, 1998 p. 70).

Another complication is that the way data have been stored does not always conform to the way it should be to derive management information. Most data structures in ICT systems are designed to support data for the primary processes of a company and not with the use in mind of decision-making processes (Tayi and Ballou, 1998).

It will be hard to quantify these problems with information quality. An indication is given by Redman (1998) citing from 3 instances, gathers that $8-12 \%$ of a organisation's expense may be the result of poor data, leading to "tangible impacts, such as customer dissatisfaction, increased cost, ineffective decision making, and the reduced ability to make and execute strategy".

A way to improve on this situation is facilitated by the new methods of ICT techniques, allowing to check the reliability of information from an uncertain source, e.g. statistically or by automatic comparison with other data.

A reassurance would be if database creators would adhere to recognised standards of operation. A guideline would be a quality assurance system based on the ISO standard. But we could find no indication that certification by adhering to any of the ISO quality standards or to formal professional information service standards as a safeguard for 
the quality of information products is a feature of these services, though we checked with several sources in Europe and the USA 4.

The kind of information services that are the subject of our research are not those that monitor internal developments and processes of a company but those that provide information predominantly consisting of descriptive textual content in the form of news items or in depth studies from outside the own organisation or numerical data that reflect the result of analyses of external developments. In some cases, information that has become available from internal learning experiences is also taken into account as such.

\section{II.2.1. Information overload}

"More information is less information"

(van Cuilenburg, 1998)

The rate of growth worldwide of scientific information has been a constant $5 \%$ for several centuries. This exponential growth results in a doubling of scientific information every 15 years. The main cause for this growth is the increase in the number of scientists (Price, de Solla, 1963, 1986). "This growth of scientific information has given rise to a debate on 'information overload', suggesting exorbitant growth of information. However, this 'information overload' is the result of the steady growth and is needed to sustain scientific progress. Slower than exponential growth would lead to diminishing returns hampering the rate of scientific progress" (Kurek et al., 2006).

Information specifically directed at business environments probably started later, but this depends on the definition of 'business'; the first industrial patent in the modern sense was published in 1474 (Wikipedia). Business information databases were available right from the start of the international networks that gave access to computerised information. The June 1977 list of 'databases on-line' already lists 70 databases that were available over international networks of which about 18 could be considered to be of interest to businesses. The December 1977 list mentions specifically databases that contain numerical data; of the about 100 different databases listed, about 60 had data on business items such as macroeconomics, stocks, companies, product prices and markets (Tomberg, 1977).

According to a number of publications, there are many managers that have the feeling that they are not able to make a systematic use of available information because of what they attribute to an exorbitant growth of the amount of information that is delivered to them; this situation is then often called an 'information overload'. An example is the statement by Edmunds and Morris (2000) in a review of this issue in business organisations that "the problem of information overload is widely recognised

\footnotetext{
4 Personal communications from Shively at Chemical Abstracts Service, Overmars at LexisNexis and Lawlor, director of the US National Federation of Abstracting and Indexing Services.
} 
today. Living in an 'information society'...business organisations...are bombarded with information whether or not they actively seek it". De Bakker (2006) found from interviews with staff of information intensive organisations that "they consider that a high information load might eventually result in inefficient information processing as large volumes of information often lack clarity, incorporating the possibility of overlooking important information, are hard to process and may result in distraction from primary job activities. Information overload is not only associated with information quantity but also with information quality".

Two studies have been conducted that may be somewhat biased as they were commissioned by the business information service Reuters, a company that has an interest in conveying the message that buying properly screened and categorised information from this publisher will result in less information overload. The titles are indicative: 'Dying for information, an investigation into the effects of information overload' (1996); 'Glued to the screen, an investigation into information addiction' (1997). The outcome of Reuters' investigations from 1000 telephone interviews with company executives is that "two-thirds of managers of companies of all sizes need very high levels of information to perform effectively, but on the other hand, 61\% of all executives feel that information overload is present in their own workplace because they are very frequently unable to handle the volumes of information they receive; $43 \%$ felt that having too much information either delayed or stopped a decision to be made; but two-thirds of the managers also believe that information is underutilised in their companies" (op cit. 1996, p.7,1997, p.8; Oppenheim, 1997). The study does not go into detail about the kind of information that is required by these executives, the kind of information that leads to overload and the kind of information that is underutilised. It does mention that managers do not keep in mind sufficiently the law of diminishing returns when searching for information, thus accumulating costly and less useful information.

Hwang and Lin (1999) analysed over 30 experiments reported from previous research on information dimension, information overload and decision quality. These show that decision makers are often required to evaluate and integrate several information cues simultaneously. Managers in the field of accountancy have a tendency to gather as much information as they possibly can and even undertake to examine a large number of marginally relevant documents. The ensuing information load can be either estimated by its diversity or its repetitiveness or both. But they found that the effect of information load on decision quality gave empirical results that did not consistently point in one direction; the optimal number of information dimensions for each task separately should be determined empirically.

The Internet which is generally applauded for having made information more accessible is also blamed for increasing the information overload of managers (Economist, 2001, p.17; Farhoomand and Drury, 2002). However, the complaints about information overload were already uttered loudly in 1996 when the Internet 
was not yet a major source of information and e-mail was not yet generally accepted as a suitable means of communication. Thus, the Internet and its linked service of email alone cannot be held responsible for this effect.

As we have shown earlier, a factor to consider when assessing the value of information in strategic management is that there are limits to the amount of information that can be collected in the preliminary phases of the rational decisionmaking process. Founding a theory or a decision on truly complete information is impossible in principle because this would require "infinite regress, whereby every argument makes an inference from assumptions and verifying each assumption calls for additional information" (Popper, 1935 s.4, 1963, p.21). Accordingly, there are always limits to the amount of information that can be collected that is relevant to an issue, limits of resources needed for the search process and limits to the time available to process every titbit of information. The earlier discussed notion of bounded rationality is thus futile when Popper's model is properly applied. Furthermore, confirmation of the data that are the basis for a decision-making process is not possible in an absolute sense; in the worst case, the data can be falsified, proven untrue or of uncertain quality at some point in this process.

In our research, we question whether there is a problem with information overload in properly organised business environments where managers maintain control over business processes. We have identified several more positive lines of thinking brought forward to prevent occurrence of overload and ways to counter already the sources of unlimited information production by better organising the origin of the information at the publishers processes; others point to the fact that managers and their organisations have sufficient so called 'coping mechanisms' to avoid being affected by this supposed 'syndrome' (de Bakker, 2006; Iastrebova, 2006).

Simpson and Prusak (1995) argue that information overload occurs as a result of a failure of the business community to recognise the ways in which information processes add value to the information. They produced a conceptual model and examined the roles of both information providers and information users with particular emphasis on the needs of managers and decision-makers for high valueadded or high quality information. They argue "that there is a need to bridge the gap between information providers and users in their respective views of each other's roles, competencies and requirements in information terms". The model they devised contains five elements of value in information under the headings of truth, guidance, scarcity, accessibility and weight. "Any process which adds value to information will do so in terms of at least one of these five elements or attributes". The model provides a way for both providers and users to communication in meaningful terms on information issues.

Van Riel in his thesis (2002, p. 187) shows that a cognitive management style has an influence on the way information is utilised by managers. "Flexibility, adaptivity and a deliberate combination of experiential and rational cognition will produce the most 
effective decision-making style, as long as the decision-maker remains aware of the dangers lurking in the turbulence of the environment and the risks of information overload".

Iastrebova $(2006$, pp. 53, 176, 179) distinguishes three coping mechanisms: humanenabled coping, technology-enabled coping and organisation-enabled coping. She supports the view that "though technology in its most general meaning is one of the most often cited factors of information overload, technology-enabled coping is also the most appropriate way of countering the issue. This implies the use of in-built technological features and functionalities in order to filter out the unwanted information ... by the use of classification, rearrangement, visualisation options to increase the efficiency of one's own information processing and the utilisation of advanced search tools to reduce the quantity of incoming information and improve the fit between information request and system output". Her conclusion is that there is no reason for irrational behaviour because of such a presumed information overload. These managers are well able to cope with large amounts of information.

Kurek et. al. (2006) agree and state that "steady enhancement of the selection options is the right response to the growth of scientific information. Technology can and will help us here in providing an instrument for the reader to effectively and efficiently manage this selection process".

De Bakker (2006) supports these views and finds that "modern ICT methods, which are commonly accused of creating this so-called overload, cannot be held responsible, in fact properly applying ICT software assists in properly digesting and selecting information; the term 'overload' is an imagined artefact; there is no convincing proof that the amount of information is the cause of the problem, rather poor organisation of filtering of incoming data is to blame. Even so, it does generate unwarranted negative publicity about the digital information services such as the Internet and other new rich information resources".

Sauter (1999) claims that sometimes, ICT tools such as data warehouses can provide so much information that users become lost in the possibilities. Other ICT tools for instance data mining, may simplify analyses by employing filters based upon specific user-defined, qualifying criteria (such as a list of employees who have held specific job titles), percentile and rank filtering (such as the top 10\% of their raw materials used). Users can specify information to be found regarding a particular business unit and compare it to that of multiple business units or to the company as a whole. Sometimes scanning by ICT tools all relevant data can help decision-makers extract similarities among events and hence inspire hypotheses.

The actual incidence of information overload seems to be mostly refuted by these studies indicating that proper organising of information input and proper manipulation of information received, allow executives to cope positively with the amount of information reaching them nowadays. Common techniques such as aggregation and summarisation are used to keep the amount of information to be analysed to a manageable quantity and filtering of incoming information by staff 
departments is quite effective to present significant and relevant items to upper management.

\section{II.3. Conclusion}

We discussed the assumption that any rational decision-making process is based on the use of available information. Without information on the details of the issue to be decided, the conditions and consequences of each of the alternatives and the arguments for a choice one way or another, the rationality of the decision-making process is at stake.

Therefore, we formulate as a second and a third hypothesis with which we test the assumptions of the value and quality of information for the strategic decision-making process.

\section{Hypothesis 2}

In answering a specific strategic issue, executives that follow a rational process, will collect all feasible information considered to be supportive for this process.

\section{Hypothesis 3}

Before it is accepted as relevant, executives thoroughly check (or have checked) all information that is believed to be suitable as a supportive resource for the decisionmaking process for its quality parameters such as robustness and reliability.

If we assume, as proposed in hypothesis 1, that the executives that we have interviewed do indeed follow a rational process when taking strategic decisions, then it follows that they make optimal use of the available information that is needed to support this process. This assumption is worded in hypothesis 2 .

As we have discussed in this chapter, information is not always to be trusted and may contain flaws that make it less useful. We assume that executives are well aware of these risks and will see to it that e.g. staff departments thoroughly check any information before it is presented to the Board. This assumption leads to hypothesis 3 . 



\section{Information and communication technology and the Internet in industry}

As computers find applications for practically every business process in the present company, this evolution has had a great influence on the way company executives need to operate nowadays. If we restrict ourselves to the more strategic issues, the decision-making process has completely changed over the last decade by the way information has become available and travels over communication services that are common now. Improved information acquisition and analysis methods such as facilitated by the Internet give readily access to networked information resources that are relevant to strategic management. The synergy of computer operations and communication services is therefore appropriately grouped in the phrase 'Information \& Communication Technology (ICT)'. Porter and Millar (1985) explain that as information enters the decision-making field from a number of diverse sources and is often processed by ICT systems before its use, "Information technology must be conceived of broadly to encompass the information that businesses create and use as well as a wide spectrum of increasingly convergent and linked technologies that process information".

The potential influence of ICT on strategic decision-making can be summarised as:

- $\quad$ accelerating the process and thus being able to use the assigned time in a more efficient manner and concluding the decision-making process before the set deadline

- diminishing uncertainty by enabling the evaluation of more decision alternatives

- better forecasting accuracy and decision-making time horizon,

- more unanimous decision-making processes through better internal and external communication

and thus

- $\quad$ being able to conclude an accurate decision-making process where previously this decision had to be postponed because of lack of information.

(Molloy and Schwenk, 1995; Teng and Calhoun, 1996; Sajor-Wood, 2000; Ticoll, 2001;Li, 2002; Laudon and Laudon, 2006, p. 21, 29, 457; IBM, 2007; Aquila-Obra et al., 2007; Kendrick, 2007).

Basically these benefits can be characterised as changes in the decision-making model; discussions on issues affecting the strategic choices and alternatives can now be better controlled with more relevant information available. However, not all innovations are only positive; in later paragraphs some of the concerns of ICT support and Internet drawbacks will be discussed.

The following figure 8 illustrates the complexity and diversity of company information systems with executive strategy support systems in the top. Each division of the company operates different processes that can be supported by ICT but also each of 
these divisions needs different approaches of such systems and thus each of these programs has its own goals and its own users, who must specify the input requirements that are designed to produce useful results.

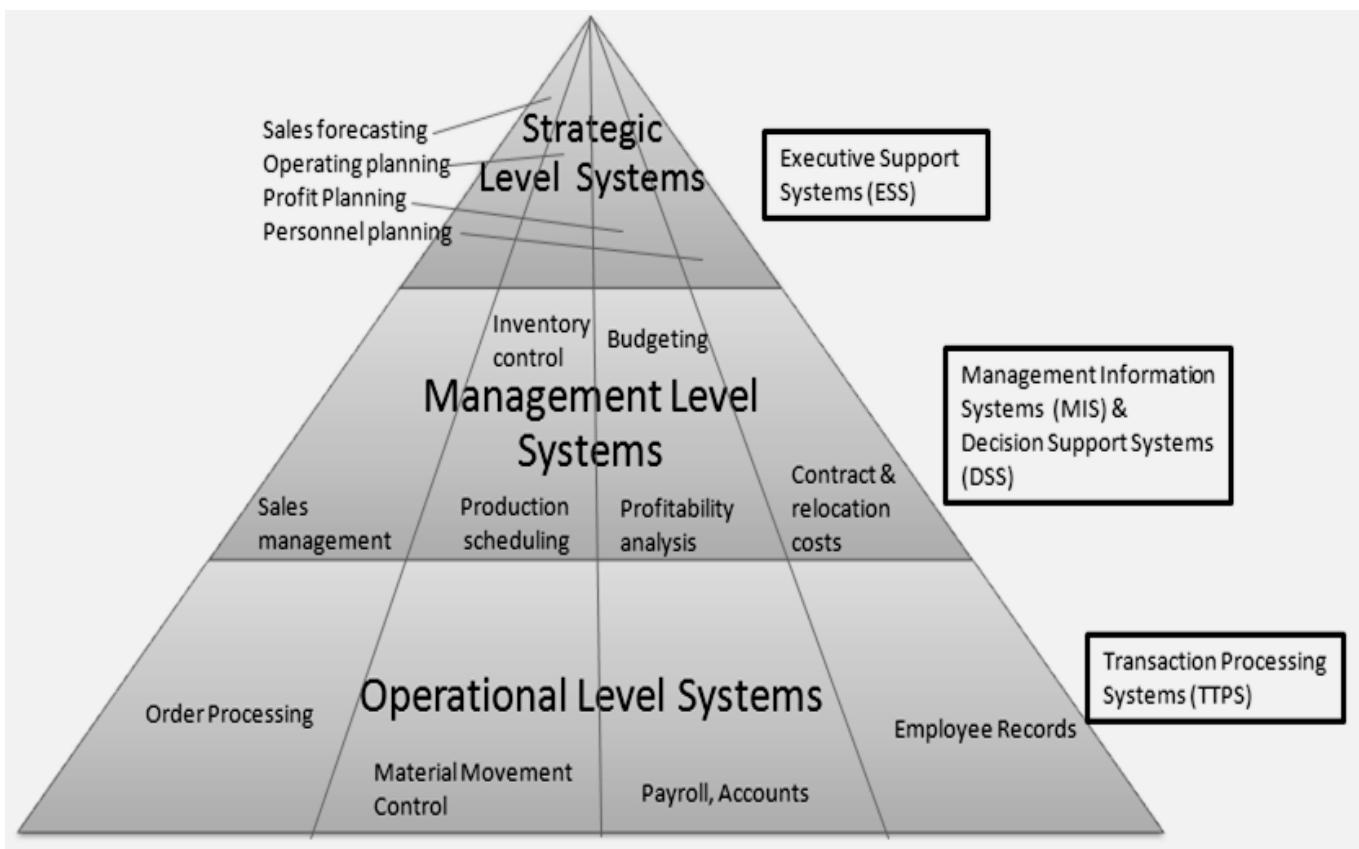

\section{Sales \& Marketing Manufacturing \& Finance \& Accounting Human Resources Production}

Figure 8:Types of company information systems by functional area.

(After Laudon and Laudon, 2003, 2006 p. 460).

Governments can give an important contribution to proper adoption of ICT in industry as demonstrated e.g. in European treaties (European Union, 2004; High Level Group, 2004). Companies are responsible for their own ICT operations, but when government policies support ICT applications in company management, these systems will become more effective. This support should take the form of proper education in ICT basics, investments in longer-term research, tax measures for industrial research; this in the interest of society at large as all such policies constitute a reinforcement for a knowledge-based economy.

Keeping this view in mind, heads of State of Government of the countries of The European Union, recognising the importance of a competitive economic growth, adopted a long-term plan in 2000 known as the 'The Lisbon Strategy Facing the Challenge: The Lisbon strategy for growth and employment'. One of the 'pillars' for this strategy is the 'Information Society': "The information society is one way of explaining what is meant by 'new information and communication technologies'. The universal use of electronic exchanges of information, convergence towards digital 
technologies, the exponential growth of the Internet and the opening up of telecommunications markets are all signs of this development".

As a further activity, in 2004 a so-called 'High-level government conference' was held under the title 'Looking into the future of ICT' emphasising the importance of ICT policy for the competitiveness of the whole economy'. This can be exemplified by trends in globalisation, development of flexible and adaptable systems and by keeping up with the advances of the 'knowledge based society'. The trend of ICT influence on the industrial society is described by Perez, consultant to the EU (2004):

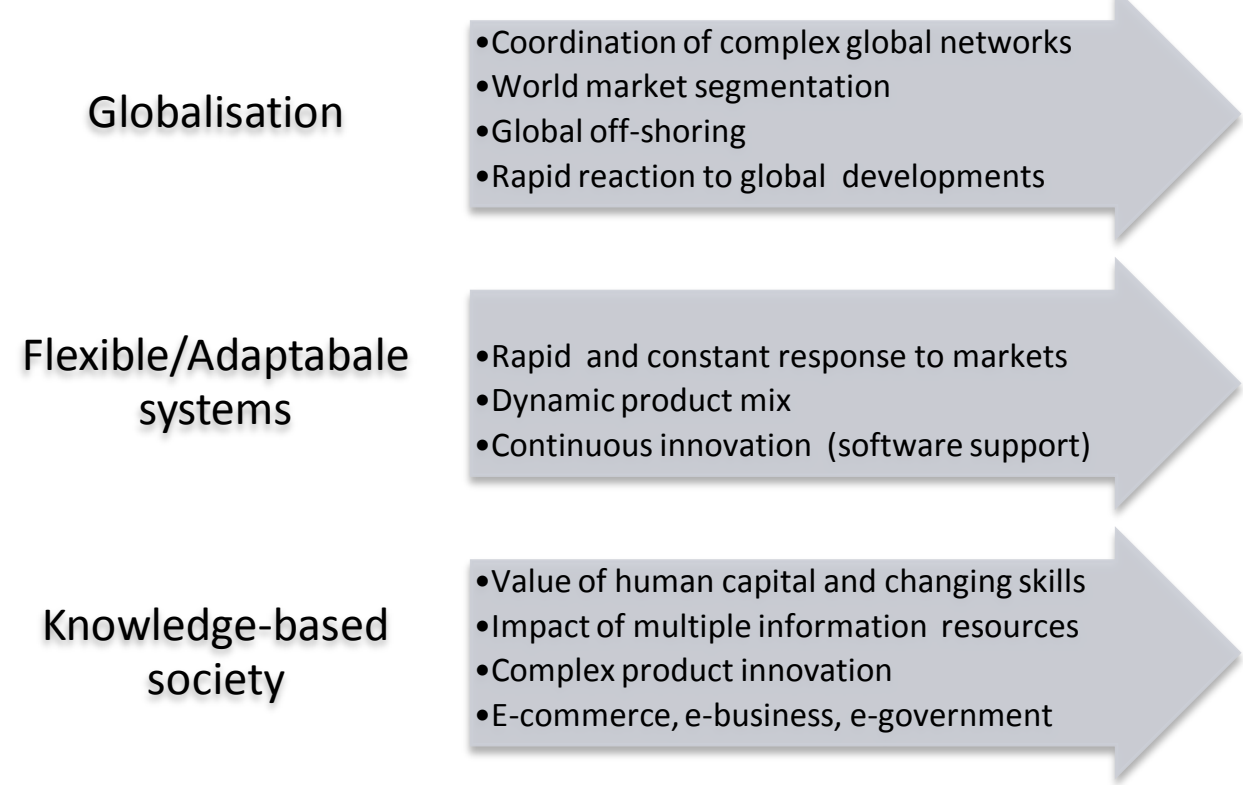

Figure 9. Trends of ICT influence on industrial development. Based on Perez, In: High Level Conference "Looking into the future of ICT" (Perez, 2004).

These trends are apparent in the civil community as well as in industry. Especially in industry, they enhance global competition and thus adequate reaction to these ICT developments will be crucial for the continuity of the company. The consequence is that executives in industry not only have to be able to use advanced ICT systems as background information tools, but also that they have to understand how business processes are changing and what opportunities, but also threats, are the result of these ICT trends. Perez stresses the influence that technological revolutions have on industry and what kind of changes European politicians must support in order that Europe can stay competitive. But again, executives of companies will have to take a lead in actually initiating change and achieving the benefits foreseen (Perez, 2004; Yip, 2005). 
Evans \& Wurster, (1997, 2000 p.25), elaborate on the information revolution that they see as completely changing the way companies obtain their competitive advantage; they analyse the intrinsic change that the Internet has brought about as follows: "Much of traditional business and strategy has been built on a fundamental trade-off between richness-sharing of extremely rich information with a small number of people, and reach-sharing less rich information with a larger number". But now digital networks are making it possible to "blow up the link" between information and its physical carrier by allowing everyone to communicate with everyone else. This means that information can now "travel by itself and it becomes possible to have both richness and reach, allowing everyone to share that information". This phenomenon is creating " $a$ new economics of information", which changes behavioural patterns and asymmetries of information access that have existed in the relations of the company with its environment.

The global information industry has changed greatly over the last few years. Recent estimates for the marketplace of industrial research information, including market, company and financial information are at about $€ 30$ milliard (billion) in 2005 and they forecast the market to grow to over $€ 40$ milliard in 2009. Growth in the global information market is primarily driven by such factors as technological advancements, increasing digitisation and globalisation resulting in growth in emerging markets. A subsequent development is that increased time spent by executives on searching for information rather than time devoted to strategic valueadded analysis, leads to outsourcing much of the searching process to specialised companies or if needed, trained information professionals in staff departments. The financial research area for instance is dominated by large global players such as Goldman Sachs, JP Morgan and until recently, Lehman Brothers (R. Sivadas, 2006).

The motive for the present study is to find out in which way such developments have an influence on the executive Board in companies; to establish whether the indicated growth and reach of the number of new digital information resources such as internal company ICT analyses of financial, production and market data and the external data available via the Internet, do influence, not just tactical and operational control but explicitly also strategic decision-making by executives.

Because of the developments of these features, a description of the foundations of computer technology, of current information resources in businesses and specifically such applications in the chemical and food industry make up a relevant chapter in this thesis.

\section{III.1. The development of computer hardware}

The first industrial revolution brought new methods of manufacturing based on iron and steam and the use of scientific reasoning to develop new products and lasted from roughly 1760 to 1830 . The second industrial revolution lasted from about 1875 to 1930. It is characterised by inventions such as electricity, the telephone, the internal combustion engine of the automobile, as well as new synthetic materials and alloys 
and innovative applications of steel and oil. These advances were made possible by the availability of capital and the creation of the modern business organisation (Smith, 2001).

Building on the accomplishments of the first and second industrial revolution, industry continued to explore new applications that led to the third industrial revolution in the second half of the $20^{\text {th }}$ century. Toffler $(1980$, p. 168) calls the third wave info-sphere' the result of the third industrial revolution. This revolution is based on the introduction of the computer, a combination of electronic memory with programs that tell the machine how to process the data it is fed. In order to code, input, store, search and disseminate data in an efficient manner, the automated digital processing of characters is a requirement. Computers were at first a scientific curiosity in the early 1950's, but between 1955 and 1965 computers began slowly to conquer the business world. Because of the omnipresence of computers handling efficiently large amounts of data and the ability to convert these data into information, present society is now often called an 'information society' or a 'knowledge society' based on an 'information economy' (Smith, 2001; Freeman and Louça, 2002, p. 301).

There are several known predecessors to the modern computer. Babbage in 1820 invented but never actually built himself, the 'Analytical Engine', a mechanical steampowered automatic calculating machine which featured an arithmetic and logic unit, memory, input/output, and sequential control by means of punched cards, the first mechanical computer capable of differentiation.

The age of automatic data processing began with Hollerith's punched card systems, which were first used to analyse the USA- census in 1890. These machines made it possible to collect the large amounts of data received and to process these data at an acceptable level of effort and cost (Hollerith, 1889).

The exact date of birth of the computer cannot be given as development of information processing machines was a process that took over a hundred years. There also is not just one inventor of the computer, as the ideas of many scientists and engineers led to its invention. These ideas were developed in the 1930's and 1940's, mostly independently of each other, in Germany, Great Britain and the USA. In Germany, Zuse developed in 1941 the world's first functional program-controlled computer with the program stored on a punched paper tape. Development of the first universal computer resulted in the ENIAC (Electronic Numerical Integrator and Computer), which was developed at the University of Pennsylvania, USA. Programs for this machine could not be stored but were entered by setting specific switches and plugs.

John von Neumann in 1944 developed ideas for a universal machine with a program stored in its internal memory. The concept of a computer in the modern sense of the word was born. The first functional von Neumann computer was built at Cambridge University, UK. This machine called EDSAC, first ran a program in 1949. The next advancement was a computer called the SEAC (Standards Eastern Automatic Computer) that was developed by the National Standards Bureau, USA in 1950. The 
first mainframe computer in private industry was ordered by General Electric in the USA in 1954 (Maxfield and Brown, 1997; Lide, 2002; Heinz-Nixdorf-Museumsforum, 2003).

This SEAC computer is of specific interest for this present research into digital information in the chemical industry because this was the first computer that was used for a variety of tasks besides mathematics; the US Patents Office was able to search for chemical structure information in a stock of chemical compounds. In these experiments 2500 cards were used to code for 250 steroidal compounds (Ray and Kirch, 1957).

In the Netherlands, the first computers became operational in the early fifties. In 1953, the Mathematical Centre of the University of Amsterdam built a relay computer that was used by Fokker Aviation to calculate airplane wing designs. Shell Research Laboratories in Amsterdam bought a British Ferranti in 1953 for statistical calculations on laboratory experiments and TNO (the national applied research institute) had a locally constructed computer for analysing properties of lenses. The infrastructure consulting firm Heidemij in Arnhem bought an IBM 650 in 1957 that was used for automating administrative tasks - KLM airlines used a computer in 1957 to solve non-linear equations.

By 1958 there were already 10 computers and in 195920 in use in The Netherlands. An idea of the costs involved can be estimated when in August 1964 Heidemij rented a new IBM360/40 mainframe computer with a memory of 64Kbytes for Dfl. 800.000 (about \$220K) per annum. (Dael, 2001, p. 114, 126; Shell Research 2007; Alberts, 2005, 2007).

\section{III.2. Applications of computers for strategic issues in industry}

Companies have systematically invested in the strengthening of their ICT infrastructure and in ICT support for the main business processes. Moreover, the Internet has facilitated many new opportunities for exchanging company data, internally and with suppliers and customers. In the eighties, companies developed information resources management systems (IRM) as one of the managerial tools controlling the many information products that the company generated internally and received from external sources. Because of this consideration, many companies created the function of Chief Information Officer (CIO) in the organisational hierarchy to support the executive level (Eliasson, 1996 p.168; Economist, 2005).

Examples of ICT services that are used can be found in company annual reports and on company web sites. Some applications that can be distinguished are those that

- $\quad$ provide reports to the executive level on processes within the company

- $\quad$ analyse and model data that become available through these reports and store these data for later follow-up analysis and retrieval (transactional systems)

- $\quad$ collect knowledge from employees in collaborative knowledge systems

- $\quad$ use software specifically developed to assist executives in making decisions

- $\quad$ provide information on the environment of the company 
make available communication tools that facilitate information exchanges throughout the organisation and enable efficiency in global operations.

The variety of such systems that have come on the market is great and in this paragraph only a short summary can be given of the developments in this field as far as they are relevant for our research (Scott Morton, 1978; Huber, 1982; Leiner et al., 1997; Lohman 1999; Meier and Füllebom, 1999; Ratan Saini et al. 2000; Hasan and Gould, 2001; Buchanan, 2006; Power, 2007).

\section{Data reporting systems}

In all larger modern industrial companies, computers nowadays routinely monitor internal processes and report on the conditions of these processes to all levels that require this information. This applies to processes such as manufacturing, inventory control, production data, sales, finances, safety etc. In this category are also human resources systems and those that report on health, safety and environmental incidents; such systems automatically monitor any remedial action that is taken. Data visualisation techniques assist executives to better understand and interpret these data by displaying results in a form that shows relations between items and possible directions (Hedelin and Allwood, 2002; Mullin, 2004; Quincirca, 2007).

\section{Analysis and modelling systems for business process optimisation}

An example of a widespread system that can analyse, simulate, model and thereby optimise business processes based on data that are collected by automated and manual input is called an Enterprise Resource Planning (ERP) system.

An example of a much used ERP system is 'marketed' by SAP, one of the largest enterprise software developers and suppliers, based in Germany. One of the ERP products is called the 'Strategic Enterprise Management - Business Information Collection'. 'SAP SEM-BIC provides functionality for automated and semi-automated collection of structured and especially unstructured business information from internal and external sources. This includes support for the entire information supply chain for sourcing of e.g. competitor or market information from the Internet: automatic search for relevant business information, editing, structuring, link with structured quantitative information, and information distribution'.

According to the suppliers of such systems, the value of ICT in decision support is shown by the fact that many modern ERP systems promise to "enhance decisionmaking by providing accurate and timely enterprise-wide information"; in 2005 " $40 \%$ of the larger US companies have implemented such exorbitantly expensive ERP systems" (Carton and Adam, 2005).

But Carton and Adam (2005) are very critical of the manufacturers' promises, stating that "the extreme standardisation of business processes inherent in ERP systems creates huge volumes of data". Unfortunately, these systems do not give sufficient handles to 
use the output efficiently and "are notoriously poor at delivering management information in a form that would support effective decision-making ... and may therefore not be beneficial from a decision-making point of view".

Another example builds on the Six-Sigma methodology (Six Sigma, 2008). Six Sigma is a "rigorous and disciplined methodology that uses data and statistical analysis to measure and improve a company's operational performance by identifying and eliminating 'defects' in manufacturing and service-related processes". One of the steps that is used is to define process improvement goals that are consistent with customer demands and the enterprise strategy. It involves the "Executive Leadership including the CEO and other members of top management. They are responsible for setting up a vision for Six Sigma implementation. They also empower the other role holders with the freedom and resources to explore new ideas for breakthrough improvements".

A basis for many such programs is provided by data warehousing or data mining. Beginning in about 1990 data warehousing of large amounts of internal and external data and the derived data mining (also called 'knowledge discovery') started to be used in companies. This type of software attempts to find patterns in raw data, and it was introduced as a 'decision support system'. In data warehousing, data from several independent sources are integrated according to a predefined model that is simpler to use than the data themselves. It is especially useful for users such as executives that do not have enough time to get involved and thus have a limited knowledge of computer systems or data structures. Data mining is in principle a statistical tool that extracts similar patterns and relationships from a large body of diverse data with the aim of finding trends and developments that would pass unnoticed by other analytic methods (Hedelin and Allwood, 2002; Lohman, 2003; Power, 2007).

\section{Knowledge Management}

A management instrument that became popular in the nineties is the concept of knowledge management (KM) systems. These are based on research by Nonaka (1994) in Japan, who studied the use of 'tacit' information, knowledge that was only 'stored' in the heads of employees and so did not contribute sufficiently to the companies' goals.

Software has been developed that provides support for collaborative sharing of knowledge, whereby collaboration refers to informal cooperative relationships that build a shared vision and understanding. This so-called collaborative knowledge management (CKM) is an approach to enabling organisational intelligence and decision support in the enterprise. CKM is based on a software environment where people work on-line; as they do what they already need to do for individual and team goals, they continuously contribute to the collective knowledge, which is then made available to everyone (Ramesh and Tiwana, 1999; Hasan and Gould, 2001).

CEO's by definition have not any peers in their company; if they want to share and confirm knowledge they can now join an executive networking group such as 'Vistage'. Such groups communicate in small meetings or over the Internet whereby strict 
confidentiality has to be ensured. These are closed user groups that can maintain an on-line resource library and facilitate exchange of experiences e.g. to supply background information for better decision-making (Barskaya, 2007).

\section{Decision Support Systems}

As early as the mid-1960's computer software was developed that aims to analyse in depth the performance of a company and its environment and to assist decisionmakers in reaching decisions based on suggestions resulting from computer programmed analyses. The concept of decision support has evolved from two main areas of research: theoretical studies of organisational decision making during the late 1950 's and early 1960's and technical work on interactive computer systems in the 1960's. Under the general term of Management Support Systems (MSS), the development on Decision Support Systems (DSS) started in the middle of the 1970's and became more accepted during the 1980's. In the middle and late 1980's Management Information Systems (MIS), Executive Information Systems (EIS) also called Executive Support Systems (ESS), Group Decision Support Systems (GDSS), and Organisational Decision Support Systems (ODSS) evolved from the single user and model-driven DSS. The purpose of such support systems is "to assist executives in their activity of decision making by providing an organised set of tools intended to impart structure to portions of the decision making situation and to improve the ultimate effectiveness of the decision outcome" (Molloy and Schwenk, 1995; MCRIT, 2000). The basis of decision support systems is to gather data, documents, personal knowledge, and business models, convert these into information, followed by generating alternatives, comparing the parameters of such alternatives and suggesting best-choices. "A model-driven DSS emphasizes access to and manipulation of financial, optimization and/or simulation models. Model-driven DSS use limited data and parameters to aid decision makers in analyzing a situation, but in general large databases are not needed for model-driven DSS. A data-driven DSS emphasizes access to and manipulation of a time-series of internal company data and sometimes external and real-time data" (Power, 2007).

An important learning aspect is that DSS can provide a means of locating and displaying previous problems, the decisions made then, and the consequences of those earlier decisions. As managers nowadays do not often accumulate 'longevity' with their organisations, DSS with historical databases can provide models that allow these managers to review previous decision processes. (Sauter, 1999; Power, 2007).

Moreau (2006) tested the effect of DSS systems with an expert system component (IDSS) and concluded that "IDSS users are more competent and work more, and are satisfied with their work. Moreover, they perceive the IDSS as being useful to the organization, and allowing them to improve the quality of their own job. Thus, IDSS use allows them to achieve task success, and the systems are perceived as positive elements in the workplace". 


\section{Information on the external environment of the company}

Most steps in the executive decision-making process require external information. Examples are information on the market situation, competitors, their products, their patents, industry sector development, economic developments in target markets, press reports concerning the organisation or its products and trends in society that affect the company. This information can be obtained by specialised staff departments that regularly monitor all relevant sources by business intelligence activities; some executives choose to receive such information straight from external sources. Three such services can be distinguished, active ad-hoc searching for relevant information on specific situations, update or alerting services that regularly supply information such as reports announcements, journal articles, press releases and news items on subjects priorly defined by company staff, and messages received from 'push technology' or RSS feeds that are used to publish frequently updated content such as news headlines and share values.

Molloy and Schwenk (1995) studied the effects of information technology on strategic decision-making and conclude that "the use of information technology led to more comprehensive decision-making processes. The ability to quickly and efficiently gather data, perform analysis and communicate the findings resulted in more data and information on alternatives being gathered, and greater volume and sophistication of analysis, and a more complete communication of the results".

To be more effective, external business intelligence systems can interact with the internal transactional systems, if possible on a real-time basis (Choo, 2002, p. 186; Atherton and Vile, 2007).

\section{Conclusion on the value of supporting software systems}

Users often complain about having to access multiple systems when trying to figure out what is going on in the business and that difficulties exist in bringing different and sometimes conflicting data sets together in a coherent way. In large company environments, it is common that many business applications have accumulated over the years, often with significant redundancy but little integration between them. But even smaller organisations often suffer from the consequences of information fragmentation (Atherton and Vile, 2007).

In 2007 an independent research firm reported on 'Barriers to good decisions' based on interviews with over 600 managers in 8 countries (Information Builders, 2007). Conclusions were that although large investments have been made by companies in becoming more efficient by implementing ERP and customer resources management (CRM) systems, information management did not fully benefit from these investments because decision making applications and processes are not up to current requirements of decision making. $54 \%$ of those interviewed lacked accurate, consistent and complete information, $88 \%$ claimed not having the right tools and $68 \%$ did not get their information delivered from such systems in easy to use format. These results show again the weight that robust information carries for executive decision- 
making and the importance of proper understanding of software developers of the competences of the users of their products.

The base of the trouble is that software developers have often taken as starting point the premise that decision-making is a structured process for which ICT systems can be produced that can analyse, simulate, model and support decision-making processes. Whether these products are successful and really perform as they promise to do is a matter that is often uncertain. IT solutions based on such structured information can hardly assist in handling strategic problems as these need an integration of information from several sources with varied structures and formats and an opportunity for executives to manipulate alternative solutions (Teng and Calhoun, 1996; Lohman, 1999; Hedelin and Allwood, 2002; Lohman et al., 2003; Wagner, 2004; Carton and Adam, 2005).

An example are Gorry and Scott Morton, $(1971,1989)$ when they fall back on Simon's earlier discussed distinction between structured and unstructured decision-making processes and take it for granted that both such processes exist. In their "Framework for management information systems", they indicate that most computerised systems are applied to support the operational types of decision-making. Moreover, they state that as strategic decision-making processes are generally not repetitious, executives are not inclined to spend much time on modelling efforts that may not be applicable in future situations. The fact that even for less-structured problems, the decision-making process can still be well-structured is ignored by those authors and is in the same way not always picked up by systems developers.

Choo (2002, p.29) is clear on the importance of asking for the correct information: "An accurate description of information requirements is a prerequisite for effective information management. Ironically, IT system designers often take this for granted and assume that information requirements can be quickly determined by examining existing paper flows and data flows".

Similarly, Wagner (2004) is convinced that "available software tools cannot fulfil the demands from a sequence of planning events to a business process, one that is ideally well-structured, iterative, and whose outputs are captured in organizational information systems. In addition to the lack of appropriate software tools, research into information systems for strategic planning has been scarce, with the result that there are very few insights available, especially for the implementation of strategic management methods into software".

Hasan and Gould (2001) phrase this concern differently, "The design of computerbased systems to support decision making is inspired by the notion that information of good quality, both in content and presentation, is essential for good decisions. There has been an unfortunate tendency to view both the computerised information systems and the decision makers as comparable information processors where the output of the computer is the input to the decision making process". This is an assumption that does not take into consideration the fact that information that can be used by executives 
has to be analysed and presented in a format that matches the decision-making process.

Stamper (2000) claims that information systems analysis and design have made very little progress since the 1950's. The fundamental ideas are still based on a paradigm that builds on a technical bias. He concludes that a high proportion of computer-based systems fail. "Estimates vary around 40-50\% of projects. They fail not for technical reasons but because the systems do not adequately serve the organisation. This indicates that the requirements specifications are often wrong. Even when they are correct, specifications are so large, complex and impenetrable that users cannot exercise their legitimate control over the systems built to meet their needs".

The earlier mentioned report of Information Builders (2007), based on interviews with managers comes to the same conclusions, i.e. that large investments have been made aiming to become more efficient by implementing ERP and CRM (customer relationship management) systems but that information management did not fully benefit from these investments; moreover, decision support applications and processes are not judged to measure up to requirements of decision making today.

\section{III.3. Technology: networks and the Internet}

The Internet can be seen as an improved information acquisition and analysis method facilitated by new information and communication technologies (ICT). Networking of publicly accessible computers started when in 1969 the US Ministry of Defense launched the first multiclient computer network, called the Advanced Research Projects Agency Network (ARPAnet) connecting computers in four locations in universities with the aim to enable researchers on defence contracts in those locations to exchange data and to collaborate in a more efficient way. In 1971 an e-mail application was introduced making it possible to exchange also textual information and messages. In 1973 the network extended an international link to European users and a year later a global commercial version called Telenet was launched.

Around that time the roots of the Internet were developed based on the standard TCP/IP protocols for all participating computers worldwide. In 1988 the Internet started to gain ground in Europe, it soon grew out as a medium for exchange of scientific data and reports (Surfnet, 2002). A few years later, but not easily pinpointed, the Internet was recognised also as having a potential as a valuable source of business information. In 1997 a US company purchased the Internet domain name 'business.com' for $\$ 150,000$, giving an indication of the value of the medium already at that time for business applications. In 1999 the same domain name was sold again, now for $\$ 7.5$ million, indicating the fast development of this field.

Smith, a Microsoft senior-vice-president (2001), states "Today the Internet, is at the heart of a third industrial revolution. This revolution is made possible by technological advances in computer hardware, software, and telecommunications, the Internet has forced companies everywhere to 're-invent' themselves and the way they do business. This transformation in business practices has caused unprecedented gains in 
productivity, generated both by improvements in efficiency and by the creation of new markets".

Summarising, the strength, the popularity and versatility of the medium is based on several unique properties made possible by a number of significant advances in technology:

- low-cost computing power based on the integrated circuit, invented in 1958,

- advanced software that makes computers more versatile and easier to use,

- $\quad$ a high bandwidth telecommunications network

and

- $\quad$ the development of the World Wide Web since 1991

- $\quad$ the availability of hyperlinks that redirect a user with one mouse click to any other site address on the Net that is related to the present site.

(Negroponte, 1995, p. 183; Berners Lee, 2000; Smith, 2001; Devezas, Linstone and Santos, 2005).

A fundamental advantage of the Internet is that all suppliers and users of information must adhere to accepted standards for each essential element (The Network Working Group, 1974, World Wide Web Consortium, 2007). Standards have become universal for elements such as the TCP/IP network protocols over which the Internet reaches its users, the File Transfer Protocol (ftp) for transfer of data files, browser software such as the Microsoft Internet Explorer and Mozilla Firefox. For companies, software applications such as Protected Virtual Private Networks (VPN) that allow staff to access their company network from home without security risks, company Intranets and company Extranets that are available to registered customers, Electronic Data Interchange (EDI) for transmission of official digital forms (such as custom declarations and inter-company records) also make use of these same standards.

An offspring from the public Internet are company-internal Intranets. In 1996-97 these corporate Intranets were developed to support information exchange and knowledge management within the organisation. This virtual space, also called the 'corporate portal', are internal web pages that "serve both as the corporate memory as well as an organizational communication device. This space enables managers to access content, manage their communication, and rely on automated workflows and routines which facilitate information distribution, sharing, and interpretation, paving the way for organizational learning" (Dias, 2001; de Alwis, 2006).

The Internet and the Intranet play a considerable role in supplying up-to-date information (and to a limited extent also historical information) that is needed for a rational strategic decision-making process. As such, the impact of the Internet is an interesting facet for our research. 


\section{Applications of network based ICT services such as the Internet}

Over the last few years, the Internet changed from mainly a system for scientists in education and research to one with practically no limit in content and audience including the business community. In this way, it has become a commodity like the telephone system; and just as other commodities it offers the integration of consumer, scientific and business applications; the same holds true for the intended user communities, it serves equally business to business and business to consumer applications. An open question is whether the Internet is just a next stage in the application of information technology or if it brings a fundamental change in business strategies and as an example, reduces the need for vertical integration in companies because of the new possibilities of electronic communication between chains in the production chain. Economists often regard productivity increases as the single best indicator of macro-economic performance because growth allows firms to raise wages without raising prices, thus creating real, non-inflationary growth. As a US Department of Commerce study notes, "After quietly improving in speed, power, and convenience since 1969, the Internet burst onto the economic scene [in the second half of the 1990s] and began to change business strategy and investment. Evidence of the Internet's economic impact can be found not only in macro-economic statistics but also in the experiences of individual companies". Surely, Internet technologies have accelerated globalisation, which is particularly suitable to promote the global strategies of multinational companies. (Porter, 2001; Smith 2001; Ticoll, 2001; Tapscott, 2001; van Wegberg and van Witteloostuijn, 2001; Devezas et al. 2005; Yip, 2005).

Even so, Porter (2001) is concerned that executives will reduce the emphasis on strategy of the company because of the impact of the Internet. He first states that "the Internet is an extremely important new technology, - an enabling technology, a powerful set of tools that can be used, wisely or unwisely, in almost any industry and as part of almost any strategy. Internet technology provides better opportunities for companies to establish distinctive strategic positionings than did previous generations of information technology". But then Porter warns that the Internet "is not necessarily only a blessing. Many have argued that the Internet renders strategy obsolete". In reality he claims, the opposite may be true because the opening up of information access that brings profits to the company, offer that profit equally to all its competitors. Therefore Porter claims, "gaining a competitive advantage through the use of the Internet requires building on the proven principles of effective strategy. Because the Internet tends to weaken industry profitability without providing proprietary operational advantages, it is more important than ever for companies to distinguish themselves through strategy. The winners will be those that view the Internet as a complement to, not a cannibal of, traditional ways of competing".

Porter's approach of the Internet is criticised by Ticol (2001) and by Tapscott (2001), who state that the Internet has a much larger influence than that of just an 'enabling technology'. "It is wrong to trivialise the Net in this way. The Net represents something 
qualitatively new - an unprecedented, powerful, interactive universal communications medium. The Net is becoming ubiquitous; it will soon connect every business and business function and a majority of humans on the planet. The Net continues to soar in reach, power and functionality. It is not only the means to link computers, but the mechanism by which individuals and organizations exchange money, conduct transactions, communicate facts, express insight and opinion, and collaborate to develop new knowledge".

There is little research into the use of the Internet as an information source for strategic decision-making. Sajor-Wood in her dissertation (2000) on the use of the Internet as 'decision support information technology for managers in the public sector', concludes that "the Internet is used in all levels of management involving a number of functional areas. Internet usage is perceived by managers as a decisionsupport information technology that contributes positively in improving their decisions".

$\mathrm{Li}$ (2002) for his dissertation, interviewed 20 strategic level managers of multinational companies' affiliates in China on 'the relationship between Internet usage and decision-making, finding that "they all felt strongly that the Internet contributes greatly in improving managerial decision-making. It would be extremely difficult for these executives to conduct their daily business if the Internet was not available".

Yip (2005) questioned managers from 115 multinational companies in diverse sectors on their use of the Internet to enhance global strategy and concludes that "managers in all industries made sure that the Internet was taken into consideration in nearly every individual activity. The greatest use at the time of the questionnaire was for $R \& D$, customer Information, and marketing". The research resulted in a number of recommendations to enhance global strategies.

There are sources that point indirectly to executive attitudes towards the Internet. The IBM Global Business Services (IBM, 2008) interviewed over 1000 CEO's worldwide on what they believe the 'Enterprise of the Future will look like. 'These executives mentioned the Internet on two accounts, "New-and existing consumersare more demanding and knowledgeable than ever. With the billion-user Internet, customers can broadcast their opinions about a product. They can link up with likeminded consumer groups and sway public opinion, not to mention company behavior". Three quarters of these CEOs view the newly empowered consumers with enthusiasm. "Here is a chance to get customer input and develop products that differentiate their company and justify premium pricing. This can be much quicker and more effective than developing products in a vacuum, only to find they missed the mark and the market".

Secondly, a common theme emerged from the interviews: "virtually all CEOs are changing their business models. Two thirds are implementing extensive innovations. Why now? Because it's possible. The Internet is allowing them to enter niche markets and reshape their processes, delivery channels and ways of partnering. Companies are 
rethinking their enterprise business model: which processes are kept in house and which are spun out to partners?".

Because active searching for specific and up-to-date information takes more time than most executives and their staff are willing to spend on information searching, information delivery companies and information integrators have started to develop personalised services that offer fast or analysed information to industry management as push (not-requested) or as pull (on request) products on Web sites. Such 'decisionfacilitating sites' do not produce long lists of options, and attributes; they elicit preferences and values and structure the information in ways that respond to the specific wish of the users' needs and values and deliver relevant content to subscribers; if agreed upon, they deliver their information straight into the company Intranet.

Services in The Netherlands of such customised information agents based on suppliers of company financial data are ANP (The Hague), Bureau van Dijk (Amsterdam), Company.info (Amsterdam), Dun\&Bradstreet (Rotterdam), Graydon (Amsterdam) LexisNexis (Amsterdam) MDinfo (Amsterdam). An international listing is shown in a later table. Generally, the more these products are personalised, the more expensive they are (Auster and Choo, 1996; Edwards and Fasolo, 2001; Citroen and Hooghoff, 2003; de Alwis, 2006;Kendrick, 2007; Aquila-Obra, 2007).

An example of a web record from 'www.company.info' (See Annex) shows a complete set of data on the sample company: Address and organisation details such as links to subsidiaries, link to Chamber of Commerce registration, news items and links to annual reports, press notices, structure of the company and information on the company managers, financial data such as consolidated balance, graphs showing turnover, profits and employee figures, web links to sector organisations, relevant government regulations and marketing reports. At the end of the record there are details such as recent financial data on companies from the company's peer group with links to their web sites.

Singh, Watson and Watson (2002) and Power (2007) discuss decision support systems (DSS) and enterprise resource planning (ERP) software and conclude from previous research that their effectiveness is not generally accepted. There are several ways that could improve these systems by using Internet input and Intranet output features Wagner (2004). One way would be in upgrading the information basis of such systems by scanning the Internet for useful information on the issues at hand. The second method is to use the company Intranet as their basis and give access to internal data warehouses featuring an easy to use web browser as the interface. Communications-driven DSS use network and communications technologies to facilitate decision-relevant collaboration and communication. Tools used include groupware, video conferencing and computer-based bulletin boards. 
One such development is an Internet based ERP, the Strategic Enterprise Management -- Business Information Collection (SEM-BIC) ${ }^{\mathrm{TM}}$ of SAP, one of the largest suppliers worldwide of ERP systems (Meier and Fülleborn, 1999). They state that "In order to improve decision support it is becoming increasingly important to combine internal and external management information. Frequently, external data is not available in numeric format. Hence, we have to link internal with external quantitative and qualitative data. Today, external information can be obtained quickly via the Internet. Since the quality and quantity of data from the Internet varies, it has to be edited to allow for systematic integration needing a higher degree of automation for data collection and analysis".

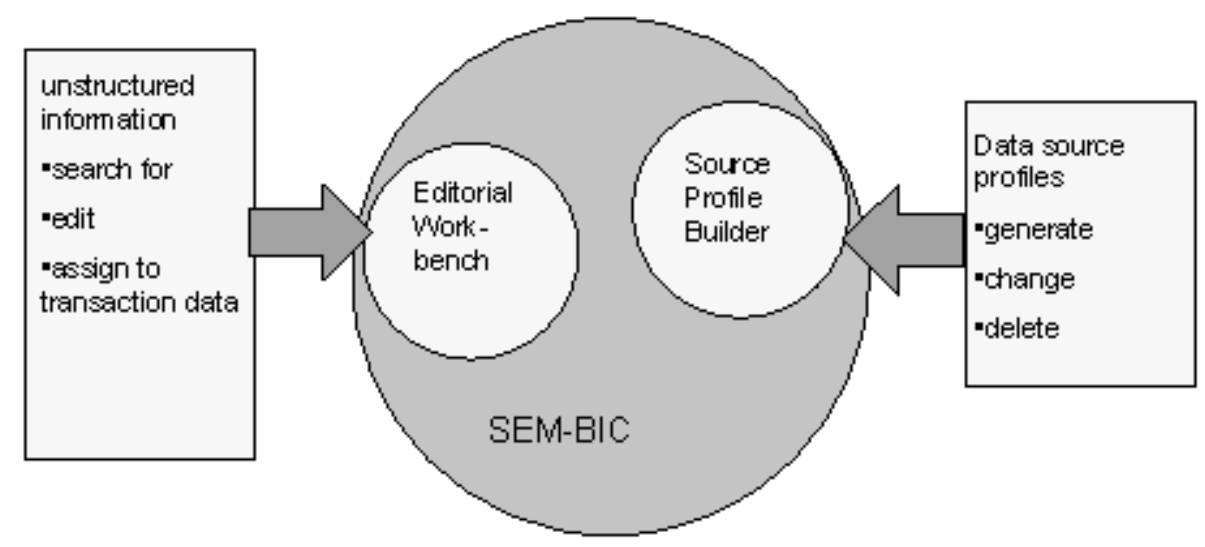

Figure 10. Information input into enterprise management system.

A similar development is that of 'enterprise knowledge portals'. Such a portal is a web page that functions as a point of access to information, a portal on the company Intranet offers access to internal company information, specific departments and services but it can also e.g. connect to software opportunities for internal collaboration. For enterprise knowledge portals, vendors deliver software and information that enables a combination of knowledge management, business intelligence, document management and decision support in an integrated Web environment. The advantage of a company portal is that it offers internal information as a single point of entry in such a structured way that searching is made simple (Power, 1998; Dias, 2001).

\section{Hazards and complexity of the Internet and related systems}

The main concerns of business users of the Internet are the difficulty of finding a specific item and the impossibility to obtain a comprehensive image of an issue because of the vast number and diversity of sources available. There is no system in the way web sites are named and there is no storage of historical facts so that it is almost impossible to confirm earlier observations. Moreover, the quality of the information that is available is in no way guaranteed because of the lack of law and 
order' on the net. Because of this complexity, managers often have difficulties understanding the potential of the system and therefore cannot always ask the right questions, specifying precisely what information is needed to resolve a particular problem.

Another issue is the lack of security that out of date software installations and careless use of hardware and software can cause. Hackers have succeeded in obtaining access and misusing company networks and have made managers wary of putting confidential information on-line, even on internal Intranets. A recent worry is the growth of so-called web 2.0 social networking communities. Instances have been reported where employees have divulged confidential information about their working environment on such systems, endangering their company.

These concerns have given the Internet a bad image with a number of executives and contributed to executives' misgivings of spending much time, certainly themselves, on consulting the Internet on strategic issues. Executives should also keep in mind that any piece of information gathered from the web is at the same time available to all competitors worldwide (Haite, 2000; Edmunds and Morris, 2000; Porter, 2001; Hedelin and Allwood, 2002; Devesas et al. 2005; Murphy, 2006).

The number of external information sources that can be useful for companies has grown tremendously and is still increasing. Many of these sources provide interesting and essential information that can be an aid in the decision-making process by supplying background facts. In a later paragraph some of the specialised sources for the chemical and food industry will be discussed.

To facilitate the retrieval of information available on the Internet, search engines have been developed that are a necessity for an efficient use of the net. However, in spite of the great effort put into improvement of present search engines, they cannot offer complete retrieval of possibly relevant material. The main reason being that search engines cannot index all information that is stored on the web, quite a number of data bases are coded in a special format such as some statistics or institutional repositories. Other relevant material may be stored in the 'deep web'; this is the store of data files that is only available to subscribing customers or members of a closed user group usually against a fee. Also, the number of different search engines (over 100 , some claim that there are over 1000) and the special capabilities of each of them are quite confusing (McCown et al., 2006; Knight, 2007).

The following two frames show how time consuming comprehensive retrieval from Internet sources can be to any company with diversified interests.

\section{Monitoring Internet sources in a chemical company}

We are monitoring over 800 internet sites for new information. About 700 of these are monitored weekly and over 100 of the better sources every day. We use a simple tool to monitor these pages. This tool goes through all of the URLs that we have entered and compares the current page to the way the page looked the last time we 
viewed it. Those pages that have changed are listed in red at the top of the list. This easy reading capability allows us to go through a large number of sites quickly, looking for new information that might be of interest.

We include a wide range of sources in our monitoring list. Many of them are specialized technology and business news in various industries. We include company sites to monitor press releases and we watch several R\&D news wires. We also watch government and university technology transfer and news pages.

As we developed all of these internet sites for monitoring technology, we make them available to other people throughout the company on an Intranet application that has a hierarchy of links by various topics. We have about 3000 links, each of which has a short description as to why somebody might want to use it.

Besides our internet-monitoring list, we gain information about new technology developments and capabilities from many other electronic sources such as information on small company developments that we monitor through SBIR $^{5}$ and venture capital databases. We also subscribe to many listservers and e-mail newsletters for various topics of interest.

Example of Internet-based business intelligence in an US company with a turnover of $\sim \$ 10$ billion (Brenner, 2005).

Financial information is one of the most offered types of information, probably because it is the most lucrative. For an insight into up-to-date financial information, the company has to make a judicious choice from a implausible number of available sources. "The Examiner Guide to News and Financial Information Aggregation Solutions' covers 36 vendors and their 300 products, and is published in a print format or as an Intranet service by P. Sefton-Williams (Foster, 2004).

\begin{tabular}{|ll|}
\hline$*$ 10K Wizard & $*$ Graydon Group \\
$*$ Alacra & $*$ Global Securities Information \\
$*$ Bureau van Dijk & $*$ Hemscott \\
$*$ Capital IQ & $*$ HighBeam Research \\
$*$ CBS MarketWatch & $*$ Hoover's \\
$*$ citywebwatch & $*$ ICC \\
$*$ Companies House & $*$ ISI Emerging Markets \\
$*$ CRIBIS SkyMinder & $*$ Kompass \\
$*$ Dialog & $*$ LexisNexis \\
$*$ EDGAR Online & $*$ MarketResearch.com \\
$*$ Economist Intelligence Unit & $*$ Moreover Technologies \\
$*$ Esmerk & $*$ NewsNow \\
$*$ Equifax & $*$ NewsStand \\
$*$ EuroInfoPool/EuroContactPool & $*$ Northern Light Group \\
\hline
\end{tabular}

5 The U.S. Small Business Administration Office of Technology administers the Small Business Innovation Research (SBIR) Program and the Small Business Technology Transfer Program. 
* Experian
* Factiva
* FT.com
* Global Insight
* OneSource

* Perfect Information

* Thomson Gale

* Yellow Brix/Fluent Media

Electronic business information services active in the USA (Foster, 2004).

\section{III.4. Computer based Information sources for the chemical and food industry}

Right from the beginning of automated information services in the early sixties, specialised companies and organisations started to offer products aimed at specific branches or sectors of science and industry. Documentation databases for chemists were one of the first new sources to be available. Users were both academia and industry with the last group primarily interested in systems that indexed chemical compounds with a potential for industrial production or biological activity and those in patent databases (Willett, 2008).

Chemical Abstracts in the US, a division of the American Chemical Society, was the first organisation to experiment with the production of chemical databases. In Europe, chemical institutions in Denmark, Germany, The Netherlands and the UK took up the possibilities of these databases soon after. The Royal Netherlands Chemical Society (Koninklijke Nederlandse Chemische Vereniging, 1970) started a current awareness service (Netherlands Organisation for Chemical Information, NOCI) aimed at chemical research in universities and industry based on the computer tapes of the Chemical Abstracts literature database in 1968. 'Hand-typed' 80-column punched cards provided input of search profiles into the computer. In 1971, there were about 150 customers for this service. In that year, the chemical industry in The Netherlands could also take part in an experimental service to search the Chemical Abstracts Service (CAS) Registry database with over 1.5 million chemical structures as an extension of a German industrial consortium, Internationale Dokumentationsgesellschafft für Chemie (Citroen 1971). In 1974 CAS started publication of Chemical Industry Notes, a bibliographic database covering worldwide business events in the chemical industry.

In 1969 the International Food Information Service in the UK started publication of the Food Science and Technology Abstracts (FSTA), covering the world's information on food science, food technology and nutrition.

Other major developments took place in the development of international telecommunication networks for transmission of textual data around 1970. Research literature databases such as Chemical Abstracts, FSTA, Medlars (from the US National Library of Medicine) and NASA space technology became accessible in Europe from host computers in the USA over normal telephone lines.

In The Netherlands, a consortium was formed by the chemical and food industry to obtain access to the Chemical Abstracts database from a European host system (Citroen 1976). The Netherlands Information Combine (NIC) contracted the European 
Space Research Organisation (ESRO, now ESA) to load this huge database (1.6 million records at that time) on its computer in Italy following NIC's specifications for use by chemical industry and academia in Europe.

Since the middle of the nineties, international chemical and food research information services have started to make a thorough use of the capabilities of the Internet (Heller, 1996; Kahn and Drey, 2002; Brenner, 2005). Depending on the type of chemistry, e.g. for chemical substances, synthesis routes and reactions, molecular motion, specific substance docking suites and calculations of potential biological activities can be accessed on-line. For the food industry, toxicological data are available from several sources.

An example is the web site 'www.Chemweb.org', started in 1996. It is a chemical virtual community portal and it delivers research and business news items and references to literature with interesting new developments, careers information, patent alerts and chemical software. Through Chemweb it is also possible to link through to items that are of interest for the chemical industry. Chemweb states that it has 250.000 registered members.

\section{Business information on the Internet for the chemical and food industry}

For industry management, a group of information sources that is important as a basis for decision-making gives access to information on business issues such as competitors' news items, markets, prices and stocks of chemical compounds, annual reports of competitor companies, news items of the industry, trade statistics etc. By scanning or subscribing to alerts from such specialised chemical and food web sites and portals, company executives can maintain coverage of developments in their industry. The number of such sites is quite large, some are specialised on particular services, but there is also a considerable overlap; it is not the place here to analyse such sites, but to get a general impression, a number of representative business services are mentioned and screen shots of web pages of these examples are reproduced in the annex.

'www.chemindustry.com' is a source that covers a number of items and links of interest to company management; one can choose regions, types of information and types of chemistry and search on e.g. market research reports; a demonstration search on 'organic chemicals in The Netherlands', yields references to 21 reports e.g. from Euromonitor International and from Gobi International such as 'Chlorine bleach in The Netherlands' and 'Toluene in the Benelux'.

A comprehensive chemical business web site is 'Chemical News and Intelligence' (www.ICIS.com); 'it is 'an on-line service dedicated to the global chemical industry and provides real-time breaking industry news from around the world, (all in a concise and quick to digest style, ideal for the busy chemical business executive), and facts, figures and analysis of major chemical companies and markets'. Services for subscribers include forecasting of specific 
markets, price alerts, ('an increasing number of managers in all sectors including production, purchasing, distribution, trade and analysis now depend on this essential online service. It gives them the latest price movements as they happen across global and regional markets').

- 'www.Chemexper.com' offers a database with 2 million different products from over 1600 chemicals suppliers. After searching for a specific compound, the site offers links to the potential suppliers to request a delivery offer.

- ' 'wwwChemConnect.com' has established itself 'as a leading independent and neutral 3rd party commodity exchange, auctions provider, bulletin-board, backend fulfilment service and market information source for NGL's, chemicals, feedstocks, polymers, fuel oil, and much more'.

- 'dir.yahoo.com/science/chemistry' is a directory site that has categorised listings of over 1300 web addresses in chemistry, including job and employment, trade directories and organisations.

These applications must be profitable, in addition to the few sites mentioned here, there are many others such as

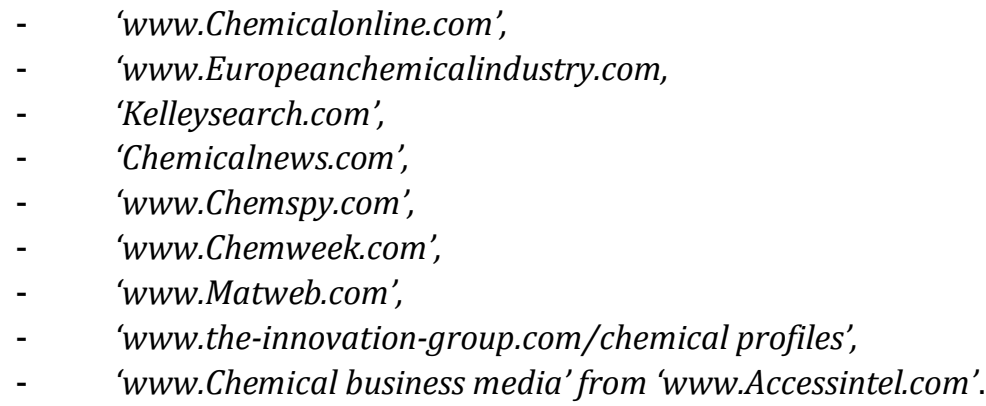

Besides those general chemical sites, there are also numerous sites for specific industries, examples shown here are ' $w w w$.Plasticstechnology.com' and the site for the pharmaceutical industry ' $w w w . P-D-R$.com' established by the Pharma Documentation Ring; a few of the PDR services such as press releases and a weekly newsletter are available free, but most of the applications are available for its members only.

'www.dmoz.org' leads to 'The open directory project', a site that offers references to web sites that have been selected by web-editors and placed in categories. The example shown here is categorised under Business: Chemical: Agrochemicals and has subdivisions for fertilisers, herbicides and pesticides and one for 'import and export'.

Similar business services as are available for the chemical industry exist for the food industries. Examples are:

- ' $\quad$ www.Foodindustry.com' a 'web newsletter showing effective Internet strategies practiced by leading food and beverage companies'. It offers access under the following headings: Ingredients, Supplies, Machinery, Magazines and News 
Resources, Packaging \& Labelling, Government and Legal, Agriculture, Careers/Education, Food safety, science \& technology, Financial/Stocks, Buyer Guides and Consumer Sites \& Trends.

and

'www.Just-food.com', a community for the food industry. It offers 'authoritative and timely business information on the international food industry with briefings, calendar of events, forums, jobs etc.'

Of interest to executives are furthermore web sites with general industrial news items such as national and European laws and regulations, patent files, environmental issues trade statistics etc. Another group of web sites of interest to executives are those of national and international branch organisations. In The Netherlands, 'www.VNCI.nl' (Vereniging Nederlandse Chemische Industrie) for the chemical industry, and 'www.FNLI.nl' (Federatie Nederlandse Levensmiddelen Industrie) for the food/nutrition industry. Congruent European institutions are 'www.CEFIC.org' (European Chemical Industry Council) and 'www.CIAA.be', (Confederation of the Food and Drink Industries of Europe). On a world scale there is 'www.ICCA-Chem.org' (International Council of Chemical Associations), 'the worldwide voice of the chemical industry, representing chemical manufacturers and producers all over the world with a production exceeding USD 1.6 trillion annually'.

\section{Hypothesis}

Web sources available on the Internet have created a completely new way of obtaining appropriate information for input into the strategic decision-making process. Staff departments nowadays routinely monitor relevant web sources and provide the executive Board with analysed information as a regular updating service or in response to ad hoc questions.

Hypothesis 4 is based on the assumption that the availability of improved information resources indeed has resulted in more efficient and effective outcomes in strategic decision-making in industry.

\section{Hypothesis 4}

Enhanced availability of multiple information resources, predominantly through specialised digital information services such as the Internet, has a positive effect on the strategic decision-making process in industry.

We intend to find out from our field research whether the speed, volume and accuracy of this information delivery has indeed profited from the strengths of the Internet and thus, whether executives can achieve a better decision-making process than in the times before the Internet could be consulted; hence this fourth hypothesis. 



\section{Research strategy and fieldwork}

In previous chapters we have discussed the process of strategic decision-making along with the way information manifests itself as an element in this process. In order to study the actual approach taken in strategic decision-making nowadays and the role of information thereby, we interviewed executives in industry asking them to elaborate on the approach by which they reached recent strategic decisions for their company. In this chapter, we focus on the design of the strategy and the fieldwork carried out in our research project.

The first step we took for our research was to select an appropriate research strategy from those applied in known studies on strategic decision-making, i.e. theoretical discussions, in-depth case studies, analysis of published accounts of companies, surveys and questionnaires, laboratory experiments and interviews. We chose to conduct personal interviews with executives that take strategic decisions for their companies and analyse the decision process followed by them in order to answer our research questions. Later in this chapter, we discuss the various methods applied and provide further arguments for this choice.

In the next step, we decided on the segment of industry that we aimed to study, we formulated an interview protocol and we tested this protocol in a few trial interviews and adapted it based on these trials. We then contacted executives in the target group of companies asking them to agree to an interview.

The empirical research for this project is a study of actual strategic decision processes as they are taken by Board executives. In order to be able to obtain a view that can be generalised, the sample has to consist of a population that is of a restricted size. We selected companies that have an annual revenue of over $\mathrm{M} € 300$ in the chemical and food industries in The Netherlands and that are independent, i.e. not completely dependent on orders from a head office in another country. We also interviewed a small sample of such industries in Germany.

In practise, this meant that from companies in each of these industries a number of executive members of the Board or of executives very close to the Board were interviewed face-to-face for one hour. We thoroughly analysed the transcriptions of the interviews for the way the decision-making took place in each of the steps taken in the process and in particular, the acquiring and use of information that is needed to take these decisions.

\section{IV.1. Strategies}

Literature study did produce few references pertaining to the exact topic of this study. Closest came two theses, that of Meijaard (1998) in Economics at the Erasmus University Rotterdam (NL): 'Decision-making in Research and Development' and that of Sajor-Wood (2000) in Public Administration at the University of La Verne (California, USA): 'The Internet: A decision-support information technology for public managers.' 
Seminal publications retrieved were those from Popper (1935), Fredrickson (1984), Simon (1960, 1987), Cyert and March (1963, 2nd ed. 1993), Mintzberg et al. (1976), Repo (1986), Eisenhardt (1992), Meadow and Yuan (1997), Choo $(2002,2006)$ and Weirich (2004).

Over the years, much research in strategic management has concentrated on strategic decision processes seeking to improve the quality of decision-making by executives. These research projects are reported based on different methodologies and techniques of which six stand out, ranging from theoretical studies to studies analysing actual issues:

- theoretical discussions and analyses of the parameters of the decision process,

- $\quad$ case studies of published accounts of the process and the outcomes of actual decisions made,

- $\quad$ analysis of published accounts of decision-making processes,

- $\quad$ surveys conducted by telephone or more recently by e-mail questionnaires,

- $\quad$ 'hands-on' laboratory experiments, often carried out by students,

- $\quad$ interviews with decision makers and analysis of the transcripts

(Langley, 1999; Hoskisson, Hitt and Wan, 1999; Scandura and Williams, 2000; Eisenhardt and Graebner, 2007).

No general guidelines can be given as to which of these methods would be more valid for the research study that we had planned, they all have their merits and treat different aspects of the spectrum of tasks in strategic decision-making. All of them bring new insights and help improve the quality of management techniques.

\section{Theoretical approach}

Most handbooks on strategic management offer theoretical discussions that give formal recommendations as a guide to 'best practices' for procedures in the process of strategic decision-making. These recommendations are based on theories developed by authors such as Simon (1947), Drucker (1973) and Cyert and March (1965, republished in 1993) that are not the result of systematic empirical research, but of anecdotic or circumstantial evidence. Examples of handbooks are Simon (1960) in 'The new science of management decision', Drucker (1973) in 'Management: tasks, responsibilities practises', and Johnson, Scholes and Whittington (2005) in 'Exploring corporate strategy'.

\section{Case studies}

According to Eisenhardt and Graebner (2007), 'building theory from case studies is a research strategy that involves using one or more cases to create theoretical constructs and propositions from case-based, empirical evidence'.

In another way, Molloy and Schwenk (1995) used case studies to explore the effects of information technology on strategic decision-making by asking CEO's from 4 firms to describe in detail recent decisions made; these CEO's and managers involved in the 
decisions were interviewed using a script with some 60 questions and additionally they studied archival material.

Iastrebova (2006, p.107), in a PhD study on managers' information overload interviewed and observed managers from three information intensive companies in different fields. In explaining her research strategy, she remarks that such a research project must be feasible, meaning that the size and profile of the target organisations should fit all feasibility constraints such as time, budget and accessibility.

\section{Analysis of published accounts of companies}

Another approach takes its input from studying public and sometimes confidential but anonymised - facts in annual reports, company news releases and in news magazines and papers such as Fortune, Business Week and the Financial Times. Examples are Mintzberg (1973) and Hitt et al. (1998). These studies reveal positive and negative outcomes of actual decisions taken and help prevent recurring errors; but the underlying processes usually remain unknown as these are hardly ever published. An exception is the case where diary accounts can be accessed; Mintzberg (1973) studied the nature of managerial work in such diaries of managers and observed their daily routines.

Hitt et al. (1998) studied successful and unsuccessful acquisitions of US firms by rating 4000 pages of published materials on 48 firms that had recently acquired another firm or that had been the target of an acquisition or that was the result of such a merger. They identified attributes and effects both from successful and unsuccessful acquisitions.

\section{Surveys or questionnaires}

Surveys are an often applied approach by which a sizeable amount of data is gathered using questionnaires sent out to a target group. Often these questionnaires yield a relatively low response that then has to be corrected for biased results before an analysis can be performed. In several cases telephone or e-mail reminders are used. The results are sometimes augmented by interviews of a sample of the respondents as a follow up of the questionnaires.

Among others we mention here Sajor-Wood (2000), Baum and Wally (2003), Yip (2005) and Frishammar and Hörte (2005) that have used this technique.

Sajor-Wood (2000) had 100 returns from managers in the public sector on her survey of the Internet as a decision support service; this enabled her to draw conclusions on Internet usage by managers experienced in using computers and those that were less computer proficient.

Baum and Wally (2003) analysed replies to questionnaires of 318 CEO's asking them about the effect of advances in communication and information processing technologies on decision speed and on firm performance.

Yip (2005) questioned managers from 115 multinational companies in diverse sectors on their use of the Internet in global management strategy. They were able to formulate a number of recommendations to enhance global strategies. 
Frishammer and Hörte (2005) analysed responses from over 170 CEO's from manufacturing firms in Sweden and found that proper management of external information is associated with positive innovation performance.

\section{Laboratory experiments}

In some studies a theory is corroborated in an experiment carried out by test persons in a laboratory setting; these persons are often students who are required to perform an action such as in a management game that is then analysed e.g. for the way decisions are reached. Examples are the studies of Lee and Cummings (2004) and Williams, Dennis and Aronson (2007) on the influence of information on decision quality. This technique is appropriate for developing hypotheses that are formulated for parts of a process to be analysed and gives an opportunity to compare different conditions for their effectivity but is often not truly representative of real world dilemmas.

Lee and Cummings (2004) involved 40 participants in an experiment to test two models of decision-making. The results showed that decision-makers stuck to either the first or second model for all decisions they were asked to take. Williams et al. (2007) tested the impact of decision support systems (DSS) on decision quality when solving a relatively well-structured decision task. Sixty-four undergraduate business students had to make a decision and although they developed a better understanding of the decision problem, actual decision quality did not improve.

\section{Interviews of a specific target group}

Eisenhardt and Graebner (2007) state that interviews are a "highly efficient way to gather rich, empirical data, especially when the phenomenon of interest is highly episodic and infrequent". Similarly, Nutt (2005) finds that research based on actual decisions offers the researcher real events to study that avoid the simplifying assumptions found in the other modes of study. Often an interview method was used to perform case studies, especially when in depth analyses had to be made whereby interviews were part of the data collection method.

Interview methods have been applied by Langley (1990), Dean and Scharfman (1996), Meijaard (1998), Nutt (2005) and by Geurts and Roosendaal (2001).

Langley (1990) interviewed CEO's of three organisations on the application of 'formal analysis in strategic decisions'. She defines formal analysis as 'any kind of systematic approach to decision-making in which the result is documented'. Langley finds that formal analysis in these organisations is in fact used for "substantive input to decisions and as a key tool of persuasion and verification in the negotiating process between levels of the hierarchy concerning actions to be taken".

Dean and Scharfman (1996) studied whether the way the strategic decision-making process is structured, has an influence on the effectiveness of the decision-making process. From interviews with decision-makers that were involved in 61 decisions they concluded that "managers who collected information and used analytical techniques made decisions that were more effective than those who did not". 
Meijaard (1998) interviewed project leaders of a number of R\&D projects in multinational chemical and food firms in The Netherlands and the USA on the nature of the decision-making process. He found that the way information is used during a $R \& D$ project can have a negative effect if this leads to repeatedly changing the goals or methods of a project that is already in progress.

Nutt (2005) studied almost 400 non-routine organisational decisions in for-profit and not-for-profit-organisations to investigate different approaches of searching for information during decision-making. This study showed that "a rational, goal-directed approach was the most effective way to search. Setting a goal proved to be the crucial step in the search for information".

Geurts and Roosendaal (2001) interviewed a sample of stakeholders in scientific communication in order to obtain qualitative and quantitative opinions on the direction of innovative change.

Eisenhardt and Graebner (2007) do sound a warning, "The risk involved in this method is that the accounts may be biased and colored by retrospective sensemaking". To avoid this risk, one needs to judge the records from different perspectives. In our research we made an effort to avoid this risk when studying the approach taken in the decisionmaking process to look also specifically for the information used in the process and the way explanations from the executives were in line with information gathered ahead of time by us from open records.

\section{Method applied for this research}

We have chosen as our research approach to discuss recently taken strategic decisions during semi-structured interviews with executives from a specific segment of industries. With these interviews we aim to analyse the actual approach executives in industry follow when taking strategic decisions, observing whether or not they follow a distinct structured approach and how they make use of information during this process.

This method would yield data in adequate detail to be able to analyse the discussions held during the interviews for the issues at stake and the subsequent actions executives take in the decision process. With these empirical results we could then test whether the hypotheses we have proposed are sufficiently supported.

We collected additional data by asking managers of information departments in industry on the methods they use to distribute information within their organisation.

In order to facilitate the analysis, we developed a model (figure 3, paragraph II.1.) representing the five phases in the decision-making process and the information that is acquired in each of these phases: starting with the preparation for a decisionmaking process by formulation of the issue and setting the objectives, followed by collection of internal information and external information on the environment of the organisation, next the specification of potential alternatives, then limiting the options by choosing between these alternatives and finally, reaching a decision.

We use this model by mapping the phases as we deduce them from the interviews onto the phases as represented in the model. If sufficient overlap is established, then 
we can assume our model to be a proper representation of the process of the population of executives studied in this research.

\section{IV.2. Fieldwork}

We started the actual fieldwork by selecting the target group of industrial companies from which we intended to interview decision-making executives. We had to select a category of companies that is well defined, homogeneous in terms of their markets and at the same time covering such a number of members that a sufficiently large sample could be obtained by interviews to be held by one person.

Answering these criteria, we selected for these interviews members of the Boards of a specific group of large companies in The Netherlands with a turnover of more than M€ 300, a group that is dynamic, is expected to yield a result that will give a coherent picture of strategic issues and objectives and that is made up of a limited number of companies.

The segment selected consisted of 20 companies in the chemical and food processing industry. These industries are a significant source of activity in the industrial world, especially so in The Netherlands where several large multinational firms of Dutch or Anglo/Dutch origin are located. In addition, a number of large international companies in these branches have subsidiaries and facilities in this country. The group has a clear structure, which meets our criteria of transparency. At the same time, their speciality of chemistry constitutes a familiar basis for our research group (Citroen, 1991). The chemical industries selected consist of companies producing base chemicals and those producing specialty chemicals. The food industries that we approached produce speciality chemicals for their own products or for sale to other companies. (VNCI, 2008, FNLI, 2008).

This sampling ensured that an almost complete coverage could be obtained for a specific segment of industry so that we could generalise the results of our research to the complete group of companies in this segment.

Additionally, we asked one technical research organisation to participate and we interviewed two executives of large chemical companies in Germany.

A limitation for this study was that several of these industries in The Netherlands are in fact subsidiaries of companies headquartered elsewhere in the world. In most cases the executives in The Netherlands do not take strategic decisions affecting these companies globally. Examples of this are DuPont, General Electric, Dow Benelux and Exxon-Mobile. Some companies are independent in name, but still belong to an international conglomerate. Examples are Douwe Egberts (Sara Lee) and Centocor and their autonomy varies.

Another limitation was that several multinational companies are located in The Netherlands, for which strategic decisions involve more than just the chemical/foods segments chosen. Examples are the Royal Dutch Shell Company and Philips Electronics, for both of which chemical processes form only a part of the activities. 
We approached all independent companies in the selected segments and only those subsidiaries that have a significant local autonomy. We addressed a letter to the CEO's of these companies asking for permission to interview the CEO or one of the other Board members; for the large multinationals, we wrote to a Division director responsible for the chemical or foods division (See annex for text of the letter). We also approached a limited number of German chemical companies to check whether there would be significant differences in the approach with Netherlands' executives. In the letter that we sent, we explained the objectives of the research project and we asked whether a member of the Board would agree to a personal interview about the process followed in specific strategic decisions and the information used during the process of decisions that the Board had taken recently. The letter also stated that the content of the conversation would be used anonymously.

Executives of thirteen companies and one technical research institute agreed to such a personal interview. In the Netherlands six companies declined because of busy schedules or lack of interest, two indicated to be available perhaps at a later date. From the sample of companies asked in Germany, 2 companies agreed to an interview. Sixteen Board members or executives directly involved with Board decisions (for two companies, two interviews were held) were thus interviewed face-to-face (or in one case by telephone) on considerations, processes, motives and changes in procedures of strategic decisions taken by the Board.

This level of response ensured sufficient coverage for a representative analysis of the selected industrial segment without bias, making it feasible to compare the collected data to establish a convergence that is useful for understanding in general sense the process by which strategic decisions are reached.

$$
\begin{array}{ll}
- & \mathrm{F}=4 \text { Food companies } \\
- & \mathrm{B}=4 \text { Base chemicals companies } \\
- & \mathrm{S}=5 \text { Specialty chemicals companies (in one case } 2 \text { executives) } \\
- & \mathrm{R}=1 \text { Research Institute. }
\end{array}
$$

Figure 11: Type and number of companies interviewed

$$
\begin{array}{ll}
- & \text { 4 CEO's, } \\
- & \text { 5 Board members } \\
- & \text { 1 Vice-President Corporate Development } \\
- & \text { 2 Division directors } \\
- & \text { 1 Staff Director Technology } \\
- & \text { 2 Staff Directors Strategic Planning \& Development } \\
- & \text { 1 Staff Director Business Development \& Innovation. }
\end{array}
$$

Figure 12: Function of the executives that were interviewed. 
The type of industries that agreed to take part in the research and the functions of the interviewees are shown in figure 11 and figure 12.

As shown, they were either chairman or member of the Board/management team or were directly involved in strategic company management. In some cases they also held direct management functions in their organisations. A list of the companies interviewed is shown in an annex.

The chemical industry can be divided in that of base chemicals and specialty chemicals. Both types are present in our sample as seen in figure 11. The food industry manufactures food ingredients to be used in their own products or to sell them to other food companies.

According to CEFIC (European Chemical Industry Council) in 2006, the world chemicals production (excluding the food industry, but including the pharma industry) was estimated at $€$ 1,640 Milliard (billion), the 25 European Union countries accounted for G€ 475 and The Netherlands for $7.6 \%$ or G€ 36 thereof. The EU chemical industry accounts for around $10 \%$ of EU manufacturing industry's gross value added (2006). (www.cefic.eu).

Facts from the CIAA (Confederation of the food and drink industries of the EU), indicate that this industrial sector has a production of over $870 \mathrm{G} €$ (2007). In the Netherlands, production was G€ 55 (2006). (www.ciaa.be)

Not all statistics agree on numbers; according to the VNCI (Association of Netherlands Chemical Industry, thus excluding the pharma and food industries), the total turnover of the 400 Dutch chemical companies in 2007 was $\mathrm{G} € 50$, being responsible for $10 \%$ of all industrial employment in The Netherlands, $15 \%$ of all production, $20 \%$ of all exports, $25 \%$ of all investments and $25 \%$ of all R\&D (VNCI, 2008).

\section{Collection of data}

Strategic decisions are defined elsewhere in this report as involving issues such as the design and long range planning strategies of the organisation, initiatives for mergers and acquisitions, large investments in new products or markets, disinvestments, make or buy options and internal reorganisations (Cray et al., 1988, 1991; Dean and Sharfman, 1996; Nutt, 1999). Therefore, these were the subjects that were expected to be discussed during the interviews.

Preparation for the interviews consisted of gathering background information on the companies concerned from sources such as company annual reports, newspapers, financial publications, news items on the Internet and trade publications. This was needed as a basis for quickly grasping the gist of an issue brought up by an executive. Also, in cases where the executive did not spontaneously come forward with an issue that had been noted in this way, he was prompted on this matter for discussion by the interviewer.

The aim of the interviews was to find out in detail the way each of the decisions had been arrived at and the reasoning behind these decisions. For each of the decision- 
making processes that they reported, the interviewer asked the executives by probing questions to explain step by step the process and the considerations and motivation for each step, the sources, quality and usage of the information sought and obtained, the alternatives that were considered and the eventual final decision made. At the end of the interview the executives were specifically asked whether they could point out changes in these procedures in the last couple of years, and the role of ICT, if any, responsible for those changes.

The sixteen interviews that we conducted lasted on average for one-hour, were semistructured, based on an interview protocol, but generally the discussion progressed smoothly without the need to strictly adhere to this protocol. Overall executives presented without notable restrictions several recently taken strategic decisions that they were willing to discuss, under a promise of anonymity. Most interviews were recorded on tape, only two executives preferred not to be recorded.

\section{Model for strategic decision-making}

In chapter II we discussed the conditions for a rational decision-making process based on the literature on this subject. For our study, we developed a model (figure 3, paragraph II.1.) in which we summarise these conditions in 5 distinct phases, including the final decision; this model can then be used to categorise the actual steps as presented by the executives in order to see if they fitted in the model.

These phases that we assume to be followed in the process to arrive at a Board decision are successively:

Preparation for a decision

- $\quad$ formulating the issue based on internal or external developments

- defining the question and set the objectives

- $\quad$ preparing a preliminary position, sometimes a flagging paper

Analysis of data from the internal and external environments

- collecting, analysing and reviewing relevant information, due diligence

- $\quad$ tracing potential alternatives

Intermediate specification of alternatives and planning of actions

- $\quad$ analysing and specification of potential alternatives

- $\quad$ planning the steps to be taken, drawing up a course of action

- $\quad$ listing the choices that have to be made and assessing the outcome

Limiting the number of potential alternatives

- $\quad$ based on parameters designed in previous phases

- discussion of consequences of implementation of each alternative

Final decision

- $\quad$ leading to action and implementation or non-action,

- followed by feedback and evaluation. 
From the reports of interviews that we held, all observations were assigned to phases and placed into the boxes of the model. The value of the analysis and the model lies in the fact that they enable a scrutiny of each step, leading to an understanding of the build up of a strategic decision and the internal and external factors that influence the process before a decision can be taken.

\section{Additional questionnaires}

In order to supplement the data obtained from the interviews, we solicited input from two other groups that actively supply information services within their companies.

1. The Combination of Netherlands' Information Managers (NIC Foundation) consists of nine corporate libraries/information centres from multinational technical corporations plus a number of scientific libraries from academic and governmental institutions. Participating companies are AkzoNobel, DSM Research, Corus Research Development \& Technology, Océ Technologies, Organon, Philips Research, Shell International Exploration \& Production, Solvay Pharmaceuticals and Unilever Research. These corporate information managers provide scientific and business information services to all potentially interested employees of the company, often to affiliates worldwide. They were asked the question whether any of them provided information directly to the Board of the company, either as a news bulletin or in answer to ad hoc questions.

2. We approached a selection of chemical information professionals contributing to the Chemical Information Sources Discussion List, CHMINF-L, which "serves since 1991 as a forum for discussion of, as well as an information source for, chemistry reference questions and more general questions and the sources used to find information needed by chemists and their companies". The CHMINF-L list counts1250 recipients of which the majority are employed by university libraries.

From the archives of the List, we selected 60 persons that had an e-mail address that indicated a function in a commercial company such as '.com or '.co.uk'. We sent out an e-mail questionnaire as a personal message to these 60 addresses in November 2007 and a follow up message was sent in March 2008.

The response was quite acceptable, 33 replies (55\%). However, 19 (36\%) of these either did not work in the expected environment or were a one-person company; two employees of pharmaceutical companies answered that they could not answer because of confidentiality reasons.

This left 14 valid answers (23\%). Examples of companies that did reply were LGC (Analyses, UK), Dow Chemical, Süd-Chemie, ExxonMobile, US-Rhodia, Procter \& Gamble, Sanofi-Adventis (US).

\section{Use of computer assisted qualitative data analysis software (CAQDAS).}

In order to assist in organising the results of the interviews and to categorise the statements of the interviewees use was made of the CAQDAS package NVivo (C).

NVivo is a qualitative analysis software aiding users in managing, organising and supporting research in qualitative data analysis projects by immediate coding of their 
ideas. Ideas can be extracted using text editing of documents and memos. Thoughts can also be located at nodes in a schedule without deliberate coding. NVIVO combines a number of techniques for linking data and shaping the data into sets and models.

The 16 interview reports were input into an NVivo database and for each key term a code was generated that could then be linked with other codes and that also could be visualised in a NVivo model.

We extracted for each code the reports that linked to that code and subsequently used these to collect data for the results chapter of this dissertation. This system turned out to have limited added value as it did not lead to linkages or tendencies that were not foreseen. 

V. Results and discussion

Our first question and the derived hypothesis 1 imply that the actual approach taken by executives nowadays in strategic decision-making is a goal oriented, rational and structured approach.

In order to come to a judgement on the validity of our assumption, the hypothesis can be tested in three ways: firstly by identifying the issues in the decisions that are discussed as strategic, secondly, by examining whether the approach chosen follows a structured path with the 5 distinct phases established in a time frame as indicated in our model, and thirdly by observing whether there is an indication of irrational processes such as bounded rationality due to a lack of time to adequately collect information or to study information that is available, merely resulting in satisficing decisions or that we could find indications about intuition being given as an explanation for a course taken. We examined each interview for clues that pointed to either a true or a false attribute on this issue.

We identified and discussed in detail thirty-two issues that had recently prompted a strategic decision by the executives. The interviews enabled us to collect sufficient facts on these elements to be able to draw relevant conclusions. The executives volunteered these issues or were provoked by the interviewer when necessary. For this report, the issues have been anonymised so they cannot be attributed to any one company or any specific decision process.

From the open atmosphere in which the discussions took place and the considered way that answers were given to the questions we raised, we conclude that the participating executives did not keep back major issues or made their handling of the processes look significantly better in retrospect. The interviews thus gave no reason for doubt, sounded convincing and are valid for the strategic issues at stake. All issues discussed appeared to be strategic decisions.

\section{V.1. Outcome of the research: strategic issues}

From features in business newspapers and news magazines, we have selected examples of strategic issues regularly published. We ordered these issues in 5 categories, mergers and acquisitions, investments, divestments, reorganisations and long-range planning. The issues reported by the executives that were interviewed fit well in those categories with the exception of long-range planning, an issue that was not brought up, possibly because it is an ongoing activity that does not proceed in a phased approach. The issues that were discussed are listed here under the headings mentioned, with an indication of the type of industry that is involved, B=Base chemicals, $\mathrm{F}=$ Food processing, $\mathrm{R}=$ Research institute, $\mathrm{S}=$ Speciality chemicals. We make this distinction because we could expect that a pattern might become visible along these types. What shows up is that base chemical industries do not make new acquisitions or divestments and that there is no apparent difference between speciality chemicals and food industries in this respect. 
The following table lists the 32 strategic issues on which executives have had to make a decision.

\section{Mergers and acquisitions}

1,2 Acquisition of a competitor company $(\mathrm{F}+\mathrm{S})$

3 Acquisition of a company with aim to sell off a division later (S)

$4 \quad$ Acquisition of several small companies (S)

$5 \quad$ Preparation for potential acquisitions (S)

\section{Investments}

6 Investment in a comprehensive R\&D facility $(F)$

7, 8 Construction of a new (main) production facility $(\mathrm{F}+\mathrm{B})$

9 Choice of a new essential manufacturing utility (B)

10 Construction of a new head office building (B)

11 Move to China and invest, replacing an obsolete production facility (F)

12 Developing a business park and outsourcing logistic activities (B)

13 Identifying new areas of potential innovation (S)

14 Engage in sport sponsoring (F)

15 Upgrading of the presently used SAP software (S)

16 Development of a company-wide Intranet (R)

17 Standardisation of internal company management software (S)

\section{Divestments/divestures/desists}

18 Divestment of a products division (F)

19 Divestment of $50 \%$ share in a secondary product (F)

20 Sale of a division outside of the core business (S)

21 Non-acquisition of a competitor 'up for sale' (F)

22 Divestment of a joint venture (S)

\section{Reorganisations/Change in strategic procedures}

23 Reorganise the management structure of the organisation (B)

24, 25 Implement a personnel reservation/selection programme $(\mathrm{B}+\mathrm{F})$

26 Self-assessment for an external review (R)

27 Internal reorganisation, creating a new management level (R)

28 Restructuring the organisation, management and work force (S)

29 Realising a 10 year plan for safety and the environment (B)

30 Setting strategic targets for the organisation (F)

31 Transition of the focus regions of the company (S)

32 Reorganise a diverged company to autonomous viability (B) 


\section{A rational and structured approach}

In one case, a company demonstrated its rational approach by ruling that 'decisions of the Board are planned according to strict standard systems or procedures, for every step parameters are stipulated and studies to be performed with information to be collected are fixed. For every project, progress is monitored by head office and prognoses are checked against real outcome at set intervals'.

From the 32 issues that we discussed with the executives, we are able to identify 102 explicitly stated decision process descriptions of the distinct phases followed during the strategic decision-making processes. In some cases, a phase could be skipped because there was no need to follow this phase. These cases are discussed below.

'Reorganisation' decision processes did not skip any of the 5 phases, this is probably due to the fact that more alternatives have to be considered and consequently, more choices have to be made.

Almost all processes start with a 'preparation' phase, the preparation for the decisionmaking process; it is not always clear what can be termed a continuous process of keeping alert on developments and at what point does the preparation precisely start. Also, several issues do not have a definite starting point because they simmered for quite some time before they became urgent. Issues originate from internal as well as environmental developments and trends. An example of such an issue where the preparation phase could be skipped is 'a long standing discussion on a divestment took effect' and an example of the 'specification of alternatives' phase: 'a tender was put up for bids on the division to be divested'.

The phase of collecting and analysing of information is mentioned slightly less often, a reason being that it is not always easy to distinguish what should be called preparation and what comes closer to analysis; this phase also generally does not have a distinct beginning or an end as during the decision process, continuously new aspects of the issues flare up that require additional information to be gathered and analysed for relevancy, quality and reliability. In cases where the analysis phase was mentioned specifically, it was also possible to distinguish between internal and external information sources.

In cases of mergers and acquisitions, analysis of external sources scores highest and the limiting/choice phase lowest as these issues usually concern one opportunity; a feedback loop is mentioned often in those cases as new information due to due diligence keeps coming up and consequently has to be analysed.

The intermediate specification of alternatives and planning phase results in a number of alternative scenario's of which the time horizon varies from short term to in one case over 10 years. This phase is skipped in $20 \%$ of the decision processes, because no valid alternatives had been found and thus no limitation was needed. 
In these preceding phases, all relevant information has now been collected, analysed and studied. Even so, taking the final decision in some cases still necessitated an intense discussion among Board members.

If we correct our analysis of all 102 decision-making processes for those instances that a phase was not deemed necessary, we see that in all cases to be decided on, all 5 phases that we defined and used in our model (figure 3) and list in our table below that needed to be followed, were indeed consistently followed.

Based on the analysis of the phases discussed during the interviews, we propose to add one extra phase to the model, i.e. the assessment of the outcome of the specified alternatives. This phase we identified in about $20 \%$ of the processes; it follows the 'limiting' phase but precedes the final decision in that it is a check whether the potential alternatives chosen do not unnecessarily harm the company's interests e.g. by 'value dilution'. This phase is most important in investment decisions. The additional assessment phase has not been used often, but is relevant as it shows that in order to come to a decision, in some cases rationality requires that additional information is studied to be able to appreciate the consequences of each otherwise valid alternative. Such an additional phase is consistent with the listing of the process as given by Koopman and Pool (1997, p. 7, 17): "before a final decision is made, positive and negative consequences of all alternatives are re-examined". This observation can be analysed in terms of an expanded version of our 5-phase model as we show in the new model of figure 13 and at the bottom of the table below.

This model does not only indicate the flow diagram of a rational and structured decision-making process, but also shows the various information sources that are consulted for strategic issues. For the first two phases more than one source is needed, because often a preliminary inspection of the issue leads to further questions. The feedback process is a special case as it means that the process in one of the last phases is interrupted in order to collect additional information and start over again with a new analysis phase. 


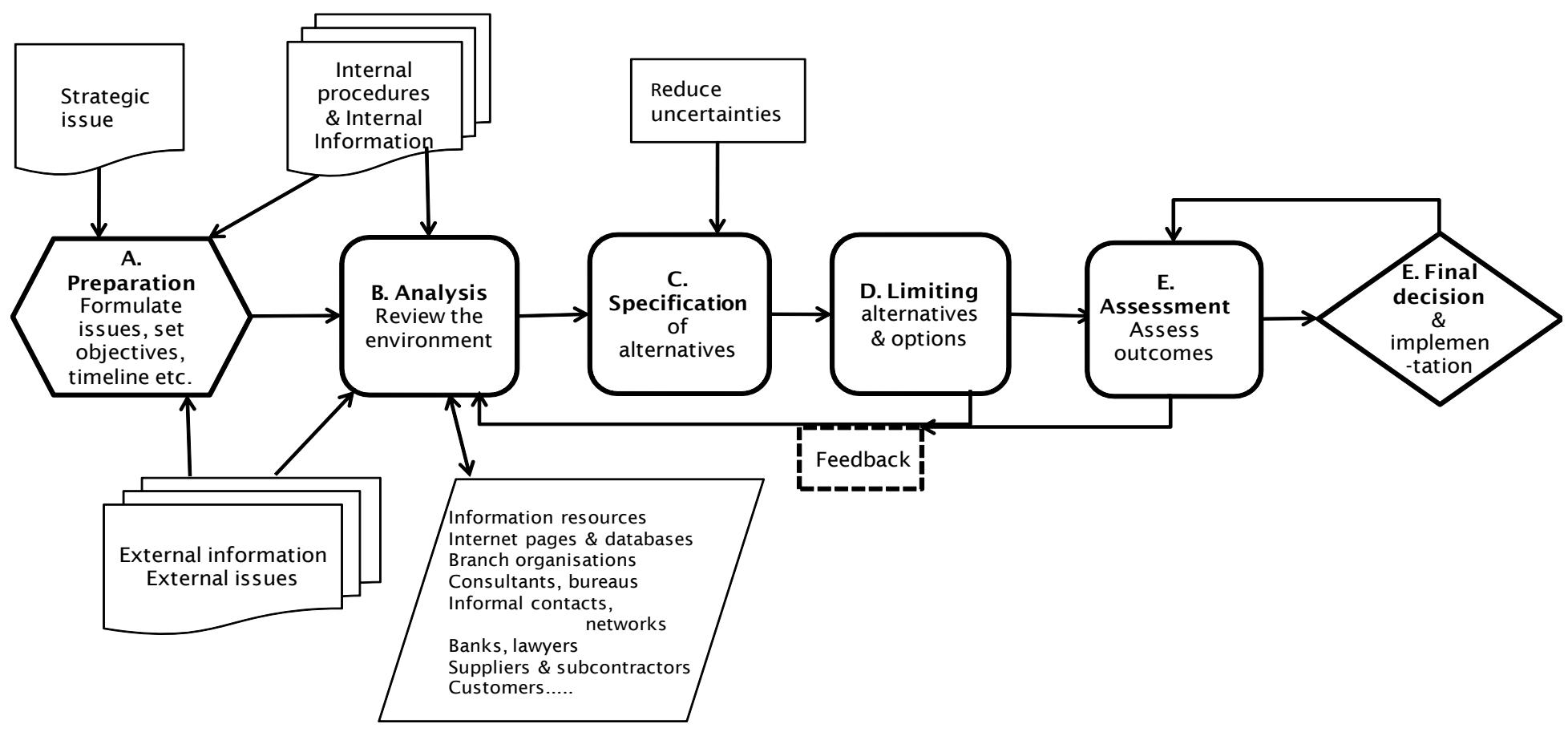

Figure 13: More complete model including 'Assessment' phase.

Bold boxes indicate the six phases in the decision process. Single line boxes contain parameters that provide input for the indicated actions.

Arrows indicate the main direction of interactions. 


\begin{tabular}{|l|l|l|l|l|l|}
\hline & $\begin{array}{l}\text { Mergers \& } \\
\text { Acquisitions }\end{array}$ & Investments & Divestures & Reorganisations & $\begin{array}{l}\text { Average \% of phases } \\
\text { passed in total }\end{array}$ \\
\hline $\begin{array}{l}\text { Total issues per type of } \\
\text { decision }\end{array}$ & 5 & 12 & 5 & 10 & $\mathrm{~N}=32$ \\
\hline & & & & & \\
\hline A-Preparation & $5(100 \%)$ & $11(92 \%)$ & $5(100 \%)$ & $10(100 \%)$ & $97 \%$ \\
\hline $\begin{array}{l}\text { B.1-Analysis Internal } \\
\text { B.2-Analysis External }\end{array}$ & $2(40 \%)$ & $4(33 \%)$ & $3(60 \%)$ & $6(60 \%)$ & \multirow{2}{*}{$100 \%$} \\
\cline { 1 - 5 } C-Alternatives & $4(80 \%)$ & $8(67 \%)$ & $3(60 \%)$ & $5(50 \%)$ & $88 \%$ \\
\hline D-Limiting options & $2(40 \%)$ & $9(75 \%)$ & $3(60 \%)$ & $8(80 \%)$ & $69 \%$ \\
\hline F-FinalDecision & $4(80 \%)$ & $12(100 \%)$ & $5(100 \%)$ & $10(100 \%)$ & $97 \%$ \\
\hline
\end{tabular}

\begin{tabular}{|c|c|c|c|c|c|}
\hline $\begin{array}{l}\text { Number of phases passed } \\
\text { per type of decision. } \\
\text { Number of phases, } \\
\text { corrected for conditions }\end{array}$ & $\begin{array}{l}4 \\
----- \\
5\end{array}$ & $\begin{array}{l}4.2 \\
----- \\
4.9\end{array}$ & $\begin{array}{l}4.0 \\
-1 \\
5\end{array}$ & $\begin{array}{l}4.4 \\
------ \\
5\end{array}$ & $\begin{array}{l}\text { Total: } \\
4.2 \\
----- \\
5\end{array}$ \\
\hline
\end{tabular}

Phases added later as occurring in a small number of decision processes as analysed from the interviews:

\begin{tabular}{|l|l|l|l|l|l|}
\hline E-Assessment & 0 & $5(42 \%)$ & $1(20 \%)$ & $2(20 \%)$ & $25 \%$ \\
\hline G-FeedBack & $4(80 \%)$ & $4(33 \%)$ & 0 & $3(30 \%)$ & $36 \%$ \\
\hline
\end{tabular}

Table showing number of phases passed in each decision process per type of strategic issue. 
The fact that it in a few cases not all phases seem to be passed can well be explained by the fact that in those cases the third step, 'alternatives', resulted in identification of only one option. No alternatives were present and therefore no choice needed to be made. The 'corrected conditions' take this effect into account and result in the conclusion that in all decisions, all phases that needed to be followed were indeed all followed.

\section{Analysis of the phases in the strategic decision-making process}

The comments made by the executives during the interviews are listed in detail in Annex 1, where a listing of the descriptions of the 102 decision process items as given by the executives is specified. The phases that are followed are itemised there one by one with duplicates between companies omitted, leaving 84 unique comments. In the next few paragraphs, an analysis of the observations made during the interviews and the comments made are given for each of the phases in the decision-making process.

\section{A. Preparation for the decision process}

In the preparation for the process, the issue is defined and formulated in such a way that relevant factors in the case at hand are identified and a first analysis of the objectives of the decision and the outcome of the process is made. An ultimate decision option, is finding out what would happen if no decision is taken at all e.g. the non-acquisition of a company $(21 \mathrm{~F})$, with the consequence that another company will buy.

During the preparation phase, internal procedures and strategic issues as well as relevant developments in the outside world are taken into account. Preparation by defining the issue and stating the objectives only in a few cases resulted in a formal initiating report.

Not always is it possible to pin down a starting point for an issue. Some issues are the result of a development over a longer time and some jumped into existence without warning. Some could be analysed in a reasonable time span and others needed immediate reaction under time pressure. Quite a few issues originated from not being satisfied with present performance of the company.

A distinction is noticeable between matters that originated internally in the company e.g. the investments $(6 \mathrm{~F}, 10 \mathrm{~B})$ and the divestment $(18 \mathrm{~F})$ and those had an external origin e.g. the acquisition and investment (1F, 7F) and the evaluation (26R). The internal issues are the ones originating mostly from poor performance of the organisation or technological ageing of facilities that is solved by reorganisations or concentrations on core businesses (9B, 19F, 28S). Computer software problems are another category (15S, 17S).

The external issues result mostly from interesting acquisition candidates coming into view $(1 \mathrm{~F}, 2 \mathrm{~S}, 4 \mathrm{~S})$ or changes in the political environmental such as legal or ecological developments $(7 \mathrm{~F}, 11 \mathrm{~F}, 29 \mathrm{~B})$. In both cases, often a preparatory document, also 
sometimes called a flagging paper was drawn up by either someone from a lower echelon or a member of the Board itself.

In the Annex, internal and external sources are indicated separately.

\section{B. Collecting and analysing of data on internal and external environments}

Input of information is the first step in this phase of the proposed model. If we look at the number of comments by executives on the different phases in the process it is clear that information plays such a major role, that executives have to acknowledge the facts in order to be able to consider an issue. Of the circa 90 different comments, 28 referred to this information collection and analysis phase; in some cases only of internal data, in most cases of both internal and external data.

As mentioned, decision support systems (DSS) were only brought up once as a direct source of information in a decision sequence.

In most cases initial preparation does not yet contain sufficient information to judge alternatives and make justified rational decisions. Further analysis is needed and information on internal and external parameters has to be identified, selected and studied. Sources of this information are internal staff, stakeholders such as customers or suppliers, open documents such as on the Internet, external consultants and in a few cases bidders for parts of companies to be sold, examples are the divestments $(18 \mathrm{~F}, 19 \mathrm{~F}, 20 \mathrm{~S})$.

Executives indicated that in almost all instances sufficient relevant and timely information is gathered from diverse sources. If information becomes available from uncertain sources and is not reliable at first sight, it is thoroughly reviewed for its credibility before being accepted as quality demands have become more stringent because of corporate governance requirements and because budgetary amounts involved become higher.

As a rule, firms now monitor continuously markets, competitors and sometimes suppliers by competitive intelligence methods involving screening of publications, news items, patents, consultant reports, web sites, advertisements etc. for items that indicate new developments and moves of companies in the same or related fields of activity. In one case, an ERP system is mentioned as a source and a store of information. Sometimes the data collected are kept in a knowledge management system.

Sufficient time seems to be available in most cases even though decision processes often are lengthy, especially where several parties are involved. In the case of acquisitions, due diligence, collecting data followed by a thorough examination of the books and records of the target company is performed. In a few cases, comparable alternatives in other organisations were analysed in order to better judge the implications of a specific solution.

In several cases, the Board was prepared for a particular issue to materialise and had previously taken precautionary measures such as continuous monitoring of 
developments to be able to act fast when an issue had 'ripened'. Examples are the acquisitions $(2 \mathrm{~S}, 3 \mathrm{~S}, 4 \mathrm{~S})$ and the case of the non-acquisition on second thoughts $(21 \mathrm{~F})$.

A distinction is made between the activities of collecting additional data and studying and analysing these additional data. First hand data comes from consultations with internal staff from the departments involved. Lacking this expertise or in cases where an external opinion is indicated, studies are also often commissioned to external bureaus. The resulting reports always have to be reviewed against internal expertise before they can be accepted. A comment was made that consultants generally are more positive/optimistic about peaks in the cycles and more negative/pessimistic on the slumps. Another comment was that 'old-fashioned' consultants do not use ICT a lot, but rely on their knowledge of the industry and their networks, resulting in analytically sharp reporting. The more 'modern' consultants supply loads of computer output with less analysis.

\section{Specifying alternatives and design of options by considering possible outcomes}

Based on the information gathered in the analysis phase, a preliminary planning can now be developed, either for the immediate future or for a longer period, in one case even for 10 years (29B). Depending on the situation, this can be a global overview of alternatives and options, more like a set of scenario's, or a detailed planning document, giving indications of procedures and timings of things to come. Several times the progress of planning depended on responses to requests for tenders or bids (18F, 20S).

Planning and design often necessitate making a selection and a simulation of parameters that have an influence on the feasibility and affordability of a desired outcome.

\section{Limiting potential alternatives}

After analysis and specification of alternatives, adequate information seemed to be present on consequences of a decision one way or another and on potential alternative courses of action to make a rational and objective choice. This choice is motivated by stating the facts that have been accumulated and the implementations of the alternatives. However, in the cases in this study the comparison of real substantial alternatives was only discussed in four of the processes (3S, 6F, 7F, 11F). A valid alternative of course that was discussed was the choice to perform an acquisition or build a new facility or decide not to do so (10B). In the end, cost and efficiency calculations always play a decisive role.

\section{E. Assessment of outcomes}

The model we propose for the decision-making process, needs to be adapted for $20 \%$ of the decisions processes discussed. Analysis of the actual phases followed in these decision-making processes showed that an additional phase was mentioned as a necessary phase in the process before a decision could be taken. In those cases, a definite choice between alternatives could not yet be made because conditions were 
not absolutely clear or two alternatives were not sufficiently different at this moment. Examples are e.g.in the construction project $(6 \mathrm{~F})$, in which several recalculations were necessary and in a complicated project (12B) where intermediate steps necessitated new reflections on the course to take. In another case the need to decide at this moment became less urgent and time was available for a further analysis.

\section{F. Final decision and implementation}

After appropriate preparations, analysis of the internal and external environment, collecting of data from relevant sources, planning the way to go ahead and designing alternatives, the Board has to come to a final decision which action to take and how to implement the decision. Sometimes this stage still needs a painstaking discussion, in most cases open ends have been treated before and the final decision follows naturally.

In a third of the cases, feedback was needed as part of the decision-making process, e.g. with the building of a new facility (7F), and a software issue (15S). Before alternatives could be properly limited or assessed, additional information had to be collected. This was also the case in an investment, where tenders by suppliers deviated from previously collected data (B9).

We did not observe that any of the executives presented an opinion in retrospect on the quality and outcome of the decisions taken, either spontaneously or as a result of some probing. In one of the cases, a now ex-executive in hindsight mentioned that errors had been made in collecting data by due diligence, but he commented that this had not significantly affected the outcome of the action. In another case, it was later announced in the press that a recent acquisition had to be 'restructured' within two years of the takeover. And in a third case, the executive that was interviewed for this study had to resign shortly after because of lack of agreement, probably over one of the projects discussed. We are not certain whether these few misjudgements are due to missing relevant information or information that does not contain up-to-date and trustworthy facts. But as already noted from Popper's reference to 'infinite regress' (1935 s.4, 1963, p.21), information unavoidably can never be complete; moreover the benefits of additional information have to be set off against the cost of obtaining it under the law of diminishing returns.

\section{Conclusion on the approaches of strategic decision-making}

The test of our first hypothesis is fourfold: firstly, to test if the issues brought up for decision are indeed of a strategic nature, secondly, whether there are clearly distinguishable phases followed in the process, thirdly, if the process can be characterised as a rational process rather than a satisficing or intuitive process and lastly if all relevant information is used in the decision-making process.

In all identified 32 cases, we have clear evidence of the strategic and purposeful nature of the decisions. Furthermore, we have seen that in all cases the process follows a structure as given in the model used and that in all cases all relevant phases 
have been observed. In addition, executives freely commented on considerations and limitations that existed during the process.

The similarity of the description of the phases encountered in the decision processes that were discussed with the executives and the fit with the model provide support for hypothesis 1. In order to arrive at conclusions on the rationality, more detailed analysis of the use of information is required. This analysis will follow the analysis of hypothesis 2 in the next section.

\section{V.2. The role of information in the decision process}

"The Board does not ask 'can you find this information' but instead says 'just get this information for us' with no concern about actual availability".

(Comment from an interview with a staff director).

In rational decision-making, information relevant to the issues that have to be decided plays a crucial role in each phase of these processes, executives have to acknowledge the facts in order to be able to consider an issue. The main reason for the use of information is a reduction of uncertainty needed to obtain the answer to an issue at hand. This is confirmed in several of our interviews when the interviewees mention that the decision-making process often starts off under uncertain conditions that evolve into more certainty when sufficient relevant and reliable information is gathered. But if an executive wishes to get the right answers to reduce this uncertainty, he is aware that he has to ask the right questions and has to appreciate himself what crucial information is still missing.

The value of information for strategic decision-making is supported by the results of our research: from the number of comments by executives on the different phases in the processes of actual decisions taken, (see Annex 1); an indication that information does play an important role, is that of the 90 unique comments made regarding the phases of the process, over 30\% referred to collecting and analysis of information used in the decision-making process. One executive remarks that "the uncertainty about decision quality has decreased as sufficient information is rapidly available to all persons concerned", demonstrating that information helps reduce uncertainty and offers better conditions for rationality than in earlier days.

The information used in the decision-making process can be distinguished in internal information based on data such as that pertaining to technical processes, financial parameters, and the customer base on the one hand and external information on developments in the technical, commercial and social/legal environment of the company on the other hand. The comments from executives relate in most cases to both internal and external information. Decisions based on internal information only were not mentioned often, probably because internal information systems nowadays have become so common that they are taken for granted. The processes to obtain these two types of information are quite different and are discussed separately in a later paragraph. 
Examples of why information is so important are comments such as:

- European operations have to cope with high costs, small margins and fixed markets, so management has to be very alert and perform proper analyses on e.g. market developments before decisions can be taken

- $\quad$ the company as a whole is more opportunity driven now and can react faster .... with sufficient information

- $\quad$ "for each strategic issue decision the required decision structure can only be obtained when it is clear that all information is available in the proper format and is reliable and can be understood by all parties concerned".

\section{Information management}

The flow of information within companies is regulated by procedures for information management. Examples of internal services are shared workspaces for project collaboration and all companies now have an Intranet for internal communication with the employees. In some cases, this also implies a system for knowledge management. The procedure for serving the company Board with information is part of these procedures. During the decision-making process, there are two phases in which information is mostly collected and analysed by the Board, the preparation phase and the analysis and review phase. The titles of staff departments that supply this information to the Board are e.g. Corporate Development, Strategy Development, Business Development \& Innovation or the Market Intelligence Group.

Some companies outsource the searching for information to specialised information services companies, but a comment was that "this is sometimes not effective when the questions and issues cannot be made explicit and unequivocal. This would result in an overload of irrelevant information".

In one case, a staff director mentioned that on an acquisition plan of the company the Board had to maintain more than the usual confidentiality and the CEO did not consult staff departments but collected information to prepare for this decision-making process himself.

Most companies have a department responsible for documentary information such as an 'information services department', often connected to the library. These departments manage the research books and journal collection and abstract services such as the Chemical Abstracts but they are often also responsible for contracts with commercial business information suppliers such as LexisNexis or Dow Jones Factiva. This information department is usually concentrated in the research location of the company. But several executives do not see the need for such departments nowadays because they interpret the new access methods to information supported by software as facilitating disintermediation: employees can nowadays easily search for and find their own information. An example is that an executive stated that his organisation had no central information service anymore: "this involves using all the sources of knowledge that one can reach by connecting oneself internally and externally and let everyone involved be connected with the relevant parts of his own environment." 
Another comment was that the technical possibilities to define queries have become much easier now, so that no information specialists are needed anymore to formulate data base searches and fewer external experts are needed. "the interpretation of data and ensuring the relevancy of information for the executives is now the bottleneck, not the process of searching."

In addition to the interviews held with company executives, we used two other methods to collect information for our study. A questionnaire that we sent out to correspondent chemical information professionals, mostly in the USA, showed that of the 14 companies that answered, the company information department in only one third of the companies- and mostly the smaller ones - provides information directly to the Board of the company, either as a news bulletin or in answer to ad hoc questions. They indicate that input to the Board level in large companies is usually organised through the marketing department, another staff department or the R\&D department. Information that is supplied through internal news bulletins also is generally screened by intermediate levels in the company before these items are presented to the Board. The other input was generated when we asked managers of internal information departments - in some cases called 'the library'- of large companies in The Netherlands whether they provided information directly to the Board. Of the 13 companies that we asked, only one could affirm that they do react to direct questions from the Board. The others all know that their information does often reach the Board, but always through intermediary staff departments. Only news bulletins, summarising external developments, are sent directly from the information department to the Board in several instances.

\section{Aspects of the use of external information}

Discussions on the use of information for strategic decision-making in the analysis phase mostly centred on that of external information. The types of external information mentioned give an insight in the types of decisions taken and in the approaches in the decision-making process.

External information types that we identified from the interviews with executives are:

- Information about economic matters in general. This includes generic items such as economic and political developments, environmental issues, legal issues

- Market information. This concerns specific trade statistics, trends in relevant generic markets, forecasts, consumers' trends and trade names

- Generic technology information. Technology related R\&D issues and trends, patents, technical market issues

- $\quad$ Specific customer information. Mostly internally collected data such as trends in consumption patterns but also customer contact persons, financial matters

- Competitor and supplier information and intelligence

- Information from governments, the European Union and Non-Governmental Organisations. 
Sources of external information identified are

- $\quad$ The public Internet and the so called 'deep internet' of hidden databases and data banks only available for subscribers or members, often at high prices.

- $\quad$ Various types of consultants and specialised research bureaus

- Research organisations such as EIRMA, the European Industrial Research Management Association.

- Branch organisations, both national and international

- $\quad$ Trade organisations, both national and international

- $\quad$ Banks and other financial experts, legal experts such as tax law specialists

- $\quad$ Customers, from customer satisfaction surveys to reports of salespeople

- $\quad$ Head Offices for subsidiary companies

- Suppliers and subcontractors

- Discussions with colleagues in networks and at conferences, e.g. in the group of IT managers in the chemical industry.

Comments that were made on sources of external information during the interviews are:

- Reports can be bought e.g. from research companies specialised in these markets. Some executives state that these are quite reliable; others comment that this information is often far from correct. A good way to check for credibility is to see how accurate the data on the own company are analysed.

- $\quad$ Before the times of ICT information resources, management was more reliant on external reports that were bought. With present expertise it is easier and faster to find information for oneself.

- Branch organisations offer an open atmosphere where experiences are exchanged and key figures are collected and published. Data such as total investments per unit product are available. Examples are the European Brewery Convention (www.ebc-nl.com) and the Brewers of Europe (ww.brewersofeurope.org) and the Association of Plastic Manufacturers (www.plasticseurope.org).

- For one branch an interviewee mentioned that there is a formal market information network maintained by a specialised trade organisation. Parties in this information network however have a tendency to play down the market size and enhance their market share. Official sources are too much dependent on such voluntary supplied data; these only give an indication of trends, not of the true state of affairs.

In most companies developments in the environment of the company are monitored so that the Board is at every moment prepared for an issue to arise. Regular detailed internally generated reports on trends in production, supply and demand, market shares and financial matters are now common practice. Similarly, in most companies data on competitors' behaviour are collected by 'competitive intelligence' and from 
specialised consultants and these are analysed regularly by departments for relevant issues for the Board and stored in an internal database. Often selected information from this data base is available on the company Intranet. From such a database ad hoc questions from within the company, sometimes from the Board, are answered. In one case an excerpt from this database is presented company-wide on a weekly basis as a current awareness service and important new matters are sent out immediately as a news flash. In another company, a group of 5-6 gatekeepers comes together bimonthly to analyse and compare the stored data and correct them where needed and to reach consensus on updates for this internal database.

One company specifically stated that strategic planning and decision process are supported by an up-to-date database that continuously follows developments in the international markets, international supply and demand developments and investment plans of competitors all over the world. It predicts longer term profitability and it assists in keeping up to date the strategic plan of the company continuously so that decisions need not wait when a sudden development occurs. Sources for this database are many, newspapers, internal reports, consultant reports, information from colleagues in conferences and other discussions, internet items, etc. and also the internal SAP system.

One company systematically develops "a strategic plan as the result of considerations within a team of managers and project managers with local sub-teams, using standardised lists of questions". Another company stressed the importance of public affairs information, new government policies, EU developments and the interaction between market and government, which is collected systematically and analysed continuously for effects on this company. The results are communicated to involved staff in the primary process and to staff units. One company reported that every year 5 internal processes are scrutinised for changes in markets, prizes, competition and integration and thus a permanent strategy review and information gathering is under way.

In several cases supporting information for Board decisions on new developments and acquisitions comes in the first place from the business units/divisions involved. However, another executive stated that "information on all kinds of global parameters are monitored centrally and communicated to the operational companies." Staying within one's own market relying on one's own expertise is an advantage and strength in obtaining reliable information. On the other hand, a comment was that the division that was going to benefit from an acquisition may not always be absolutely objective and realistic in its arguments and be too optimistic and eager.

A special case are those companies in our population that operate in the Business-tobusiness (B2B) market. It is hard to obtain sound information about this market because of the complicated logistics; statistics on imports and exports e.g. those supplied by trade organisations can provide some clues. In those cases the companies had to collect the information themselves. 


\section{Aspects of the use of internal information}

As mentioned before, reports of monitoring of internal processes and parameters is common now in all companies. An executive remarked that "the most important aspect of modern computerisation is the increased speed with which weekly and sometimes daily information becomes available on all processes and results within the company and so facilitates our decisions." But for internal information to be effective, another mentioned, the flow of information has to be open; "information that is kept in a closet is worthless; lack of open information creates rumours and reduces motivation and trust", a way out is a knowledge management programme because this helps to generate a more open atmosphere. Another positive aspect of the facilitation of communication within the company is that this leads to more multidisciplinary projects and less duplication.

The Intranet is used in several companies to share successes of the company, that appear in the news: "it makes people more engaged, aligned. Starting the computer in the morning brings up first the Intranet" was a comment.

In one case, a reorganisation was completed reducing the number of levels in the organisation with the aim to improve the flow of information.

\section{Conclusion on the role of information}

The results of our research as discussed here provide an answer to our second question and a test for hypothesis 2 , that states that in answering a specific strategic issue, executives that follow a structured process, will collect all information considered to be supportive for this process. Moreover, we have observed that this information is used to provide a rational underpinning of the decisions made in each phase. This constitutes a first test to the rational aspect of hypothesis 1 .

The second scrutiny method that we use to test rationality consists of observing whether there are arguments that point to other than a rational approach to strategic decision-making such as those mentioned in part of the literature on strategic management. The result is that we did not observe during our interviews any indication of these arguments, such as unduly great time pressure, 'satisficing' solutions or 'bounded rational' decisions due to limited cognitive capabilities of executives or of lack of information that might have resulted in intuitive approaches, nor did we find any signs of internal conflicts or political manoeuvring about which way to proceed or undue avoidance of uncertainty.

Only in 3 out of 32 cases was there an indication later that the resulting decision has not been optimal that could be perceived as an indication for non-rational behaviour. However, in two cases this can be ascribed to known reasons: in one case this was owing to insufficient due diligence, in the other case it was probably a misjudgement of market developments. These are errors in the process, rather than non rational behaviour. 


\section{V.3. Quality of information for strategic decision-making}

In this paragraph we will now test hypothesis 3 that considers the fact that before it is accepted, information is judged for its quality, i.e. its robustness and reliability.

Earlier we stated that quality in the decision-making process can be appreciated by objective measures even if quality is seemingly a subjective parameter with no generally acknowledged definition. We identified as an objective measure of management performance a standard called 'the ISO Quality Management System', issued by the International Organisation for Standardization (ISO). We did not encounter any mention of this quality system for executive decision-making in our study. We also asked a number of international producers of information services whether they adhered to an ISO standard for their processes. None of these companies apparently used such a standard and only two answered that they have a formal quality control system in place. But by applying their own quality methods, they consider their quality system to be sufficiently effective.

We paid particular attention to the way sources of information are selected, consulted and verified by executives and staff departments. These sources are multiple and depending on their origin and credibility are taken at face value or put up for scrutiny by experts, be it internal or external. Staff departments responsible for supplying information to the Board check external information for robustness before it is delivered to the Board. If the quality of the information is not up to standard or cannot be verified, it is put aside. But even so, executives do often check information themselves, one reason being that staff departments are not always aware of the strategic plans of the Board.

In all discussions held, the aspect of the quality of information used by the Board was stressed. Generally, information that arrives 'bottom up' is trusted more than information provided by external sources. Correct strategic decisions can only be taken on correct and full information. As one executive phrased it: "quality of information means integrity, robustness, able to stand up for scrutiny, but very important is also a guarantee of completeness, wholeness". Or as another CEO phrases it: "we rely on well checked, reliable, robust and relevance rated information"

Some more cautionary comments that were made: regarding the quality of information were that "the value of these open data is notoriously only moderately reliable." And "information can be 'manipulated' as is seen by the example of client satisfaction reports". Another comment was that "consultant reports always have to be verified internally, they are in general not more accurate than one's own predictions and often have a different content if asked again after 3 months". These comments show that executives are well aware of the prudence with which external information has to be treated.

For benchmarking of company performance, information is considered to be one of the key performance indicators, an example is the opportunity for benchmarking 
firms on publicly available performance measures. In order to measure the quality of the internal information service, a benchmark is mentioned as a useful tool. In one specific case of a takeover, the result of the benchmark showed that the acquiring company was in fact better informed than its former competitor.

There were also comments on the manner in which companies ascertain that the information they receive is reliable:

- Information integrity is certified by a small information technology committee as watchdogs, on quality, timeliness and proper analyses of data

- $\quad$ Deviations from earlier trends have to be signalled to the management

- $\quad$ Each information item that is to be communicated to others has to be confirmed by management to be accurate. This is adhered to strictly because of the 'Right to Know' laws in the USA

- $\quad$ Reports of analysts are cross checked for accuracy, often at the request of the Board, either by one's own experts or other external bureaus, to give more security and 'objectivate' the information

The considerations discussed in this paragraph confirm that hypothesis 3: 'Before it is accepted as relevant, executives thoroughly check (or have checked) all information that is believed to be suitable as a supportive resource for the decision-making process for its reliability and other quality parameters' can be accepted as a true representation of practise by executives in industry.

\section{V.4. Changes in decision-making processes due to increased availability of information}

The last hypothesis to be tested is hypothesis 4 , which pertains to a central item in our study, namely to find out whether there is a marked difference in the way the strategic decision-making process proceeds now that information has become available so much easier and faster in the last few years. This is hard to establish in a validly measurable manner. Most executives commented that indeed information has become much easier to obtain. As an example a comment was that "marketing information is hardly searched for actively, it is continuously available" offering the facility to follow closely and continuously the behaviour of new products in the market. A factor mentioned is that globalisation, since about 1995, makes a difference because the pace of decision-making in this branch is very important. A significant answer was given by a staff director: "all information that is needed by the Board seems to be available nowadays, though one never can be sure. The improvement over the last years from Internet is tremendous: Finding information before the Internet must have been horrible". But this executive also said that not all problems are solved yet, information on Asian developments is still hard to obtain as language is a major obstacle when viewing Chinese or Japanese web pages.

Another comment was that: "now that information has become a 'super-commodity', searches that used to take 10 days can now be done in 10 minutes. In earlier days market 
information could only be obtained from paid marketing consultants, now three quarters of this information is available on the Internet. But at the same time this reduces the value of information, everybody can access the same facts and thus creative analysis is needed to maintain ones' competitive advantage".

Changes in availability of information have brought changes in the way information is used in companies. But information overload because of too many sources or too many documents is not an issue that was mentioned. Apparently, these executives and their staff departments apply effective coping mechanisms to deal with the stream of information reaching them.

The facilitation of global knowledge exchange brings with it the fact that competition becomes fiercer as any innovation becomes public earlier than before and time to react is correspondingly shorter. Some companies are able nowadays to perform research on a worldwide 24-hour schedule, they "forward results as a baton in a relay race" to their affiliates anywhere in the world. As a consequence of these developments a staff director remarked that the question from the Board no longer is whether some required item of information is available, but "get this information for us, no matter where this item can be found as long as it is reliable and complete and timely".

These developments show that external information sources thus play a more important and valuable role in decision-making by industry management than was possible before.

Although we agree that much more information is now available, several executives remarked that "this does not necessarily mean that decisions can be made faster: evaluation of this greater mass of information takes more time and not everything is yet available electronically." And a comment also made is "that easier information access is not always cheaper, costs have to be made to acquire the information and each time the cost/benefit ratio has to be kept in mind".

We conclude that even if there can be no proof, the indications for an increased influence of ICT achievements over the last few years on many, but not all, cases of the process of strategic decision-making sound convincing.

Our hypothesis 4 asserts that 'enhanced availability of multiple information resources, predominantly through specialised digital information acquisition and analysis methods such as facilitated by the Internet, has a positive effect on the efficiency of the strategic decision-making process'. Although this positive effect is hard to substantiate conclusively, we have shown several indications to this effect. We have shown that such an improvement can be characterised as a change in the decision-making model with more sources being consulted. With more relevant information available, discussions on issues affecting the choices and alternatives can now be better controlled which confirms this hypothesis which can be accepted as a valid statement. 


\section{V.5. Developments of ICT services in industry}

Results as presented here are obtained partly from the interviews with executives, but also from annual reports and web sites of the companies where the interviews were held. They are relevant for the study of the decision-making process in that they convey how much executives nowadays are dependent on well functioning ICT services when taking a rational decision approach.

ICT developments are discussed in chapter III of this dissertation. The comments of the interviewees recorded here represent current practise in the selected sample of companies, not an overview of ICT developments in general.

- $\quad$ computerised models such as for purchasing of base materials have completely taken over manual control and are based on worldwide developments in market trends; output of a facility is now fully directed by demand variations

- $\quad$ ICT makes it possible for us to compare cost prices easily; this competition drives suppliers to do everything to lower their prices; a disadvantage is that suppliers in this way are less concerned with maintaining quality; another disadvantage is that there are no personal relations anymore between the purchase department and the suppliers thus there is no possibility anymore to discuss specific requirements

- $\quad$ design of new facilities and other large investments have benefited from ICT advances. A relevant example is the use of modelling software that improves significantly control of production processes through simulations. This software 'looks ahead to capitalise on opportunities and identify problems before they occur'

- communication with parent companies in other countries has improved tremendously over the last few years; with Netmeeting and video conferencing facilities, international meetings can be reduced.

Not all comments were exclusively positive on the applications of ICT. One executive maintained that acquisition processes are not much influenced or improved by new ICT developments. Another mentioned that for the strategic processes that concern mainly internal readjustments, ICT systems do not play a large role, the Board's attention is focussed on the content.

We investigated to which extent the decision-making process is supported by information from management information systems (MIS), decision support systems (DSS) or enterprise resource planning (ERP) software. But in none of the interviews the use of such a decision support system was mentioned and only in one case did an executive refer to an enterprise resource planning (ERP) system as a direct source of information in a decision sequence. A statement was made that although ICT plays an important role in evaluating processes and models, an ERP system that is used for financial analysis is of little use for strategic planning. This is confirmed by another interviewee, who stated that ICT is used predominantly for optimising operations, 
planning, exchange of capacity data and minimising transportation costs; it is used far less for strategy or Board issues.

Strategic decisions on the purchase or development of ICT systems can be a complicated matter. In one documented case, the basis for the strategic decision to develop a new ERP system proved wrong, apparently because it did not perform as had been contracted and the Board had to decide later not to deploy this system despite the substantial investments made and the equally large damages on customer relations that might result from not deploying this software. The business unit concerned suffered in fact a significant reduction in sales caused by a loss of market share following customer service problems that resulted from the systems changes.

Overall these results show that ICT plays an important role and has an influence on the Boards' strategic decision-making process. ICT is applied either as an aid in collecting appropriate information or as a tool to monitor and adjust important internal processes that have a bearing on strategic matters.

\section{V.6. Strategic value of decisions}

How strategic are the issues that were decided by these executives? The decisions discussed in the interviews may be judged on the level of 'strategicness' using a number of parameters and the sources of the issues. Either the issues discussed resulted from internal matters necessitating a Board decision, several times an issue was raised by the Board members themselves, or it resulted from an external event or development that changed conditions and required action from the Board.

The strategic decisions that came to the surface in the interviews have a significant influence on the longer-term strategies and core activities of the companies. In this vein, internal reorganisations that were decided at Board level were mostly dictated by external factors and were aimed at improving the strategic fit of the organisation with its goals. Operational angles played only a minor role in these cases.

Another way for measuring the strategic value of decisions is the level of 'obligation' for a decision, e.g. if the law is changed, there is no alternative than to decide for a correction if some company sector does not comply, but the manner in which this is accomplished still needs a strategic choice. This is the case with the decisions to 'construct a new (main) production facility' and the 'choice of a new essential manufacturing utility.

Then there is the matter, discussed earlier, of autonomy. If the local Board of Directors is not free to make its own decisions, but has to follow head office orders or report back to head office before a decision can take effect, there is less 'strategic value' involved. In most cases however, head office directives leaves sufficient freedom to local executives so that a local decision with strategic significance is still needed. This was the case with the new production facility, the 'realisation of a 10 year project for improving safety and the environment and the 'upgrading of the SAP software'. 
The fact that some decisions seem to be less strategic than others can also be explained by looking at the differences in competitiveness and uncertainty these companies operate in. For food companies competition and pace of change is exceptionally high as public attention sets the innovative trend. For base chemicals, the main competitive factors are logistics and increases in productivity. For chemical specialties companies, product innovations are the prime drivers (VNCI, 2008). 


\section{Conclusions}

The objective of this research is to study the approach executives follow in making strategic decisions and to what extent they use information in this process, in particular whether the use of information has changed over recent years due to the increased availability of information through new information acquisition and analysis methods such as the Internet becoming common practice.

Previous research recognises three different approaches to strategic decision-making, in the first approach executives apply a structured and rational process following a number of distinct phases leading up to a final decision whereby they make use of all feasible and appropriate information available.

In the second approach, executives take such decisions in a 'satisficing' process, with less structure, in which the amount of information utilised is determined by bounded rationality and cognitive limitations of the decision-maker. Still other studies imply that intuition plays an important role, in such cases it is not possible to discern a structure in the decision-making process.

This leads to the following four hypotheses to be tested in our research. As we assume that the way that information is used in the strategic decision-making process is dependent on the approach taken in this process, we first have to clarify this process. The hypotheses follow the order in which we treat the subject of our study.

- $\quad$ Strategic decisions by executives are reached in a rational, well-structured process with the purpose to come to the best possible results under the conditions that apply in each specific case.

- In answering a specific strategic issue, executives that follow a rational process, will collect all feasible information considered to be supportive for this process.

- $\quad$ Before it is accepted as relevant, executives thoroughly check (or have checked) all information that is believed to be suitable as a supportive resource for the decision-making process for its quality parameters such as robustness and reliability.

- Enhanced availability of multiple information resources, predominantly through specialised digital information services such as the Internet, has a positive effect on the strategic decision-making process in industry.

In order that we could properly interpret the results of our research, we have studied in a theoretical framework the various approaches to strategic decision-making taken by executives as they are described in the literature as well as the utilisation of information and the value, the quality and the sources of management information as a factor in these different approaches.

From the various methods used previously to study strategic management practises, we analysed the decision-making process by making use of interviews of executives in a selected segment of the chemical and food industry, in The Netherlands. This 
method we contend, provides a first-hand insight in the processes these executives actually followed in some recently taken decisions.

\section{Approach to the strategic decision-making process}

Our first hypothesis implies that the actual approach executives nowadays take in strategic decision-making is a rational and structured approach characterised by a number of definable distinct phases in time. In order to test this hypothesis, we developed a model outlining the phases that are followed in a structured process and we use this model as an analysis instrument to study the approach taken by executives in this process. The phases in the proposed model showing the structure of the process are successively:

- $\quad$ preparation for the decision process to be initiated and setting the objectives,

- collecting and analysing of relevant information on internal and external environments,

- $\quad$ specification of alternatives and design of options,

- $\quad$ limiting the potential alternatives and options,

and

reaching an optimal final decision followed by implementation.

The test of our first hypothesis is fourfold: firstly, to test if the issues brought up for decision are indeed of a strategic nature, secondly, whether there are clearly distinguishable phases followed in the process, thirdly, if the process can be characterised as a rational process rather than a satisficing or intuitive process and lastly if all relevant information is used in the decision-making process.

The results show that in all identified 32 cases, we have clear evidence of the strategic and purposeful nature of the decisions. Furthermore, we have seen that in all cases the process consistently follows a structure as given in the model used and that in all cases all relevant phases have been observed.

In some processes we observe an additional phase, that of 'assessment of outcomes'; it is a final check on the potential alternatives that are chosen and it serves to judge whether these do not unnecessarily harm the company's interests e.g. by 'value dilution'; this phase follows the phase of 'limiting alternatives' but precedes the final decision.

The similarity of the description of the phases encountered in the decision processes that were discussed with the executives and the fit with the model provide support for hypothesis 1 . This does not yet give sufficient support for the aspect of rationality, but the results of the test of hypothesis 2 provide more support.

The third scrutiny method that we use to test rationality as assumed in hypothesis 1 consists of observing whether there are arguments that point to other than the rational approach to strategic decision-making such as those mentioned in part of the literature on strategic management. The result is that we did not during our interviews observe any indication of these arguments, such as unduly great time 
pressure, 'satisficing' solutions or 'bounded rational' decisions due to limited cognitive capabilities of executives or of lack of information that might have resulted in intuitive approaches, nor did we find any signs of internal conflicts or political manoeuvring about which way to proceed or undue avoidance of uncertainty.

From the results of the research, we consistently observe indications that executives that are responsible for strategic management of industrial organisations follow a structure as given in our model of the decision-making process even though a broad spectrum of issues has to be resolved.

We therefore can conclude that these executives follow a structured and phased course that is rationally valid and reflected on, that they have operated judiciously when taking important strategic decisions for their organisation and that they display no sign of hasty or irrational behaviour leading to bounded rational or satisficing decisions.

\section{Information as a factor in decision-making processes}

All executives that were interviewed confirm that appropriate information indeed is used intensively in the decision-making process and that there is an awareness of the type of information that is needed, either as a continuous preparation on events that can be anticipated, or at the spur of the moment when a new opportunity or a new issue to be decided arises.

More specifically, internal and external information relevant to the issues to be decided both play a role in each phase of the decision process. In the preparation phase and in the analysis phase, information is collected from as many sources as possible; often developments are monitored so that the Board is at every moment prepared to take a timely action.

We note that regular detailed internal reports on developments of production, market shares and financial matters are now common practice. Similarly, in most companies data on competitors' behaviour are collected by 'competitive intelligence' or from specialised consultants and these data are analysed regularly. Staff departments responsible for strategy and business development and market intelligence are the departments that executives consult for information needed in decision-making processes. Furthermore, most business units collect information on their own branches and send summaries of analysed information up to the executive management.

The process of disintermediation, whereby information users search for the information without an intermediary, is not clear yet, but the effect of the trend is noticeable. One executive formulates this by stating that the technical possibilities to define queries have become much easier so that no information specialists are needed anymore to formulate data base searches and fewer external experts are needed. But several other companies still have an information management department employing information specialists. We note that in all companies externally obtained information is controlled by experienced staff e.g. technical information specialists, 
market and business intelligence searchers, strategy developers and legal people, either within the company or by outside agents such as banks, branch organisations or consultants.

In one case, an important source of information mentioned was the peer network of the CEO himself.

The facilitation of global information exchange brings with it that competition becomes fiercer as any innovation becomes public earlier than before and time to react is correspondingly shorter. Some companies even perform research now on a worldwide 24-hour schedule, continuing the activity where colleagues in another time zone halt.

The kind of external information that we have observed as obligatory for strategic decision-making is information about market developments such as trade statistics and trends and forecasts, consumers' and customer information, information on competitors and suppliers, but also technology information and related R\&D issues, patents and technical market issues; in most cases there is also a need for information on economic and political developments, environmental issues and legal issues from governments, the European Union and Non-governmental organisations. Information on competitors and markets and above all trends in their behaviour is collected by business intelligence. For all these categories we know that the availability and accessibility has increased with the developments of new ICT technologies.

From the attention that we note that is paid by executives to the use of information and the kind of sources that are consulted it follows that information plays a major role in all decision processes observed and we see that executives recognise the abundance of relevant information available and that they use this information to provide a rational underpinning of the decisions made in each phase. Accordingly, our second hypothesis, on the use of information in a rational decision-making process is supported by these findings.

\section{Quality of information}

In all discussions held we note that the aspect of the quality of information used by the Board is stressed as an important condition for any type of information to be trusted as a supportive base for strategic decision-making. Correct strategic decisions can only be taken on correct and full information. Quality of information means integrity, clarity, robustness, stand up for scrutiny, timeliness but very important is also a guarantee or acknowledged limitation of completeness. Generally, information that arrives internally 'bottom up' is trusted more than information provided by external sources. Information from open data sources and even from consultants is considered only moderately reliable and could even have been 'manipulated'.

As information is collected from multiple sources, such information varies much in quality as defined here and depending on the origin and credibility of the source, it is taken at face value or thoroughly cross checked for accuracy by either internal expertise in staff departments or by an external consultant before it is accepted. In 
some cases it is double checked by the executives themselves, one reason being that not always does the staff department know the strategic plans of the Board.

By these considerations our third hypothesis, pertaining to the efforts made for assurance of the quality of information received, is confirmed and can be accepted as a true representation of practise by executives in industry.

\section{Information overload}

We observe that executives agree that increases in availability of information unavoidably lead to an increased volume of information arriving on their desks. When in the literature 'information overload' is signalled, this implies that those executives would not be able to properly handle this increased flow. But information overload as a result of too many information sources or too many documents was not observed and thus did not appear to be an issue. Having more relevant information at hand, does add to the comfort factor and feeling that the ultimate decision has been supported by a more rational process than was possible before such information sources became available. The conclusion therefore is that information overload is not an issue for these well organised executives who are protected by staff departments from receiving unnecessary information and that they can well cope with the increased information flow that they experience.

\section{Information and communication technology}

Our research shows that ICT nowadays plays a major role in the process of information gathering. New resources of information such as facilitated by the Internet advance this process in unprecedented ways. We find that according to these executives, having all this information available makes preparation of a case for the colleagues in the Board and the process of analysis of alternatives easier and helps giving a feeling of confidence that all options have been properly considered. Especially reliable data on the performance of competitors and market conditions give executives assurance that they can judge more comfortably and rationally the consequences of their actions.

Most companies have constructed internal databases containing historic and current information on competitors, customers, suppliers etc. Such a database is consulted to answer ad hoc questions from the Board or can be used as an aid in strategic planning and preparation for decisions to be taken. In most companies relevant information for the employees is communicated through an Intranet leading to more multidisciplinary projects and less duplication of efforts.

Decision support systems were not mentioned in any of the interviews. Only in one case did we hear an executive refer to an enterprise resource planning (ERP) system as a direct source of information in a decision sequence. Data on internal processes and finance are nowadays available from advanced ICT systems in all those large organisations and are available as background support. However, the type of decisions that are considered to be strategic do not show direct dependence on such operational data. 


\section{Changes in decision-making due to new information developments}

We would like to ascertain whether the developments we observe in the use of information have a marked and measurable influence on the way the strategic decision-making process proceeds nowadays compared to pre-Internet days, until about 1997. In this year the first mention of the Internet appeared in Harvard Business Review, apart from earlier articles on e-commerce.

Regrettably, we find that not many of the interviewees have been in their present function for sufficiently long time to judge and moreover, the change has come so gradually that it would be hard to measure anyway.

From the developments in availability and accessibility of information we can conclude that external information sources play a more important and valuable role in decision-making by industry management than was possible before. We note that executives no longer ask the question whether some required bit of information is available, but rather where this item can be found reliably and completely within the time that is available. Better availability of information does not necessarily accelerate the decision-making process, as more information requires more time to analyse, judge for reliability, discuss and digest.

We can obtain circumstantial evidence of the changes caused by these new developments if we pay attention to the categories of information that executives consult nowadays. Knowing how the availability of the sources for this information has improved over recent years, facilitated by the Internet, we can draw some conclusions as to the changes that must have taken place in that period.

As we mentioned before, executives access and use information on topics such as markets, competitors, technology and environmental issues. For all these categories we know that the availability and accessibility has increased with the developments of new ICT technologies.

Hypothesis 4 covers our assumption about the positive effects of increased availability of information. Although this positive effect is hard to substantiate conclusively, we have shown several indications to this effect. We have shown that such an improvement can be characterised as a change in the decision-making model with more sources being consulted. With more relevant information available, discussions on issues affecting the choices and alternatives can now be better controlled which confirms this hypothesis which can be accepted as a valid statement.

\section{Further research}

Earlier we commented on the differences between the Anglo-Saxon and the Rhenish management styles. But as the large companies that we studied operate in a global market, we expect that there is little reason to believe that executives in other Western countries with similar responsibilities and under similar conditions would operate in a much different way. Further study in countries adhering to the AngloSaxon management style could show whether this assumption remains valid. 
Insight in the rationality or non-rationality of the process can be enhanced by further research studying the process in relation to its content. This is the realm of decision psychology and is well covered in the literature.

In this study we concentrated on the decision making process of executives and the utilisation of management information in this process. It is only by studying this combination of process and information that conclusions can be drawn on the rationality or non-rationality of the process.

With respect to the utilisation of information it is interesting to investigate how the used information is being certified, either by external or internal sources. For internal information these processes have been seen to be well organised. For external information the effect of the observed disintermediation requires stronger certification of the information and this calls for clear, transparent certification methods as e.g. are being used in scientific information. The natural, exponential growth of information of whatever kind and in particular information that can be all too easily retrieved from the internet requires all the more strict certification standards. 

VII.

\section{Reference List}

Agor, W. (1986). The logic of intuition: How top executives make important decisions. Organizational Dynamics, 14(3), 5-18.

Aguila-Obra del, A.R., Padilla-Melendez, A., \& Serarols-Tarres, C. (2007). Value creation and new intermediaries on Internet. An exploratory analysis of the online news industry and the web content aggregators. International Journal of Information Management, 27(3), 187-199.

Albert, M. (1991) Capitalisme contre capitalisme. Editions du Seuil., ISBN 2-02013207-9

Alberts, G. (2005). Reckoners, calculations and calculators (Rekenaarsters, rekenwerk en rekentuig). Euclides, 80(4).

Alberts, G. (2007). Computers in The Netherlands (Computers in Nederland). http://www.science.uva.nl/math/home.cfm. Last checked: 3-5-2007.

Allen, B. (1990). New developments in economic theory: Information as an Economic Commodity. American Economic Review, 80(2), 268-273.

Allison, G.T. (1971) Essence of a decision: Explaining the Cuban missile crisis. Boston: Little, Brown and Co., ISBN 0-673-39412-3

Allison, G.T. \& Zelikow, P. (1999) Essence of a decision: Explaining the Cuban missile crisis. New York: Longman., ISBN 0-321-01349-2

Andriessen, D. \& Stam, C.D. (2004). The intellectual capital of the European Union Diemen, The Netherlands: Centre for Research in Intellectual Capital.

Atherton, M. \& Vile, D. (2007). The business intelligence inflexion point: Information is a right, not a privilege.

http://whitepapers.theregister.co.uk/paper/view/199/bi-inflexion. Last checked: 9-7-2008.

Auster, E., Choo, C.W., (eds.), (1996) Managing information for the competitive edge. New York: Neal-Schuman Publishers., ISBN 978-1555702151

Australian Library and Information Ass. (1996). Policy statement on information as a commodity and its importance to economic development. www.alia.org.au/policies/information.commodity.html. Last checked: 1-122008.

Barskaya, G. (2007). How to pick an executive networking group that's right for you. The Scientist, 21(12), 79.

Baum, J.R. \& Wally, S. (2003). Strategic decision speed and firm performance. Strategic Management Journal, 24, 1107-1129. 
Berens, W., Brauner, H., Strauch, J., eds. (2005) Due Diligence bei Unternehmensakquisitionen. Stuttgart: Schäffer-Pöschel Verlag., ISBN 3-7910-2338-1

Berkien, T. (2006). Transforming information specialists into intelligence professionals. Online, 30(5), 27-31.

Berners-Lee, T. (2000) Weaving the Web. The original design and ultimate destiny of the World Wide Web. HarperBusiness, USA., ISBN 0-0625-1587-X

Bock, P. (2001) Getting it right; R\&D methods for science and engineering. Academic Press., ISBN 0-12-108852-9

Boles, T. \& Messick, D. (1995). A reverse outcome bias: The influence of multiple reference points on the evaluation of outcomes and decisions. Organizational Behavior and Human Decision Processes, 61(3), 262-275.

Bonabeau, E. (2003). Don't trust your gut. Harvard Business Review, 81(5), 116-123.

Brenner , M. (2005). Technology intelligence at Air Products: Leveraging analysis and collection techniques. Competitive Intelligence Magazine, 8(3), 6-19.

Brouthers, K.D., Andriessen, F., \& Nicolaes, I. (1998). Driving blind: Strategic decisionmaking in small companies. Long Range Planning, 31(1), 130-138.

Buchanan, L. \& O'Connell, A. (2006). A brief history of decision making. Harvard Business Review, 84(1), 32-41.

Burke, L. \& Miller, M. (1999). Taking the mystery out of intuitive decision making. Academy of management executive, 13(4), 91-99.

Calhoun, K., Teng, J., \& Myun Joong, C. (2002). Impact of national culture on information technology usage behaviour: An exploratory study of decision making in Korea and the USA. Behaviour \& Information technology, 21(4), 293302.

Carr, C. (2005). Are German, Japanese and Anglo-Saxon strategic decision styles still divergent in the context of globalization? Journal of Management Studies, 42(6), 1155-1188.

Carrington, K. (2003). Decision making, open systems and nonequilibrium. In J.Rabin (ed.), Encyclopedia of public administration and public policy (pp. 328-332). London: Dekker. ISBN 0-8247-4240-0.

Carton, F. \& Adam, F. (2005). Understanding the impact of enterprise systems on management decision making: An agenda for future research. The Electronic Journal of Information Systems Evaluation, 8(2), 99-106.

Choo, C.W. (1996). The knowing organization: How organizations use information to construct meaning, create knowledge and make decisions. International Journal of Information Management, 16(5), 329-340. 
Choo, C.W. (2002) Information management for the intelligent organization: The art of scanning the environment.Medford, NJ: Information Today. ISBN 1-57387125-7

Choo, C.W. (2006) The knowing organization. How organizations use information to construct meaning, create knowledge, and make decisions. New York: Oxford University Press., ISBN 0-19-517677-4

Choo, C.W. (2007). Information seeking in organizations: Epistemic contexts and contests. Information Research, 12(2), Available: http://InformationR.net/ir/12-2/paper298.html. Last checked 1-12-2008.

Citroen, C.L. (1971). Verspreiding van chemische informatie (Dissemination of chemical information). Chemisch Weekblad, 69(8), T12-T19.

Citroen, C.L. (1976). Chemical Abstracts in an on-line interactive information system. Open, 8 (February), 63-70.

Citroen, C.L. \& Konings, C.A.G. (1991). Databases for chemical information (Databanken voor chemische informatie). In J.W.A. Klaessens (ed.), Computers in Chemistry (Computers in de Chemie) (pp. 116-141). The Hague: Stichting Centra voor Micro-Elektronica. ISBN 90-72983-05-X

Citroen, C.L. \& van Loen, R. (1994). Merging business and technology intelligence helps companies keep their finger on the pulse: the TNO Experience. Journal of AGSI (Association for Global Strategic Information), 3(3), 90-95.

Citroen, C.L. \& Hooghoff, P. (2003). Informatie in bedrijf: Externe informatie (Information in the company: External information). In M. van Eck Poppe (ed.), Information in the Company: Manual for successful management of information (Informatie in Bedrijf: Werkboek voor succesvol informatiebeheer) (pp. 48-66). Amsterdam: Otto Cramwinckel. ISBN 9-0757-2768-2

Cleveland, H. (1981). The extrapolation of metaphors. Public Administration Review, 41(5), 584-593.

Columbia University (2007). Hollerith 1890 census tabulator.

http://www.columbia.edu/acis/history/census-tabulator.html. Last checked: 1-12-2008.

Conlisk, J. (1996). Why bounded rationality? Journal of Economic Literature, xxxiv (June), 669-700.

Corner, P.D., Kinicki, A.J., \& Keats, B.W. (1994). Integrating organizational and individual information processing perspectives on choice. Organization Science, 3, 294-308.

Crawshaw, S. (1992). Strategic analysis for an information business. Strategic change, $1(1)$. 
Cray, D., Mallory, G.R., Butler, R.J., Hickson, D.J., \& Wilson, D.C. (1988). Sporadic, fluid and constricted processes: Three types of strategic decision making in organisations. Journal of Management Studies, 25(1), 13-39.

Cray, D., Mallory, G., Butler, R., Hickson, D., \& Wilson, D. (1991). Explaining decision processes. Journal of Management Studies, 28(3), 227-251.

Cyert, R.M. \& March, J.G. (1993) A behavioral theory of the firm. Malden, USA: Blackwell Publishers Inc., ISBN 0-631-17451-6

Cyert, R.M. \& March, J.G. (2002). A summary of basic concepts in the behavioral theory of the firm. In G. Salaman (ed.), Decision making for business; A reader. ( London: Sage Publications. ISBN 0-7619-7410-5

Cyert, R.M., Simon, H.A., \& Trow, D.B. (2008). Observation of a business decision. Journal of Business, 29(4), 237-248.

Dane, E. \& Pratt, M.G. (2007). Exploring intuition and its role in managerial decision making. Academy of Management Review, 32(1), 33-54.

Davis, J.H., Schoorman, F.D., \& Donaldson, L. (1997). Toward a stewardship theory of management. Academy of Management Review, 22(1), 20-47.

de Alwis, G. \& Higgins, S. (2001). Information as a tool for management decision making: a case study of Singapore. Information Research, 7(1). http://InformationR.net/ir/7-1/paper114.html. Last checked: 15-12-2008.

de Alwis, G., Majid, S., \& Chaudhry, A.S. (2006). Transformation in managers' information seeking behaviour: A review of the literature. Journal of Information Science, 32(4), 362-377.

de Bakker, S. (2006). Organizational members within the information society: Coping with information overload (Thesis). University of Amsterdam.

De Wit, B. \& Meyer, R. (2005) Strategic synthesis, resolving strategy paradoxes to create competitive advantage. London: Thomson Learning. ISBN 1-86152-965-1

Dean, J.W. \& Sharfman, M.P. (1996). Does decision process matter? A study of strategic decision-making effectiveness. Academy of management J., 39(2), 368-369.

Devezas, T., Linstone, H., \& Santos, H. (2005). The growth dynamics of the internet and the long wave theory. Technological Forecasting and Social Change, 72(8), 913-935.

Dias, C. (2001). Corporate portals: A literature review of a new concept in information management. International Journal of Information Management, 21(4), 269287.

Dollinger, M. (1988). Confucian ethics and Japanese management practices. Journal of Business Ethics, 7(8), 575-584. 
Drucker, P.F. (1967). The effective decision. Harvard Business Review, 45(1), 92-98.

Drucker, P.F. (1973) Management: Tasks, responsibilities, practices. NY: Harper\&Row, ISBN 0-06-091207-3

Drucker, P.F. (1994). Next big lesson for bosses: The ABC of 'InfoLiteracy'. Forbes ASAP, Business Review Weekly, (August), 104-109.

Economist Intelligence Unit (2005). Business 2010. Embracing the challenge of change. http://www.eiu.com/site_info.asp?info_name=eiu_SAP_business2010\&rf $=0$. Last checked: 15-12-2008.

Edmunds, A. \& Morris, A. (2000). The problem of information overload in business organisations: A review of the literature. International Journal of Information Management, 20(1), 17-28.

Edwards, W. \& Fasolo, B. (2001). Decision technology. Annual Review of Psychology, 52, 581-606.

Eisenhardt, K.M. (1989). Agency theory: An assessment and review. Academy of Management Review, 14(1), 57-74.

Eisenhardt, K.M. \& Zbaracki, M.J. (1992). Strategic decision making. Strategic Management Journal, 13 (Special issue, Winter 1992), 17-37.

Eisenhardt, K.M. (1998). Strategic decision making as improvisation. In V.Papadakis \& P. Barwise (eds.), Strategic Decisions (pp. 251-258). Berlin: Springer, ISBN 978-0-7923-9987-2

Eisenhardt, K.M. \& Graebner, M.E. (2007). Theory building from cases: Opportunities and challenges. Academy of Management Journal, 50(1), 25-32.

Eliasson, G. (1996) Firm objectives, controls and organization. The use of information and the transfer of knowledge within the firm. Kluwer Academic Publishers. ISBN 0-79-233870-7

Eom, S.B., Lee, S.M., Kim, E.B., \& Somarajan, C. (1998). A survey of decision support system applications (1988-1994). The Journal of the Operational Research Society, 49(2), 109-120.

European Union (2004). Lisbon strategy of the European Community. http://europa.eu/scadplus/glossary/lisbon_strategy_en.htm. Last checked: 29-7-2008.

Evans, P.B. \& Wurster, T.S. (1997). Strategy and the new economics of information. Harvard Business Review, 75(5), 70-82.

Evans, P.B. \& Wurster, T.S. (2000) Blown to bits. How the new economics of information transforms strategy. Boston: Harvard Business School Press, ISBN 0-87584877-X 
Fahey, L. \& Prusak, L. (1998). The eleven deadliest sins of knowledge management. California Management Review, 40(3), 265-276.

Farhoomand, A.F. \& Drury, D.H. (2002). Managerial information overload. Communications of the ACM, 45(10), 127-130.

Feigenbaum, A. (1961) Total quality control; Engineering and management; the technical and managerial field for improving product quality, including its reliability, and for reducing operating costs and losses. McGraw-Hill, New York, ISBN 0-07-020354-7

Filipe, J. (2000) Enterprise information systems. Kluwer Academic Publishers, ISBN 079-236239-X

FNLI (2008). Federation Netherlands Food Industry. www.fnli.nl/overfnli/About_FNLI.php. Last checked: 2-12-2008.

Foss, N.J. (2002). The rhetorical dimensions of bounded rationality: Herbert A. Simon and organizational economics. IVS/CBS Working Papers 2002-07, Copenhagen Business School; http://ep.lib.cbs.dk/download/ISBN/8778690862.pdf, Last checked 15-122008

Foss, N.J. (2003). Bounded rationality in the economics of organization: "Much cited and little used". Journal of Economic Psychology, 24, 245-264.

Foster, P. (2008). What's new. A roundup of new products and initiatives. Business Information Review, 21(4), 252-261.

Fredrickson, J.W. (1984). The comprehensiveness of strategic decision processes: Extension, observations, future directions. Academy of Management Journal, 27(3), 445-466.

Freeman, C. \& Louça, F. (2002) As time goes by. From the industrial revolutions to the information revolution. Oxford, UK: Oxford University Press, ISBN 978-0-19-925105-6

Frishammar, J. \& Hörte, S. (2005). Managing external information in manufacturing firms: The impact on innovation performance. J.Prod.Innov.Manag., 22, 251266.

Furner, J. (2003). Little book, Big book: Before and after Little science, Big science: A review article, Part I. Journal of Librarianship and Information Science, 35(2), 115-125.

Furner, J. (2003). Little book, Big book: Before and after Little science, Big science: A review article, Part II. Journal of Librarianship and Information Science, 35(3), 189-201. 
Garvin, A. (1993) The art of being well informed. Garden City Park, NY, Avery Publishing Group, ISBN 0-89-529576-8

Gerhart, B. \& Fang, M. (2005). National culture and human resource management: Assumptions and evidence. International Journal of Human Resource Management, 16(6), 971-986.

Geurts, P.A.T.M. (1999) From problem to research (Van probleem naar onderzoek). Bussum, NL: Coutinho, ISBN 90-6283-143

Geurts, P.A.T.M. \& Roosendaal, H.E. (2001). Estimating the direction of innovative change based on theory and mixed methods; the scientific communication and information system as an example. Quality \& Quantity, 35, 407-427.

Gorry, A. \& Scott Morton, M. (1971). A framework for management information systems. Sloan Management Review, 13(1), 55-70.

Gorry, A. \& Sharfman, M.P. (1989). A framework for management information systems (Reprint). Sloan Management Review, 30(3), 49-60.

Gross, D. (1997) Forbes greatest business stories of all time. New York: Forbes, ISBN 978-0-471-19653-2

Gura, T. (2003). Obesity drug pipeline not so fat. Science, 299(5608), 849-852.

Haite, S. \& Bossart, F. (2000) Internet für Unternehmen. Das 5x5 Erfolgsprinzip. Remscheid, Germany: SmartBooks Publishing AG., ISBN 39-08-48924-5

Hammond, J., Keeney, R., \& Raiffa, H. (2006). The hidden traps in decision making. Harvard Business Review, 84(1), 118-126.

Harper, S. (1988). Intuition: What separates executives from managers. Business horizons, 1988(September/October), 13-19.

Harvey, M.G. \& Lusch, R.F. (1995). Expanding the nature and scope of due diligence. Journal of Business Venturing, 10, 5-21.

Hasan, H. \& Gould, E. (2001). Support for the sense-making activity of managers. Decision Support Systems, 31(1), 71-86.

Haspeslagh, P. \& Jemison, D.B. (1991) Managing acquisitions: Creating value through corporate renewal. New York: The Free Press, MacMillan, ISBN 0-02-9141656

Hawley Committee (1995). Information as an asset: The Board Agenda; a consultative document for chairmen, chief executives and boards of directors developed on behalf of the KPMG IMPACT Programme. London: KPMG.

Hedelin, L. \& Allwood, C. (2002). IT and strategic decision making. Industrial Management \& Data Systems, 102(3), 125-139. 
Heinz-Nixdorf Museum (2003). The invention of the computer. www.hnf.de Last checked: 1-12-2008.

Heller, S.R. (1996). Chemistry on the internet - The road to everywhere and nowhere. Journal of Chemical Information and Computer Sciences, 36(2), 205-213.

Hellige, J.B. (1990). Hemispheric asymmetry. Annual Review of Psychology, 41(1).

Herodotus (440 B.C.). The History, Book VI. http://www.livius.org/he-hg/herodotus/logos6_19.html. Last checked: 1-122008.

High Level Group (2004). Facing the challenge: The Lisbon strategy for growth and employment. http://ec.europa.eu/growthandjobs/pdf/kok_report_en.pdf. Last checked: 15-12-2008.

Hitt, M., Harrison, J., Ireland, D., \& Best, A. (1998). Attributes of successful and unsuccessful acquisitions of US firms. British Journal of Management, 9, 91114.

Ho, S. (1997). Competitive strategies through Sun Tze's Art of warfare. Strategic change, 6(May), 133-147.

Hofstede, G., Neuijen, B., Ohayv, D., \& Sanders, G. (1990). Measuring organizational cultures: A qualitative and quantitative study across twenty cases. Administrative Science Quarterly, 35(2), 286-316.

Hofstede, G. (2001). A summary of my ideas about national culture differences. http://feweb.uvt.nl/center/hofstede/page3.htm. Last checked: 1-12-2008.

Hollerith, H. (2007). An electric tabulating system. The Quarterly, Columbia University School of Mines, Vol. X(16), 238-255.

Horton, F. \& Lewis, D. eds. (1991) Great information disasters. London: Aslib, ISBN 0-85142-255

Horton, R. (2004). Vioxx, the implosion of Merck, and aftershocks at the FDA. Lancet, 364(9450), 1995-1996.

Hoskisson, R., Hitt, M., \& Wan, Y. (1999). Theory and research in strategic management. Journal of Management, 25(3), 417-456.

Hough, J. \& White, M. (2003). Environmental dynamism and strategic decision-making rationality: An examination at the decision level.. Strategic Management Journal, 24, 481-489.

Huber, G. (1982). Organizational information systems: Determinants of their performance and behavior. Management Science, 28(2), 138-155. 
Hussey, D. (1997) The Strategic decision challenge. John Wiley \& Sons, ISBN 0-47197480

Hutzschenreuter, T. \& Kleindienst, I. (2006). Strategy-process research: What have we learned and what is still to be explored. Journal of Management, 32(5), 673720.

Hwang, M. \& Lin, J. (1999). Information dimension, information overload and decision quality. Journal of Information Science, 25(3), 213-218.

Iastrebova, K. (2006). Managers' information overload. The impact of coping strategies on decision-making performance (Thesis). Rotterdam: Erasmus University. ISBN 90-5892-111-5

IBM Global Business Sevices (2008). The enterprise of the future; Global CEO study. www.ibm.com/innovation/nl/ceostudy. Last checked: 24-7-2008.

Information Builders (2007). No barriers to good decisions. www.informationbuilders.nl/business_intelligence/good_decisions/index.ht ml. Last checked: 15-12-2008.

International Organization for Standardization (2003) ISO standards compendium ISO 9000 - Quality management. Geneva: International Organization for Standardization ., ISBN 92-67-10381-4

International Organization for Standardization (2008). ISO management standards. www.iso.org/iso/iso_catalogue/management_standards/iso_9000_iso_14000 .htm. Last checked: 1-12-2008.

Jensen, M. \& Meckling, W. (1976). Theory of the firm: Managerial behavior, agency costs and ownership structure. Journal of Financial Economics, 3, 305-360.

Johnson, G., Scholes, K., \& Whittington, R. (2005) Exploring corporate strategy. Harlow, UK: FT Prentice Hall. ISBN 978-140588733-5

Kahn, D. \& Drey, J. (2002). Finding chemical information on the Web - The user's viewpoint. Free Pint www.freepint.com/issues/040402.htm. Last checked: 78-2008.

Kendrick, T. (2007). The winning mindset: Effective competitive intelligence research on the internet. Business Information Review, 24(4), 228-235.

Kets de Vries, M. (2005). The dangers of feeling like a fake. Harvard Business Review, 83(9), 108-116.

Kettelhut, M. (1991). Using a DSS to incorporate expert opinion in strategic product development funding decisions. Information \& Management, 20(5), 363-371.

Khatri, N. \& Ng, H.A. (2000). The role of intuition in strategic decision making. Human Relations, 53(1), 57-86. 
King, D.W. \& Griffiths, J. (1991). Indicators of the use, usefulness and value of scientific and technical information. In Online Information 1991 Conference (pp. 361377). Oxford, UK: Learned Information

Kist, J. (1991). Disaster at Arnhem: The role of information during the operation 'Market Garden' in September 1944. In D.L.E.Horton \& Lewis D. (eds.), Great information disasters. London: Aslib. ISBN 0-85142-255-1

Kleindorfer, P., Kunreuther, H.C., \& Schoemaker, P.J.H. (1993) Decision sciences; An integrative perspective. Cambridge, UK: Cambridge University Press, ISBN 0-521-33812-3

Knight, C. (2007). The top 100 alternative search engines. www.readwriteweb.com. Last checked: 24-7-2008.

Knorr-Cetina, K. \& Preda, A. (2001). The creation and incorporation of knowledge in economic activities: Epistemization of economic transactions. Current Sociology, 49(4), 27-44.

Kolman, L., Noorderhaven, N., Hofstede, G., \& Dienes, E. (2003). Cross-cultural differences in Central Europe. Journal of Managerial Psychology, 18(1), 76-88.

Koninklijke Nederlandse Chemische Vereniging (Royal Netherlands Chemical Society) (1970). Computer-based chemical information. In H. Evers (ed.), Symposium on Computer-Based Chemical Information, 1968, The Hague, NL: Koninklijke Nederlandse Chemische Vereniging.

Koopman, P.L. \& Pool, J. (1997) Management and decision-making in organisations: A strategic perspective (Management en besluitvorming in organisaties: Een strategisch perspectief). Assen, NL: van Gorkum., ISBN 90-232-2725-5

Kraaijenbrink, J. (2007). Engineers and the Web: An analysis of real life gaps in information usage. Information Processing \& Management, 43(5), 1368-1382.

Kurek, K., Geurts, P.A.T.M., \& Roosendaal, H.E. (2006). The split between availability and selection. Business models for scientific information, and the scientific process? Information Services \& Use, 26(4), 271-282.

Langley, A. (1990). Patterns in the use of formal analysis in strategic decisions. Organization Studies, 11(1), 17-45.

Langley, A., Mintzberg, H., Pitcher, P., Posada, E., \& Saint-Macary, J. (1995). Opening up decision making: The view from the black stool. Organization Science, 6(3), 260-279.

Langley, A. (1999). Strategies for theorizing from process data. Academy of Management Review, 24(4), 691-710. 
Laudon, K. \& Laudon, J. (2006) Management information systems: Managing the digital firm. New York: MacMillan., ISBN 0-13-153841-1

Lee, M. \& Cummings, T. (2004). Evidence accumulation in decision making: Unifying the "take the best" and the "rational" models. Psychonomic Bulletin \& Review, 11(2), 343-352.

Lehner, U. \& Nuhn, H. (2005). Due diligence in Asien. In W.Berens, H. Brauner, \& J. Strauch (eds.), Due Diligence bei Unternehmensakquisitionen (pp. 719-753). Stuttgart: Schäffer-Pöschel Verlag. ISBN 37-910-2338-1

Leiner, B., Cerf, V., \& Clark, D. (1997). The past and future history of the internet. Communications of the ACM, 40(2), 102-108.

Li, A. (2002). The relationship between internet usage and decision making: The case of information technology (IT) managers in China (Thesis). Nova Southeastern University, USA.

Li, A.M., Yatrakis, P., Turner, D., Yen, B., \& Hsu, J. (2003). The relationship between Internet usage and decision making: The case of information technology (IT) managers in China. Journal of applied management and entrepreneurship, 8(3), 48-68.

Lide, D. (2002). A century of excellence in measurements, standards, and technology (Rep. No. NIST Special Publication 958). Boca Raton: CRC Press

Lohman, F.A.B. (1999) The effectiveness of management information (Thesis). Delft: Delft University of Technology, ISBN 90-9013365-8

Lohman, F.A.B., Sol, H., \& de Vreede, G. (2003). The illusion of effective management information: A critical perspective.

http://doi.ieeecomputersociety.org/10.1109/HICSS.2003.1174786 Last checked: 15-12-2008.

Mackenzie Owen, J. (1999). Knowledge management and the information professional. Information Services \& Use, 19(1), 7-16.

March, J. (1991). Exploration and exploitation in organizational learning. Organization Science, 2(1), 71.

Marschak, J. (1968). Economics of inquiring, communicating, deciding. The American Economic Review, 58(2), 1-18.

Martinsons, M. \& Davison, R. (2007). Strategic decision making and support systems: Comparing American, Japanese and Chinese management. Decision Support Systems, 43(1) , 284-300.

Maxfield, C. \& Brown, A. (1997). Bebop bytes back: An unconventional guide to computers. www.maxmon.com/1000bc.htm. Last checked: 1-12-2008. 
McCown, F., Liu, X., Nelson, M., \& Zubair, M. (2006). Search engine coverage of the OAIPMH corpus. IEEE Internet Computing, 10(2), 66-73.

MCRIT Decision. (2000). What's an executive support system? www.mcrit.com/assembling/assemb_central/WhatESS.htm. Last checked: 4-11-2008.

Meadow, C. \& Yuan, W. (1997). Measuring the impact of information: Defining the concepts. Information Processing \& Management, 33(6), 697-714.

Meier, M. \& Fülleborn, A. (1999). Integration of external management information from the Internet in SAP strategic enterprise management (SEM) (Integration externer Führungsinformationen aus dem Internet in SAP strategic enterprise management) Wirtschaftsinformatik, 41(5), 449-457.

Meijaard, J. (1998). Decision-making in research and development (Thesis). Tinbergen Institute Research Series no. 192, Amsterdam: Thesis Publishers.

Mellers, B.A., Schwartz, A., \& Cooke, A.D.J. (1998). Judgement and decision making. Annual Review of Psychology, 49, 447-477.

Miller, C.C. \& Ireland, D. (2005). Intuition in strategic decision making: Fiend or foe in the fast-paced 21st century? Academy of management executive, 19(1), 19-30.

Miller, S.J., Hickson, D.J., \& Wilson, D.C. (2002). Decision-making in organizations. In G.Salaman (ed.), Decision making for business; a reader (pp. 74-92). London: SAGE Publications. ISBN 7-6197411-3

Miller, S.J., Wilson, D., \& Hickson, D. (2004). Beyond planning: Strategies for successfully implementing strategic decisions. Long Range Planning, 37(3), 201-218.

Mintzberg, H. (1973) The nature of managerial work. NY: Harper\&Row., ISBN 0-06-044556-4

Mintzberg, H., Raisinghani, D., \& Théorêt, A. (1976). The structure of unstructured decision processes. Administrative Science Quarterly, 21(2), 246-275.

Mintzberg, H. (1979) The structuring of organizations: a synthesis of the research. Englewood Cliffs: Prentice Hall, ISBN 0-13-853771-2

Mintzberg, H. \& Waters, J. (1985). Of strategies, deliberate and emergent. Strategic Management Journal, 6(3), 257-272.

Mintzberg, H. \& Waters, J. (1990). Studying deciding: An exchange of views between Mintzberg and Waters, Pettigrew and Butler. Organization Studies, 11(1), 116. 
Mintzberg, H., Ahlstrand, B.W., \& Lampel, J. (1998) Strategy safari: A guided tour through the wilds of strategic management. New York: The Free Press., ISBN 0-68-484743-4

Molloy, S. \& Schwenk, C. (1995). The effects of information technology on strategic decision making. Journal of Management Studies, 32(3), 283-311.

Moreau, É. (2006). The impact of intelligent decision support systems on intellectual task success: An empirical investigation. Decision Support Systems, 42(2), 593607.

Mullin, R. (2004). Dealing with information overload. Analysis and routing strategies emerge as the chemical industry focuses on what information it needs rather than how much is generated. Chemical \& Engineering News, 82(12), 19-24.

Munton, D. \& Welch, D. (2007) The Cuban Missile Crisis. NY: Oxford University Press., ISBN 0-19-517859-9

Murphy, C. (2006). Competitive intelligence: What corporate documents can tell you. Business Information Review, 23(1), 35-42.

Negroponte, N. (1996) Being digital. New York: Vintage Books., ISBN 0-679-43919-6

Network Working Group (1974). Specification of Internet Transmission Control Program. http://tools.ietf.org/html/rfc675. Last checked: 1-12-2008.

Nonaka, I. (1991). The knowledge-creating company. Harvard Business Review, 69(nov/dec), 96-104.

Nonaka, I. (1994). A dynamic theory of organisational knowledge creation. Organization Science, 5(1), 14-37.

Noorderhaven, N. (1995) Strategic decision making. Wokingham, UK: Addison-Wesley Pub. Cy., ISBN 0-201-59393-9

Nutt, P. (1993). The formulation process and tactics used in organizational decision making. Organization Science, 4(2), 226-251.

Nutt, P. (1999). Surprising but true: Half the decisions in organizations fail. Academy of management executive, 13(4), 75-90.

Nutt, P. (2005). Search during decision making. European Journal of Operational Research, 160(3), 851-876.

Oppenheim, C. (1997). Managers' use and handling of information. International Journal of Information Management, 17(4), 239-248.

Oppenheim, C. (2003). Studies on information as an asset I: Definitions. Jounal of Information Science, 29(3), 159-166. 
Oppenheim, C. (2003). Studies on information as an asset II: Repertory grid. Journal of Information Science, 29(5), 419-432.

P-D-R \& Patients not Patents (2008). Abbott Laboratories deletes safety concerns from Web. www.patientsnotpatents.org/documents/AbbotteditsWikipedia.pdf; Last checked 5-12-2008.

Papadakis, V. \& Barwise, P. (1998) Strategic decisions. Berlin: Springer, ISBN 978-07923-9987-2

Papadakis, V. \& Barwise, P. (1998). Strategic decisions: An introduction. In V.Papadakis \& P. Barwise (eds.), Strategic Decisions (pp. 1-16). Berlin: Springer, ISBN 978-0-7923-9987-2

Papadakis, V. \& Barwise, P. (2002). How much do CEO's and top managers matter in strategic decision-making? British Journal of Management, 13, 83-95.

Partovi, F. (2007). An analytical model of process choice in the chemical industry. International Journal of Production Economics, 105(1), 213-227.

Perez, C. (2004). The new techno-economic paradigm and the importance of ICT policy for the competitiveness of the whole economy. In High Level Conference "Looking into the future of ICT", Amsterdam

Perkins, W.S. \& Rao, R. (1990). The role of experience in information use and decision making by marketing managers. Journal of Marketing Research, 27(1), 1-10.

Pettigrew, A. (2001). Management research after modernism. British Journal of Management, 12(Special Issue), S61-S70.

Pirsig, R.M. (1974) Zen and the art of motorcycle maintenance. An inquiry into values. NY: William Morrow \& Cy. Inc., ISBN 0-688-00230-7

Popper, K.R. (1935) Logik der Forschung. Vienna: Julius Springer.

Popper, K.R. (1963) Conjectures and refutations. London: Routledge and Kegon.

Popper, K.R. (1972) Objective knowledge. An evolutionary approach. Oxford: Clarendon Press, ISBN 0-19-875024-2

Porter, M.E. (1985) Competitive advantage; creating and sustaining superior performance. NY: Free Press, ISBN 0-684-84146-0

Porter, M.E. \& Millar, V.E. (1985). How information gives you competitive advantage. Harvard Business Review, 63(4), 149-174.

Porter, M.E. (2001). Strategy and the Internet. Harvard Business Review, 79(3), 62-78. 
Power, D.J. (2007). A brief history of decision support systems.

http://dssresources.com/history/dsshistory.html. Last checked: 1-12-2008.

Price, D.J. de Solla (1963) Little science, big science. New York: Columbia University Press, ISBN 0-231-04956-0; (1986) Little Science, Big Science-- and Beyond, Edition: reissue, revised, ISBN 0231049560.

Prusak, L. \& Matarazzo, J. (1992) Information management and Japanese success. Washington, DC: Special Libraries Association/Ernst \& Young, ISBN 0-87111383-X

Prusak, L. (2001). Where did knowledge management come from? IBM Systems Journal, 40(4), 1002-1006.

Quocirca (2007). Business intelligence for all. http://software.silicon.com/applications/0,39024653,39167876,00.htm Last checked: 15-12-2008

Ramesh, B. \& Tiwana, A. (1999). Supporting collaborative process knowledge management in new product development teams. Decision Support Systems, 27(1-2), 213-235.

Ray, L. \& Kirsch, R. (1957). Finding chemical records by Digital computers. Science, 126, 814-819.

Redman T.C. (1998). The impact of poor data quality on the typical enterprise. Communications of the ACM, 41(2), 79-82.

Reeves, C. \& Bednar, D. (1994). Defining quality: Alternatives and implications. Academy of Management Review, 19(3), 419-445.03637425

Repo, A.J. (1986). Economics of information in information science (Rep. No. 645). Espoo, Finland: Technical Research Centre of Finland, ISBN/ISSN 951-382760-7

Repo, A.J. (1987). Economics of information. Annual review of Information Science and Technology, 22, 3-35.

Repo, A.J. (1989). An approach to the value of information: effectiveness and productivity of information use in research work (Rep. No. 51). Espoo, Finland: Technical Research Centre of Finland, ISBN/ISSN 951-38-3342-9

Reuters Business Information (1996). Dying for information? An investigation into the effects of information overload in the UK and worldwide London: Reuters Business Information., ISBN/ISSN 1-901249-00-X

Reuters Business Information (1997). Glued to the screen. An investigation into information addiction worldwide London: Reuters Business Information. ISBN 0-901249-06-8 
Rowley, J. (1998). What is information? Information Services \& Use, 18, 243-254.

Sabherwal, R. \& Grant, J. (1994). Integrating external and internal perspectives of strategic information technology decisions. In N.Venkatraman (ed.), Research in strategic management and information technology (pp. 107-143). London: Jai Press.

ISBN 1-55938-782-3

Saini, R., Saxena, P.K., \& Kalra, P.K. (2000). Internet enabled synergistic intelligent systems and their applications to efficient management of operational organizations. Information Sciences, 127(1-2), 45-62.

Sajor-Wood, R. (2000) The Internet: A decision-support information technology for public managers (Thesis). University of La Verne, CA, USA.

Salaman, G. (2002) Decision making for business; a reader. London, UK: SAGE Publications, ISBN 0-7619-7410-5

Sauter, V. (1999). Intuitive decision-making. Communications of the ACM, 42(6), 109 115.

Scandura, T. \& Williams, E. (2000). Research methodology in management: Current practises, trends, and implications for future research. Academy of Management Journal, 43(6), 1248-1264.

Schendel, D. E.\& Hofer, C.W. (eds.), (1979). Strategic Management, a new view of business policy and planning. Boston: Little, Brown \& Cy, ISBN 0-31-677312-3

Schneider, S. (1989). Strategy formulation: The impact of national culture. Organization Studies, 10(2).

Schoemaker, P.J.H. \& Russo, J.E. (1993). A pyramid of decision approaches. California Management Review, 36(1), 9-31.

Schwenk, C. (1986). Information, cognitive bias and commitment to a course of action. Academy of Management Review, 11(2), 298-310.

Schwenk, C. (1988). The cognitive perspective on strategic decision making. Journal of the American Society for Information Science, 25(1), 41-55.

Scott Morton, M. (1978). Some perspectives on computerized management decision making systems. http://dspace.mit.edu/handle/1721.1/1937. Last checked: 15-12-2008.

Shell Research Laboratory (2007). MIRACLE - Mokums industrial research automatic calculator for laboratory and engineering. http://www.xs4all.nl/ onnoz/miracle/. Last checked: 4-7-2008.

Simon, H.A. (1947) Administrative behavior; a study of decision-making processes in administrative organization. New York: Free Press., ISBN 0-02-929000-7 
Simon, H.A. (1957) Models of man: Social and rational. Mathematical essays on rational human behavior in a social setting. John Wiley, NY.

Simon, H.A. (1960) The new science of management decision. USA: Prentice-Hall, ISBN 0-13-616136

Simon, H.A. (1978). Rational decision-making in business organizations. Nobel memorial lecture.

http://nobelprize.org/nobel_prizes/economics/laureates/1978/simonlecture.pdf. Last checked: 1-12-2008.

Simon, H.A. (1987). Making management decisions: The role of intuition and emotion. Academy of management executive, 1(February), 57-64.

Simon, H.A. (2007). A behavioral model of rational choice. Quarterly Journal of Economics, 69(1), 99-118.

Simpson, C.W. \& Prusak, L. (1995). Troubles with information overload--Moving from quantity to quality in information provision. International Journal of Information Management, 15(6), 413-425.

Sinclair, M. \& Ashkanasy, N. (2005). Intuition. Myth or a decision-making tool? Management Learning, 36(3), 353-370.

Singh, S., Watson, H., \& Watson, R. (2007). EIS support for the strategic management support. Decision Support Systems, 33, 71-85.

Sivadas, R. (2006). Outsourcing research information: An introduction. http://www.freepint.com/issues/191006.htm\#tips. Last checked: 1-12-2008.

Six Sigma (2008). New to Six Sigma. A Six Sigma guide for both novice and experienced quality practitioners.

http://www.isixsigma.com/library/content/six-sigma-newbie.asp. Last checked: 9-7-2008.

Smith, B. (2001). The Third industrial revolution: Policymaking for the Internet. Columbia Science and Technology Law Review [On-line]. www.stlr.org/html/volume3/smith.pdf. Last checked: 1-12-2008.

Stamper, R. (2000). New directions for systems analysis and design. In J.Filipe (ed.), Enterprise information systems (pp. 14-17). Dordrecht, NL: Kluwer Academic Publishers. ISBN 0-79236239-X

Stewart, T. \& Lev, B. (2001). Accounting gets radical. The green-eyeshade gang isn't measuring what really matters to investors; Fortune Magazine. http://money.cnn.com/magazines/fortune/fortune_archive/2001/04/16/30 1042/index.htm. Last checked: 15-12-2008. 
Sudman, S., Bradburn, N.M., \& Schwartz, N. (1996) Thinking about answers: The Application of Cognitive Processes to Survey Methodology. San Francisco: Jossey-Bass Publishers, ISBN 0-7879-0120

Surfnet \& Roders, E. (ed.) (2002). Is the Internet organised? (Het Internet georganiseerd?), brochure.

www.surfnet.nl/publicaties/brochures/organisaties/.

Last checked: 2-12-2008.

Tai, N. (2002). Common financial due diligence issues in Asia, the seven deadly sins. Perspective, Spring, 15-18.

Tapscott, D. (2001). Rethinking strategy in a networked world. http://www.strategybusiness.com/press/article/19911. Last checked: 15-12-2008.

Tayi, G.K. \& Balou D.P. (1998). Examining data quality. Communications of the ACM, 41(2), 54-57.

Teng, J.T.C. \& Calhoun, K.J. (1996). Organizational computing as a facilitator of operational and managerial decision making: An exploratory study of managers' perceptions. Decision sciences, 27(4), 673-710.

Teng, J.T.C., Calhoun, K.J., Cheon, M.J., Raeburn, S., \& Wong, W. (1999). Is the East really different from the West: A cross-cultural study on information technology and decision making. In Proceedings of the 20th International Conference on Information Systems (pp. 40-46). Charlotte, North Carolina: ICIS1999-X

Ticoll, D., Shuman, J., Twombly, J., Finken, S., \& Yeo, J. (2001). Strategy and the Internet. Harvard Business Review, 79(6), 137-144.00178012

Toffler, A. (1980) The third wave. Toronto: Bantam Books., ISBN 0-553-14431-6

Tomberg, A. \& Pratt, G. (1977). Data bases on line. On-line Review, 1(2, 4), 91-98.

Toms, E. (2000). Serendipitous information retrieval. http://www.ercim.org/publication/ws-proceedings/DelNoe01. Last checked: 15-12-2008.

Tosi, H., Brownlee, A., Silva, P., \& Katz, J. (2003). An empirical exploration of decisionmaking under agency controls and stewardship structure. Journal of Management Studies, 40(8), 2053-2071.

TUDelft Library (2007). Annual report 2007. www.library.tudelft.nl/consumption/groups/btudwebsite/documents/xmlcontribution/381451.pdf Last checked: 15-12-2008.

TUDelft Library (2007). Virtual knowledge centres. http://vkc.library.tudelft.nl. Last checked: 1-12-2008. 
van Cuilenburg, J. (1998). Diversity revisited: Towards a critical rational model of media diversity. In K. Brants, J. Hermes, \& L. van Zoonen (eds.), The media in question: Popular cultures and public interests (pp. 38-50). Newcastle Upon Tyne, UK: Sage. ISBN 0-76-195723-5

van Dael, R.L.H. (2001). Something with computers: The ICT professional (Iets met computer: Over beroepsvorming van de informaticus) (Thesis). Katholieke Universiteit Nijmegen, The Netherlands, ISBN 90-5166-827-9

Van der Berg, C., Brinkman-Dzwig, Z., Citroen, C.L., \& Popescu, I. (2003) Knowledge mapping: Virtual knowledge centre and Special interest group for Delft Cluster libraries. Delft: Delft Cluster.

van der Meij, B. (2007). Knowledge management 2.0: The next generation. Intellectueel Kapitaal, 6(1), 14-15.

van Heusden, B. \& Joma, R. (1999). Toward organizational semiotics. The semiotic review of books, 10(1), http://www.chass.utoronto.ca/epc/srb/srb/organizational.html Last checked 15-12-2008

van Riel, A. (2002). Effective decision making in the High-tech service innovation process. (Thesis) University Maastricht, Maastricht, The Netherlands, ISBN 90 52783667

van Riel, A., Ouwersloot, H., \& Lemmink, J. (2003). Antecedents of effective decision making: A cognitive approach (Rep. No. 2003/045). Maastricht, The Netherlands: Research School of Economics of Technology \& Organization.

van Riel, A., Lemmink, J., \& Ouwersloot, H. (2004). High-technology service innovation succes: A decision-making perspective. Journal of Product Innovation Management, 21(5), 348-359.

van Wegberg, M. \& van Witteloostuijn, A. (2001). Strategic management in the new economy: Modern information technologies and multichannel contact strategies. Multiunit Organization and Multimarket Strategy, 18, 265-306.

Vandenbroucke, L. (1984). Anatomy of a failure: The decision to land at the Bay of Pigs. Political Science Quarterly, 99(3), 471-491.

Venkatraman, N. \& Henderson, J. (1994) Research in strategic management and information technology. Greeenwich, CT, USA: JAI Press, ISBN 1-55938-782-3

VNCI (Association Netherlands Chemical Industry) (2008). Facts \& figures chemical industry 2007. www.vnci.nl/Files\%5CDIVEXTRA\%5C/058-029-F\&F-20088LR.pdf. Last checked: 15-12-2008.

Waddington, P. (1995). Information as an asset: The invisible goldmine. Business Information Review, 12(1), 26-36. 
Wagner, C. (2004). Enterprise strategy management systems: Current and next generation. The Journal of Strategic Information Systems, 13(2), 105-128.

Weirich, P. (2004) Realistic decision theory: Rules for nonideal agents in nonideal circumstances. Oxford: Oxford University Press, ISBN 0-19-517125-X

Wildenbeest, F. (2002). Measuring human capital (De meting van human capital). Management control \& accounting, 6(3), 8-11.

Willett, P. (2008). From chemical documentation to cheminformatics: 50 years of chemical information science. Journal of Information Science, 34(4), 477-499.

Williams, M., Dennis, A., \& Aronson, J. (2007). The impact of DSS use and information load on errors and decision quality. European Journal of Operational Research, 176, 468-481.

Williams, S. (2002) Making better business decisions. US: Thousand Oaks, ISBN 0-7619-2421-3

Wilson, T. (1997). Book review "Managing information for the competitive edge", Choo \& Auster eds. Information Processing \& Management, 33(6), 811-812.

World Wide Web Consortium (2007). Leading the Web to its full potential. http://www.w3.org/. Last checked: 1-12-2008.

Yip, G. \& Dempster, A. (2005). Using the Internet to enhance global strategy. European Management Journal, 23(1), 1-13. 


\section{Summary}

The focus of this dissertation is on the use of information in the strategic decision-making process by executives in industrial organisations and how these processes have changed in recent years e.g. under the influence of increased availability of information resources. The emphasis thereby is on the process, not on the resulting decision itself.

Decisions taken by executives of large corporations are mostly of a strategic nature; they are complex, non-routine, cannot be managed easily by existing procedures and have not previously been encountered in the same form. The strategic issues that are the subject of the decisions we studied involve considerable change such as strategy development, mergers and acquisitions, large investments and sometimes disinvestments, new products and new markets, make or buy options, organisational issues and long-range planning strategies.

Many studies in strategic management take the position that executives reach strategic decisions after a structured process of careful consideration of circumstances, alternatives and consequences. Information on matters such as competition, markets, technologies and the societal environment affecting the organisation specifies the implications of the feasible alternatives for the decision to be made and plays a crucial role in obtaining the parameters of these alternatives. Making decisions presupposes that adequate information is available that enables an executive director or a board of directors to reach the best possible decision under the circumstances.

This position however is not uncontested. In several studies, arguments are presented claiming that human beings only have limited cognitive capabilities and can only comprehend and use a limited amount of the information that is available. As a consequence, they have to rely on bounded rational processes rather than rational processes. In strategic decision-making, this leads to the view that executives reach decisions in a basically unstructured process accepting 'satisficing' instead of optimal solutions. Again another point of view is that in some cases, decisions primarily based on an intuitive process can lead to equally proper outcomes.

Our research centres on the use of information because we argue that this is a factor that influences the structure of the strategic decision-making process. As implied, the executive that follows a rational approach collects and uses ample information in a structured decision-making process passing through a number of distinct phases in time. In this process, information plays an all-important role throughout. The satisficing executive follows a decision-making process that is based on using a limited amount of information of all that is available and the decisionmaking process is less structured. For the intuitive executive, the exact role of information cannot be determined and the decision-making process is unstructured as mostly previous experience and learning constitute the knowledge base for the 
decision in an intuitive process. The manner in which information is used in the decision-making process thus differs in each of the three approaches to this process. Investigating the role and extent of usage of information in the process therefore can be a factor in discerning which approach to the decision-making process is actually followed by the executives.

The issue of the substance of strategic management information is seldom discussed or analysed as such in this context; moreover, in many studies on company performance, management information is considered a production factor that is readily available and its accessibility is 'taken for granted' in the process. Over the last few years, resources for management information have increased with the change of the Internet from mainly a research-oriented system to one that has additionally become a source of relevant information also for a business audience by its diverse content. Because of these developments, the question is no longer whether some required bit of information is available, but where this item can be found in the shortest time. Also, new methods have become available for the task of collecting information in each step of the decision-making process such as preparing for a case, constructing, documenting and comparing alternatives, thus enabling faster and more comfortable choices. There is a risk associated with this increased availability of information, that of being plagued by an overload of information. There are however several methods to cope with this problem by proper organisation of the information flow, if needed, assisted by computer procedures. Equally, checking the reliability of a received piece of information from an uncertain source is facilitated by the new methods of ICT techniques, e.g. statistically or by comparison with other data.

In order to be able to draw conclusions for this study, we have considered several aspects of information requirements such as the quality, the sources and the actual use of available information during the process of strategic decision-making.

In the theoretical chapters of this thesis, we have reviewed and discussed the literature on strategic management that has an implicit bearing on the structure of the process of strategic decision-making and a thorough analysis of the different approaches to the process. This is followed by a similar review and discussion of the strategic role of management information in the decision-making process, its value and the advances in computer applications facilitating the availability of information are indicated. As the objective of our study lies in the identification of the changed role of information as a management tool, we gave a short historical overview of the advances and significance of developments in information and communication technology. We paid particular attention to the development of the Internet, especially as it offers new services for the chemical and food industries.

As a result of our theoretical discussion, we have formulated four hypotheses that have been tested in the fieldwork for this research. Hypothesis 1 refers to the decision-making process: 'strategic decisions by executives are reached in a rational, well-structured process with the purpose to come to the best possible results under 
the conditions that apply in each specific case'. Hypothesis 2 states that 'in answering a specific strategic issue, executives that follow a rational process, will collect all feasible information considered to be supportive for this process'. Hypothesis 3 is about the quality of the information that is used: 'before it is accepted as relevant, executives thoroughly check (or have checked) all information that is believed to be suitable as a supportive resource for the decision-making process for its quality parameters such as robustness and reliability'. Hypothesis 4 is prompted by the ICT developments, stating that 'enhanced availability of multiple information resources, predominantly through specialised digital information services such as the Internet, has a positive effect on the strategic decision-making process in industry'.

In order to facilitate the analysis of the structure of the decision-making process and test the hypotheses, we have developed a model that shows the successive phases in this process: starting with the preparation for a decision-making process by formulation of the issue and setting the objectives, followed by collection of internal information and external information on the environment of the organisation, next the specification of potential alternatives, then limiting the options by choosing between these alternatives and finally, reaching a decision. As part of our research, we have evaluated whether this model adequately describes the decisionmaking process for actual decisions taken by executives in industry.

For our fieldwork, we first compared several methods by which decisionmaking has been studied in the literature, such as theoretical discussions and analyses of the decision process, case studies, analysis of published accounts of decisionmaking processes, surveys or questionnaires, 'hands-on' laboratory experiments and interviews with decision makers. We choose to use the last method, of personally interviewing executives, discussing by which process they have reached some recent decisions, because in this way we could accurately collect relevant first-hand data on the way they undertook the decision-making process and observe how they used information in specific recent issues that came on their agenda. The responding executives were all members of the Board or executives directly reporting to the Board of companies in the chemical and food processing industry with a turnover of $€ 300$ million or more in The Netherlands and to a lesser extent in Germany. We chose that segment of the industry as our target group because this limited segment of industry could be covered by a significant number of interviews to be able to generalise our findings about the decision-making processes and the use of information thereby to the population of companies in the process industry.

We identified and discussed in detail thirty-two issues that had recently prompted a strategic decision by the executives and we are able to identify 102 explicitly stated decision process descriptions of the distinct phases followed during the strategic decision-making processes. Almost all processes start with a 'preparation' phase, the grounding for the decision-making process; issues originate from internal as well as environmental developments and trends. The next phase is that of collecting and analysing of information, this phase generally does not have a distinct beginning or an 
end as during the decision process, continuously new aspects of the issues flare up that require additional information to be gathered and analysed for relevancy, quality and reliability. In cases where the analysis phase was mentioned specifically, it was also possible to distinguish between internal and external information sources. The intermediate specification of alternatives and planning phase results in a number of alternative scenario's; all relevant information has now been collected, analysed and studied. Even so, taking the final decision in some cases still necessitates an intense discussion among Board members.

If we correct our analysis of all 102 decision-making processes for those instances that a phase was not deemed necessary, we see that in all cases to be decided on, all 5 phases that we defined and used in our model that needed to be pursued, were indeed consistently followed.

Based on the analysis of the phases discussed during the interviews, we propose to add one extra phase to the model, i.e. the assessment of the outcome of the specified alternatives. This phase we identified in about $20 \%$ of the processes; it follows the 'limiting' phase but precedes the final decision in that it is a check whether the potential alternatives chosen do not unnecessarily harm the company's interests e.g. by 'value dilution'. The additional assessment phase has not been used often, but is relevant as it shows that in order to come to a decision, in some cases rationality requires that additional information is studied to be able to appreciate the consequences of each otherwise valid alternative.

In rational decision-making, information relevant to the issues that have to be decided plays a crucial role in each phase of this process; executives have to acknowledge the facts in order to be able to consider an issue. The main reason for the use of information is a reduction of uncertainty needed to obtain the answer to an issue at hand. The value of information for strategic decision-making is supported by the results of our research. The information used in the decision-making process can be distinguished in internal information based on data such as that pertaining to technical processes, financial parameters, and the customer base on the one hand and external information on developments in the technical, commercial and social/legal environment of the company on the other hand. Most companies have a department responsible for documentary information such as an information services department', often connected to the library. This information department is usually concentrated in the research location of the company. But several executives do not see the need for such departments nowadays because they interpret the new access methods to information supported by software as facilitating disintermediation: "employees can nowadays easily search for and find their own information".

In most companies developments in the environment of the company are monitored so that the Board is at every moment prepared for an issue to arise. Regular detailed internally generated reports on trends in production, supply and demand, market shares and financial matters are now common practice. Similarly, in most companies data on competitors' behaviour are collected by 'competitive 
intelligence' and from specialised consultants and these are analysed regularly by staff departments for relevant issues for the Board and stored in an internal database. Often selected information from this database is available on the company Intranet.

Based on the results of our fieldwork and analysis we have come to judge whether we can confirm the statements made in our four hypotheses. The test of our first hypothesis is fourfold: firstly, to test if the issues brought up for decision are indeed of a strategic nature, secondly, whether there are clearly distinguishable phases followed in the process, thirdly, if the process can be characterised as a rational process rather than a satisficing or intuitive process and lastly if all relevant information is used in the decision-making process.

As we have indicated, in all decision-making processes discussed, strategic issues were the subject of the decisions and all five phases that we had deemed necessary for a structured process were indeed followed. Furthermore, we note the similarity of the description of the phases encountered in the decision processes that were discussed with the executives and the fit with our model.

These results are both confirmations of hypothesis 1 . The results of our research as discussed on the use of information in the decision-making process confirm our hypothesis 2 . Moreover, we have observed that this information is used to provide a rational underpinning of the decisions made in each phase. This conclusion also constitutes a test to the rational aspect of hypothesis 1 .

Another scrutiny method that we used to test rationality consists of observing whether there are arguments that point to other than the rational approach to strategic decision-making such as those mentioned in part of the literature on strategic management. The result is that we did not observe during our interviews any indication of these arguments, such as unduly great time pressure, 'satisficing' solutions or 'bounded rational' decisions due to limited cognitive capabilities of executives or of lack of information that might have resulted in intuitive approaches, nor did we find any signs of internal conflicts or political manoeuvring about which way to proceed or undue avoidance of uncertainty. As discussed here, all four tests for the hypothesis 1 are positive.

In all discussions held, the aspect of the quality of information used by the Board was stressed. Generally, information that arrives 'bottom up' is trusted more than information provided by external sources. Correct strategic decisions can only be taken on correct and full information. Sources of information that are selected and consulted are multiple and depending on their origin and credibility are taken at face value or put up for scrutiny by experts, be it internal or external. Staff departments responsible for supplying information to the Board check external information for robustness before it is delivered to the Board. If the quality of the information is not up to standard or cannot be verified, it is put aside. But even so, executives do often check information themselves, one reason being that staff departments are not always aware of the strategic plans of the Board. These considerations confirm that 
hypothesis 3 can be accepted as a true representation of practise by executives in industry.

Changes in availability of information have brought changes in the way information is used in companies. But information overload because of too many sources or too many documents is not an issue that was mentioned. Apparently, these executives and their staff departments apply effective coping mechanisms to deal with the stream of information reaching them.

The facilitation of global knowledge exchange brings with it the fact that competition becomes fiercer as any innovation becomes public earlier than before and time to react is correspondingly shorter. Some companies are able nowadays to perform research on a worldwide 24-hour schedule, they "forward results as a baton in a relay race" to their affiliates anywhere in the world. These developments show that external information sources thus play a more important and valuable role in decision-making by industry management than was possible before. Although we agree that much more information is now available, several executives remarked that "this does not necessarily mean that decisions can be made faster: evaluation of this greater mass of information takes more time and not everything is yet available electronically."

We conclude that even if there can be no proof, the indications for an increased influence of ICT achievements over the last few years on many cases of the process of strategic decision-making sound convincing. Although this positive effect is hard to substantiate conclusively, we have shown several indications to this effect. We have shown that such an improvement can be characterised as a change in the decisionmaking model with more sources being consulted. With more relevant information available, discussions on issues affecting the choices and alternatives can now be better controlled which confirms hypothesis 4 which can be accepted as a valid statement.

From the results of the research, we consistently observe indications that executives that are responsible for strategic management of industrial organisations follow a structure as given in our model of the decision-making process even though a broad spectrum of issues has to be resolved.

We therefore can conclude that these executives follow a structured and phased course that is rationally valid and reflected on, that they have operated judiciously when taking important strategic decisions for their organisation and that they display no sign of hasty or irrational behaviour leading to bounded rational or satisficing decisions. 


\section{Het proces van strategische besluitvorming: De rol van informatie}

\section{Samenvatting}

De focus van dit proefschrift ligt op het gebruik van informatie bij het proces van strategische besluitvorming door het bestuur van productiebedrijven en in hoeverre dit proces is veranderd in de afgelopen jaren, bijvoorbeeld onder invloed van de toegenomen beschikbaarheid van informatiebronnen. De nadruk daarbij ligt op het proces, niet op de daaruit voortvloeiende beslissing.

Besluiten genomen door het bestuur van grote bedrijven zijn meestal van strategische aard, ze zijn complex, niet-routinematig, kunnen niet eenvoudig worden afgewikkeld met bestaande procedures en zijn nog niet eerder in dezelfde vorm voorgekomen. De strategische problemen die wij hebben bestudeerd betreffen aanzienlijke veranderingen zoals strategie ontwikkeling, fusies en overnames, grote investeringen en soms desinvesteringen, nieuwe producten en nieuwe markten, make-or-buy opties, wijzigingen in de organisatie en strategieën voor de planning op langere termijn.

Veel studies in strategisch management verdedigen het standpunt dat bestuurders strategische beslissingen nemen na een gestructureerd proces van zorgvuldige afweging van de omstandigheden, alternatieven en consequenties. Informatie over zaken als concurrentie, markten, technologieën en de maatschappelijke ontwikkelingen die van invloed zijn op de organisatie laten de consequenties zien van de alternatieven voor het te nemen besluit en deze informatie speelt een cruciale rol bij het verkrijgen van de kenmerken van deze alternatieven. Bij het nemen van besluiten veronderstellen we dat er voldoende informatie beschikbaar is voor een directeur of een Raad van Bestuur om het best mogelijke besluit te nemen onder de heersende omstandigheden.

Dit standpunt is echter niet onomstreden. In diverse studies wordt gesteld dat de mens beperkte cognitieve vermogens heeft en slechts een beperkt deel van de informatie die beschikbaar is kan begrijpen en gebruiken. Als gevolg daarvan zijn zij afhankelijk van 'begrensd ('bounded') rationele processen' in plaats van 'rationele processen'. Bij strategische besluitvorming leidt dit tot de opvatting dat bestuurders tot besluitvorming komen in een in feite ongestructureerd proces waarbij zij genoegen nemen met bevredigende ('satisficing') in plaats van optimale oplossingen. Nog een andere zienswijze is dat in sommige gevallen besluiten die voornamelijk gebaseerd zijn op een intuïtief proces tot even goede resultaten kunnen leiden.

Ons onderzoek is gericht op het gebruik van informatie, omdat wij van mening zijn dat dit een factor is die van invloed is op de structuur van de strategische besluitvorming. Dit impliceert dat een bestuurder die een rationele benadering volgt tijdens de gestructureerde besluitvorming volop informatie verzamelt en gebruikt gedurende een aantal afzonderlijke, tijdsgebonden fasen. In dit proces speelt informatie een uiterst belangrijke rol. De bestuurder die genoegen neemt met een 
slechts bevredigende uitkomst, neemt een besluit gebaseerd op een beperkt gebruik van de beschikbare hoeveelheid informatie en de besluitvorming is minder gestructureerd. Voor de intuïtieve bestuurder, kan de exacte rol van informatie niet worden bepaald en de besluitvorming is ongestructureerd omdat voornamelijk vroegere ervaringen en kennis de basis vormen voor de beslissing in zo een intuïtief proces. De wijze waarop informatie wordt gebruikt bij het besluitvormingsproces verschilt dus in elk van de drie benaderingen van dit proces. Onderzoek naar de rol en de omvang van het gebruik van informatie in het proces kan dus een factor zijn die helpt bij het beoordelen welke benadering van de besluitvorming bestuurders in feite volgen.

De inhoud van strategische management informatie wordt in deze context zelden expliciet besproken of geanalyseerd; bovendien wordt informatie in veel studies over bedrijfsvoering beschouwd als een productiefactor die altijd 'vanzelfsprekend' bereikbaar en beschikbaar is voor het proces. In de afgelopen jaren is het aantal bronnen van management informatie toegenomen als gevolg van de verandering van het Internet van een systeem voornamelijk gericht op onderzoek tot een systeem dat door zijn gevarieerde inhoud ook een bron is van relevante informatie voor zakelijke toepassingen. Vanwege deze ontwikkelingen is de vraag niet langer of bepaalde informatie beschikbaar is, maar waar deze in de kortst mogelijke tijd kan worden gevonden. Ook zijn er nieuwe methoden beschikbaar gekomen voor het verzamelen van informatie in elke fase van het besluitvormingsproces, zoals bij de voorbereiding van het proces en van de argumentatie en ook voor het verzamelen, documenteren en vergelijken van alternatieven, waardoor er sneller en comfortabeler keuzes gemaakt kunnen worden. Er is een risico verbonden aan deze toegenomen beschikbaarheid van informatie, namelijk dat men gehinderd kan worden door overbelasting met informatie. Er zijn echter verschillende manieren om het hoofd te bieden aan dit probleem door een goede organisatie van de informatiestroom, eventueel aangevuld door toepassing van computers. Nieuwe ICT-methoden, bijvoorbeeld met behulp van statistische methoden of door vergelijking met andere gegevens, vergemakkelijken het controleren van de betrouwbaarheid van ontvangen informatie uit een onduidelijke bron.

Om conclusies te kunnen trekken voor deze studie, hebben wij aandacht besteed aan diverse aspecten van de eisen te stellen aan informatie zoals de kwaliteit en de bronnen ervan en aan het feitelijke gebruik van beschikbare informatie tijdens het proces van strategische besluitvorming.

In de theoretische hoofdstukken van dit proefschrift hebben we de publicaties over strategisch management die een impliciete invloed hebben op de structuur van het proces van strategische besluitvorming onderzocht en besproken en hebben we een grondige analyse gemaakt van de verschillende benaderingen van dit proces. Vervolgens hebben we een soortgelijke evaluatie en discussie gehouden over de strategische rol van management informatie in het besluitvormingsproces; daarbij hebben we het belang aangegeven van de vooruitgang op het gebied van computer 
programma's die de toegankelijkheid van informatie verbeteren. Omdat het doel van onze studie is het bestuderen van de veranderde rol van informatie als een management instrument, hebben we een kort historisch overzicht gegeven van het belang van de ontwikkeling van de informatie- en communicatie technologie. We hebben daarbij speciaal aandacht besteed aan het Internet, omdat daarmee nieuwe diensten voor de chemische en de levensmiddelenindustrie geboden worden.

Als resultaat van onze theoretische discussie, hebben we vier hypotheses geformuleerd die zijn getest in het veldwerk van dit onderzoek. Hypothese 1 verwijst naar het proces van besluitvorming: 'Strategische beslissingen van bestuurders worden bereikt in een rationeel, goed gestructureerd proces met het doel te komen tot de best mogelijke resultaten onder de voorwaarden die van toepassing zijn in elke specifieke situatie'. In hypothese 2 wordt gesteld dat 'Bestuurders die een rationeel proces volgen, bij het behandelen van een specifieke strategische kwestie alle mogelijke informatie zullen verzamelen die beschouwd kan worden als ondersteunend voor dit proces'. Hypothese 3 behandelt de kwaliteit van de informatie die wordt gebruikt: 'Voordat ze wordt geaccepteerd als relevant, controleren bestuurders grondig (of laten ze deze controleren) de kwaliteit van alle informatie op parameters zoals robuustheid en betrouwbaarheid, wanneer verwacht kan worden dat deze informatie geschikt is als een ondersteunend hulpmiddel voor de besluitvorming'. Hypothese 4 wordt ingegeven door de ICT-ontwikkelingen: 'Verbeterde beschikbaarheid van een groot aantal informatiebronnen, voornamelijk via gespecialiseerde digitale diensten zoals het Internet, heeft een positief effect op het proces van strategische besluitvorming in de industrie'.

Om de analyse van de structuur van het besluitvormingsproces en het toetsen van de hypotheses te vergemakkelijken, hebben we een model ontwikkeld dat de opeenvolgende fasen in dit proces aangeeft: te beginnen met de voorbereiding van het besluitvormingsproces door de formulering van het probleem en het vaststellen van de doelstellingen, gevolgd door het verzamelen van interne en externe informatie over de maatschappelijke omgeving van de organisatie, vervolgens de specificatie van de mogelijke alternatieven, dan het beperken van de opties door te kiezen tussen deze alternatieven en ten slotte het nemen van een besluit. Als onderdeel van ons onderzoek hebben we beoordeeld of dit model adequaat het besluitvormingsproces beschrijft voor beslissingen die zijn genomen door bestuurders in de industrie.

Voor ons veldwerk hebben we eerst verschillende methoden vergeleken waarmee besluitvorming in de literatuur is onderzocht, zoals theoretische discussies en analyses van het proces, case studies, analyse van gepubliceerde verslagen van zulke processen, enquêtes of vragenlijsten, laboratorium experimenten en interviews met bestuurders. Wij hebben gekozen voor het toepassen van de laatste methode, die van persoonlijke interviews met bestuurders, waarbij we hebben besproken welk proces zij bij een aantal recente beslissingen hebben gevolgd; op deze manier konden wij nauwkeurig uit de eerste hand gegevens verzamelen over de manier waarop zij het besluitvormingsproces hebben aangepakt en konden wij observeren hoe zij 
informatie hebben gebruikt in specifieke recente kwesties die op hun agenda kwamen. De geïnterviewde bestuurders waren allen leden van de Raad van Bestuur of bestuurders die rechtstreeks rapporteren aan de Raad van Bestuur van bedrijven in de chemische en levensmiddelenindustrie in Nederland en ook een tweetal in Duitsland, met een omzet van ten minste $€ 300$ miljoen. We kozen voor dit segment van de industrie als onze doelgroep omdat dit beperkte segment van de industrie zou kunnen worden gedekt door een significant aantal interviews waarmee we onze bevindingen over de besluitvorming en het gebruik van de informatie daarbij over de populatie van bedrijven in de procesindustrie kunnen generaliseren.

Wij identificeerden en bespraken in detail 32 kwesties die onlangs een strategische beslissing van de bestuurders tot gevolg hadden en we konden 102 expliciete beschrijvingen van de afzonderlijke fasen gevolgd tijdens deze strategische besluitvormingsprocessen onderscheiden. Bijna alle processen begonnen met een 'voorbereidingsfase', de basis van een besluitvormingsproces; de kwesties bleken afkomstig uit zowel interne ontwikkelingen als ontwikkelingen en trends in de omgeving van de bedrijven. De volgende fase was die van het verzamelen en analyseren van informatie, deze fase had in het algemeen geen duidelijk begin of einde omdat tijdens het besluitvormingsproces voortdurend nieuwe aspecten van de problematiek opkwamen die vereisten dat aanvullende gegevens opgezocht en geanalyseerd werden op relevantie, kwaliteit en betrouwbaarheid. In die gevallen waarin de analysefase specifiek werd genoemd, was het ook mogelijk om een onderscheid te maken tussen interne en externe informatiebronnen. De tussenliggende fase van specificatie van alternatieven en planning resulteerde in een aantal alternatieve scenario's: alle relevante informatie waren dan al verzameld, geanalyseerd en bestudeerd. Niettemin vereiste het nemen van de definitieve beslissing in sommige gevallen nog steeds een hevige discussie tussen de leden van de Raad.

Wanneer we onze analyse van alle 102 besluitvormingsprocessen corrigeren voor die gevallen waarbij een fase overgeslagen kon worden, dan zien we dat in alle zaken waarover beslist moest worden, alle 5 fasen die we noodzakelijk achtten en die we hadden gedefinieerd en toepasten in ons model, inderdaad consequent gevolgd werden.

Gebaseerd op de analyse van de fasen besproken tijdens de interviews, stellen wij voor om een extra fase in het model op te nemen, namelijk de beoordeling van de gevolgen van de in aanmerking te nemen alternatieven. Deze fase vonden we in ongeveer $20 \%$ van de processen; ze volgt op de beperkende fase, maar komt vóór de definitieve beslissing aangezien daarbij wordt nagegaan of de gevonden alternatieven niet onnodig het bedrijf schaden, bijvoorbeeld door verwatering. Deze aanvullende beoordelingsfase komt niet vaak voor, maar is relevant omdat ze laat zien dat om tot een besluit komen, in sommige gevallen rationeel handelen vereist dat aanvullende informatie wordt bestudeerd om de gevolgen van elk redelijk alternatief te kunnen vaststellen. 
Bij rationele besluitvorming speelt relevante informatie over de kwesties die moeten worden beslist een cruciale rol in elke fase van dit proces; bestuurders dienen de feiten te kennen om een kwestie te kunnen beoordelen. De belangrijkste reden voor het gebruik van informatie is om de onzekerheid te verminderen wat van belang is om het antwoord te vinden op een voorliggende kwestie. De waarde van informatie voor het nemen van strategische beslissingen wordt bevestigd door de resultaten van ons onderzoek. De informatie die in het besluitvormingsproces wordt gebruikt kan worden onderscheiden in interne informatie gebaseerd op gegevens met betrekking tot technische processen, financiële parameters en het klantenbestand aan de ene kant en externe informatie over de ontwikkelingen in de technische, commerciële en sociale/juridische omgeving van het bedrijf aan de andere kant. De meeste bedrijven hebben een afdeling of informatiedienst die verantwoordelijk is voor de verzorging van documentaire informatie, vaak verbonden aan de bibliotheek. Deze informatiedienst is doorgaans deel van de R\&D afdeling van het bedrijf. Maar verschillende bestuurders zien tegenwoordig de noodzaak niet meer voor dergelijke diensten, omdat zij menen dat nieuwe methoden voor de toegang tot informatie, ondersteund door software, de vervanging van informatie-intermediairs gemakkelijker maken: werknemers kunnen tegenwoordig moeiteloos hun eigen gegevens opzoeken en vinden.

In de meeste bedrijven worden maatschappelijke ontwikkelingen relevant voor het bedrijf continu gevolgd, zodat de Raad op elk moment voorbereid is op een kwestie die kan ontstaan. Regelmatig verschijnende gedetailleerde intern gegenereerde rapporten over trends op het gebied van productie, vraag en aanbod, marktaandelen en financiële zaken zijn nu algemeen. Ook worden in de meeste bedrijven gegevens over het gedrag van concurrenten verzameld door 'competitive intelligence' en betrokken van gespecialiseerde consultants; deze informatie wordt regelmatig door stafdiensten onderzocht op relevante onderwerpen voor de Raad en opgeslagen in een interne database. Vaak zijn delen van de informatie uit deze databank beschikbaar op het Intranet van het bedrijf.

De resultaten van ons veldwerk en analyse maken het ons nu mogelijk te beoordelen of we de beweringen in onze vier hypothesen kunnen bevestigen. De toets van onze eerste hypothese is vierledig: ten eerste, de test of de kwesties die in aanmerking zijn gekomen voor een besluit, inderdaad van strategische aard zijn, ten tweede, of er duidelijk te onderscheiden fasen gevolgd zijn in het proces, ten derde, of het proces kan worden gekarakteriseerd als een rationeel proces veeleer dan een bevredigend ('satisficing') of intuïtief proces en ten slotte of alle relevante informatie in het besluitvormingsproces wordt gebruikt.

Zoals we al hebben aangegeven, betroffen alle besluitvormingsprocessen die zijn besproken strategische kwesties en werden alle vijf de fases die we noodzakelijk achtten voor een gestructureerd proces inderdaad gevolgd. Bovendien merken wij de overeenkomst op van de besluitvormingsprocessen in de beschrijving van de fases zoals die werden besproken met de bestuurders en het feit dat deze passen in de fases van ons model 
Deze resultaten zijn beide bevestigingen van hypothese 1 . De resultaten van ons onderzoek betreffende het gebruik van informatie in het besluitvormingsproces bevestigen onze hypothese 2 . Bovendien hebben we geconstateerd dat deze informatie wordt gebruikt om een rationele onderbouwing te geven aan de besluiten die in elke fase genomen worden. Deze conclusie vormt ook een toets voor het rationele aspect van hypothese 1 .

Een andere controlemethode die wij gebruikten om rationaliteit te toetsen bestaat uit het observeren of er argumenten aanwezig zijn die verwijzen naar een andere dan een rationele benadering van strategische besluitvorming, zoals die wordt genoemd in een deel van de literatuur over strategisch management. Het resultaat is dat we tijdens onze gesprekken geen indicatie hebben gezien van deze argumenten zoals ongewenste grote tijdsdruk, bevredigende ('satisficing') oplossingen of begrensd ('bounded') rationele beslissingen te wijten aan de beperkte cognitieve vermogens van bestuurders of van het ontbreken van gegevens die kunnen hebben geleid tot intuïtieve benaderingen, noch hebben we enig teken gezien van interne conflicten of politiek manoeuvreren over de wijze van optreden of van het onnodig vermijden van onzekerheid. Zoals gezegd, alle vier de toetsen voor hypothese 1 zijn positief.

In alle interviews, werd het aspect van de kwaliteit van de informatie die gebruikt wordt door de Raad benadrukt. In het algemeen wordt informatie die vanuit de organisatie komt meer vertrouwd dan informatie die door externe bronnen wordt geleverd. Correcte strategische beslissingen kunnen slechts worden genomen op basis van correcte en volledige informatie. Daarvoor zijn er vele bronnen van informatie die worden gekozen en gebruikt. Afhankelijk van hun herkomst en geloofwaardigheid worden ze op voorhand vertrouwd of ter toetsing doorgegeven aan interne of externe deskundigen. Stafafdelingen die verantwoordelijk zijn voor het verstrekken van informatie aan de Raad controleren externe informatie op robuustheid voordat deze wordt doorgezonden aan de Raad. Informatie waarvan de kwaliteit niet aan de norm voldoet of die niet kan worden geverifieerd wordt niet gebruikt. Maar niettemin controleren bestuurders vaak zelf nog de informatie; een van de redenen daarvoor is dat stafafdelingen niet altijd kennis hebben van de strategische plannen van de Raad. Deze overwegingen bevestigen dat hypothese 3 kan worden aanvaard als een ware representatie van de praktijk van bestuurders in het bedrijfsleven.

Ontwikkelingen in de beschikbaarheid van informatie hebben veranderingen gebracht in de manier waarop informatie wordt gebruikt in bedrijven. Maar overbelasting door informatie als gevolg van een te veel aan bronnen of documenten is niet een probleem dat werd genoemd. Blijkbaar passen deze bestuurders en hun stafafdelingen effectieve methodes toe bij het omgaan met de stroom van informatie die hen bereikt.

Door de toename van de wereldwijde uitwisseling van kennis wordt de concurrentie feller omdat elke innovatie eerder dan vroeger publiek bekend wordt en de tijd om te reageren navenant korter is. Sommige bedrijven kunnen tegenwoordig 24-uur per etmaal wereldwijd onderzoek uitvoeren waarbij ze de resultaten door- 
geven aan hun vestigingen overal in de wereld "als het stokje bij een estafette". Deze ontwikkelingen tonen derhalve aan dat externe informatiebronnen een belangrijker en meer waardevolle rol spelen bij de besluitvorming door bestuurders in de industrie dan vroeger mogelijk was. Hoewel we het er over eens zijn dat er tegenwoordig veel meer informatie beschikbaar is, merkt een aantal bestuurders op dat "dit niet noodzakelijkerwijs betekent dat de beslissingen sneller kunnen worden genomen: het evalueren van deze grotere hoeveelheid informatie kost meer tijd en niet alle informatie is al elektronisch beschikbaar".

We concluderen dat hoewel er geen bewijs voor is, de aanwijzingen voor een toegenomen invloed van de ICT mogelijkheden in de afgelopen jaren bij veel processen van strategische besluitvorming overtuigend klinken. We hebben deze ontwikkeling op diverse wijzen aangetoond, ondanks dat dit positieve effect moeilijk overtuigend te onderbouwen is. Wij hebben laten zien dat een dergelijke verbetering kan worden gekarakteriseerd als een verandering in het model van het besluitvormingsproces waarbij meer informatiebronnen worden geraadpleegd. $\mathrm{Nu}$ meer relevante informatie beschikbaar is, kan de discussie over zaken die invloed hebben op de keuzes en alternatieven beter worden beheerst, wat onze hypothese 4 bevestigt en die daarmee dus kan worden aanvaard als een geldige verklaring.

Uit de resultaten van ons onderzoek, zien we steeds dat bestuurders die verantwoordelijk zijn voor het strategisch management van industriële ondernemingen consequent een structuur volgen zoals die in ons model van de besluitvorming wordt voorgesteld, ook al moet een breed spectrum van onderwerpen worden behandeld.

We kunnen dus concluderen dat deze bestuurders een gestructureerde en gefaseerde weg volgen die rationeel is en waarover is nagedacht en dat zij deskundig zijn opgetreden bij het nemen van belangrijke strategische beslissingen voor hun organisatie en dat ze geen tekenen van overhaast of irrationeel gedrag tonen dat zou kunnen leiden tot beperkt rationele of slechts beperkt bevredigende beslissingen. 


\section{List of figures}

Figure 1: A parallel process model of strategic decision making (Corner et al. 1994).

Figure 2: The transactional representation of decision-making (Nutt, 1993).

Figure 3: Model proposed in this study for the structure of the decision-making process.

Figure 4: Model comparing rational decision-making versus bounded rationality

Figure 5: Strategic role of information.

Figure 6: The world of business intelligence

Figure 7: Matrix showing a topology of information products and services

Figure 8: Types of company information systems

Figure 9: Trends of ICT influence on industrial development.

Figure 10: Information input into enterprise management system.

Figure 11: Type and number of companies interviewed

Figure 12: Function of the executives that were interviewed.

Figure 13: Suggested model for the strategic decision-making process. 


\section{Annex 1 Description of phases in the decision process.}

\section{A1. Preparation: Internal issues requiring a strategic decision}

Over the last few years it became clear that existing facilities needed extensive renewal.

- The restructuring was initiated by Head Office that observed negative developments in sales and profits.

- The decision to sell one of the divisions in order to concentrate on core products was taken by Head Office that observed negative developments in sales and profits.

- Ineffective decision lines gave rise to the decision to restructure the management.

- $\quad$ This decision was needed to concentrate on core business for profitability reasons.

- Initiated by the obsolete state of the present technology and production facilities.

- $\quad$ Initiated by split off from parent company, team of experts installed to specify targets.

Essential software did not function properly; a paper was prepared for the Board.

- $\quad$ The large number of acquisitions and mergers resulted in fragmented data models that had to be standardised in order to be effective company-wide.

- $\quad$ In response to an internal requirement, a flagging paper was prepared for the Board.

- $\quad$ In response to an internal requirement, planning started 6 years ago.

- $\quad$ A long standing discussion on a disinvestment took effect.

- $\quad$ Forced by lay-offs and trust in future expansion led to considering this HRM option.

- A new Board with less technical experience took office, so a change in structure of the organization was needed.

\section{A2. Preparation: External issues requiring a decision}

An attractive company was put up for sale by a competitor.

- Developments on the international market were followed closely and the consequences gave reason to start accurate calculations.

- $\quad$ Board needed to start looking for more global presence.

- $\quad$ Constant intelligence, combing through the market; gathering of reliable and up-to-date information identified this opportunity.

Already for 5 years this company was seen as a desirable 'bride', but only now the owner was willing to discuss take-over.

- Technical ageing of the present facility and forthcoming environmental requirements gave occasion to a study into possible solutions.

- $\quad$ The need arose from an external request, as part of a continuous process. 
- $\quad$ Decision by Head Office, driven by societal discussions on the environment and safety.

- $\quad$ At the time the data gathered seamed sufficient to give the go-ahead for the transition.

- Continuous screening of national and international developments for useful areas of research.

- $\quad$ Continuous screening of national and international developments for potential acquisition candidates.

\section{B1. Analysis: Internal data to be collected}

Internal analysis showed that profitability of a production line was to insufficient.

- $\quad$ Both products were known to be produced in similar processes and are used synergetically so would form a welcome addition.

- $\quad$ However, the large bid by a competitor was calculated to be more than we were willing to pay.

- $\quad$ Comments about the forthcoming processes were solicited, mostly from middle level management.

- $\quad$ Continuous monitoring of maintaining the strategy set out initially and of adaptation by the groups involved has to ensure that the proper development is chosen.

- Use of internally available information and contributions from internal echelons were collected.

- Local ICT-managers were contacted and came to agree on a preferred data model.

- $\quad$ Thorough scrutiny of all processes in company for risks, losses, wastes etc.

\section{B2. Analysis: Internal and external data studied}

Due diligence involved to collecting sufficient financial, economic, juridical and market share data, as well as technical and operational information on the intended company.

- Internal and external implementations of KM/Intranets were studied.

- $\quad$ Several members of the RvB gathered information in comparable organisations.

- One of the Board members examined and reported on the value of this investment as a communication tool in relation to costs involved.

- $\quad$ A study was initiated in order to collect data on the issue to be decided.

- $\quad$ A study was commissioned into possible solutions to both issues.

- $\quad$ In the study, deficiencies in safety and long term efficiency were pinpointed.

- $\quad$ The analysis of profitability led to a disinvestment decision.

- $\quad$ Many items had to be studied and each required its own information sources and internal expertise; specialised consulting firms, banks etc. assisted in this process.

- $\quad$ The new Board analysed the situation and found unneeded complexity, lack of discipline, loss of market share etc. 
Economic and spatial analyses were made and local authorities were consulted; similar developments elsewhere were noticed and cost/benefit calculations made.

- $\quad$ Analysis of outsourcing option cost benefits, long term profitability assessed.

- $\quad$ Alternative solutions and their parameters were studied by a large group of people during several months.

- $\quad$ Promising areas were tested for applicability in own environment and probed whether further research was needed.

- Shareholders were consulted and the opinion of the management of the Division involved was sought.

- $\quad$ Explore changes in markets, customer base, products, environment, internal performance. Consult internal stakeholders.

\section{Specification of alternatives}

- As the situation was critical, a short-term plan of action and strategy was formulated that could be commented on and this was refined about a year later.

- $\quad$ An investigation was started to see if further research could be shared with other parties.

- A confidential planning document was prepared after consultation with key staff.

- $\quad$ Blueprints were drawn up and revised as years went by.

- $\quad$ Detailed plans including strategies, implementation steps and budgets were drawn up.

- $\quad$ As required by Head Office, a 10 year plan was made with options for faster implementation.

- $\quad$ A tender was put up for bids on the division/production facility to be divested.

- $\quad$ Suppliers were asked to tender for the contracts according to strict procedural rules of Head Office.

- A bidding process was initiated and several suppliers were asked for their vision and pricing.

- $\quad$ Negotiations with the other shareholders and organising an auction process took about a year.

- $\quad$ Envisage optimal use of fitting parts of company to be acquired and merger of less fitting parts with own division intended to be divested.

- $\quad$ The Project Management Office of Head Office was involved in the planning phase.

\section{Choices to be made}

Gradually conviction was reached that a proactive course was the better one to take.

The analyses showed that one solution was to be preferred over the others on grounds of costs, market trends, customer distribution, supply facilities etc. The choice between the alternatives was made on the basis of mostly economic principles, tradition versus much increased efficiency. 
- $\quad$ The choice of measures to be taken was based on observations on structure and culture and business information obtained from Head Office.

- Experience in similar take-overs facilitated the choice. But crucially, not hesitating to lose the deal must be an option if one does not want to spend more money than is justified.

- Preparation seemed to have been so thorough and pointing in one direction, that no further choice needed to be made.

- $\quad$ The choice was made for a standard ERP package based on experiences in similar industries.

\section{E. Assessment of outcomes}

After acquisition of a competitor facility, reshuffling of product groups led to new ideas.

- $\quad$ Calculations showed that the investments needed were not in line with the company's strategy. At the same time an alternative solution was identified.

- $\quad$ Targets are set on all goals according to the information gathered in previous phase.

- $\quad$ The result of the project team studies indicated the direction to go ahead, but left detailed development of the options to the local management.

- The choices were in an ongoing process of assessment-report generation.

\section{F. Final decision}

- $\quad$ The plan was presented to Board of Directors and accepted in view of positive view on the future of the Division and the need for rapid innovations.

- $\quad$ The decision was reached unanimously by RvB after proper preparation.

- The decision was made by the Board of Directors with consent of the Supervisory Board, taken into account strategic fit and cash available.

- $\quad$ The decision was reached by the Board after small adaptations.

- $\quad$ The decision was reached by the Board based on technical opportunities and financial requirements.

- $\quad$ Positive decision was given after review and all options were under control.

- $\quad$ As the price offered was reasonable, the decision followed naturally.

- $\quad$ Based on outcome of an auction process a decision could be made.

- $\quad$ The scheme was approved by the Chairman and the Board of Head Office.

- $\quad$ Partner companies were contracted and the go-ahead for the investments was given by Head Office.

A go-ahead was given by the highest authority in the Group after a check of arguments. 
Annex 2 Companies from which executives were interviewed for this study.

- $\quad$ AkzoNobel

- CSM

- Dow Benelux

- Koninklijke DSM

- $\quad$ Koninklijke Grolsch

- Henkel

- Hercules NL

- Lanxess

- Quest International

- $\quad$ Shell Chemie NL

- Sabic NL

- TNO

- Unilever NL

Wavin 


\section{(5) \\ University of Twente \\ The Netherlands}

Mr. Name

Company n.v.

P.O. Box .....

Your reference

Phone

0793213167

Our reference

clc/2006/23new

Fax

0842236482

Date

14 November 2006

Email

c.l.citroen@utwente.nl

Subject $\quad$ Research into strategic decision making

Dear Mr. Name,

At the moment I am engaged in the fieldwork for my PhD study on the subject of 'Changes in decision processes through application of new information resources and systems'.

This research concentrates on the strategic decision process in companies in the chemical, pharmaceutical and food industries, focussing on the role that information plays in that process.

The research is part of a programme at the University of Twente, at the School of Business, Public Administration and Technology under direction of Professor Hans Roosendaal. In this research programme, the value chain of information is studied, particularly how it is influenced by technology.

I collect the data for this research through personal interviews with executives of companies in the above sectors. I have already interviewed executives of firms such as CSM, Dow Benelux, DSM, Quest International, Shell Nederland Chemie and Wavin. As you are an executive of a company very relevant to my subject area, I should appreciate it if you or a colleague on the Board would agree to be interviewed about 2 or 3 strategic decisions that you have taken recently.

The content of our conversation of course will remain confidential. If you would prefer me to treat respondents anonymously in the final report, this will be done; if needed, I can additionally sign a non-disclosure agreement.

A synopsis of my research project and a short curriculum vitae are included.

I do hope that you are willing to make one hour available for this interview in the near future; I will contact you in the next week to see if I may make an appointment.

Yours sincerely,

Charles L. Citroen.

Palestrinarode 38, 2717 GB Zoetermeer

c.l.citroen@utwente.nl 


\section{Annex 3 E-mail questionnaire}

Sent out to members of the discussion list of chemical information professionals.

Dear Donna,

I would very much like to receive some input from you on the subject of 'Information flow to the executive/Board level in (chemical) industry' - which is the topic of my doctoral research.

(I have been a member of the ACS Chemical Information Division since 1968 and have worked for many years as an information scientist for industry mostly in The Netherlands).

Some people say that nothing has changed in the way decisions are reached in the Board room with the arrival of Internet and other innovative information services, others are more optimistic and belief that executives are well aware of the kind of information resources that can be tapped nowadays.

So please help me find out how these matters are organized in the USA (or another country) and answer the 4+ questions that I have listed below, of course they will be recorded anonymously.

1. Are (some of the) information services that you supply directly delivered to the Board of your company?

--Yes --No.

1a. If so, do these mostly answer ad hoc questions from the Board, are they delivered at your own initiative or supplied on a regular basis?

--Ad hoc

--Own initiative

--Regularly

1b. If not so, are you aware whether your information services reach the Board of your company through an intermediate level in your company (such as the marketing department or a strategic planning department)?

--Yes --No.

1c. Or alternatively, are the information services that you supply mostly used as input for reports that are produced by e.g. the marketing department or a strategic planning department?

--Yes --No.

2. Do you have an indication whether executives in the Board are aware of information resources that have become readily available over the last few years through new mechanisms such as Internet search engines, alerting services, RSS feeds etc, covering important items such as prices, markets, competitor data, patents etc.? 
If you care to, can you roughly describe your function in the company and give an indication if this is a company in base chemicals, fine chemicals, food chemicals, engineering, the pharma industry or other?

This is a request directed at you as a chemical information scientist that works in industry, I have selected addresses from the CHMINF-List of which I am a long-time member, (so this isn't spam).

Thank you very much for your help, my report is expected to be out in 2008 .

||||||||||||||||||||||||||||||||||||||||||||||||||||||||

Charles Citroen

Senior PhD student

38 Palestrinarode, 2717 GB Zoetermeer NL

Tel.: +31(0)793213167

e-mail: c.l.citroen@utwente.nl or c.citroen@hccnet.nl

web: home.hccnet.nl/c.citroen 


\section{Annex 4 Sample of web pages with business information for the chemical and the food industries.}

\section{www.company.info Friesland Foods}

\section{frieslandfoods}

Adres $\quad$ Route I Kaart
Koninklijke Friesland Foods N.V.
Blankenstein 142
7943 PE
Postbus 124
7940 AC Meppel
Nederland
t: +31 (0)522 276276
f: +31 (0)522 276444
www.frieslandfoods.com
www.coberco.com
id: 01070161
G Uittreksel

\section{Organisatie}

Friesland Foods is een internationaal opererende onderneming die natuurlijke, voedzame en zuivelproducten, vruchtendranken en ingrediënten ontwikkelt, produceert en vermarkt.

De omzet van Friesland Foods over 2006 was $€ 4,7$ mld de winst bedroeg $€ 128$ $\mathrm{mln}$. Het aantal werknemers (2006) is 15.312. Friesland Foods N.V. is ingeschreven in het handelsregister op 30-12-1994.

Sector: Groente- en fruitverwerking | Zuivelproductenvervaardiging | Maaltijd en maaltijdingrediënten

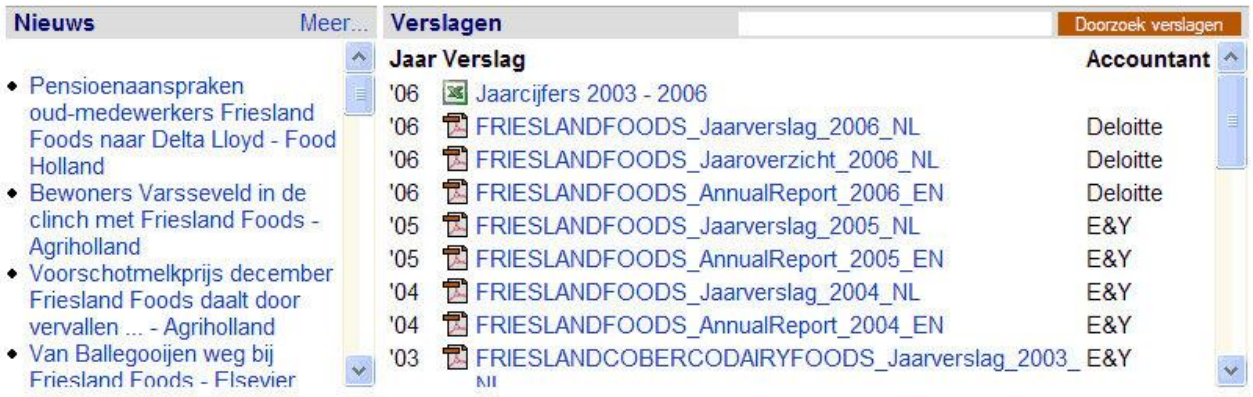

\section{Persberichten}

\section{Datum $\vee$ Nieuws $\vee$}

12-11-2007 Vernieuwde wei-eiwit fabriek Friesland Foods Domo in Workum Friesland Foods Domo heeft de vernieuwde fabriek voor de productie van wei-eiwitten in Workum in gebruik genomen. Met de uitbreiding van de productiecapaciteit...

01-10-2007 Friesland Foods verhoogt voorschotmelkprijs met 6,00 euro Friesland Foods verhoogt de voorschotmelkprijs voor leden-melkveehouders met 6,00 euro per 100 kilo melk met ingang van oktober. De eiwitprijs bedraagt 7,27 .

01-10-2007 Friesland Foods Domo selects IMCD as its European distribution partner Introduction: Friesland Foods Domo is concentrating its pharmaceutical and food ingredients distribution with one partner: IMCD. This decision is part of... $\checkmark$ Categorie $\vee$ Investments, Strategy

Products

Strategy

\begin{tabular}{|c|c|c|c|c|c|c|}
\hline \multirow{2}{*}{$\begin{array}{l}\text { Structuur } \\
100 \% \text { Aandeelhoudersrelaties }\end{array}$} & \multicolumn{3}{|l|}{ Management } & \multicolumn{3}{|c|}{ Excel | EUittreksel } \\
\hline & Naam $\vee$ & Functie $\vee$ & $B C G \vee$ & Leeft $\vee$ & In functie $\vee$ & $\wedge$ \\
\hline \multirow{13}{*}{$\begin{array}{l}\text { Zuivelcoöperatie Friesland } \\
\text { Foods U.A. } \\
\text { L Koninklije Friesland Foods } \\
\text { N.V. } \\
\text { L Friesland International } \\
\text { B.V. } \\
\text { L Friesland Brands B.V. } \\
\text { L Friesland Foods B.V. } \\
\text { L Friese Ekologische } \\
\text { Zuivel B.V. } \\
\text { L Kaashandel } \\
\text { Culemborg B.V. } \\
\text { L A.L. Hoogesteger } \\
\text { Fresh Specialist B.V. } \\
\text { L Bontje Kaas B.V. } \\
\text { L Consalac B.V. }\end{array}$} & Boudewijns, André & Bestuurder & B & 52 & 2005 & \\
\hline & Priem, Johannes & Concerndirecteur & $\mathrm{B}$ & 53 & 1997 & \\
\hline & Spierings, Theodorus & Bestuurder & $B$ & 43 & 2005 & \\
\hline & van Ballegooijen, Bertus & Directeur & B & 42 & 2006 & \\
\hline & Attema, Sijbren & Voorzitter RvC & C & 47 & 1997 & \\
\hline & Boer, Pieter & Commissaris & $\mathrm{C}$ & 47 & 1999 & \\
\hline & de Boer, Jentje & Comm & C & 45 & 2004 & \\
\hline & Draijer, Jakob & Com & $\mathrm{C}$ & 62 & 1998 & \\
\hline & Gerritsen, Walter & Commissaris & C & 36 & 2005 & \\
\hline & Jorritsma, Jorrit & Commissaris & $\mathrm{C}$ & 53 & 1999 & \\
\hline & Keurentjes, Franciscus & Commissaris & C & 50 & 2006 & \\
\hline & Peelen, Jan & Commissaris & C & 67 & 2000 & \\
\hline & Scheffers, Hendrik (Henk) & Commissaris & C & 59 & 2005 & \\
\hline
\end{tabular}




\begin{tabular}{|c|c|c|c|c|c|}
\hline \multirow[t]{2}{*}{ Balans (Geconsolideerd) } & \multicolumn{4}{|c|}{$31-12-200331-12-200431-12-200530-12-2006$} & \multirow{2}{*}{$\begin{array}{r}\quad 05 \rightarrow{ }^{\prime} 06 \\
\% \\
\end{array}$} \\
\hline & $x € 1.000$ & $x € 1.000$ & $x € 1.000$ & $x € 1.000$ & \\
\hline \multicolumn{6}{|l|}{ Activa } \\
\hline \multicolumn{6}{|l|}{ Vaste activa } \\
\hline Immateriële vaste activa & 591.000 & 571.000 & 606.000 & 606.000 & $0 \%$ \\
\hline Materiële vaste activa & 774.000 & 789.000 & 855.000 & 835.000 & $-2 \%$ \\
\hline \multirow[t]{2}{*}{ Financiële vaste activa } & 38.000 & 43.000 & 44.000 & 28.000 & $-36 \%$ \\
\hline & 1.403 .000 & 1.403 .000 & 1.505 .000 & 1.469 .000 & $-2 \%$ \\
\hline \multicolumn{6}{|l|}{ Vlottende activa } \\
\hline Voorraden & 415.000 & 429.000 & 455.000 & 490.000 & $8 \%$ \\
\hline Overige vorderingen & 103.000 & 88.000 & 81.000 & 120.000 & $48 \%$ \\
\hline Handelsdebiteuren & 400.000 & 390.000 & 405.000 & 427.000 & $5 \%$ \\
\hline \multirow[t]{2}{*}{ Liquide middelen } & 77.000 & 74.000 & 134.000 & 145.000 & $8 \%$ \\
\hline & 995.000 & 981.000 & 1.075 .000 & 1.182 .000 & $10 \%$ \\
\hline Totaal Activa & 2.398 .000 & 2.384 .000 & 2.580 .000 & 2.651 .000 & $3 \%$ \\
\hline
\end{tabular}

\section{Passiva}

\section{Grafieken}

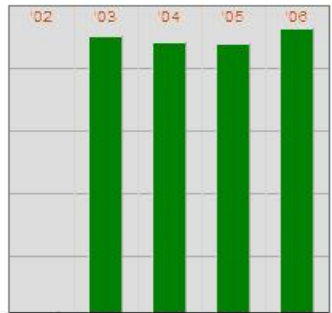

Bedrijfsopbrengsten (omzet)

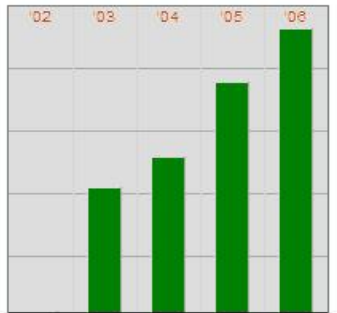

Winst

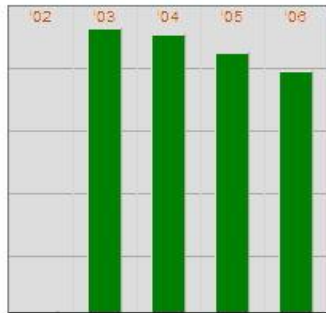

Werknemers

\section{Relevante links}

\section{Sector}

Biologica

FNLI - Levensmiddelen

Nederlandse Zuivel Organisatie

Productschap Zuivel

Productschappen Vee, Vlees en

Eieren

PVE - Vlees, Vis en Eieren

Productschap Tuinbouw

Wet en toezicht

Mrante on Hornoniant

\begin{tabular}{|c|c|}
\hline Marktr & rapporten \\
\hline Datum & Rapport \\
\hline 06-'07 & 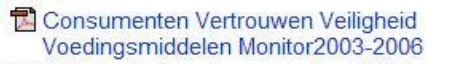 \\
\hline 04-'07 & 包E K O- Monitor Jaarrapportage2006 \\
\hline 03-'07 & ت Sector Trends Zuivelindustrie \\
\hline 03-'07 & 荬 Sector Groente En Fruit \\
\hline 03-'07 & 包 Meerjarenvisie2007-2010 Melkveehouderi \\
\hline 03-'07 & 国 Nederlandse Agrosector2006-2007 \\
\hline $02-^{\prime} 07$ & 国Plantprotection Products E U \\
\hline $02-' 07$ & Agricultural Statistics2007 \\
\hline
\end{tabular}

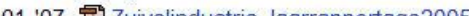

Auteur
VWA
Biologica
ABN Amro
ABN Amro
PZ
Ministerie van LNV
Eurostat
Eurostat
Earilitairo Arranicatio

\section{Peer group} Organisatie

VION Holding

Alfred C. Toepfer International

Vion

Koninklijke Friesland Foods

Cargill

Eurospecialities Foods

Zuivelcoöperatie Campina U.A.

Friesland Foods

Nutreco Holding

\section{Omzet $(€) \quad$ Winst $(€)$ Werkn. EBIT Solv. Winst/werkn. $(€)$ Land Jaar}

$7,340,874,000 \quad 70,313,000 \quad 15,306 \quad 137,037,000 \quad 59 \%$

$\begin{array}{lllll}5,817,254,102 & 46,128,775 & 2,132 & 92,423,838 & 25 \%\end{array}$

$\begin{array}{lllll}5,173,940,000 & 23,249,000 & 8,820 & 56,828,000 & 48 \%\end{array}$

$4,675,000,000 \quad 128,000,000 \quad 15,312 \quad 257,000,000 \quad 37 \%$

$3,772,353,000 \quad 71,090,000 \quad 2,010 \quad 127,894,000 \quad 30 \%$

$3,757,532,000 \quad 65,471,000 \quad 21,431 \quad 253,800,000 \quad 68 \%$

$3,623,600,000 \quad 42,500,000 \quad 6,302 \quad 63,700,000 \quad 33 \%$

$3,161,100,000 \quad 22,100,000 \quad 4,957 \quad 52,400,000 \quad 13 \%$

$3,009,000,000 \quad 520,500,000 \quad 7,305 \quad 114,700,000 \quad 58 \%$
Toon alles | $\mathbf{3}$ Benchmark

$\begin{aligned} 4,594 & \text { NL 2006 } \\ 21,636 & \text { NL 2006 } \\ 2,636 & \text { NL 2004 } \\ 8,359 & \text { NL 2006 } \\ 35,368 & \text { NL 2006 } \\ 3,055 & \text { NL 2006 } \\ 6,744 & \text { NL 2006 } \\ 4,458 & \text { NL 2006 } \\ 71,253 & \text { NL 2006 }\end{aligned}$




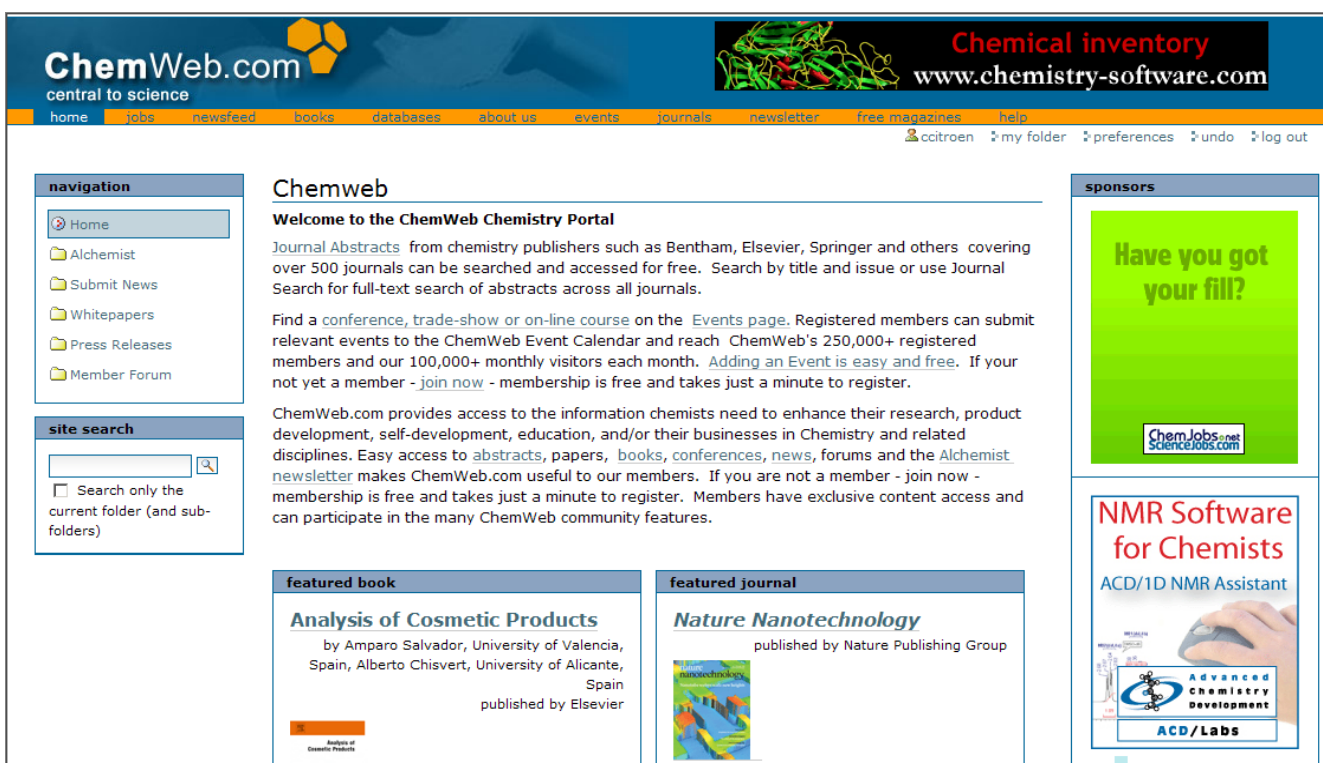

www.chemweb.com

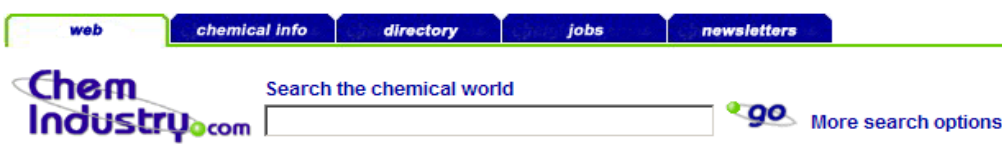

Biotech Polymers Petrochem Agro \& Food Metals \& minerals Lab supplies Environment Chemical info

\section{Industry Sectors}

Chemical Distributors $\cdot$ Custom Manufacturing $\cdot$

Adhesives. Agrochemicals $\cdot$ Automotive $\cdot$ Carbon Prod. Catalysts $\cdot$ Coatings $\cdot$ Construction $\cdot$ Detergents $\cdot$ Food

Ingredients $\cdot$ Dyes $\cdot$ Surfactants $\cdot$ Fibers $\cdot$ Gases . Inorganic $\cdot$ Specialty $\cdot$ Oil \& Gas $\cdot$ Organic $\cdot$ Polymers $\cdot$ Additives $\cdot$ Solvents $\cdot$ Detergents $\cdot$ Lubricants $\cdot$ Metals Petrochemicals $\cdot$ Water $\cdot$ Ceramics $\cdot$ Explosives $\cdot$

Monomers $\cdot$ e-Marketplaces ...

\section{Scientific Equipment \& Lab Supplies}

Research Chemicals • Lab Process Equipment •

Chromatography • Elemental Analysis • Lab

Consumable $\cdot$ Furniture $\cdot$ Glassware $\cdot$ Lab Automation

Microscopy • Particle Size - Physical Measuring •

Spectroscopy ...

\section{Software}

Bioinformatics $\cdot$ CAD $\cdot$ LIMS $\cdot$ Testing $\cdot$ Modeling \&

Drawing $\cdot$ Process Control $\cdot$ Safety \& Enviro. ERP \&

Supply Chain - Simulation \& Optimization...

Resources

Events $\cdot$ Portals $\cdot$ Patents $\cdot$ Calculators $\cdot$ Databases .

News $\cdot$ Journals $\cdot$ Organizations - Academic Institutes

Magazines, newsletter subscriptions • Chemical Expert Consultants ...

\section{Featured Partners}

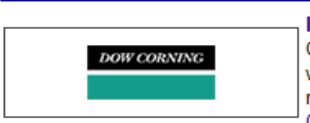

Is there a link between sustainability and innovation?

Companies today must build innovation considerate of energy usage, waste reduction and water consumption. Experts explore the relationship between innovation and long term sustainable development Click for more.

\section{Pharma \& Biotech Industry}

Agrobiomaterials - Animal health $\cdot$ Antibodies . Bioreagents - Tissue Engineering • Clinical Labs • Clinical Research • Blood • Diagnostics • Genomics - Drug Delivery $\cdot$ Enviro Biotech Nutraceuticals $\cdot$ Implants $\cdot$ Intermediates . Libraries - Medical Devices • Pharmaceuticals • Peptides, Proteins, Enzymes ...

\section{Industrial Equipment}

Distributors - Used $\cdot$ Processing $\cdot$ Electrical . Instrumentation $\cdot$ Control $\cdot$ Analyzers $\cdot$ Agitators • Compressors • Glass Lined $\cdot$ HVAC - Material Handling $\cdot$ Packaging $\cdot$ Piping $\cdot$ Pumps $\cdot$ Safety Valves $\cdot$ Centrifuges $\cdot$ Filters $\cdot$ Scrubbers . Classifiers - Tanks $\cdot$ Heat Exchangers $\cdot$ Feeders . Silos $\cdot$ Blenders $\cdot$ Boilers $\cdot$ Chillers $\cdot$ Size Reduction - Conveyors - Calibrations $\cdot$ Lasers Scales - Data Acquisition - Motors - Pharma Equipment • eMarketplaces ...

\section{Services}

Engineering $\cdot$ Business \& Finance $\cdot$ Consultants Construction - IP, Law Firms $\cdot$ Compliance .

Testing $\cdot$ Training $\cdot$ Maintenance $\cdot$ Operating • Technology Transfer • Jobs ..

\section{Chemlndustry.com Newsletter of Useful Sources: This month's selection}

Home Login List your site

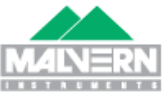

Malvern Instruments Ltd

Featured Suppliers (Ads.)

PEATAYMIDES USED CHEMICAL AND PHARMACEUTICAL PROCESS EOUIPMENT

CEMTRIFUUES

GET RT homet GET HT TOT TESS

Equipment Search $\Leftrightarrow$

Seamlessly Adapting Through Process Improvements, Supply
Chain Flexibility rall Excellen LogiChem 2008

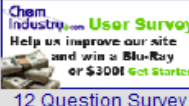

12 Question Survey

Chemjobs.net powered by Sciencelobs.com Chemistry Jobs 


\section{GLO B A LSPEC application notes patents product catalogs}

\section{The Engineering Search Engine'}

Find:

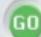

Word Count: dsm (41517)

Find more sites organized by subject here:

Major chemical suppliers

Delft. In Delt z in drie zogenoemde business groups van DSM gehuisvest: - DSM Anti-Infectives - DSM Bakery

Ingredients - DFS Food Specialties [M ore results]

URL: http:itwww.dsm.cominl_Nu'htmlidgs shomepage. htm in Dutch [Translate]

\section{WWW.DSM.COM}

... WWW DSM COM it appears that your..

URL: http: /Ww dsm.com

2. DSM - DSM Markets - Home

DSM - DSM Markets - Home i/* A bout DSM DSM Markets Imestors Media Sustainability

Governance... A Print Contact Sitemap DSM Corporate Go...

URL: http:/hww.dsm.comien_US/htmlibusinessimarkets_home. htm

DSM High Performance Fibers B.V. (Heerlen)

Chemical manufacture

URL: http:imwwidsm.nuhpi [ranslate

3. DSM - Innovatieve producten en diensten op het gebied van Life Sciences en Materials Sciences

... Scienc es en Materials Sciences About DSM DSM Markets Imestors Media Sustainability Governance ... in Print Contact Sitemap DSM ...

URL: http:iswiwidsm.nl

Ne oResins (Waalwijk)

URL: http:i Mww neoresins.com/ [Translate]

\section{DSM NeoResins - Home}

... downloaded in PDF format. DSM has built new factory irDSM NeoResins - Home We offe waterbome...

URL: http:iswiw neoresins.com

DSM Food Specialties Netherlands

Enzymes, cultures, fementation starters, flawur enhancers, yeast extracts, HVPs, natural betacarotene LC.PUFA's, aroma chemic als, preservatives... Health ingredients including arachidonic ac id, pr..

URL: http:itwww dsm-foodspecialties.c omv [Translate]

5. DSM - Food Specialties - Leading producer of food ingredients

... of food ingredients About DSM DSM M arkets Investors Media Sustainability Govemance... in

Print Contact Sitemap DSM .

URL: http:iswwidsm-foodspecialties.com

\section{DSM Engine ering Plastics}

Plastic and polymers manufacturing company

URL: http: / www dsmep com in English [Translate]

6. DSM - Engineering Plastics - Home

... in Print Contact Sitemap DSM Corporate Go Engineering Plastics Applic ationsDSM -

Engineering Plastics - Home About DSM ...

URL: http:iswiwidsmep com

Featured Suppliers (Ads.)

\section{Make a break for Chemjobs.net}
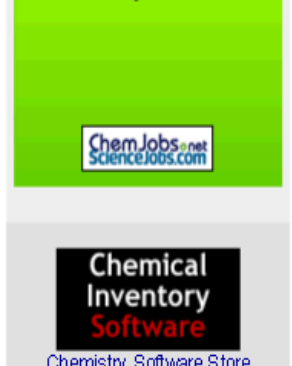

Chemistry Software Store

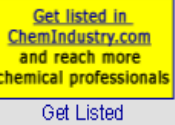

Chemjobs.net powered by Sciencelobs.com

Chemistry Jobs

Popular searches

Popular searches by subject

\section{Resources}

Market research

ChemWeb - chemistry portal

Chemistry jobs

The Alc hemist

Useful Sourc es newsletter

Useful Sourc es archive

Free newsletters

Free magazines

Latest Science Articles 


\section{Free Press Release}

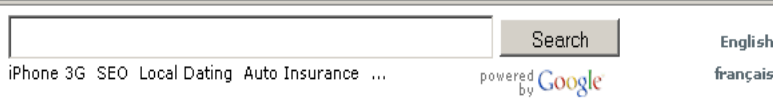

Home | Release Features | Success Stories | Release Tips | Joumal | FAQ | Search | Submit Release | Members'Area

\section{European chemical industry}

\section{Power Market Tools}

Have all your energy market analysis updating livel watovin.intstream.com

\section{REACH}

How will it effect your business? Consulting and

Registration Support

wouve. intertek. comirohs

Chemical 360 by Emergys

Monitor and improve performance; Designed for the

chernical industry

wow.emergys.com

Chemical Storage Systems

High quality custom plastic tanks UK leading manufacture

nutur.torbesgroup.co.uk

\section{AV Ads by Google}

Personal Products Adorning EU Chemical Industry

The European chemical industry has declined from its top slot, giving way to Asia but it hasnâ€' 't lost its position of prominent chemical consumer owing to its stable personal products (2008-01-23)

\section{Expand your search}

Notification Software all american unempoyment paperpiecing scrapobooking bedford pa mind reader corporate showcase paper craft patterns. pots cast iron cookware movie trivia quiz YouandMeinLA.com diving bag Mobile Phone Deals Uk traffic generating articles illuminating message drivemocion Bay area real estate Collin Herring fake checkscam paycheck stub paycheckstub mobster New Gospel Artist
Why Free Press Release? | Login | Register

\section{Submit free press release}

see your news here immediately

\section{Ads by Google}

Chemical Oxidation

Chemical Companies

Textile Chemicals

Chemical Toilet

\section{Promote news}

Charlotte, NC Auto Glass consumers welcom

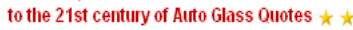

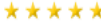

Fixmywindshield.com allows Charlotte, NC consumers to get reasonably priced Auto Glass Quotes 24 Hours a day 7 Days a week. (2008-07-20)

\section{http://europeanchemicalindustry.com}

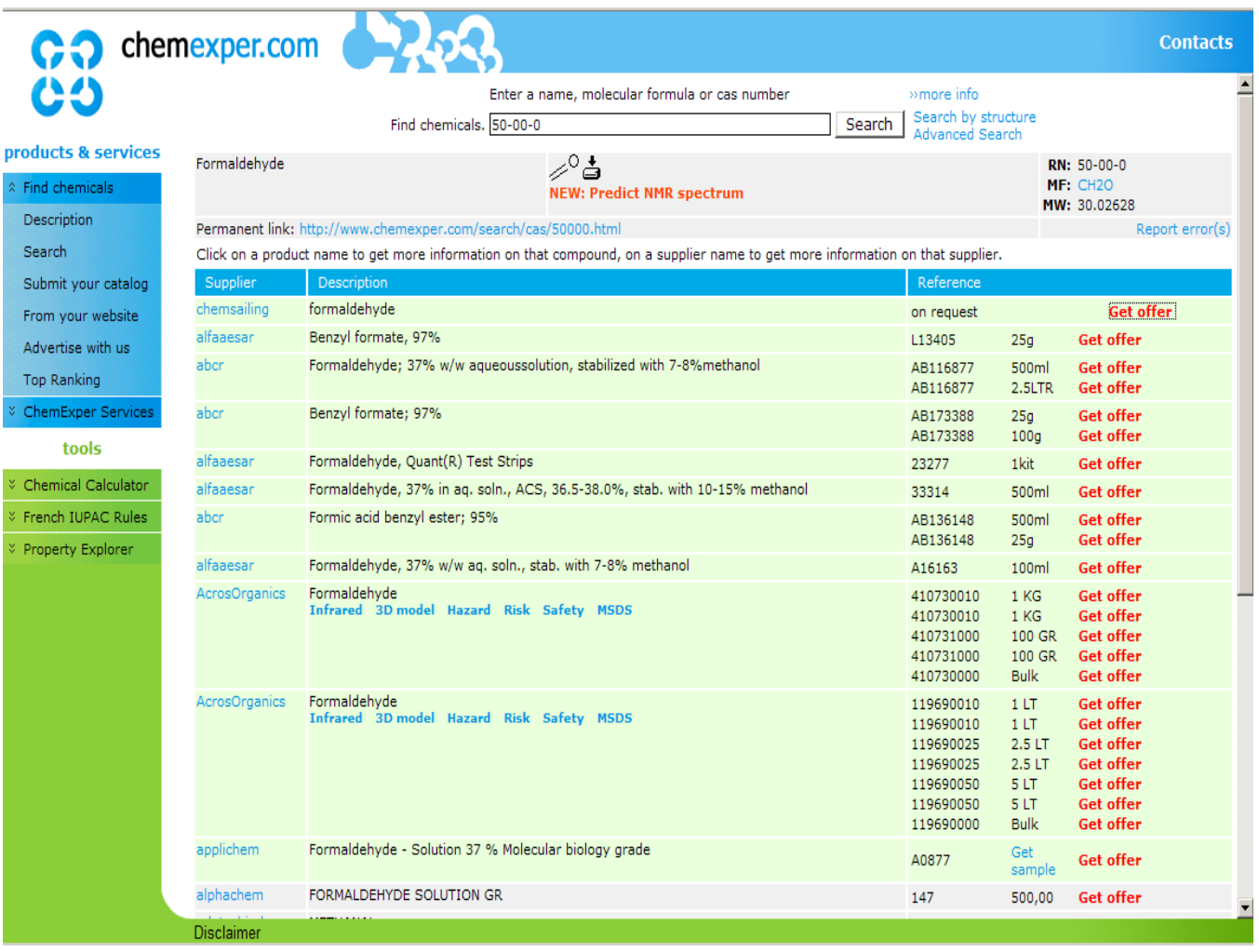


Log in FREE trial request $\square$ FREE e-newsletters sign-up is $\mathrm{R}$

Trusted market intelligence for the global chemical and energy industries
Search ICIS articles

Advanced sea

\section{Home News Prices Magazines Supplier Search Training Events Blogs Forums Audiowisual Intelligence} Chemical Intelligence | Company Intelligence | PremiumOptions | Plants and Projects | Who's Who

\section{Intelligence}

Giving you background on the major players in the chemical industry worldwide and an overview of the main chemicals covered by our ICIS news and ICIS pricing products, the chemical intelligence and company intelligence pages give you essential information to broaden your knowledge. Subscribers have the benefit of additional information via the comprehensive who's who and Plants and Projects databases.

The company intelligence section of ICIS provides you with an overview of the key companies within the chemical industry worldwide; their key activities, structure and details of key personal within the company, as well as links to recent stories relating to that company to allow you to research their latest business developments. Browse the list of companies covered.

Chemical Intelligence provides you with comprehensive information about key groups of cherricals and individual chemicals. Giving background information on the uses of each chemical and an overview of the market in each key region that ICIS pricing reports on for that particular chemical, Cherrical Intelligence pages are a useful resource for finding the latest chemical and cherrical company information.

Browse the categories below or use the Chemic als $\mathrm{A}-\mathrm{Z}$ page to find the information you require.

Bulk industrial chemic als

Inorganic Chemicals

Organic Chemicals

Petrochemicals-Aromatics

Aromatics

Petrochemicals-0lefins

Petrochemicals-0ther

Polymers, Rubbers \& Resins

Who's Who is a comprehensive online directory of full contact details for over 3,600 companies and 11,000

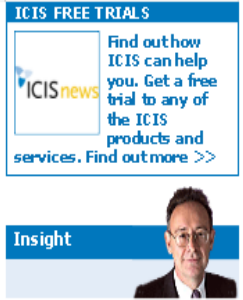

INSIGHT: Making the most of a mini-price

bubble

"There is no disputing that

there has been a real and

tangible improvement in

demand from some

end-users." more

PICISTV More from

lapowiby ICIS radio Americas mebruany 16, 2009
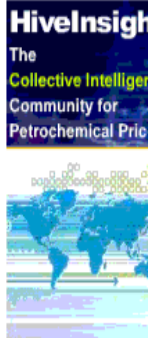

Join the

collective

intelligence

community

for

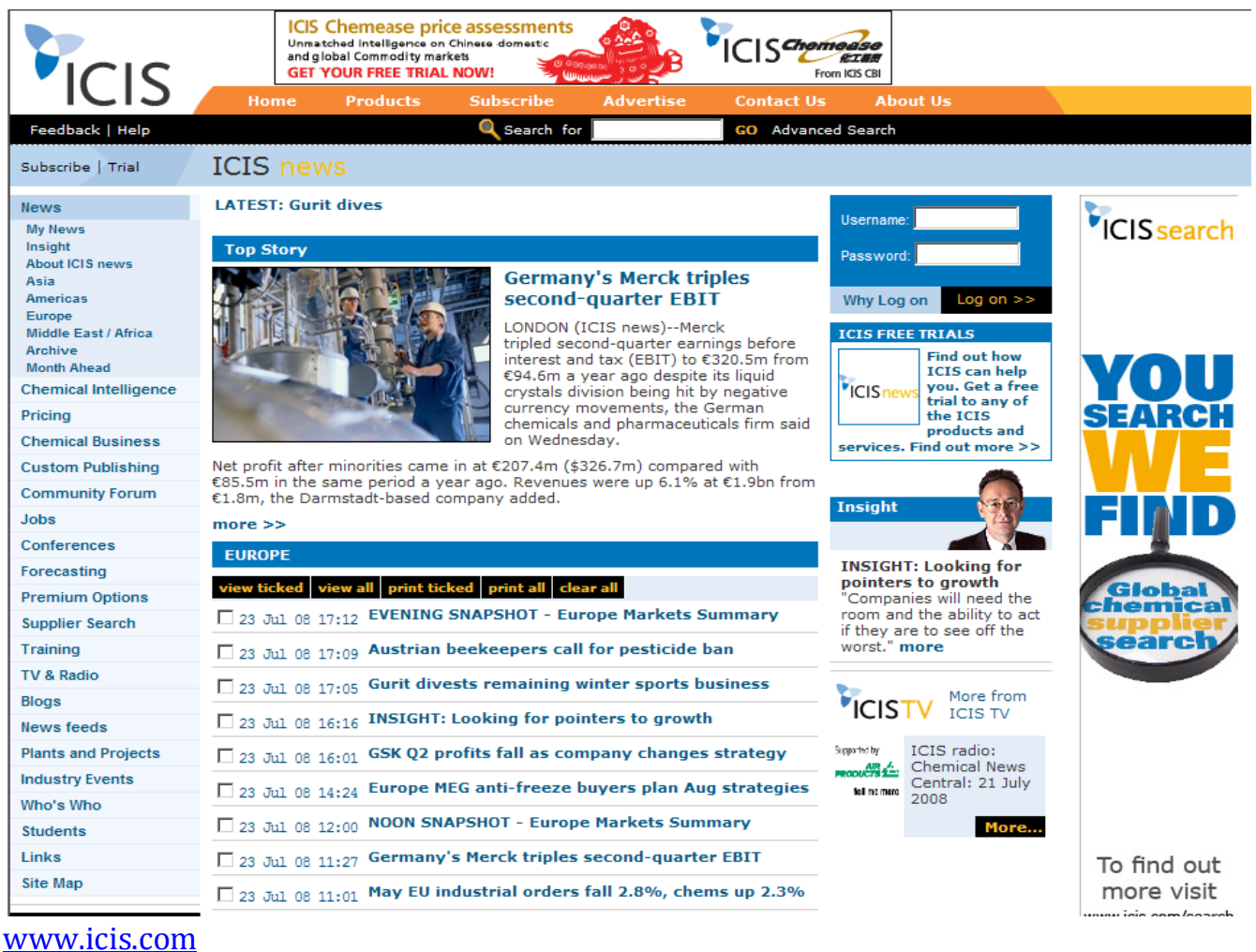




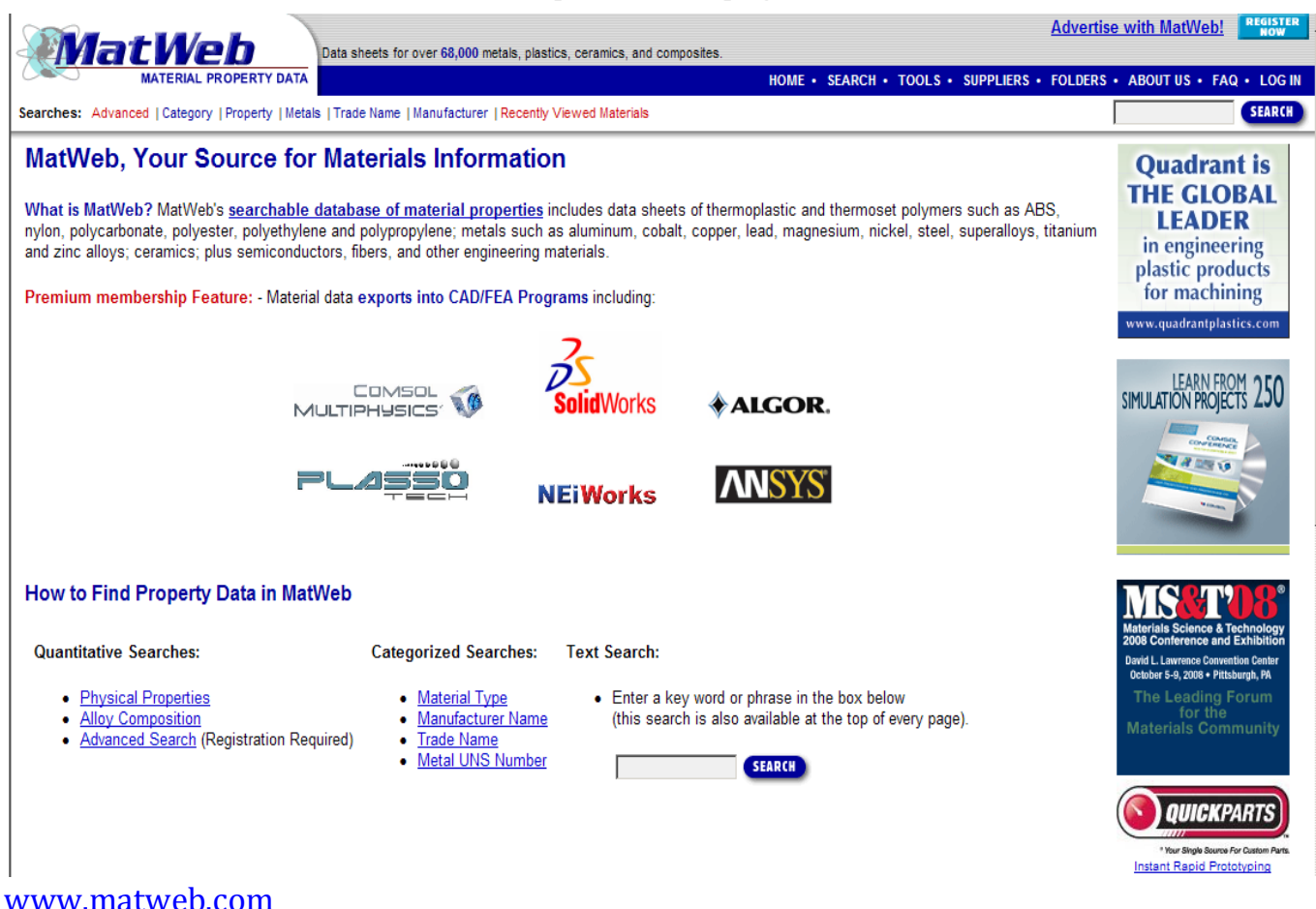

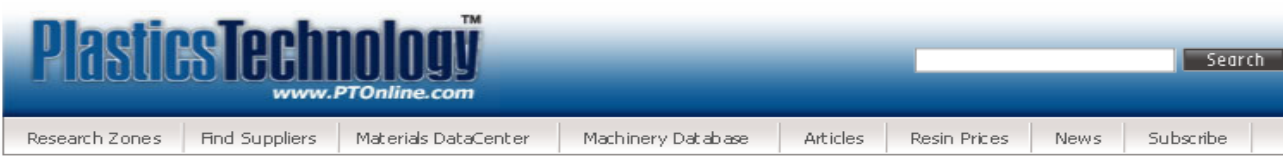

\begin{tabular}{l} 
Brow se Research Zones \\
Injection Molding \\
\hline Extrusion \\
\hline Materials \\
\hline Blow Molding \\
\hline Compounding \\
\hline Auxiliary Equipment \\
\hline Tooling \\
\hline Testing \& Quality \\
Control \\
\hline
\end{tabular}

\section{Research}

Current Issue

Asticle Archive

E-Update Nemsletter

Find Suppliers

Materials DataCenter

Machinery D atabase

\section{The Industry}

Molders' Hourly Rates

Extrusion Index

Injection Index

Industry Events

Helpul Links

Helpullinks

\section{The Magazine}

Subscribe Renew

Advertise

Contact U:

www.ptonline.com
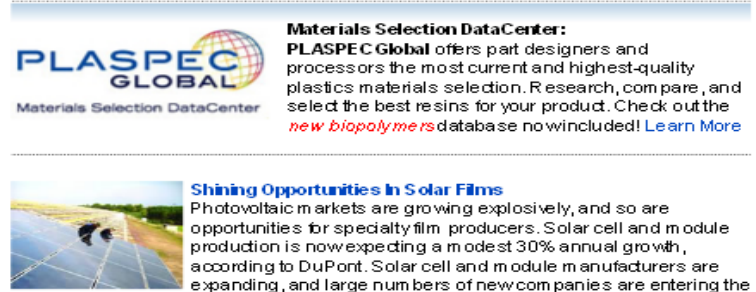

Shining Opportunities in S olar Films

Photowoltaic $m$ arkets are growing explosively, and so are opportunities for specialty film producers. Solar cell and module production is nowexpecting a modest $30 \%$ annual growth acoording to DuPont. Solar cell and m odule m anufacturers are expanding, and large num bers of newcom panies are entering the field.

Read Complete Astide

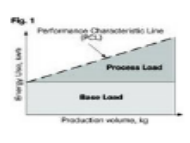

Know Your Plant's Energy Fingerprint

There are no excuses. Energy use is variable and controllable. Enere are no excuses. Energy use is vanable and controllable. loa load and a process load. These can be com bined to give the enorm ance charactenisticLine (PCL), which describes the energyperorm ance or the site. The realityis that energy use Read Complete Astide

Resin Prices: February 2009

Resin Prices Bottom Out

The free fall in resin prices appeared to end with a thump last month. Makers of PE, $P P$, and $P \backslash C$ resins were posting price increases, at least part of which are likely to go through. OnlyPS prices have yet to find a bottom.
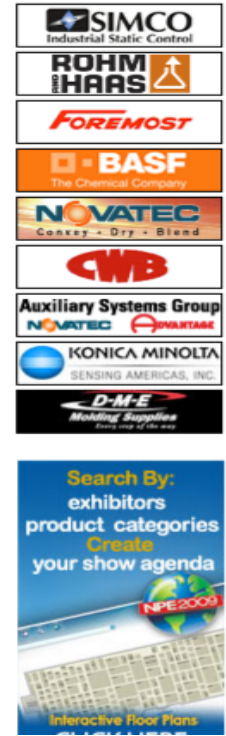


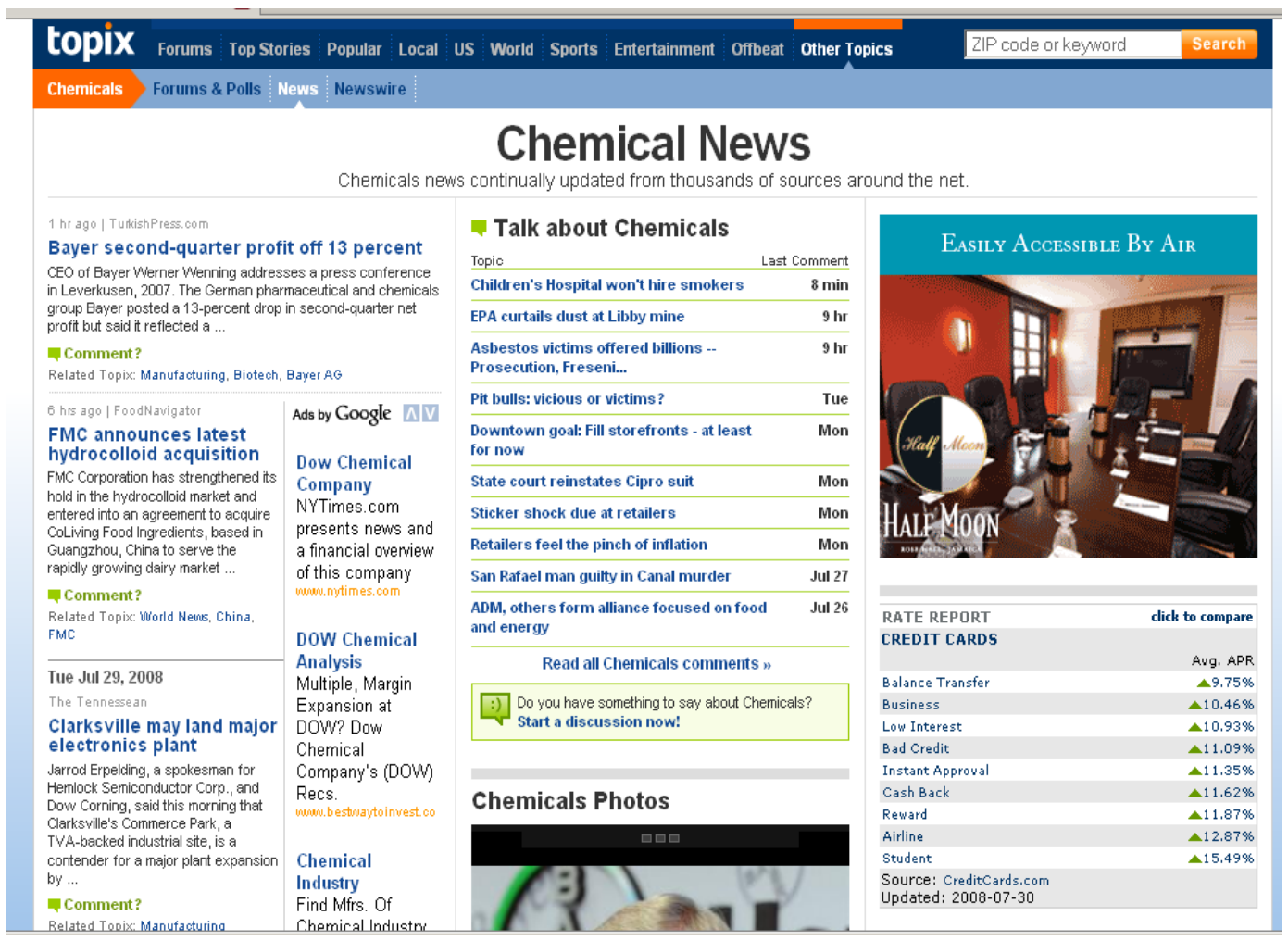

\section{www.topix.com}

Below you will find the latest Chemical Industry News from our news server site Acquisitions, mergers, share prices, new chemical industry trading agreements, petrochemical updates, pharma industry news and a whole lot more. Check the main page for the Chemspy chemistry news section and the sidebar on the homepage has links to many other related chemical industry resources and databases. Grab the Chemspy newsfeed to keep up to date with chemical info news

\section{Please reload this page to view the headlines}

Gor Hot Energy Stocks.

from: Dil \& Gas, Green Energy Solar, Ethanol, Wind, Biofuels. Sponsored Link. mm.Top EnergyStocks.00m Tue Jun 172008 13:32:00 GMT+0100 (GMT Daylight Time)

GoJ Punjab Chemicals profit rises 276.56 percent.

from: Webindia123 Tue Jun 172008 13:32:00 GMT+0100 (GMT Daylight Time)

God Specialty chemicals maker Omnova Solutions' 2nd-qtr loss narrows on sales by Asian business.

from: Canadian Business Magazine Tue Jun 172008 13:29:00 GMT+0100 (GMT Daylight Time)

GoDrohm and Haas Announces a Comprehensive Set of Actions to Restore Profitability...

from: Street Insider Tue Jun 172008 13:27:00 GMT+0100 (GMT Daylight Time)

GoJTrigon investment ICP applies for potash permits..

from: Stockwatch sub Tue Jun 172008 13:25:00 GMT+0100 (GMT Daylight Time)

GoJ Rohm and Haas Announces a Comprehensive Set of Actions to Restore

\section{www.chemspy.com}

Chemspy Chemical Info

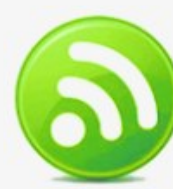

For more information about the Chemspy site, suggestions, or offers of support

please email

ChemSpy. Blog content has now amalgamated with

Sciencebase, please click the RSS button to subscribe to the Sciencebase feed to keep up with chemical information and news and a whole lot more. Chemspy is supported independently of editorial content by an online Coupons section. 


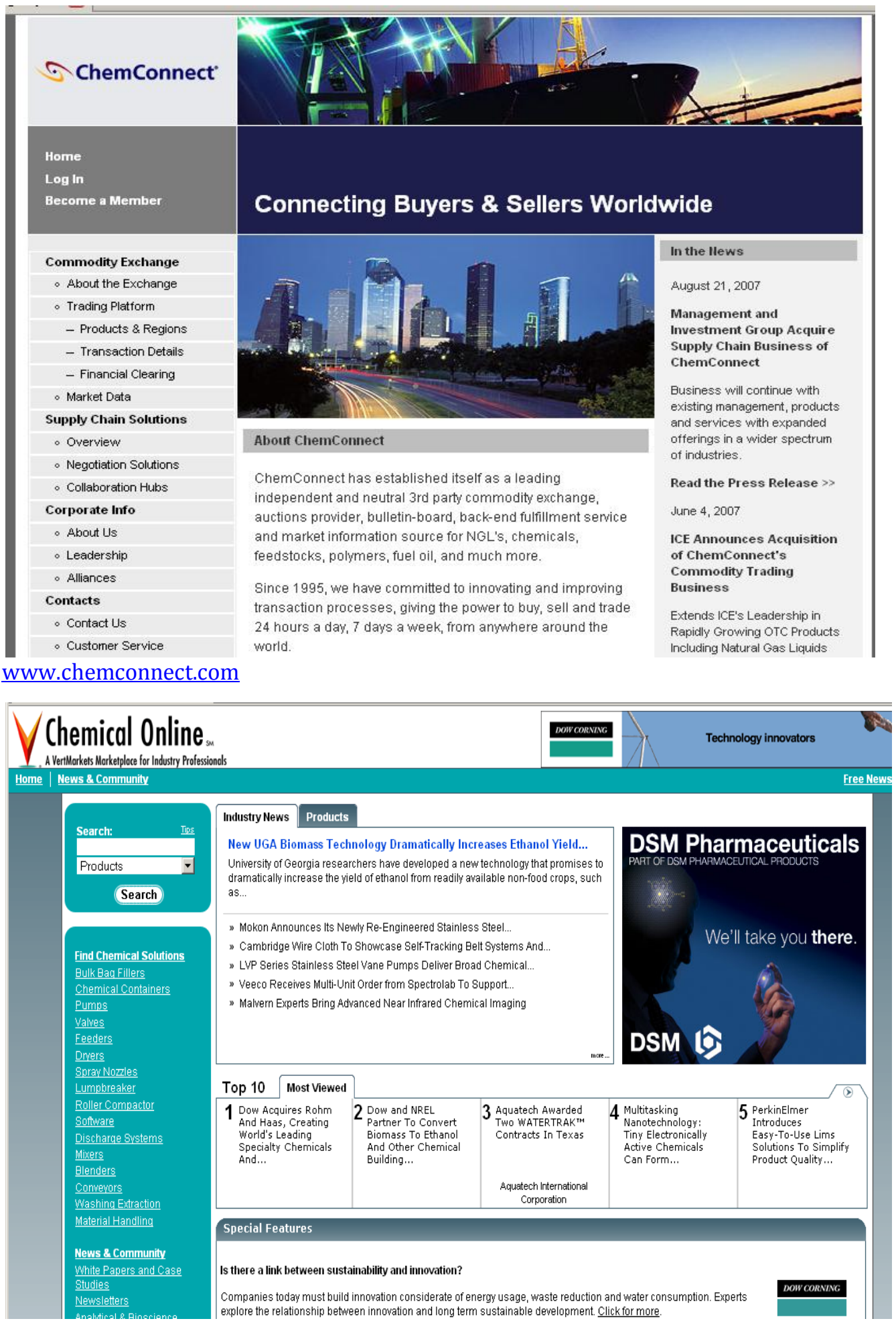




\section{(P.D.R}

Corporate

\section{Hembers of P-D-R}

Contact P-D-R

Board

Group Photo

History

Publications

Press Releases

Aims

\begin{tabular}{|c|}
\hline $\begin{array}{c}\text { Conditions } \\
\text { of P-D-R }\end{array}$ \\
\hline $\begin{array}{c}\text { Pharma Business } \\
\text { Information }\end{array}$ \\
\hline $\begin{array}{c}\text { For P-D-R } \\
\text { Members only }\end{array}$ \\
\hline
\end{tabular}

Thanks to DlMDifor hosting our s erver

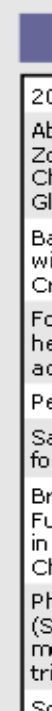

\begin{tabular}{|c|c|c|}
\hline 20090217_cdiffuktrial_en_tcm28-24092 & 17.02 .2009 & Sanofi Aventis \\
\hline $\begin{array}{l}\text { Abbott Nutrition Announces Voluntary Recall of } \\
\text { ZonePerfedtR Chocolate Caramel Cluster Bars, } \\
\text { Champions }{ }^{\mathrm{TM}} \text { Chocolate Peanut Butter Bars and } \\
\text { Glu cerna(B) Chocolate Peanut Bars }\end{array}$ & 17.02 .2009 & Abbott Labs \\
\hline $\begin{array}{l}\text { Bayer Crop Science signs research agreement } \\
\text { with the Leibniz Institute of Plant Genetics and } \\
\text { Crop Plant Research }\end{array}$ & 16.02 .2009 & Bayer \\
\hline $\begin{array}{l}\text { For the first time, doctors can pre dict which } \\
\text { eepatitis B patients have the highest chanoe to } \\
\text { achieve tre atment sucoess with Pegasys }\end{array}$ & 16.02 .2009 & \\
\hline Peace and quiet in open-plan offices & 13.02 .2009 & Bayer \\
\hline $\begin{array}{l}\text { Sandoz receives European Commission approval } \\
\text { or bio similar filgrastim }\end{array}$ & 13.02 .2009 & $\begin{array}{l}\text { Novartis } \\
\text { International AG }\end{array}$ \\
\hline $\begin{array}{l}\text { Bristol-Myers Squibb Foundation Announoes } \\
\text { =unding of More Than } \$ 1.17 \text { Million to Bridge Gaps } \\
\text { n Hepatitis C Aw are ness, Prevention and Care in } \\
\text { China, India and Taiwan }\end{array}$ & 13.02 .2009 & Bristol-Myers Squibb \\
\hline $\begin{array}{l}\text { Thase III studies of in vestigation al Trilipix }{ }^{\mathrm{TM}} \\
\text { (SLV348/ABT-335), in comb ination with statins, } \\
\text { me ets primary end points on improving LDL, } \\
\text { riglycerides and HDL }\end{array}$ & 12.02 .2009 & Solvay S.A \\
\hline
\end{tabular}

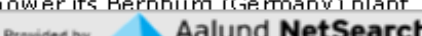

12.02.2009 Solvau S.A $\checkmark$

\section{Next Annual General Meeting, Se pt. 22-25, 2009 Le esburg, VA, USA} Latest Press Release

\section{P-D-R Member Companies}

\section{awa ABBOT}

AST RAZENECA

BASF BASF

EAT r.tur- BAYER HEALTHCARE

(1) BOENRINGER INGE HEM

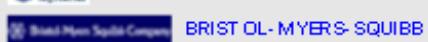

colarry CSL B日INING

Sheey EI LILLY

FERAING FERRING

GLAXOSMITHKLINE

GLAXÖOMMITHK

HOFFMANHLLA-ROCHE

MERC KKG $K A$

MECK \& $\mathrm{CO}$

NOVARTIS

NOVO NORDISK

MYCOMED

SCHEING PL OUGH

PFIZER

SANOFI-AVBNTIS

SOL VAY PHARMACEUTICALS

UCB

WYET H

www.p-d-r.com 


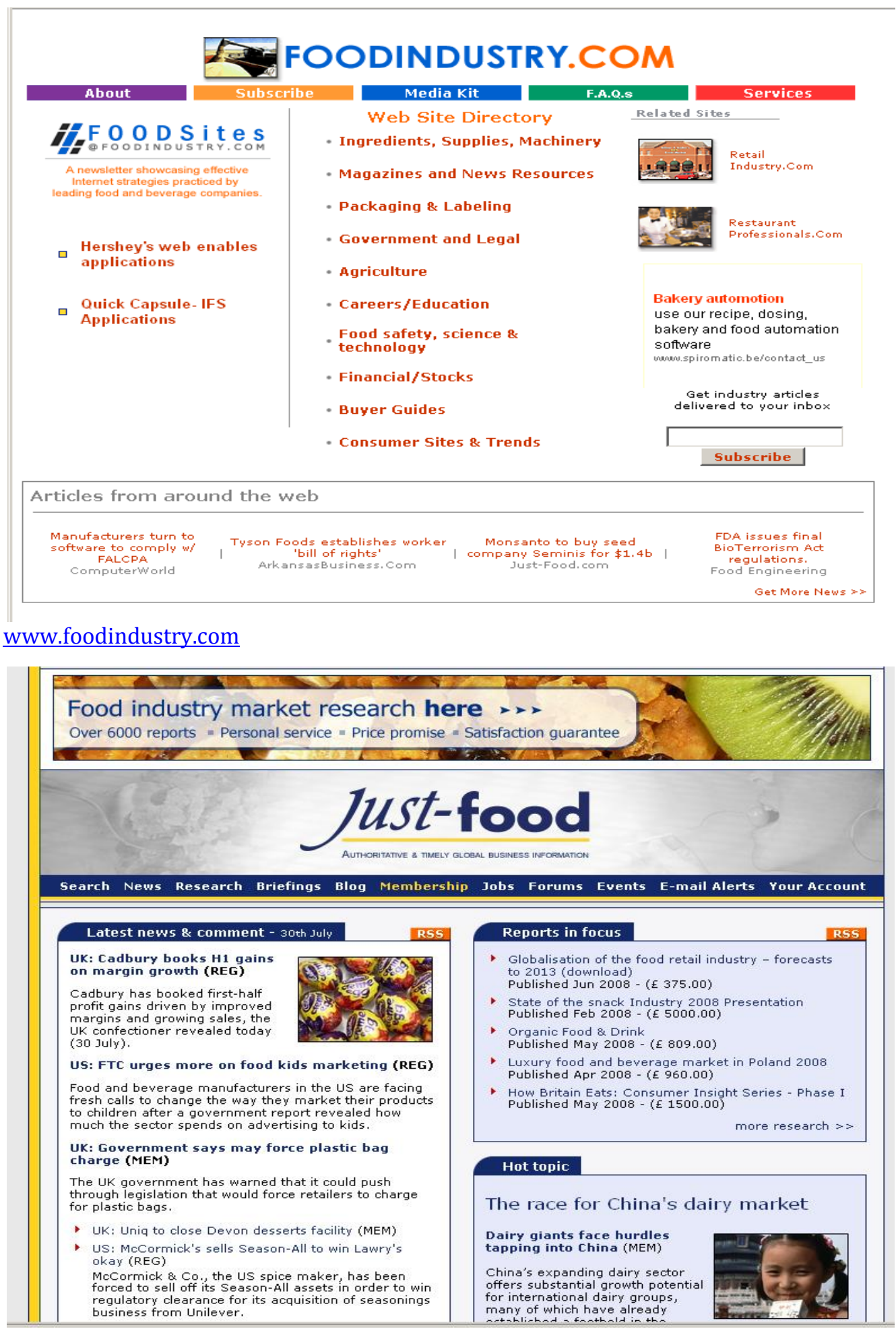


$-192-$ 


\section{Biography}

Charles Citroen studied organic chemistry at the University of Amsterdam. He took an interest in chemical information services and followed an internship at Chemical Abstracts Service (Columbus, Ohio, USA) in 1968/1969.

His professional career started at a pharmaceutical firm, he then worked for the Royal Netherlands Chemical Society as director of the computerised information service for chemical research. In 1977 he moved to TNO, the Netherlands Organisation for Applied Scientific Research where he became head of the Central Information Service. His last employment was as senior consultant for external projects in information management at the Delft University of Technology-Library from 1994-2003.

Since 1967 Citroen has been active in organising information services. First in specific industries, then as an intermediary between service providers and users in university settings and industrial research. Citroen has also been active in training users in applying automated information systems, both in his home country and abroad where he managed projects in China, Hungary, India and Eritrea.

Citroen was co-founder of the European Association of Information Services (EUSIDIC) and of the Association of Online Users (VOGIN) in The Netherlands

He is a Fellow of the UK Chartered Institute of Library and Information Professionals and recipient of the Ernie Hyde award for contributions to the Chemical Structure Association.

c.citroen@hccnet.nl 